\title{
Design and Analysis of Microalgal Open Pond Systems for the Purpose of Producing Fuels
}

\section{A Subcontract Report}

\author{
J. C. Welssman \\ R. P. Goebel \\ Microbial Products, Inc. \\ Fairfield, California
}
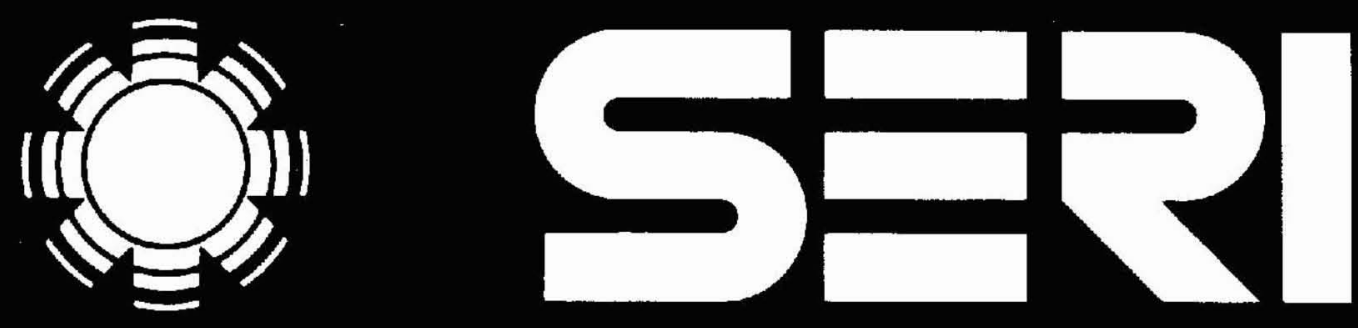

Solar Energy Research Institute A Division of Midwest Research Institute

1617 Cole Boulevard

Golden, Colorado 80401-3393

Operated for the

U.S. Department of Energy

under Contract No. DE-AC02-83CH10093 


\section{-Design and Analysis of Microalgal Open Pond Systems for the Purpose of Producing Fuels}

\section{A Subcontract Report}

J. C. Weissman

R. P. Goebel

Microbial Products, Inc.

Fairfield, California

April 1987

Prepared under Subcontract No. XK-3-03153-1

Solar Energy Research Institute

A Division of Midwest Research Institute

1617 Cole Boulevard

Golden, Colorado 80401

Prepared for the

U.S. Department of Energy

Contract No. DE-AC02-83CH10093 


\section{NOTICE}

This report was prepared as an account of work sponsored by the United States Government. Neither the United States nor the United States Department of Energy, nor any of their employees, nor any of their contractors, subcontractors, or their employees, makes any warranty, expressed or implied, or assumes any legal liability or responsibility for the accuracy, completeness or usefulness of any information, apparatus, product or process disclosed, or represents that its use would not infringe privately owned rights.

Printed in the United States of America

Available from:

National Technical Information Service

U.S. Department of Commerce

5285 Port Royal Road

Springfield, VA 22161

Price: Microfiche A01

Printed Copy A11

Codes are used for pricing all publications. The code is determined by the number of pages in the publication. Information pertaining to the pricing codes can be found in the current issue of the following publications, which are generally available in most libraries: Energy Research Abstracts, (ERA): Government Reports Announcements and Index (GRA and I); Scientific and Technical Abstract Reports (STAR): and publication. NTIS-PR-360 available from NTIS at the above address. 


\section{PREFACE}

The Solar Fuels Research Division of the Solar Energy Research Institute manages a program of research and development on the production of microalgae and their conversion to liquid fuels (e.g., gasoline and diesel) for the U.S. Department of Energy, Biofuels and Municipal Waste Technology Division. As part of the effort, three subcontracts were awarded in 1983 to design and provide cost estimates for the construction of a microalgae facility on a scale suitable for commercialization.

This report is the final report submitted by Microbial Products, Inc. for the project entitled "Design and Analysis of Microalgal Pond Systems for the Purpose of Producing Fuels." This work was supported through SERI subcontract No. XK-3-03153-1 as part of the Aquatic Species Program.

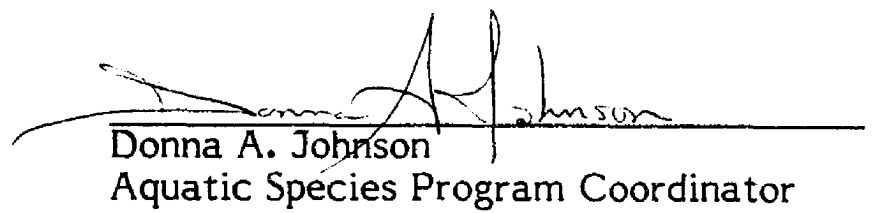

Approved for

SOLAR ENERGY RESEARCH INSTITUTE

Stanley R. Bull, Director

Solar Fuels Research Division 
SUMMARY AND CONCLUSIONS

\section{OBJECTIVES}

The purpose of this report is to present a detailed analysis and desian of a two acre experimental microalgal production facility that can be used to test the technical and economic potential of a commercial size facility 11000 acres). The design is based on extensive assessment of biological and technical requirements and important considerations such as resource use and availability and the impact of design assumptions on final product cost. Design feasibility and cost estimates are based on actual data obtained from standard cost estimating procedures. consultant input, and vendor quotes.

The proposed facility can be used to test the following important assumptions and concerns about microalgal biomass production.

1. Performance of a lowest cost design.

2. Efficiency of nutrient utilization. particularly carbon.

3. Achievement of high lipid productivity.

4. Reliability of a cost effective biomass harvesting method.

5. Longterm maintanence of biological and engineering standards of performance in a system with a high level of internal recycle.

\section{DESCRIPTION OF THE EXPERIMENT}

The site chosen for the experimental systen is in Brawley, in California's Imperial Vallev, on a one thousand acre farm which borders the Salton Sea. The clinate is favorable for microalgal cultivation, with virtually a vear round growing season. It is representative of the warmer, drier regions of the American Southwest. Ample land is available for both the experimental system and for potential scale up. Virtually anv water resource can be simulated by varying the mixture of the two water resources available: water from the Salton Sea, which is as saline as ocean water, and grondwater from an existing well which produces 1700 gallons per minute. Flexible lease agreements can be negotiated with the land owners for use of the site and facilities.

The proposed experimental system is sized to allow validation of the commercial size facility with a minimum of extrapolation. The choice of two one acre growth ponds is based on an optinization of this validation requirement and cost of the experimentation. Three smaller growth ponds, of $50 \mathrm{~m}^{2}$ each, are included for testing scaled down subsystem options. These can be constructed and operated at lower cost than the one acre versions, and used to determine which options show the most promise and thus should be tested at the larqer scale. The $50 \mathrm{a}^{2}$ ponds will also be used in growth and harvesting studies. The harvesting subsystens for the one acre ponds are designed to directly emulate the full size subsystems so that translation of successful results concerning this important aspect. to the commercial scale, is assured. 
The experimental system also includes a covered, anaerobic lagoon to be used for determining the extent to which nutrients can be recovered and recycled back to the growth ponds. This is essential to validate the economic predictions of the full scale design.

INNOVATIVE CONCEPTS, DESIGNS, AND TESTS

The designs and systems presented in this report include many concepts and experiments which are innovative. The design and operation of a low cost system is innovative in and of itself. The successful achievement of process and procuctivity goals in such a system would be an important advance in the state of microalgal technology and in its prospects for application. The cost effectiveness is realized by minimizing capital costs of the system and achieving efficient use of inputs. Extensive engineering analysis of carbonation, mixing, and harvesting subsystems has elucidated both the lowest cost, most efficient options and the essential parameters needed to construct. test, and evaluate these subsystems. The use of growth ponds sealed with clay and $l$ ined with crushed rock results in construction cost savings of $50 \%$ relative to ponds lined with synthetic memoranes. In addition a low cost but efficient design allows improvements in technology, like productivity enhancement, to have the fullest impact on final product cost reductions.

In addition to the innovations in construction, the operational efficiency of the design is novel in being both higher and more feasible than that attained by any previous system concept of comparable scale. This efficiency is not achieved by fanciful optiaism, but rather by concerted effort to ascertain what can be done and how to do it effectively. The recvele fraction of nutrients such as carbon, nitrogen, phosphorus, and water, must be high, realizable, and not achieved simply by substituting extreme capital and operating cost increases in one area for cost savings in another. The water chemistry analysis has led to operational specifications which minimize water use and virtually eliainate losses of carbon dioxide to the atmosphere. The carbon dioxide injection system is designed for $95 \%$ efficiency, but is still low cost. The construction of a large scale, covered anaerobic lagoon, to convert and recycle carbon, nitrogen, and phosphorus nas not been attempted at the scale analyzed here. Yet, this recycle of non-product biomass is essential for achieving economic affordability.

The low cost biomass harvesting concept presented in this report is a najor innovation, adapting the advances in other disciplines for application in microalgal systems. The concept is to tailor high molecular weight polymers for flocculation and coagulation of aloal biomass, indueing characteristics which allow collection of the biomass in sedimentation ponds. These pands are designed for inexpensive construction and operation. Successful achievement of performance goals will represent another major breakthrough in algal production technology. 
Attainment of the lipid oroductivity assumed in this report. $30 \mathrm{gm} / \mathrm{m}^{2} / 0$ average with $50 \%$ as lipid, in the system as outlined, would again represent a major advance. Algal strains with high lipid accumlating capability will be used in the experimental system to test productivity goals. The management strateqies developed and the environmental conditions existing in the ponds will be evaluated for effect on productivitv. Understanding the inhibition of productivity by high levels of dissolved oxygen. and developing means to alleviate it, is a possible route to achieving enhanced productivity.

\section{CONCLUSIONS OF ECONOMIC ANALYSIS}

The systen described, with designs for efficient use of inputs included, is analyzed in the report in terms of the costs of the algal biomass produced and the unextracted lipid "oils" it contains. At the 1000 acre scale, the production cost of the biomass is $\$ 205 / m t$. The lipid only orice is $\$ 62 / 061$. The sensitivity analysis presented shows that both the recvele of nutrients that do not leave in the lipid product stream. and the low capital cost of the system are essential for attaining further product cost reductions. The impact of higher productivity is only significant under these conditions. Increased productivity aust not be accompanied by a decrease in the efficiency of use of inputs, significant increases in systen construction costs, nor by reduction in lipid content of the biomass. When system performance 35 maintained, a $50 \%$ increase in biomass productivity results in a $20 \%$ decrease in final product cost. If carbon is not recycled and system costs increase in proportion to the increase in productivity, then the cost reduction is well under $10 \%$. Use of a system which is more than twice as expensive to construct as the one presented in this report renders the econonics of fuel production untenable. Production costs are most sensitive to the price and recycle effiency of $\mathrm{CO}_{2}$, the content of lipid in the biomass, and the combination of the cost of capital and the cost of system construction. However, the systen must be desianed and constructed so that each component which contributes to the final cost is minimized, in order for the concept to approach affordability and for further innovations to have any inpact.

\section{RELATIONSHIP OF THE PROPOSED EXPERIMENT TO PROBLEMS IN FUEL PRODUCTION FROM MICROALGAE}

Any estimate of the cost of producing lipids from algal biomass is dependent on the assumptions used to generate the inputs to the economic model. It is necessary to determine which are most important and thus deserving of attention, and which are reasonablv valid. Four questions must be answered in order to evaluate the overall feasibility of the concept: can inexpensive $\mathrm{CO}_{2}$ be found and can it be used efficiently, does a large enough water resource exist which can make up for the losses incurred, can strains be found which form lipids at high rates of production and which will dominate the pond flora, and can methods be devised for harvesting the biomass inexpensively. 
The resource evaluation questions cannot, for the most part, be answered at the present time. However. it is clear that the efficiency of utilization of the resources will be part of the determnination of how large the resource base must be. In the case of water, the production system must be operated with a high recvele ratio. This has yet to be tested for an extended period of time or on a meaninatul scale at the recvele level needed here. This is proposad in the experiment. In the case of $\mathrm{CO}_{2}$, the systen must be designed to recyele as much of the non-lipid carbon as possible, the injection systems must be $90+\%$ efficient, and the managenent of the pond operations must such that virtually no outgassing occurs. In the engineering analyses given in the report, several means are presented to do all of these. In the experimental plan, efficiency of $\mathrm{CU}_{2}$ use is given the highest priority, including the testing of an anearobic lagoon for nutrient recycle.

The harvesting of the algal suspension is a problem that will require continuous attention in terms of applying new developments in polvmer chemistry to a changeable pond environment. A repertoire of polymers must be avallable for use when a contaminant arises which has.different flocculating characteristics from the desired strain.

The discovery of productive, lipid forming strains, which are highly competitive as well, is a basic requirement. However, productive accumulation of carbohydrates or protein has been looked for and found. There is no reason to believe lipid cannot be prolifically produced as well. The sensitivity analvsis indicates that high lipid content, $40-50 \%$ of the bionass is necessary, but that overall lipid productivity need not be higher than 25 $t / a c r e / y r$. Before increases in productivity have too much effect, the operating costs of the system must be reasonably low. Once these costs have been lowered, the capital costs become more important. While on the surface it may appear that increased productivity is a panacea, closer examination reveals that this is so only under one condition: lowest $\mathrm{CO}_{2}$ requirement and cost. combined with low capital cost which is not increased significantly in order to attain the higher productivity. The systen designed, and to be tested during the proposed experiment, is a low cost system, operating efficiently in terms of $\mathrm{CO}_{2}$, and 1 inited in terms of productivity only by the availability of productive algal strains.

The last requirement, that the strain be dominant, way depend on how unusual lipid accumulation by algae turns out to be. Enough strains which are known to store lipids must be identified, so that once a universal harvesting method is developed (as the polymer flocculation method potentially is), one could be relatively sure that nitrogen depletion will lead to the desired product despite the identity of the particular strain. This needs to be demonstrated. 
TABLE OF CONTENTS

Page

SECTION 1.0 Introduction .................. 1

1.1 Objectives................. 1

1.2 State of the Art.................. 1

1.3 Organization of the Report..............4

SECTION 2.0 Water Resources.................. 5

2.1 Characteristics of Water Resources......... 5

2.2 Large Scale Design Water............. 11

2.3 Experimental System Water Resources and Growth Media.................. 11

SECTION 3.0 Analysis of Carbonation Systems . . . . . . . 12

3.1 Introduction.............. 12

3.2 Covered Area Carbonators--Bubble Covers.... . 12

3.3 In-Pond Carbonation Sumps.......... 13

3.4 Recycle of Non-Lipid Carbon Fron Extraction

Resjdues................ . 22

3.5 Oxygen Desorption................... 22

3.6 Chemical Enhancement of Carbon Dioxide Transfer . . 24

3.7 Large Scale System Carbonator Design . . . . . . 24

3.8 Experimental Systen Designs and Tests....... 25

SECTION 4.0 Analysis of Mixing Systems........... . 26

4.1 Open Channel Flow................ 26

4.2 Paddle Wheels . . . . . . . . . . . . . 27

4.3 Gas Lift Mixing... . . . . . . . . . . . 28 
TABLE OF CONTENTS (CONT.)

Page

4.4 Mixing System Specification........... 33

SECTION 5.0 Analysis of Harvesting Systems.......... 34

5.1 Introduction................ 34

5.2 Capital Costs of Primary Harvesting Devices.... 34

5.3 Pretreatment options............. 35

SECTION 6.0 Analysis Overview and Implications for System Desion 37

6.1 Water Chemistry...... . . . . . . . . 37

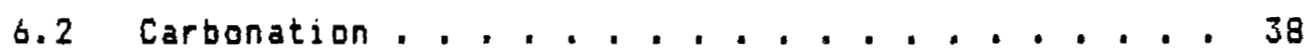

6.3 Nutrient Recycle............... . 39

6.4 Nutrient Losses.................. 41

6.5 Mixing System................. 41

6.6 Mixing Velocity and Depth............. 42

6.7 Pond Lining. . . . . . . . . . . . . . 43

6.8 Harvesting System................. 44

6.9 Productivity Enhancement and Species Control . . 44

6.10 Effluent Disposal................45

SECTION 7.0 Pand Construction..................... 46

7.1 Pond size and Geometry.............. . 46

7.2 Pond and System Configuration . . . . . . . . 48

7.3 Pond Design Alternatives and Costs........ . 53

SECTION 8.0 Harvesting System Design ............. 64

8.1 Microstraining.................64 64 
TABLE OF CONTENTS (CONT,)

Page

8.2 Belt filtration.......,.,.,.,. . 68

8.3 Settling................... 71

SECTION 9.0 System Wide Costs............... 79

9.1 Water Supply and Distribution.......... 79

9.2 Carbon Dioxide Supply and Distribution..... . 84

9.3 Nutrients, . . . . . . . . . . . . . 84

9. 4 Blowdown Disposal system. . . . . . . . . . . 85

9.5 Buildings.................... 85

9.6 Roads and Drainage.... . . . . . . . . 86

9.7 Electrical Supply and Distribution . . . . . . 86

9.8 Machinery. . . . . . . . . . . . . . 87

9.9 Other costs................. . 87

SECTION 10.0 Large Scale System Operations and Operating Costs . 88

10.1 Operations Overview . . . . . . . . . . 88

10.2 Operational Costs of a 1000 Acre System..... 91

SECTION 11.0 Economic Analysis of a 1000 Acre Production System.95

11.1 Base Case................ 95

11.2 Sensitivity of Base Case to Productivity Changes. . 95

11.3 Sensitivity of the Base Case to Carbon Recycle. . 98

11.4 Recycle Case: Productivity Sensitivity. . . . 100

11.5 Recycle Case: Sensitivity to $\mathrm{CO}_{2}$ Price.... . 100

11.6 Recycle Case: Sensitivity to Lipid Content. . . 105 
TABLE OF CONTENTS (CONT.)

Page

11.7 Recycle Case: Sensitivity to Depreciable

Capital Investment ........... 105

11.8 Recycle Case: Sensitivity to Cost of Capital., 108

11.9 Recycle Case: Sensitivity to Polymer Dose... . 108

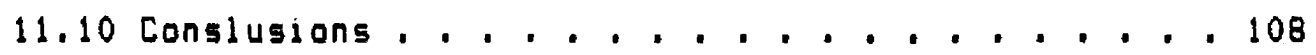

SECTION 12.0 Experimental System Design and Construction Costs . 112

12.1 Site Description.............. 112

12.2 Experimental System Description and Justification. 115

12.3 Alternative 5ites............. 116

12.4 Experimental System Design . . . . . . . . 117

SECTION 13.0 Experimental System Operation and Costs . . . 132

13.1 Introduction............. 132

13.2 Systen Construction .............. 132

13.3 Experjmental Plan .............. 133

13.4 Operations Sumary and Experimental Priorities. . 138

13.5 Experimental Schedule............ 139

13.6 Budget Description.............. 139

BUDGET............................ . 143

REFERENCES . . . . . . . . . . . . . . . . . . . 144

APPENDIX I Carbon Dioxide Transfer . . . . . . . . . 145

APPENDIX II Gaslift Pumps for Combined Pumping and Gas

Contacting in Algal Production Systems . . . . . . 154

APPENDIX III Pond System Design: Background Information... . 176

APPENDIX IV Harvesting Systen Design: Background Information . . 183

APPENDIX $\vee$ Design of Anaerobic Lagoon . . . . . . . . . . 185

APPENDIX VI Sensitivity Analysis: Cost Sumary Tables.... . 194 


\section{LIST OF TABLES}

Table

Page

2-1 Chemistry of Water Resources................. b

3-1 Covered Carbonator - \% Areal Coverage . . . . . . . . . 14

3-2 Effect of Assumed Transfer Rate on Sump Depth . . . . . . 17

3-3 Sump with Gas Recycle.................... 18

3-4 Average Hold-up and Lift in 1.5 m Deep Carbonation Sumps... 20

3-5 Average Hold-up and Lift in Counter - Current Sumps . . . . . 21

4-1 Effect of Sump Depth on Air Lift Efficiency......... 30

4-2 Gas Lift Efficiency as a Function of Liquid Velocity... . 30

4-3 Lift and Efficiency of a Draft Tube Air Lift System ..... 31

6-1 Nutrient Partitioning in an Anaerobic Lagoon . . . . . . . . 40

b-2 Recycle of Nutrients................. 40

7-1 Pond Design Calculations - single Pond........... . 49

7-2 Pond Design Calculations - Pond System . . . . . . . . 50

7-3 Growth Pond Cost Sumary - 192 Hectare System . . . . . . 63

8-1 Microstrainer Design Assumptions . . . . . . . . . 65

8-2 Capital Costs of Microstrainer Harvesting Option . . . . . 69

8-3 Capital Costs of Belt Filtering Harvesting Option...... 70

8-4 Settling Pond Systen flow Rates.............. 75

8-5 Capital Cost of Settling Pond Harvesting Option . . . . . 77

8-6 Estimated Operating Costs of Harvesting Options . . . . . 78

9-1 192 Hectare Systen Capital Cost Sumary . . . . . . . . . 80

9-2 192 Hectare Systen - Electrical and Maintanence Cost Sumary. 81 
LIST OF TABLES (CONT.)

Table

Page

9-3 Capital Cost of Water Supply System . . . ....... . 82

9-4 Capital Cost of Carbon Dioxide Distribution System.... . 95

9-5 Capital Cost of Buildings................ . 86

10-1 Base Case Desion Parameters................. 91

10-2 Total Operating Costs - Base Case............ . 93

10-3 Labor Required for 1000 Acre System . . . . . . . . . 94

11-1 Base Case Economic Analysis............... . 96

11-2 Economic Model Input Parameters.............. 97

11-3 Base Case: Sensitivity to Productivity . . . . . . . . 98

11-4 Economic Analysis: Base Case + Recycle........... 99

11-5 Recycle Case: Productivity Sensitivity . . . . . . . . 101

11-6 Recycle Case: Sensitivity to CO2 Price.......... . 104

11-7 Recycle Case: Sensitivity to Lipid Content........ 106

11-8 Recycle Case: Sensitivity to DCI........... 107

11-9 Recycle Case: Sensitivity to Cost of Capital....... 109

11-10 Recycle Case: Sensitivity to Cost of Capital at $2 \times$ DCI. . . 110

11-11 Recycle Case: Sensitivity to Polymer Dose........ . 111

12-1 Climatic Conditions at the Proposed Experimental Site . . . 112

12-2 Chemical Composition of Experimental Site Water Resources . . 115

12-3 0.4 Hectare Pond Design Calculations........... 120

12-4 0.8 Hectare Systen Calculations . . . . . . . . . . . 121

12-5 0.8 Hectare System Pand Costs ............... 123 


\section{LIST OF TABLES (CONT.)}

Table

Page

12-6 $50 \mathrm{~m}^{2}$ Ponds Cost Breakdown............... 124

12-7 Experimental System Settling Pond Cost.......... 126

12-8 Experimental System Water Storage Pond... . . . . . . . 128

12-9 Experimental Systen Buildings Cost............ 129

12-10 Experimental Systen Cost Summary............ 131

13-1 Experimental System - Pond Equipment Cost . . . . . . 139

13-2 Laboratory....................... 141

13-3 Operating Materials and Supplies.............. 142

13-4 Direct Labor ............ . . . . . . . . 142 


\section{LIST OF FIGURES}

2-1 Carbonate Chenistry of Seawater . . . . . . . . . . 7

2-2 Carbonate Chenistry of Conditioned Type Il Water .125 Blowdown Ratio.. . . . . . . . . . . . . . . . 8

2-3 Carbonate Chemistry of Conditioned Type II Water 25 Blowdown Ratio................... . 9

7-1 Effect of Pand Size on Wall Lengths.............. . 47

7-2 Effect of Pond Size on Pond Costs.............. 47

7-3 Pond system Layout...................... . 51

7-4 Single Pond Lavout. . . . . . . . . . . . . . . . 52

7-5 Wall Construction Alternatives . . . . . . . . . . 55

7-6 Paddle Wheel Design (Typical)............. 61

8-1 Microstrainer-based Harvesting Schematic . . . . . . . 67

8-2 Settling Pond systen Layout. . . . . . . . . . . . . 72

9-3 Harvesting Pond Details.................. . 74

8-4 Settling Pond Flush System and Secondary Thickening . . . . 76

9-1 Water Distribution System............... 83

11-1 Recycle Case: Sensitivity to Productivity ........ 102

12-1 Location of Experimental Systen ............. 113

12-2 Experiemental site................... 114

12-3 Experimental Site - Plan View............... 118

12-4 Experimental Site - Section View............. . 119

12-5 Experimental System settling Pond............. . 125

13-1 Experimental Schedule... . . . . . . . . . . . . 140 
SECTION 1.0

INTRODUCTION

\subsection{OBJECTIVES}

The objective of this report, as described in the statment of work, is to develop a cost effective design for a microalgae culture facility, that meets specified location, resource, and product requireaents. The conceptual design and operating options presented are based on field and laboratory experiments, conducted by Microbial Products, Inc., engineering cost analysis, and assessment of the work in the literature.

In developing the design and analysis, the major decision in choosing among identified alternatives has been potential cost effectiveness and econoric efficiency. This approach is based on the fact that the ultimate success of microalgae-based fuels will be determined by market economics.

\subsection{STATE OF THE ART}

An evaluation of the state of the art of algal bionass production can be based on information from actual producing plants and from extrapolations of results of experimental facilities. In the former, the costs of constructing the system approach $100 \times 10^{3}$ /acre, the resource base is well-defined but $l i n i t e d$ and relatively expensive, and the final cost of the biomass is \$2-5/dry 16 . The costg derived fron extrapolation vary extensively and are generally based on unrealistic assumptions used. For this reason, only the results of Weissman and Goebel [1], Benemann et al [2], and Laws [3] will be used in the following discussion. These investigations are, in any case, among the most recent and thus the latest in the state of the art.

The three major technical and economic concerns of algal biomass production are: the cost and availability of the two major resources $\left(\mathrm{CO}_{2}\right.$ and water), the costs of constructing and maintaining the system, and the design and costs of the biomass harvesting and processing systens. At present none of these concerns has been resolved for a process which must produce the biomass at a cost of $\$ .05 / 1 \mathrm{~b}$ as nust be accomplished for fuel precurser bionass.

\subsubsection{Hajor Resources}

Despite the effort that has been put into identifying the water resources available for large scale algal biomass production, no suitable resource has yet been identified. The reasons for this are 1) data on groundwaters 
are sparse, non-random, and difficult to compile and 2) the selection criteria have not been fully applied so that the resource data have not been properly evaluated. It is not possible to conduct a comprehensive investigation of water resource availability. Rather it seeas more useful to state the criteria which any water resource must meet in order to be suitable for use in a low cost algal biomass production system. In discussing the water availability, it is important to consider the interdependencies anong the water, land and $\mathrm{CO}_{2}$ resources required for algal production systens.

In existing production facilities, systen sizes vary from 1-20 acres and the anount of water required is small. Thus water fron wells with special characteristics or inexpensive irrigation waters, already available for agriculture are used. When unique growth media are required, as in the high bicarbonate medium for Seirulinge production, recycling of the growth medium is necessary, further lowering the water denand. For fuel production from microalgae, the scale increases 50-5000 fold, changing the resource question entirely. Now the agricultural water, which is not too costly per se, is not utilizable because the competition from conventional agriculture makes the land too expensive. This leaves only three water resources left for consideration: seawater, groundwater that is too saline for agriculture, and agricultural drainage water.

In the U.S., coastal property with access to seawater is extremely expensive. However, since so much work has been done in seawater, and since this is really the only unlinited water resource, we will consider the consequences of using it. One thing that nust be kept in mind when considering the use of seawater is that much more water aust be used since the initial salinity is already high. One really cannot consider even a 50-100\% increase in the salinity, due to evaporation, for two reasons. First, salinity restricts the number of species that will tolerate the medium and there are already very many species screening cricteria. Second, the growth rate and productivity of algae on waters with increasing salinity, above seawater, decreases rapjdly even for species which tolerate the higher salinity [4].

Saline groundwater is the priae candidate for algal bionass production, because it may be the only resource avajlable in large enough quantities at low enough cost, where land is inexpensive. The groundwater resources identified to date [5], are most likely useable, after conditioning, as will be shown below. However, the size of the resource base is only speculative at present. Nonetheless use of saline groundwater will be a basic assuption in this report and serves as an example of a theme to be repeated throughout the reporti the assumptions used will often be speculative, but it will be shown that the alternatives are much too costly to be seriously considered. The major effort will be to demonstrate that the speculative assumptions are the only economic alternative. 
Agricultural drainage waters are becoming a larger and larger resource as irrigation waters are made more available in the semi-deserts of the U.S. southwest. These drainage waters are becoming recognized as a major waste disposal problen. Although use of these waters poses some of the same problens as the use of irrigation water lavailable where land is relatively expensive) the credits for evaporating some of this water may outweigh the expenses. The following analysis will thus cover the use of seawater and several types of saline groundwaters, delineating the consequences that the characteristics have on the design of low cost algal biomass systems.

The major resource necessary for fuel precurser production from microalgae is carbon dioxide. Even at $\$ 40 /$ ton, $\mathrm{CO}_{2}$ is likely to comprise over $50 \%$ of the operating costs. Its requirement is proportional to bionass production so that increasing the output of a system, per acre, does little to alleviate the cost burden of $\mathrm{CO}_{2} . \mathrm{CO}_{2}$ is available in moderate to large quantities fron three resources: wells, refinery cracking processes, and power plant off gases. The logisticg of siting a pond system close to both water and $\mathrm{CO}_{2}$ resources poses one of the nost difficult problems. We will not delve into this area except to say that at least in the future enough $\mathrm{CO}_{2}$ is available for large systen use even if power plants ust be built to supply it. The design considerations will emphasize efficient use of $\mathrm{CO}_{2}$, assumed to be available at various specified costs. Algal biomass production systeas in operation today use commercial $\mathrm{CO}_{2}$ produced at refineries and trucked or trained to the pond site. Costs of this range fro \$50-100/ton. This is the $\mathrm{CO}_{2}$ resource that will be specified for the experimental systen developed.

\subsubsection{Pond_Construction_Costs.}

State of the art systems are 5 mall and very expensive per unit area to construct. Although the recovery of the cost of construction can be spread over many years, none of the existing systens could make a profit if the product value were not greater than about \$10/dry lb. High construction costs and the large scale of the systems required to produce energy combine to discourage private investment. Thus the designs specified in this report were devised to keep capital costs of construction as low as possible while still achieving production goals. For exanple, pond lining with plastic membranes was considered too expensive to buy and install initially, as well as being a potential aaintenance probles. A crushed rock lining, on the other hand, is much less expensive. The theme of our approach is repeated intensive algal production has not been atteapted in large ponds, sealed with clay and lined with crushed rock, but we feel that in order for the process to approach affordability, this option aust be specified. 


\subsubsection{Bi gomas Harvesting.}

Perhaps the foremost technical problen in low-cost alqal biomass production has been recovering the cells from suspension. Besides simple sediaentation, there is no method yet developed that is inexpensive. All straining, filtering, and chemical flocculation methods presently being analyzed are too expensive. Induced bioflocculation, possjbly aided by stall doses of chemical flocculant, followed by sedimentation or flotation are potentially effective aeans of harvesting which would not be too costly. Both conventional and the proposed means will be analyzed in the body of the report.

\subsection{ORGANIZATION OF THE REPORT}

The report contains thirteen sections including this introduction. In sections 2.0 - 5.0 the analyses which serve as the basis for design criteria are presented. The chemistry of the water resource is the subject of section 2.0. The water used and the blowdown ratio assumed determines the carbon storage capacity and $\mathrm{pH}$ arange of operation. This determines the transit time between carbonation stations, which is needed as an input to determining the pond size.. The design criteria for two different types of carbonators is the subject of Section 3.0. In Section 4.0 two methods for mixing are analyzed: paddlewheels and gas-lift pupps. The results are stated in terms of efficiency and power requirements to obtain channel mixing velocities of $20 \mathrm{~cm} / \mathrm{s}$. Harvesting systems is the subject of Section 5.0. The methods analyzed include flocculation, with and without saall chemical doses, followed by either a two-step sedimentation system, air/Do flotation using a foan collection device, microstraining, or belt filtration. Section b. 0 sumarizes the analyses of preceding sections, provides an overview of other important considerations not previously presented, and discusses the implications of the analytic results on the design and operation of a large scale algal production system. In Sections 7.0-9.0, the design of large scale ponding system is presented along with the construction costs. The cost of operating such is presented in Section 10.0. The sensitivity of the economics of algal biomass production to changes in the initial assumptions and design is the subject of section 11.0. Finally, the experimental system which is to be used to validate the operation of the proposed systen, is presented in Sections 12.0 and 13.0 . 
SECTION 2.0

WATER RESOURCES

\subsection{CHARACTERISTICS OF WATER RESOURCES}

The chenical composition of the water resource has several primary consequences for both the design and operation of the systen. Pond size and/or the number of carbonation stations per pond is determined by the carbon storage capacity of the water. Since it ig least expensive to restrict the "power" corridor to one end of the channels, one carbonation station per pond is optimal unless this criterion restricts pond size to less than about 10 acres. In that case, pond construction will be more expensive because more carbonation stations will be needed per pond, requiring a more extensive $\mathrm{CO}_{2}$ and electrical distribution system. The water chenistry will also exert a selection criterion on the algal species. Thus the species must be screened for performance on the anticipated water resource. The water available ay also require soae conditioning prior to use. For algal systems this is likely to be the case when the water hardness (Ca in particular) and carbonate exceed the solubility product at the projected pH range. The situation is more acute when the calcium concentration exceeds the alkalinity. In both cases some water softening will be required. The conditioning is achieved at lowest cost by the addition of sodium carbonate, followed by settling. If removal of agnesium is also required, then both lime and sodium carbonate need to be added.

In Table 2-1, several water resources are shown along with the corresponding carbon chemistry and water conditioning requireaents. Also shown are the outgassing consequences, the precipitation of calciul carbonate, and the levels of dissolved $\mathrm{CO}_{2}$. Figures $2-1,2,3$ show the $\mathrm{pH}$ dependency of these factors and thus the data upon which the specified pH range of operation was chosen. This range is linited on the acid side by 105 s of $\mathrm{CO}_{2}$ due to outgassing and on the basic side to 1) low $\mathrm{CO}_{2}$ concentration and 2l calciua carbonate precipitation. The latter is critical in waters in which there is a lot of calcium which could precipitate causing a turbidity problen and especially critical where the alkalinity is low, as in seawater. Here calcium carbonate precipitation results in a major loss of buffering and carbon storage capacity. When the calcium concentration is low $(1-4 \mathrm{~mm})$ and the alkalinity moderately high (12-40mM), precipitation is not a problen. The figures were constructed assuming infinite solubility of calcium carbonate. At finite solubility (indicated in the figures) the figures are still accurate when carbonate alkalinity is much greater than calcium concentration. On the other hand, seawater chemistry changes considerably as calciun carbonate precipitates. 
Table 2-1. Chemistry of Hater Resources

\begin{tabular}{|c|c|c|c|c|c|c|}
\hline & Seawater & Salton Sea & Type I & LOW TDS & Type II L & Exp't. \\
\hline BDR & .95 & .95 & .125 & .25 & .125 & .125 \\
\hline $\begin{array}{l}\text { Ca removed } \\
\text { ppm }\end{array}$ & - & 600 & 500 & $0-40$ & 125 & 1100 \\
\hline $\begin{array}{l}\mathrm{Na}_{2} \mathrm{CO}_{3} \\
\text { added, pp }\end{array}$ & - & 1500 & 1250 & $0-100$ & 0 & 2750 \\
\hline Cost/acre/yr & $r, \$$ & 5000 & 2400 & 200 & 0 & 300 \\
\hline TDS,gn/1 & 35 & 34 & 32 & 10 & 32 & 32 \\
\hline$K 1 \times 10^{-6}$ & 1.05 & 1.05 & 1.05 & .88 & 1.05 & 1.05 \\
\hline$k 2 \times 10^{-9}$ & 9.55 & 9.55 & 9.55 & .18 & 9.55 & 9.55 \\
\hline$k 5 \times 10^{-6}$ & .5 & .5 & .5 & .05 & .5 & .5 \\
\hline$C a, m M$ & 10.3 & 10.3 & .5 & $1-4$ & $1-4$ & $1-4$ \\
\hline$A 1 \mathrm{~K} ., \mathrm{MH}$ & 2.3 & 2.3 & 32 & 12 & 32 & 24 \\
\hline pH range & $6.5-8.0$ & $6.5-8.0$ & $\begin{array}{l}8-8.5 \\
8-9\end{array}$ & $\begin{array}{l}7.5-8.5 \\
7.5-9.0 \\
7.5-9.5\end{array}$ & $\begin{array}{c}8.0-8.5 \\
8-9\end{array}$ & $\begin{array}{l}8.0-8.5 \\
8.0-9.0\end{array}$ \\
\hline C stor, in & .85 & .85 & $\begin{array}{l}4 \\
8\end{array}$ & $\begin{array}{l}0.9 \\
2 \\
3.5\end{array}$ & $\begin{array}{l}4 \\
8\end{array}$ & $\begin{array}{l}3 \\
6\end{array}$ \\
\hline $\begin{array}{l}\text { c out, } \\
g m / m^{2} / d\end{array}$ & 5 & 5 & $\begin{array}{l}2 \\
2\end{array}$ & $\begin{array}{l}3 \\
3 \\
3\end{array}$ & $\begin{array}{l}2 \\
2\end{array}$ & $\begin{array}{r}<2 \\
2\end{array}$ \\
\hline $\mathrm{CO}_{2}, \mathrm{AM}$ & $.68-.02$ & $.68-.02$ & $\begin{array}{l}.25-.06 \\
.25-.01\end{array}$ & $\begin{array}{l}.4-.04 \\
.4-.01 \\
.4-.003\end{array}$ & $\begin{array}{l}.25-.06 \\
.25-.01\end{array}$ & $\begin{array}{l}.20-.05 \\
.20-.01\end{array}$ \\
\hline $\begin{array}{l}\text { C storage } \\
\text { time,hrs }\end{array}$ & 1 & 1 & $\begin{array}{r}5 \\
10\end{array}$ & $\begin{array}{l}1 \\
2.5 \\
5\end{array}$ & $\begin{array}{r}5 \\
10\end{array}$ & ${ }^{4} 8$ \\
\hline
\end{tabular}




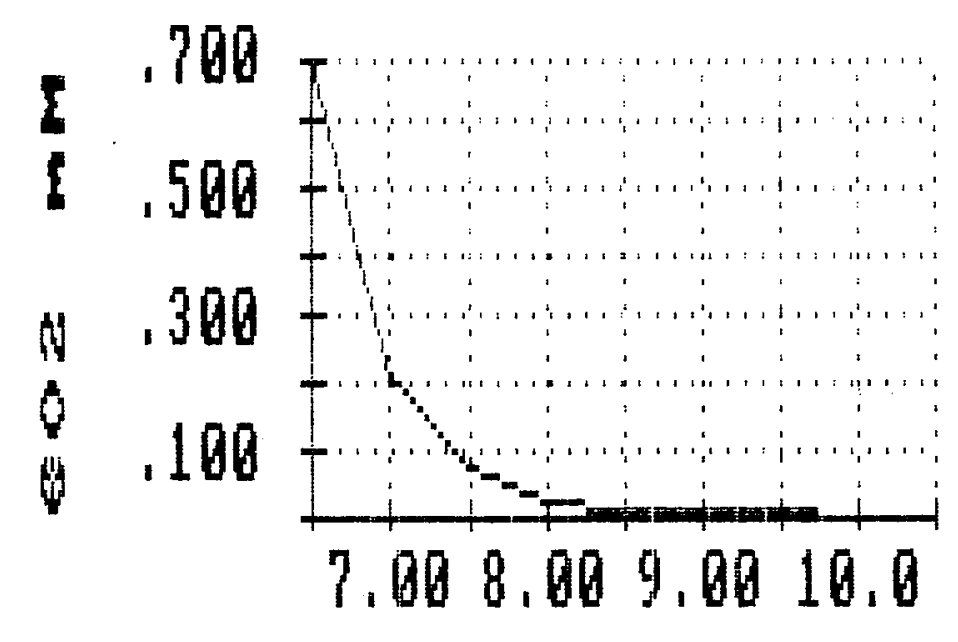

$\mathrm{pH}$

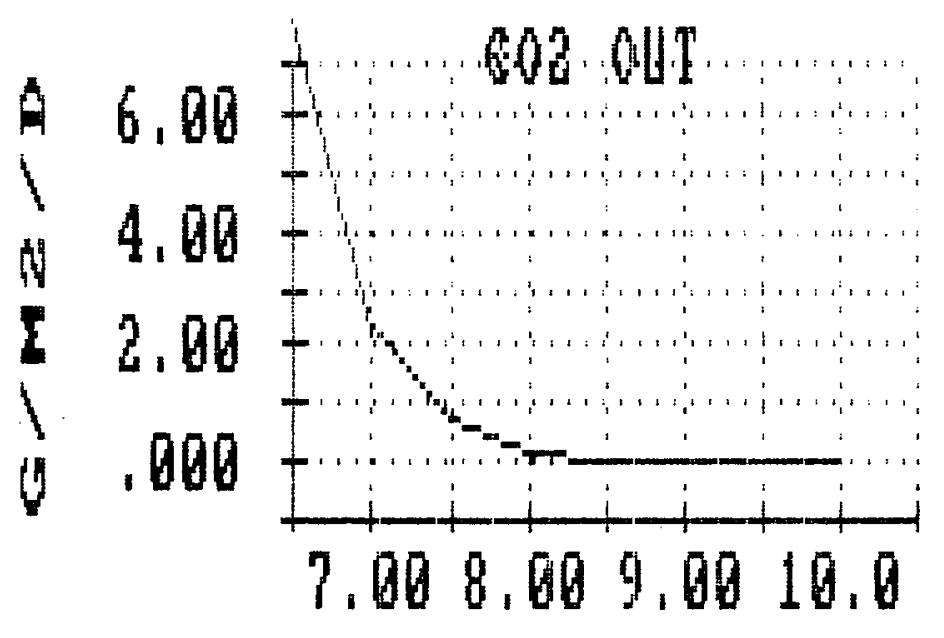

pht

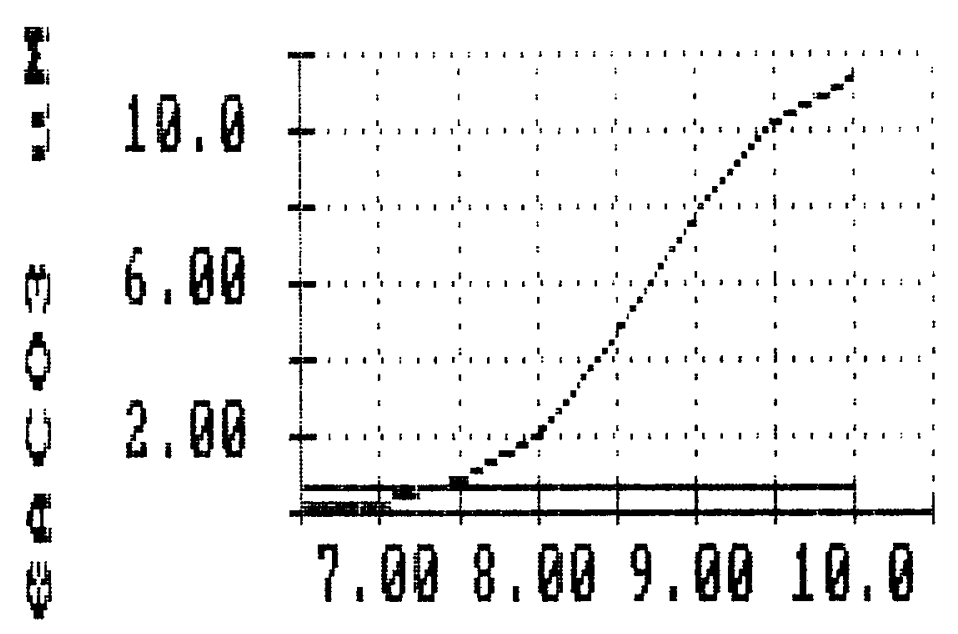

pH

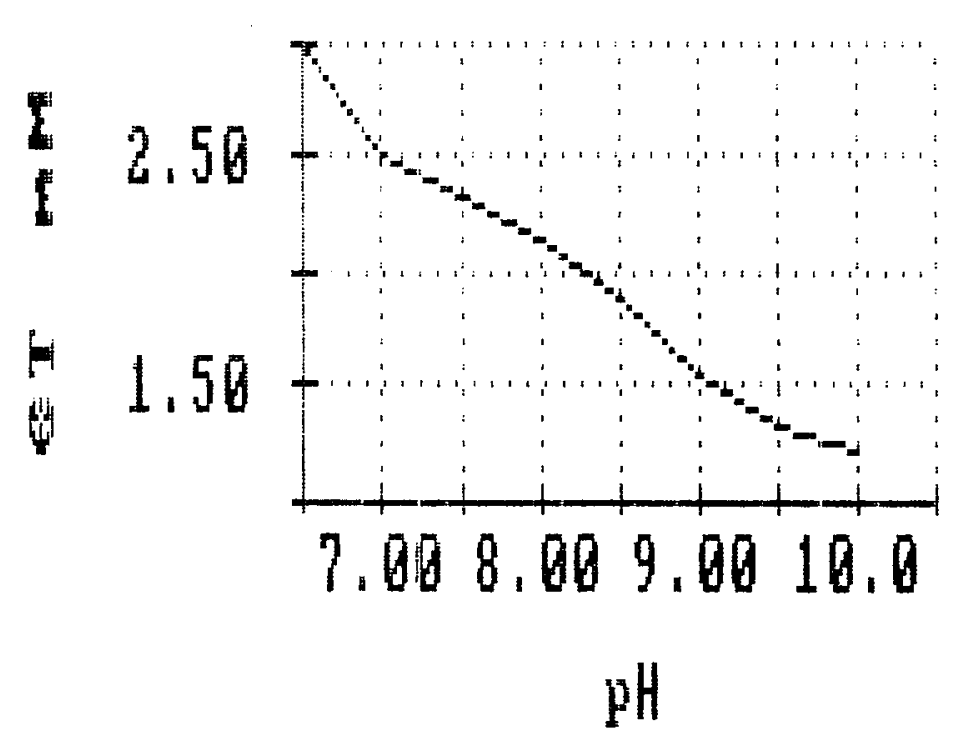

Figure 2-1. Carbonate Chemistry of Seawater (or partially conditioned Salton Sea) 


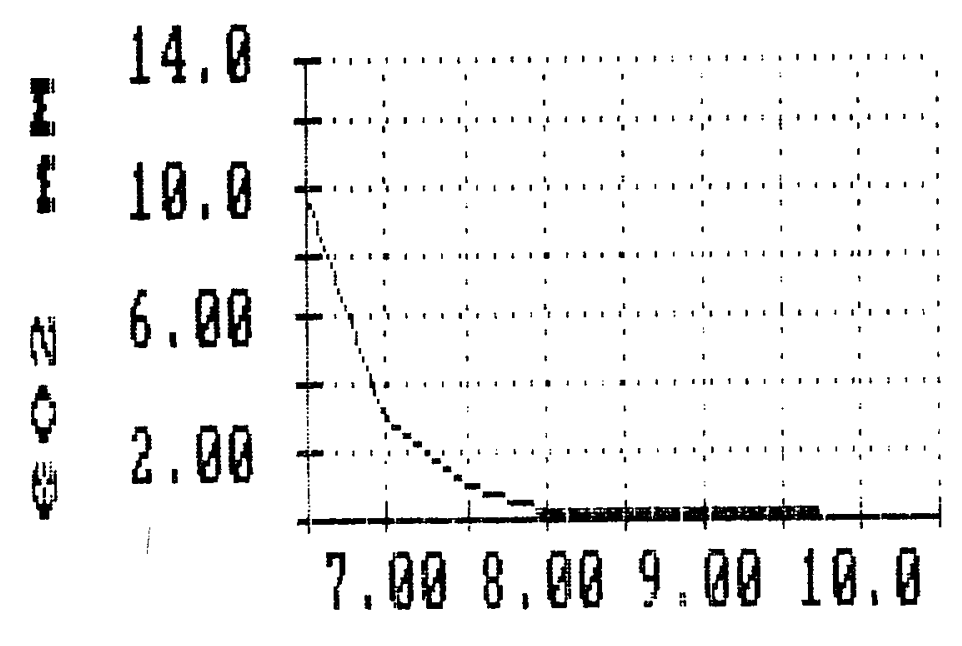

$\mathrm{pH}$
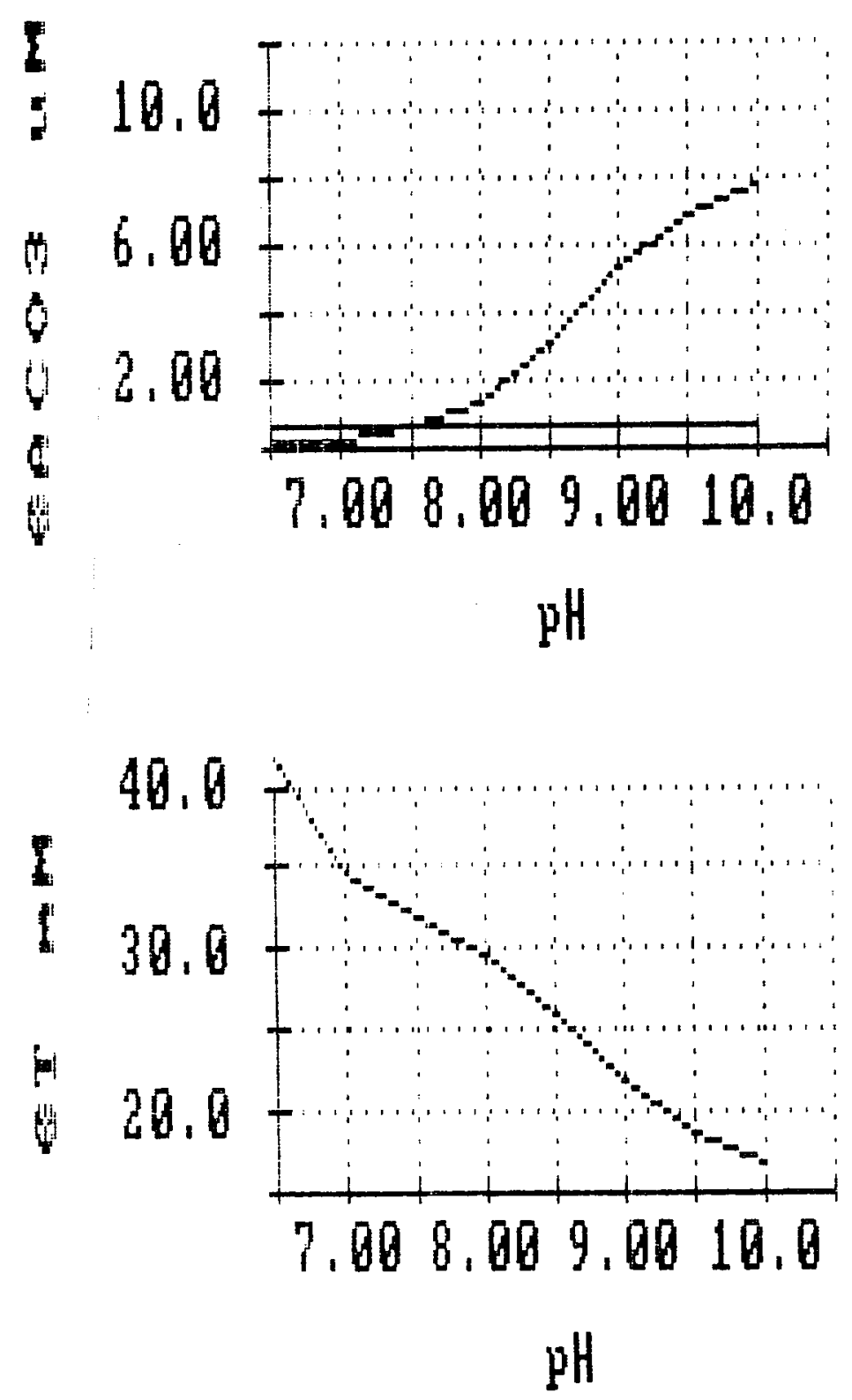

Figure 2-2. Carbonate Chemistry of Conditioned Type II Water: Alkalinity $=32 \mathrm{meq} / \mathrm{L}$ Blowdown $=.125$ 

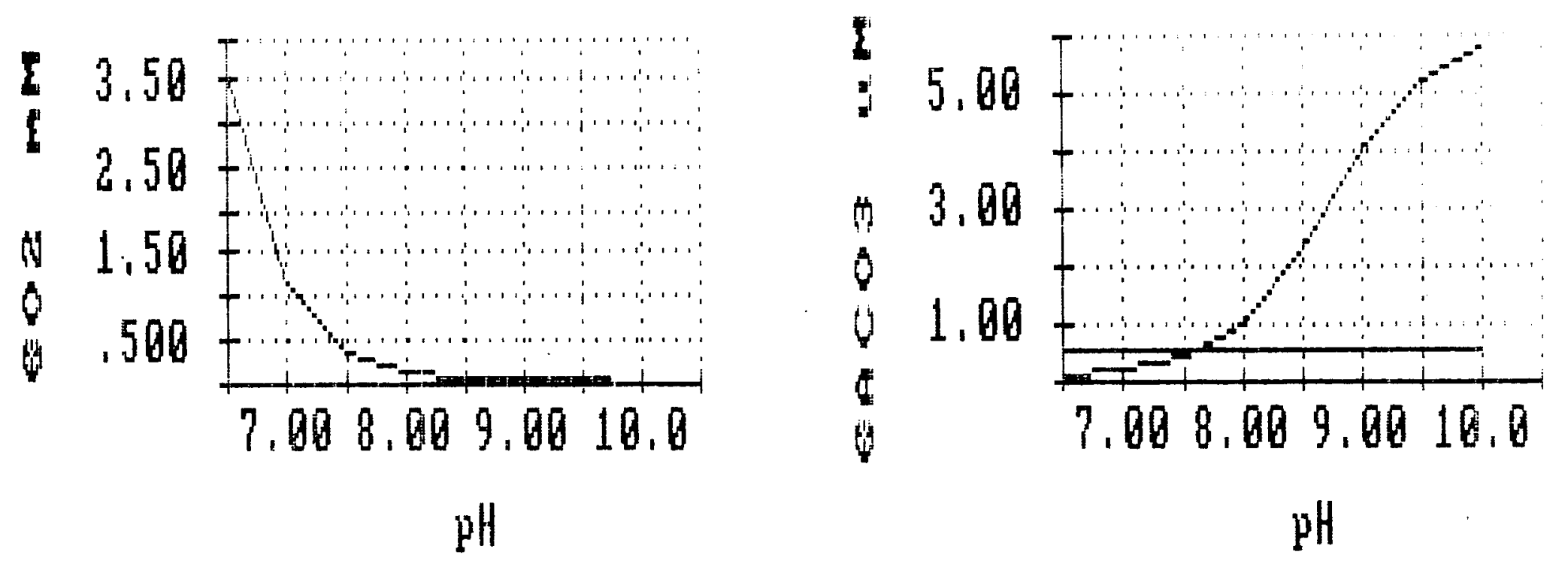

6
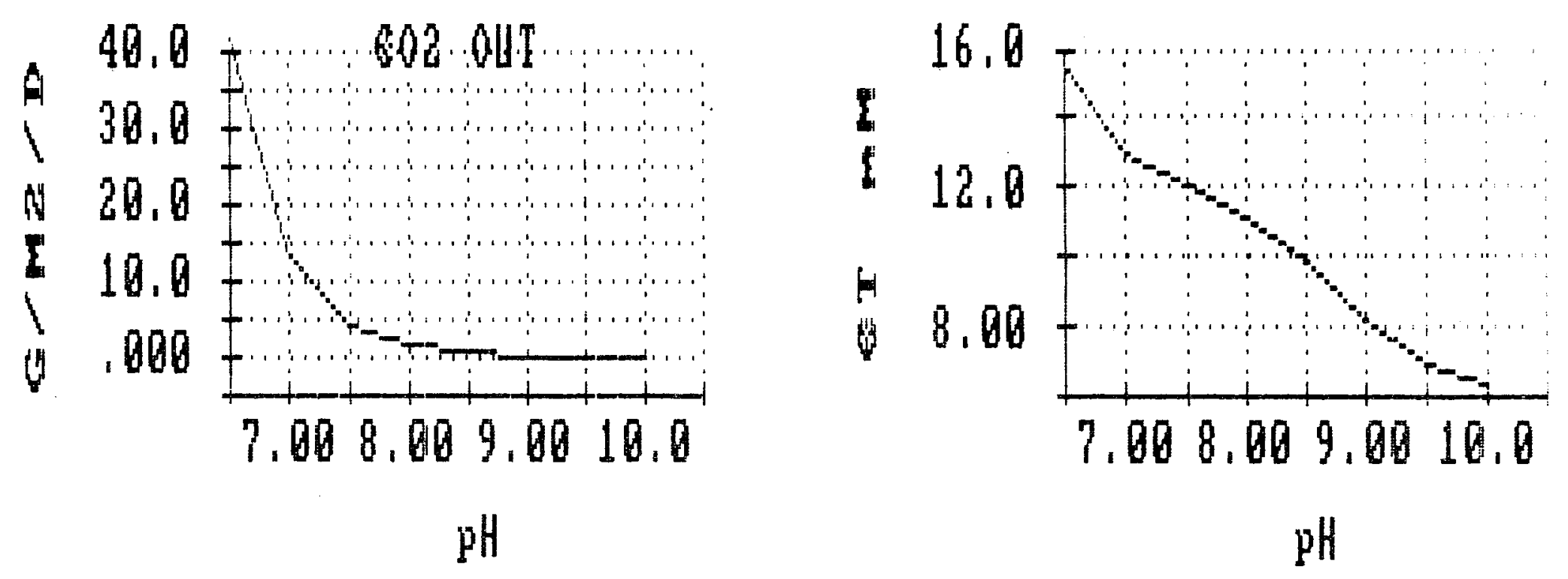

Figure 2-3. Carbonate Chemistry of Type II Water: Alkalinity $=12 \mathrm{meq} / \mathrm{L}$ Blowdown ratio $=.25$ 
Six water resources are characterized in Table 2-1. The first two represent high TDS waters which cannot bear much concentration due to evaporation without severely limiting the number of species which will grow productively. Thus seawater is a resource that requires substantial blowdown. The Salton Sea water can be used at the proposed experimental site in southern California to simulate seawater as ance through resource, after conditioning to remove more than half of the calciua. (Salton Sea water has 2.5 times as much calcium as regular seawater). For seawater the upper limit on $\mathrm{pH}$ is rather strictly set by calcium carbonate precipitation because the alkalinity is so low, as discussed above. The lower limit is set, by $\mathrm{CO}_{2}$ outgassing, at pH about 6.5. Due to the low alkalinity, only about one hours worth of carbon can be stored in the water. If pond depth were halved only a half hours worth of carbon could be stored.

The saline groundwaters examined by SERI were evaluated for their usefulness in open ponds systems. Generally speaking, the major water resource cited, the Type 1 Low is unsuitable for this application. It has too much calcium, requiring $\$ 2400 / a c r e / y r$ for conditioning in chemical cost alone. Although the Type I moderate has a more favorable ratio of alkalinity to calcium, it ends up requiring more sodiun carbonate because it must be blown down aore. The low waters can bear an eight fold concentration whereas the moderate can bear only a twofold concentration. The Type I high has a favorable alkalinity to calciun ratio meaning that the calciun can be removed by equilibration with air in a settling pond to allow precipitation of calcium carbonate, followed by sedimentation. However the water is 50 high in TDS that it cannot be concentrated further and thus too much of it would be required. Not only does it become very expensive to pump so much water, but there is no evidence that enough of this resource exists. So for the purposes of analysis the Type 1 waters are unsuitable. If similar water, but lower in calcium were found it could be utilizable. At 50 tons/acre/yr algal productivity, and a blowdown ratio of . 125 , the chenical cost of calcium removal is about a half cent per kg dry wt. of bionass per 100 ppm calcium.

A similar analysis reveals that the Type II water of TDS a 4ppt can be used despite its high calcium. The much higher alkalinity results in precipitation of most of the calcium as calciun carbonate upon equilibration with the air. The low Type II water can be concentrated many fold in terms of TDS. It is not elear whether high TDS or high alkalinity would first limit the extent to which this water type could be concentrated. Whether magnesium would precipitate as the water concentrates is an issue that must be addressed by experimentation. If not there would be no water conditioning costs beyond a settling pond and possibly some flocculant to remove calcium carbonate precipitates. If magnesiun needed to be removed, lime would be used. A complete water conditioning analysis would be needed. However, preliminary analysis indicates that about $6-8$ m 1 ime would reduce the magnesium content $60 \%$, the alkalinity $70 \%$, leave little residual calcium, and increase the $\mathrm{pH}$ to about 9-9.5. This would cost about one cent per $\mathrm{kg}$ biomass. The uncertainty in the water conditioning status results in an uncertainty in the alkalinity of the treated water. Starting with an excess of alkalinity over calcium of $10 \mathrm{mM}$, an eight fold concentration by evaporation in the ponds would lead to a "steady state" alkalinity of $80 \mathrm{mM}$. This would require a pH of close to 9 to avoid considerable outgassing. It might be difficult to find organisms which grow well at such a high alkalinty and $\mathrm{pH}$ (although the $\mathrm{CO}_{2}$ concentration would still be quite high). 


\subsection{LARGE SCALE DESIGN WATER}

The water source selected for the large scale system design is Type 11 saline groundwater with an initial TDS of 4 ppt. Since removal of calcium, some agnesium, and concomitant alkalinity is likely, the design includes a water holding pond to be used to sediment precipitates. After conditioning and evaporative concentration with a .125 blowdown ratio the steady state salinity is 32 ppt with an alkalinity of $32-60$ m. It is assumed that calciun and magnesium have been lowered to levels which do not cause precipitate problems. Of course, it is also assumed that an adequate resource base exists for this type water.

Given this water resource, with an alkalinity of greater or equal to 32 m, the upper limit of $\mathrm{pH}$ is dictated by the growth response of the algae to $\mathrm{CO}_{2}$ concentration. If the organism grows well at or below air levels of $\mathrm{CO}_{2}$ then the $\mathrm{pH}$ could go up to 9 or higher. If it requires higher $\mathrm{CO}_{2}$ then a pH of 8.5 is more suitable. The low limit is set by outgassing, which increases steeply below $\mathrm{pH} 8$ due to the high alkalinity as shown in Figure 2-3. But, also due to the high alkalinity, large amounts of carbon can be stored with a small change in pH. With just one carbonation station per pond, a pond of 40 acres could be operated. For a 5 maller pond, the pH range could be narrowed, further lowering the outgassing loss fby increasing the low pH liait) or increasing the minimun $\mathrm{CO}_{2}$ concentration (by decreasing the high $\mathrm{pH}$ limit).

\subsection{EXPERIMENTAL SYSTEM WATER RESOURCES AND GROWTH MEDIA}

The proposed experimental site is located in Brawley, California in the Imperial Valley. The site borders the southwest side of the Salton Sea. Water from the sea is available by pipeline or by drilling a shallow well. An existing 1700 gph well provides brackish ( 2.5 ppt) groundwater. As discussed above, saline groundwaters can be expected to contain high levels of alkalinity after concentration. On the other hand waters that are originally highly saline, like seawater, contain little alkalinity. The water resources available on the proposed site can be mixed in various proportions, after conditioning, to obtain waters that are representative of both high and low alkalinity resources. The primary experimental alkalinity will be $24 m e q / 1$. In sone cases, however it will be convenient to operate at lower alkalinities. The basic formula for the experimental water resource for the demonstration system is a mixture of Salton Sea water lafter reaoval of all of the $\mathrm{Ca}$ ) and well water in a ratio of about 19:1 achieving a TDS of 4 ppt and an alkalinity of about 3 meq/1. After evaporation, the TDS is 32 ppt and the alkalinity is $24 \mathrm{meq} / 1$. Any starting TDS is achievable by using a different ratio of Salton Sea water to well water. This allows variation of the concentration of major ions (although not independently) and blow down ratio. Since only the salton Sea water needs conditioning, the cost per acre per year is about $\$ 300$. The conditioning can be achieved by addition of 1 ime and soda ash if both calcium removal and magnesium removal is required. If only calciun is to be reaoved, soda ash alone is added. The practical methods of water conditioning that would be used at the large scale will be tested in 5 mall scale holding ponds. 
SECTION 3.0

ANALYSIS OF CARBONATION SYSTEMS

\subsection{INTRODUCTION}

In the last section, the carbon storage capacity of several waters was analyzed. This, along with the constraints of minimizing dissolved $\mathrm{CO}_{2}$ level at the lowest $\mathrm{pH}$ and maximizing it at the highest $\mathrm{pH}$ defined both the pH range of operation and the transit time allowed between carbonation stations. This transit time was based on the summertime daily demand averaged over 12 hours, which is equal to the production of $4 \mathrm{gm} / \mathrm{m}^{2} / \mathrm{hr}$ of algal biomass. When demand is lower, the ph range can be narrowed and or the carbon inflow rate diminished. In this section the means with which this maximal rate is supplied from the gas strean to the pond liquid is analyzed. The basic chemical engineering of gas-liquid transfer is presented in two appendices; $A I$ and AII. The results for two different types of carbonators, a bubble cover and an in-pond sump, are discussed below. Along with the parameters relevant to each manner of transfer, the consequences on the mixing requirements of the ponds are analyzed.

\subsection{COVERED AREA CARBONATORS--BUBBLE COVERS}

By covering a 5 mall percentage of the pond area with a membrane-covered structure submerged at its edges, gas transfer can occur passively through the pond surface under the cover. The cover serves to trap a gas volume with a high concentration of $\mathrm{CO}_{2}$. The flow of gas under the cover can be turbulent or laminar, depending on the placement of the injection sites. Laminar flow allows somewhat higher stripping efficiencies since the gas bled off will contain the lowest $\mathrm{CO}_{2}$ concentration. A gas bleed is necessary since desorption of oxygen and nitrogen will occur under the cover. If the percent coverage is low the bleed rate needed is even a lower percentage of the inflow rate, so it has little effect on the carbon transfer efficiency.

The percent coverage of the pond depends on the transfer rate of $\mathrm{CO}_{2}$ under the cover. As detailed in Appendix AI, this depends on the hydaulics under the cover, i.e., the rate of turnover of an element of water surface. Several techniques can be used to increase this surface renewal rate. Anything which increases the hydraulic slope under the cover, like increasing the flow velocity by lowering the depth, increases the renewal rate. However, since the area of coverage is not negligible, the effect of this increased mixing on the overall power and head loss must be considered. Alternatively, the roughness coefficient under the cover can be increased. The means proposed for doing this is to increase the roughness of the underside of the cover and place the cover partially in contact with the water. This "rippled" cover design can be effected by using a corrugated aterial for the cover. In this manner the average surface element lifetine for a $20 \mathrm{~cm}$ deep pond mixed at $20 \mathrm{~cm} / \mathrm{s}$, could be decreased from 505 to less 
than 45 (corrugation spacing of $5 \mathrm{~cm}$ ). This, too, will increase the head loss and mixing power required but only about 5-10\%, auch less so than if the same low turnover time were achieved by lowering the depth to $10 \mathrm{~cm}$ and increasing the velocity to $40 \mathrm{~cm} / \mathrm{s}$ under the cover. As shown below this latter design increases the overall ixing head and power required by $50 \%$.

The results of the analysis are shown in Table $3-1$. Three basic cases are detailed: a pond $30 \mathrm{~cm}$ deep nixed at $15 \mathrm{~cm} / \mathrm{s}$, a pond $20 \mathrm{~cm}$ deep aixed at 20 $\mathrm{cm} / \mathrm{s}$, and a shallow pond only $10 \mathrm{~cm}$ deep mixed fast at $30 \mathrm{~cm} / \mathrm{s}$. Several simplifying assumptions were made in constructing the table; the major ones being that temperature is constant at $30^{\circ} \mathrm{C}$, that the water can store the carbon transferred, and that the dilution by $\mathrm{O}_{2}$ outgassing is negligible. It can be seen from the results that a low concentration $\mathrm{CO}_{2}$ gas phase (like flue gas) would require much to high a percent coverage in all caseg. In order for the coverage to be less than $5 \%$, a turnover tiae of less than 10 5 is required, which is theoretically equivalent to a mass transfer coefficient of .04-.05 $\mathrm{m} / \mathrm{hr}$. The coefficients used in the construction of Table 3-1 were obtained from empirical correlation of stream flow data (see Appendix Al). The coefficients measured by Weissaan and Goebel [1] in high rate ponds $20 \mathrm{~cm}$ deep mixed at $20 \mathrm{~cm} / \mathrm{s}$ were higher by a factor of 3.4 than those calculated using the correlation. If the higher, measured values are used then each of the values for \% coverage in Table 3-1 could be peduced by multiplying by .3. The percent coverage for cases 2 a and 3 then become $8 \%$ and $4 \%$ respectively. If in addition, the rippled cover is used instead of the 5 mooth one, then the covered area for case $2 \mathrm{a}$ is reduced fron $8 \%$ to $2 \%$. In case 3 , this reduction is only from $4 \%$ to $2 \%$ since the turnover time was initially shorter.

The assumption here is that a covered area carbonator is feasible if the percent coverage is low labout $2 \%$ ). This may be achievable with a smooth cover in shallow, fast mixed ponds, in $20 \mathrm{~cm}$ deep ponds if the area under the cover is made shallow, or in these moderately deep, moderately mixed ponds if a rippled cover is used. The effects on aixing head and power can be expected to be significant when a portion of the pond is made shallow, but 5 mall when the roughness and wetted perineter are increased by a rippled cover.

\subsection{IN-POND CARBONATION SUMPS}

An alternative way of transferring $\mathrm{CO}_{2}$ to the pond water ig to inject the gas at or near the botton of a sump which spans all or part of the channel. As in the case of the covered carbonator, theoretical results must be taken as only approximate since the actual process involved is complex. In all of these gas transfer problems, the real answer is only obtained from the operation of pilots. Nonetheless, the theoretical treatments do give a sense of what is possible and econonically feasible. The chemical engineering treatment of sump carbonation is detailed in Appendix Il. The major results of that analysis and the major uncertainties involved will be sumarized first. 
Table 3-1. Covered Carbonator - \% Areal Coverage

\begin{tabular}{|c|c|c|c|c|c|c|c|}
\hline Case & $1 a$ & $1 b$ & $2 a$ & $2 b$ & $2 c$ & 32 & 36 \\
\hline $\begin{array}{l}\text { Depth } \\
\text { Ca }\end{array}$ & 30 & 10 & 20 & 10 & 20 & 10 & 10 \\
\hline $\begin{array}{l}\text { Vel. } \\
\mathrm{cm} / \mathrm{s}\end{array}$ & 15 & 45 & 20 & 40 & 20 & 30 & 30 \\
\hline & .013 & .070 & .022 & .061 & .085 & .047 & .085 \\
\hline$c$ in * & 380 & 2200 & 640 & 1900 & 2465 & 1400 & 2465 \\
\hline c req.* & 166 & 166 & 166 & 166 & 166 & 166 & 166 \\
\hline \% area & 44 & 8 & 26 & 10 & 6.7 & 12 & 6.7 \\
\hline $\begin{array}{l}\text { head } \\
\% \text { 1a }\end{array}$ & 100 & 170 & 300 & 450 & $-\infty$ & 1700 & -- \\
\hline $\begin{array}{l}\text { power } \\
\% \text { la }\end{array}$ & 100 & 170 & 400 & 600 & --- & 3500 & --- \\
\hline \multicolumn{8}{|c|}{ 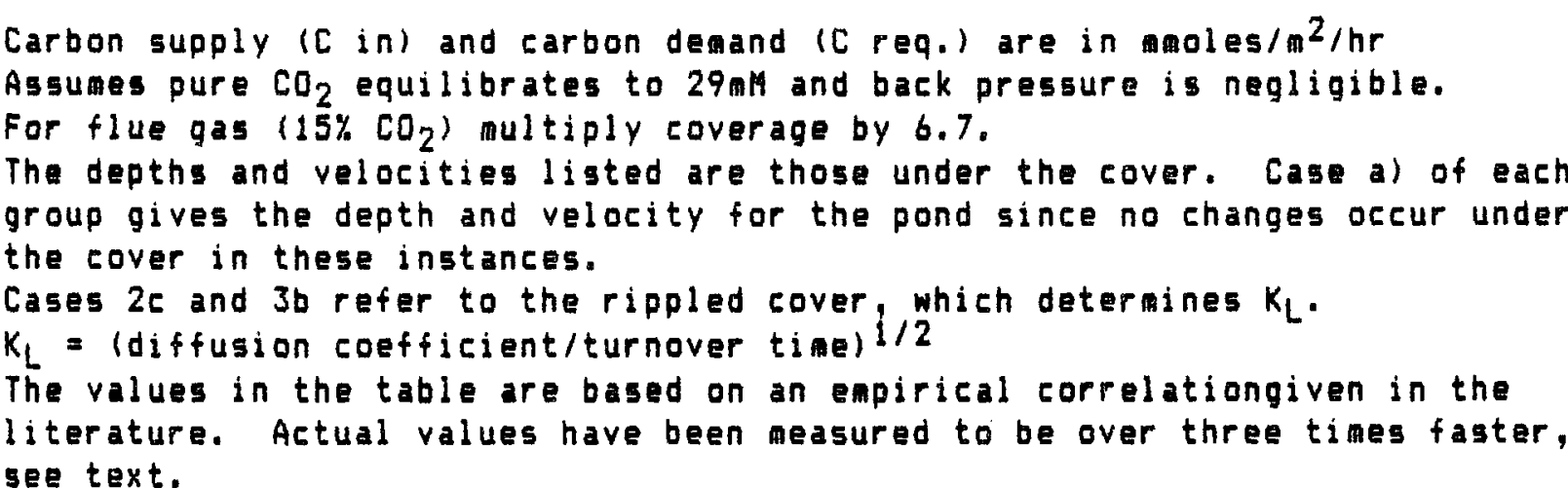 } \\
\hline
\end{tabular}


Gas transfer is qualitatively different in sumps. Under bubble covers the hydraulics of the flow under the cover determines the ixing that is needed to disrupt the thin filn which effects transfer and ixes the dissolved gas with the bulk liquid. In sumps it is the movement of the bubble swarm relative to the flowing liquid which "renews" the transfer surface. Thus the behavior of bubble swarms determines transfer rates. This behavior is quite complicated and the models used thus only appoximate the actual process.

The major uncertainties in the modeling are the bubble size distribution, the consequent average rise velocity relative to the water, and thus the average rate of gas-liquid transfer. In the treatment in Appendix II, an average bubole rise velocity, relative to the water, of $30 \mathrm{~cm} / 5$ was assumed. It was further assumed that the mass transfer rate distribution is very narrow. These assumptions have eapirical justification, in that it has been found that after about .5-1.0 meter of $r$ ise the bubbles coalesce to a minimum equilibriun size with these characteristics. However it has been noted [6,7] and easured $[1,6,7]$ that in shallow sumps the transfer rates exceed, by a large factor, those predicted on the basis of this equilibrium. Consequently, we will analyze the sensitivity to assumed transfer rate. Given a transfer rate, one can estimate the average bubble dianeter and then the rate of rise. With this information, the basic parameters of sump transfer can be calculated. These paraneters are the depth of the sump required to strip a specified percentage of $\mathrm{CO}_{2}$ and the gas hold-up which determines (for a given sump depth) the head gained by the water column in co-current flow or the head opposing the water flow in counter-current flow. One more case of interest is when the sump does not contain a baffle to direct the water flow. In this case of "lateral" flow the gas has little effect (except causing some extra turbulence) on water head.

The average hold-up,e, is given by the following formula for co-current flow:

$$
e=Q_{g} C_{p e} /\left(Q_{L}\left(1+V_{B} / V_{L}\right)+Q_{g} C_{p e}\right\}
$$

$Q_{Q}$ is the gas flow rate, $Q_{L}$ is the water flow rate, $V_{B}$ is the average rise velocity of the bubbles relative to the water, $V_{L}$ is the water velocity, and $C_{p e}$ is the average pressure correction factor for the compression of the gas at subsurface depths. Appendix Table AII-1 gives values for this correction factor as a function of depth. For pure $\mathrm{CO}_{2}$ a further correction factor is required since the voluae of gas decreases with time as gas is absorbed. This factor is the $10 \mathrm{~g}$ mean of the flow rate at the entrance to the sump and at the exit. There is also a pressure factor to account for the fact that most of the gas volume is at the lower depths. This is somewhat arbitrarily assigned the value of $p_{a t n} / p_{2 / 3}$, but is only of the order of $10 \%$ for shallow sumps. For counter-current flow the term inside the parentheses in the denominator becones $V_{B} / V_{L}-1$ where $V_{B}>V_{L}$ and both are considered absolute (positive) values. The hold-up is related to the lift or head by:

$$
h_{0}-h_{j}=h_{0}-K V_{L}^{2 / 2 g}
$$


where $h_{0}$ is the level of outflow above the sump sparger, $h_{i}$ is the distance between the inflow liquid level and the sparger level, $g$ is the acceleration of gravity, and $K$ is a friction factor for $105 s e s$ upon entry, transit through, and exiting the sump. These losses are small at low liquid velocities.

As discussed in Appendix II, the stripping rate of oxygen has been found to be $.7 \% / \mathrm{s}$ or, at a bubble rise velocity of $30 \mathrm{~cm} / \mathrm{s}$ in till water, .7\%/foot. The transfer for $\mathrm{CO}_{2}$ is related to that of oxygen by the ratio of the diffusion coefficients to the two-thirds power times the ratio of the solubilities. At $20^{\circ} \mathrm{C}$ this ratio is about 18 , yielding a stripping rate for $\mathrm{CO}_{2}$ of $12.5 \% / \mathrm{s}$. Table 3-2 shows the sump depth required for stripping 95\% of the inflowing gas from the bubbles given several different stripping rates per second. This stripping rate has to be considered an unknown parameter since measured values have been found to depend on sump depth, some have been found to be much greater, and the bubble size is known to depend on sparger type and flow rate as well[6,7]. For low flow rates, spargers which produce fine bubbles (and hence are more expensive) can be used. These will likely provide transfer rates higher than those calculated based on the oxygenation experiences, since it may take a considerable fraction of the sump height for an equilibriun bubble size to be reached. As flow rate increases, due either to the use of recycle or in the flue gas utilization case, not only does initial bubble size increase in a device specific manner, but the type of device may need to be changed to one which can handle the higher flow rates at moderate cost. Ususally this means that the device produces larger bubbles to begin with. To add to the uncertainty, the salinity of the mediun affects the equilibrium bubble size and the rate of attainment of equilibrium due to the inhibitory action of charged species on bubble coalescence. Significant enhancement of transfer rates has been seen at TDS as low as 5 ppt [8].

The lowest rate shown in Table 3-2 corresponds to the rate found for oxygenation (adjusted for $\mathrm{CO}_{2}$ ), the next lowest is considered the minimum value that would exist in a shallow sump when purified $\mathrm{CO}_{2}$ is used, and the last is a value which is similar to that found by Weissman and Goebel [1] in a water column of $20 \mathrm{~cm}$. The table shows the sump depths for co-current, counter-current, and lateral (no baffle to direct water flow) flow. In addition, the bubble size and bubble rise velocities calculated from the analysis of Aiba et al[7] which would yield the given stripping rate, are shown. These values must be taken as highly approximate, but do aid in choosing sparger type. As bubbles get above .2-.25 $\mathrm{cm}$, they change fron being rigid spheres to having deformable walls. One consequence of this is that the rate of gas transfer fron the bubbles becomes somewhat insensitive to bubble size because the volume to surface area ratio decreases with deformation. At even moderate gas flow rates, the turbulence prevents the bubble size from getting very uch larger than .5-1 cm. In the end, only experimentation will yield reliable results and design specifications. 
The cost of construction of a sump depends on sump depth. Not only does the material requirement increase with depth, but in addition, deep sumps require nore expensive construction methods. For this reason, the suap depth is to be kept below 1.5 or so. Costs of construction in this range of depth are relatively low.

A method that can be used to keep the sump shallow is to cover it with a membrane, capture the gas, and recycle it via a blower back down to the sparger. Given a sump depth of 1.5 meters, the recycle ratio required to achieve 90-95\% (using pure $\mathrm{CO}_{2}$ ) or $80 \%$ (using flue gas) overall stripping of carbon is shown in Table 3-3 for several different conditions. A lower removal efficiency is used for flue gas because the back pressure from dissolved $\mathrm{CO}_{2}$ becomes significant as carbon is stripped from the dilute gas. Since the depth of the sumps cannot be predicted precisely, recycle adds flexibility to the ways in which a given sump depth $c$ an be made adequate.

Table 3-2. Effect of Assumed Transfer Rate on Sump Depth

Transfer Rate, Removal/s

Bubble Diameter, col

Rise Velocity, ca/s 2

Distance Traveled/s, cm

Co-current

Lateral

Counter-current.

Time Required, 95\% Overall

Renoval, 5

Sunp Depth, 95\% Overall

Removal,

Co-current

Lateral

Counter-current

Liquid velocity $=20 \mathrm{~cm} / \mathrm{s}$

Id Rate-2/3 [7]

2 [7] and Stoke's Law
13

$>.2$

30

50

30

10

23

11.5

7

2.3

4.2

1.7

1.8

0.5
25

.125

15

35

15

--

12

6

29

9

--

50

08

9 
Table 3-3. Sump With Gas Recycle

\begin{tabular}{|c|c|c|c|}
\hline & $\begin{array}{l}\text { Transfer Rate } \\
\text { K Removal/s }\end{array}$ & $\begin{array}{l}\text { Overall } \\
\text { Removal, } \%\end{array}$ & 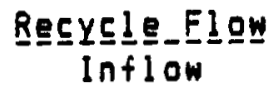 \\
\hline \multicolumn{4}{|l|}{ Pure $\mathrm{CO}_{2}$} \\
\hline \multirow[t]{4}{*}{ Co-current } & 25 & 90 & .37 \\
\hline & 25 & 95 & .44 \\
\hline & 13 & 90 & 1.8 \\
\hline & 13 & 95 & 1.9 \\
\hline \multirow[t]{3}{*}{ Lateral } & 25 & 90 & .04 \\
\hline & 13 & 90 & .9 \\
\hline & 13 & 95 & 1.0 \\
\hline \multirow[t]{2}{*}{ Counter-current } & 13 & 90 & .05 \\
\hline & 13 & 95 & .1 \\
\hline
\end{tabular}

$15 \% \mathrm{CO}_{2}$

$\begin{array}{llll}\text { Co-current } & 25 & 80 & .96 \\ & 13 & 80 & 6.5 \\ \text { Lateral } & 13 & 80 & 3.0 \\ \text { Counter-current } & 13 & 86 & .01\end{array}$

Sump Depth $=1.5$ meter

Liquid velocity $=20 \mathrm{~cm} / \mathrm{s}$ 
Table 3-4 gives the average hold-up as a function of $\mathrm{CO}_{2}$ denand for co-current flow in a sump of depth $1.5 \mathrm{~m}$. This gives a range of head lift to be expected during carbonation. The assumed stripping rate way be too high for flue gas relative to pure $\mathrm{CO}_{2}$ since the gas flow rates, and consequently the hold-up are so high. The lift for the flue gas case in which inflow of gas is provided 24 hours a day is just sufficient to mix the 8 hectare pond. However, the $\mathrm{CO}_{2}$ injection efficiency is quite low.

Table 3-5 gives results for counter-current flow. Here the water velocity can be lowered by widening the sump beyond the value of the pond depth to prevent wash-through of the average bubble, and to reduce the head opposing the channel flow. As can be seen from the table, the opposing head is already significant when pure $\mathrm{CO}_{2}$ is used and prohibitive when flue gas is used. To a good approximation, the hold-up is inversely proportional to sump width. An equation is given in the Table 3-5 relating hold-up to transfer rate, sunp volume, and gas flow for the case in which the liquid velocity is equal to the average bubble rise velocity but opposed to it. In this case hold-up depends on the steady state ratio of gas to liquid volumes. It can be decreased by deepening the sump.

The values of hold-up and head shown in Tables 3-4 and 3-5 were calculated for an eight hectare pond, which was the size chosen for the large scale design. If a pond size of four hectares was chosen, halving the flow of $\mathrm{CO}_{2}$ into the sump, no adjustment is required in hold-up and head if the length to width ratio is changed so that channel width is also halved (thus halving the liquid flowrate). By maintaining the same length to width ratio of 20 , the liquid flowrate only decreases by a factor of 1.4 . Thus the ratio of gas to liquid flowrates in the sump decreases by a factor of 1.4 , decreasing hold-up and head by the same factor at low flowrate ratios, and somewhat less at high ratios. Head attained with gas lift pumps is discussed more fully in Section 4.0 . 
Table 3-4. Average Hold-up and Lift in 1.5 . Deep Carbonation Sumps

Co-current, transfer rate $=25 \% / \mathrm{s}, V_{B}=15 \mathrm{~cm} / \mathrm{s}$

\begin{tabular}{|c|c|c|c|}
\hline $\mathrm{CO}_{2}$ req. , gm/ $/ \mathrm{R}^{2} / \mathrm{hr}$ & 8.6 & 8.6 & 4.3 \\
\hline Gas Composition, $\% \mathrm{CO}_{2}$ & 100 & 13 & 100 \\
\hline
\end{tabular}

No Recycle, Overall Removal $=71 \%$

Input Gas Flowrate, 1/5 $\quad 167 \quad 1129 \quad 83 \quad 561$

Gas flowrate/Liq.flowrate $\quad .056 \quad 065028$

$\begin{array}{lllll}\text { Hold-up, } \% & 2.9 & 26 & 1.5 & 14.7\end{array}$

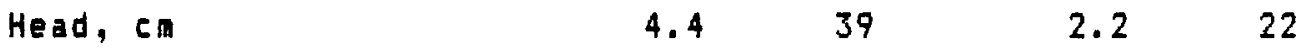

With Recycle

$\begin{array}{lllll}\text { Overall Removal, \% } & 95 & 80 & 95 & 80\end{array}$

$\begin{array}{lllll}\text { Input Gas Flowrate, 1/s } & 116 & 925 & 58 & 462\end{array}$

Gas flowrate/Liq.flowrate $\quad .06 \quad 1.04 \quad 03 \quad .032$

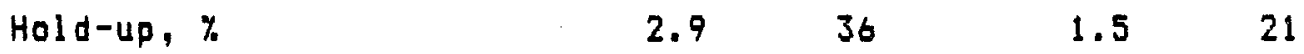

Head, en $\quad 4.4 \quad 54 \quad 2.2 \quad 33$

$\mathrm{CO}_{2}$ req. $=(1.2)(1.8) \times$ algal productivity (either 4 or $2 \mathrm{gm} / \mathrm{m}^{2} / \mathrm{hr}$, includes $20 \%$ for increased $C$ content of high lipid producing algae.

Pond area $=8$ hectare

Input gas flowrate at 1 atm, $30^{\circ} \mathrm{C}$.

Liquid flowrate through sump $=17251 / 5$ (43.1 wide channel, 20 ch deep, $V=$ $20 \mathrm{~cm} / \mathrm{s}$, sump spans channel, sump width equals pond depth)

For pure $\mathrm{CO}_{2}$ cases, gas flowrate (for ratio) is log mean of gas flow rate at suap botton and sump top, pressure corrected.

See Table 3-3 for recycle ratios. 
Table 3-5. Average Hold-up and Lift in Counter-Current Sumps

Counter-current, transfer rate $=13 \% / \mathrm{s}, V_{B}=30 \mathrm{~cm} / \mathrm{s}$

$\begin{array}{lcccr}\mathrm{CO}_{2} \text { req.,gm/mihr } & 8.6 & 8.6 & 4.3 & 4.3 \\ \text { Gas Composition, } \% \mathrm{CO}_{2} & 100 & 15 & 100 & 15 \\ \text { No Recycle, Overall Renoval } & =86 \%, \text { Sump Depth }=1.5 \mathrm{~m} \\ \text { Input Gas Flowrate, 1/5 } & 128 & 860 & 64 & 430 \\ \text { Gas flowrate/Liq.flowrate } & .03 & .50 & .015 & .25 \\ \text { Hold-up, \% } & 5.3 & 48 & 2.7 & 32 \\ \text { Head, } 6 \text { m } & 8.0 & 72 & 4.1 & 48\end{array}$

With Recycle, Sump Depth $=1.0 \mathrm{~m}$

$\begin{array}{lcccc}\text { Overall Removal, \% } & 95 & 85 & 95 & 85 \\ \text { Recycle Ratio } & .31 & .17 & .31 & .17 \\ \text { Input Gas Flowrate, 1/5 } & 116 & 870 & 58 & 435 \\ \text { Gas flowrate/Liq.flowrate } & .047 & .59 & .023 & .30 \\ \text { Hold-up, \% } & 8.1 & 52 & 4.2 & 36 \\ \text { Head, ca } & 8.1 & 52 & 4.2 & 36\end{array}$

Counter-current, $v_{B}=V_{L}$

Pure $\mathrm{CO}_{2}:$

Holdup = Input gas flowrate/transfer rate/sump depth/sump Xsec. area Flue gas: hold-up gets very large as unabsorbed gas builds up, until channeling occers.

For conditions see Table 3-4. 


\subsection{RECYCLE OF NON-LIPID CARBON FROM EXTRACTION RESIDUES}

Since carbon is one of the most expensive inputs to the system, and since only part of the carbon is extracted in lipid products, recycle of the carbon remaining in the unextracted residues must be considered. An effective method of processing the residues is to anaerobically digest then. A covered lagoon is specified in the large scale design for this. With $60 \%$ of the algal biomass as Jipid and $90 \%$ of this extracted, the residues contain $46 \%$ of the algal carbon. 65\% of this will degrade in the lagoon to methane and $\mathrm{CO}_{2}$ in a ratio of $6: 4$. The other $35 \%$ will be split between the two liquid compartaents of the lagoon: the sludge and the lagoon water. Both the gaseous components and the lagoon water (effluent) can be recovered. The digester gas is combusted to operate an engine generator. The resultant flue gas is about $14 \% \mathrm{CO}_{2}$, and contains $31 \%$ of the original algal carbon. Mixing this with the pure $\mathrm{CO}_{2}$ input, in a ratio (by volume at STP) of $7: 1$, yields a gas containing $35 \% \mathrm{CO}_{2}$. If this is then injected into the ponds with a 90-95\% efficiency, and the dissolved carbon in the digester effluent is recyeled back to the ponds, the result is a decrease in overall $\mathrm{CO}_{2}$ input from $2.4 \mathrm{~kg} / \mathrm{kg}$ algae to $1.6 \mathrm{~kg} / \mathrm{kg}$ (see Table $6-3$ ).

The 35\% $\mathrm{CO}_{2}$ gas phase can be introduced into the ponds just as any other gas phase. Now, however, an overall stripping efficiency of $90 \%$ is assumed as opposed to $95 \%$ with pure $\mathrm{CO}_{2}$ since backpressure reduces the driving force near the top of a sump. Again, the transfer rate is not certajn. With $90 \%$ overall removal, the sump would have to be 5.3 weep if the transfer rate is $13 \% / 5$ and 1.3 deep if the rate is $25 \% / 5$, for lateral flow of the pond relative to the bubbles. If the gas is injected co-currently, wore head can be gained than in the pure $\mathrm{CO}_{2}$ case due to the larger gas volune. For the two transfer rates, the sump depths required are 7-9 and $2.3-3$. respectively. The lifts obtained are 28-53 cm and 17-27 cm respectively. Thus the lift gained by co-current injection of a mixture of pure and recycled digester flue gas matches the mixing requirements of the system when moderate transfer rates are assumed.

The recycle of non-lipid carbon has perhaps the greatest potential for reducing the cost of the lipids produced of any single factor. This will be more fully discussed in several ensuing chapters.

\subsection{OXYGEN DESORPTION}

The desorption of oxygen, and nitrogen to a lesser extent, affects the efficiency of $\mathrm{CO}_{2}$ transfer in both sumps and under covers. The ratio of oxygen mass transfer to $\mathrm{CO}_{2}$ transfer depends approximately on the $r a t i o$ of driving forces, since diffusion coefficients are siailar. Assuning no $\mathrm{CO}_{2}$ back pressure, which is very nearly true in the pure $\mathrm{CO}_{2}$ case even with $95 \%$ absorption, and a dissolved oxygen concentration that is $500 \%$ of saturation, the dilution of $\mathrm{CO}_{2}$ by $\mathrm{O}_{2}$ under a covered area carbonator is only about 
10\%. That is, at steady state the gas phase under the cover would be over $90 \% \mathrm{CO}_{2}$ and the bleed rate would be about $10 \%$. If $\mathrm{CO}_{2}$ moved by plug flow across the "ripple" covered channel, then at the end the transfer rate would be slowed somewhat by oxygen dilution, but the gas bled off would have a higher oxygen concentration. Similarly, in sumps the $\mathrm{CO}_{2}$ transfer rate would decrease near the top of the sump where the dilution of the gas phase with oxygen is greatest. This dilution would not affect transfer significantly in the pure $\mathrm{CO}_{2}$ case, because ample driving force of $\mathrm{CO}_{2}$ would remain until very near the top of the sump. Since flue gas is already dilute in $\mathrm{CO}_{2}$, further dilution would also not be significant except at the tail end of transfer. It should be noted, however, that the back pressure of dissolved $\mathrm{CO}_{2}$ may be significant when carbonating moderately alkaline waters to near neutral pH when flue gas is used, with or without further dilution by oxygen.

Potentially more serious is the desorption of supersaturated oxygen in a sump due to nucleated bubble formation. Using the mass transfer coefficient for outgassing through the surface of a $20 \mathrm{~cm}$ deep pond $\mathrm{mixed}$ at $20 \mathrm{~cm} / \mathrm{s}$ and the supersaturation level of $500 \%$ found by Weissman and Goebel [1], sbout $40 \%$ of the oxygen produced outgassed due to mass transfer through the surface of the pond. Since these conditions existed for prolonged periods of time, $60 \%$ can be estimated to have desorbed due to nucleated bubble formation. If oxygen loss in a suap, for example, reduced steady state levels to $200 \%$ supersaturation, the mass transfer loss through the pond surface would be only 25\% of the oxygen produced. At the lower Do nucleated bubble formation would be substantially reduced, implying that about 50\% of the oxygen produced would need to be removed in the sump to maintain such a low DO. The rest of the oxygen desorbs, due to nucleated bubble formation, through the pond surface. The rate of desorption through the surface by bubble formation (as distinguished from nass transfer) calculated from the above condition $(500 \%)$ is $.007 \mathrm{mM} / \mathrm{s}$. In order for the DO to be dropped from $500 \%$ to $200 \%$ by sparging air in a sump with gas residence time of 45 , the desorption rate would have to be 25 times as great. At this point no data exists concerning the desorption of supersaturated oxygen due to carbonation or aeration. However if such a reduction was attained it would dilute the gas volume of pure $\mathrm{CO}_{2}$ by $30-80 \%$, depending on the ratio of input gas flow rate to the flow rate of pond liquid through the carbonator. This would have impact on sump design, i.e., sump depth required for a given transfer efficiency, especially in sumps with recycle. The desorption of supersaterated oxygen and the impact on suap design will be tested in the proposed experinental systen. Of course, if very efficient removal of oxygen were attainable, a separate sump just for this purpose would be constructed ahead of the carbonation sump. In the case of flue gas carbonation, the dilution is 5-10\%, which would further aggravate the backpressure problem for transfer near the top $25 \%$ of the sunp. 
The desoprtion in sumps by sparged gas will be used to determine the practicality of using aeration as a means of preventing the build-up of oxygen to inhibitory levels, i.e., to determine how many sumps would be required to maintain the DO within specified limits.

\subsection{CHEMICAL ENHANCEMENT OF CARBON DIOXIDE TRANSFER}

A detailed discussion of the chemical reactions of $\mathrm{CO}_{2}$ with other dissolved species, and the effect of this on transfer coefficients, is given in Appendix I. Even at the highest alkalinities and $\mathrm{pH}$ inagined for algal ponds, the enhancement due the reaction of $\mathrm{CO}_{2}$ and hydroxyl ions is negligible. The $\mathrm{pH}$ independent, first order reaction of $\mathrm{CO}_{2}$ and water to form bicarbonate is fast enough to enhance transfer rates that have not already been enhanced hydraulically by increased surface renewal. The two processes are competitive, so that the chemical enhancenent is still very snall in sumps, where surface renewal rates are on the order of 100-150 per second. The covered area systems were designed so that surface renewal rates were as high as possible to increase transfer rates. The renewal rates discussed above were on the order of .25/s for $2 \%$ coverage and $.016 / \mathrm{s}$ for 13\% coverage. Chemical enhancenent due to a first order reaction goes as the square root of $1+k / s$ where $k$ is the reaction rate constant and $s$ is the surface renewal rate. $k$ is equal to about $.02 / 5$. Thus physical transfer rates would have to be small, meaning high areal coverage, for chemical enhancement to have much effect. It may be of interest that several catalysts which have significant effect on the first order rate constant may be present in an algal system. These include carbonic anhydrase which is often secreted by algae and phosphate which is a media component.

Enhancement due to these can be tested by comparing transfer in media not including these species to that in media which does contain then.

\subsection{LARGE SCALE SYSTEM CARBONATOR DESIGN}

The Base Case design specification of the carbonation systen for the large scale system will be taken as a 1.5 m deep sump for the introduction of pure $\mathrm{CO}_{2}$. Pure $\mathrm{CO}_{2}$ mixed with anaerobie digester flue gas serves as a case with significant cost reduction possibilities. The use of unpurified power plant flue gas would most likely require deeper sumps. In addition, unless the power plant is actually within about $1 \mathrm{~km}$ fron the pond systen, the transport of dilute $\mathrm{CO}_{2}$ becones too expensive [2]. Thus even if power plant derived gas is used to serve multiple large pond systems [9], it may well have to be purified for transport.

The shallow depth of the sump is still considered adequate due to the flexibility provided by gas recycle. The introduction of the $\mathrm{CO}_{2}$ will be controlled by pH on an on/oft basis. Due to the lag time for return of the water to the carbonation station, 2.5 hours for an eight hectare pond, the low limit pH set point nust allow for storage of enough $\mathrm{CO}_{2}$ to meet the aximum demand for two transit times. At lower demand the upper pH reached in the pond will not be as great as when the demand is high. Thus the flow 
rate of $\mathrm{CO}_{2}$ must be able to meet the expected average hourly demand, which may change over long time periods (seasons). An alternative way of controlling $\mathrm{CO}_{2}$ input is to control the flow rate of gas so that a specified amount of carbon is stored. This could be acconplished with a microcomputer controller, programmed to calculate or determine from a table, carbon storage as a function of pH change. One would want to use such a system in situations where the alkalinity is low, requiring many carbonation stations per unit area. Such a scheme would preclude installing more stations than needed to meet the maximum hourly demand, i.e., only enough carbon is needed for one as opposed to two transit times.

\subsection{EXPERIMENTAL SYSTEM DESIGNS AND TESTS}

The experimental system is designed to allow determination of the carbonation parameters and design specifications needed to remove most of the uncertainty that now exists. In addition, several of the alternative types of carbonation systems described above will be constructed and tested. Yet the primary method is still considered to be shallow sumps with pure $\mathrm{CO}_{2}$. Tests will include measurement of overall transfer efficiency, in both uninoculated mediun and algal suspensions, as a function of sparger type, gas flow rate, gas to liquid flowrate ratio, sump depth, and pond DO. DO renoval will also be measured. Covered carbonators with smooth and rippled surfaces will be tested for transfer efficiency as a function of covered area, hydraulic slope under the cover, and bleed rate. If necessary gas recycle will be tested in sumps as well. 


\subsection{OPEN CHANNEL FLOW}

Some form of mixing is requared to maintain cells in suspension, to prevent thermal stratification, and to disperse nutrients. The most widely used formula for open channel flow is the Manning's formula:

$$
V=-\cdot .67 \mathrm{~S} .5
$$

n

where: $V$ = velocity, meters/sec

$A_{h}=$ hydraulic radius, meters (a depth for wide channels)

$S$ = hydraulic slope = head loss/unit length

$n$ = Manning's roughness, sec meters -0.3

For a given velocity and channel length, the equation can be rearranged to solve for the head los5:

$$
h_{L}=\frac{L V^{2} n^{2}}{R^{1.33}}
$$

where: $h_{L}=$ head 1053 , meters

$L=$ channel length, meters

Typical values of $n$ are 0.010 for very smooth surfaces, 0.014 for unfinished concrete, 0.017-0.025 for smooth earth (canals and ditches), 0.029 for gravel. A value of 0.018 was used in the head 1055 calculations for the large scale ponds. These ponds will be lined with graded crushed rock, rolled to a smooth finish. The mixing power requirement is given by:

$$
P=\frac{9810 \mathrm{AV}^{3} \mathrm{n}^{2}}{0.3 \mathrm{e}}
$$

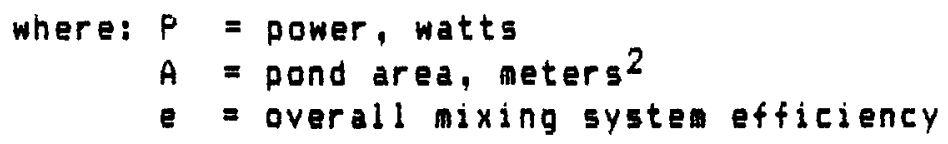

Note that the power varies as the cube of the mixing speed, and actually increases slightly at lower depths. The efficiency term includes both the hydraulic efficiency of the pumping device and that of the orive. Overall efficjencies can be a high as $70 \%$ for large centrifugal pumps, whereas $30-40 \%$ is more typical for paddle wheels or airlift pumps. 


\subsection{PADDLE WHEELS}

Paddle wheels have emerged as a preferred method for mixing high-rate ponds for the following reasons: (1) They are well matched to the pumping requirements of high-rate ponds in that they are high volume, low head devices (i.e. high specific speed); (2) Their gentle mixing action minimizes damage to colonial or flocculated algae, which improves harvestability; (3) They are mechanically simple, requiring ainimum of maintanence; (4) Their orive train can easily be designed to acconodate a wide range of speeds (high turn-down ratio) without drastic changes in efficiency; (5) They do not require an intake sump, but simply a shallow depression for maximum efficiency. Some of the disadvantages are: (1) The paddle wheel itself must be custon designed; (2) They are large relative to other types of mixers, especially at higher heads; (3) They are fairly expensive, though not particularly so for a low shear type pump. (4) For practical purposes, the maximum head is limited to 0.5 meters. This would only be a constraint in very large ( $>20$ hectares) ponds, or at high ( $>30 \mathrm{~cm} / \mathrm{sec}$ ) velocities in moderate sized ponds.

The two primary competitors for pond mixing are air lift pumps and Archenedes screw pumps. The air lift pump has a lower initial cost, but is generally considered to be a low efficiency device. Actual efficiencies appear to be very design specific, although theoretical efficiencies (see Section 4.3) are comparable to paddle wheels. In practice, the potential efficiency of paddle whels are probably greater. About $10 \%$ of the losses in paddle whel systens can be attributed to the variable speed unit, which may not be necessary in the long run. Air lift pumps probably produce higher shear forces than paddle wheels, which could interfere with autofloccualtion. The Archemedes screw punp has been successfully used for high rate pond mixing, but has a higher first cost and requires an intake sump. At high heads (>0.5 meter), the screw pump may be more economical than paddle wheels.

Although paddle wheels are chosen in the large scale system design, the experimental systen will include one $50 \mathrm{~m}^{2}$ pond mixed with an air ijt. This will allow studies of combined mixing and carbonation as outlined in the next section. The optimization of mixing systems, although of interest, is not as critical a technical issue as harvesting or species control.

The actual design of the paffle wheels is covered in section 7.3 . 


\subsection{GAS LIFT MIXING}

\section{3 .1 Introduction}

Gas lift mixing is an alternative to paddlewheel mixing which doesn t require large, custom fabricated mechanical parts. It is an interesting option in systems for which carbon is supplied via an in-pond sump due to the potential for combining the carbonation and mixing systems. In this section, gas lift is analyzed in its own right, but is also related to the carbon demand of the system. When flue gas is used for carbonation the lift may be derivable from the carbonation alone for part of the time, but most likely an air supply svstem would need to be available to substitute for the flue gas when carbon demand is low and during the nighttime. When pure $\mathrm{CO}_{2}$ is used, supplementary air would always be required.

\section{3 .2 Gas_Lift__íning Without_Earbonation}

The basic relations needed to analyze gas lift mixing are derived in Appendix 11. Two of them are used in the following discussion and are thus reproduced. The efficiency of the gas lift is given by, for adiabatic compression of air:

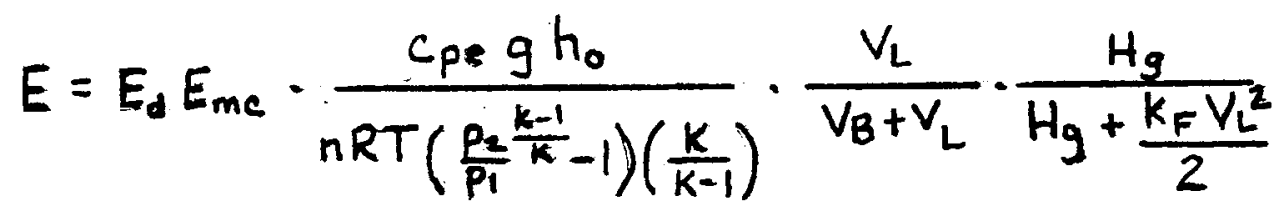

Cpe is an average correction factor for compression of air with depth $g$ is the acceleration of gravity, $980 \mathrm{~cm} / \mathrm{s} / \mathrm{s}$

$h_{0}$ is the depth of the sump in $c$ a

$V_{L}$ is the liquid velocity in the sump in $\mathrm{cm} / \mathrm{s}$

$V_{B}$ is the average rise of the gas bubbles relative to the liquid in $\mathrm{cm} / \mathrm{s}$ $H$ is the lift in en

$K_{F} V_{L} 2 / 2$ is the total friction loss for liquid entering, traversing and leaving the sump

Eme is the compressor motor efficiency

$E_{d}$ is the dynanic efficiency which covers losses due to the irreversible nature of the real compressor and is taken equal to .7

$n R T\left(\frac{p_{2}}{p_{i}} \frac{k-1}{k}-1\right)\left(\frac{k}{k-1}\right)$ is the theoretical adiabatic work of compression of the gas $/ \mathrm{cm}^{3}$ $K=C_{p} / C_{v}=1.4$ for air

$n T R=\left(1.218 \times 10^{-2} \mathrm{~mol}{ }^{0} \mathrm{~K}\right)\left(8.31 \times 10^{7} \mathrm{erg} / \mathrm{mol}{ }^{0_{K}}\right)=1.012 \times 10^{6}$ for 1 $6 m^{3}$ gas entering the compressor at 1 atm at any temperature. 
The lift is equal to the aas hold-up times the sump deoth minus fiuid flow losses:

$$
H=e h_{0}-\frac{k_{F} V^{2}}{2 g} \quad e=\frac{Q_{g} / Q_{L}}{\left(1+\frac{V_{B}}{V_{L}}\right) / c_{p e}+Q_{g} / Q_{L}}
$$

For shallow sumps, <10 meter or so, Table 4-1 shows that the efficiency doesn't change with sump deoth for constant ratio of gas and liquid velocities. For moderate liquid velocities, all terms in equation 4-1 are nearlv equal to unity except for the efficiency factors and the velocity ratio term. Thus the efficiency is governed by the velocity ratio. Table 4-2 shows the overall efficiency as a function of liquid velocity. Gas bubble rise velocity was taken as $30 \mathrm{~cm} / \mathrm{s}$ which is consistent for a situation where the flow rate of gas is not expected to be verv low. The efficiencv is onlv $25 \%$ at the design liquid velocity of $20 \mathrm{~cm} / \mathrm{s}$. Increasing this to $40 \mathrm{~cm} / \mathrm{s}$, by narrowing the sump to baffle distance to $10 \mathrm{~cm}$. increases efficiency to $34 \%$. Further increases in efficiency require even higher liquid velocities (relative to gas bubble rise rate) which could be attalned by directing pond channel flow into a shallow sump leading into a set of draft tube entrances. The liquid velocity increases linearly with the ratio of channel cross sectional area to total draft tube cross sectional area. If this option is chosen then the efficiency can be much higher. Usually, however, large velocities are used for systems with very large lift, because the velocity head, which is significant at high velocity, is easily lost upon exit from the or aft tube.

The lift is determined by the ratio of gas and liquid flow rates through the sump as well as the ratio of the velocities. The two dependencies on velocity ratio act together in that decreasing the ratio of gas to liquid velocities. increases both the efficiency and the lift. Table 4-3 gives the efficiency in terms of liquid velocity and lift for a system with three draft tubes. The fluid losses are significant when the liquid velocity exceeds 100 $c \pi / 5$. 


\section{Table 4-1. Effect of Sump Depth on Air Lift Efficiency}

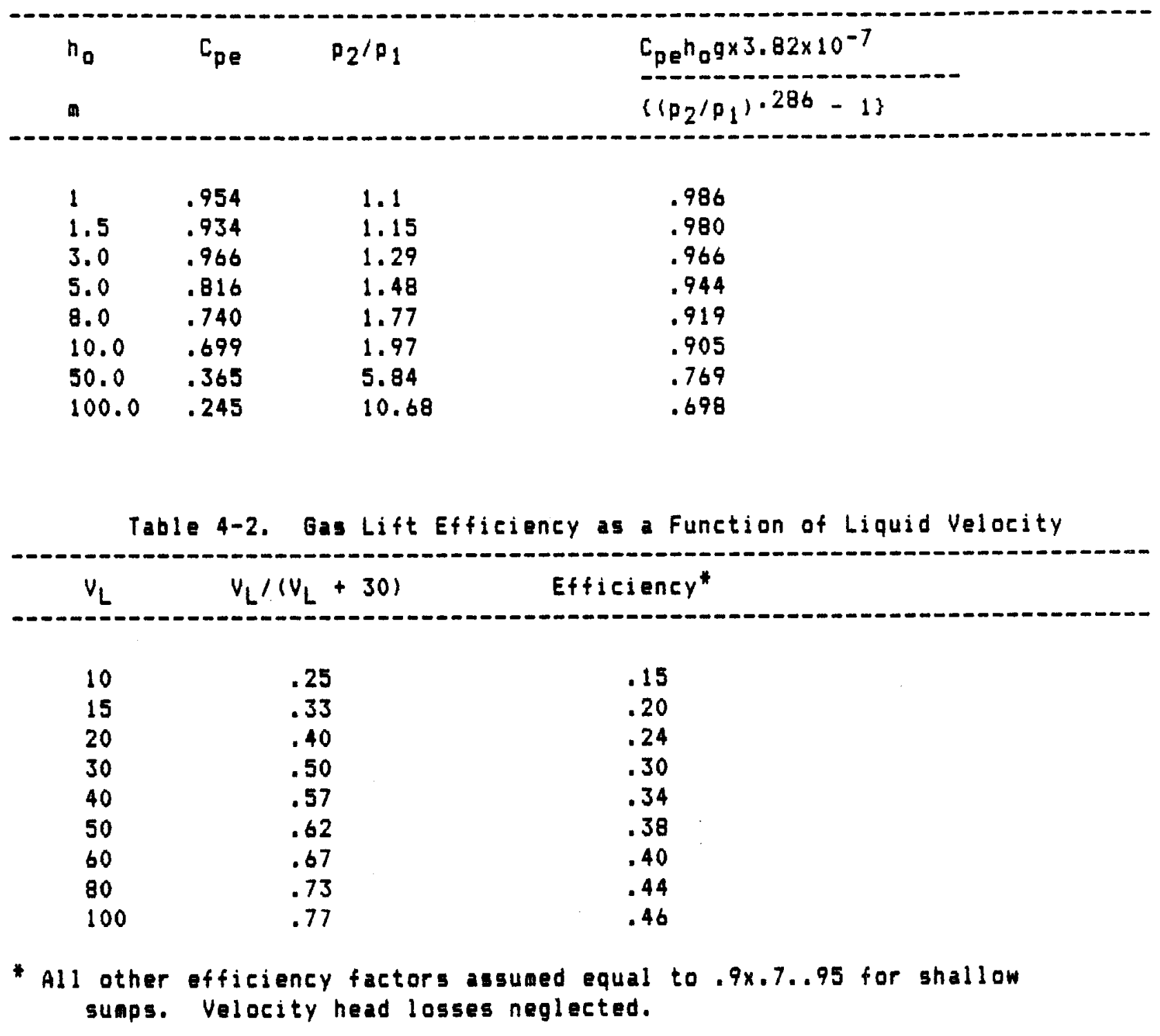


Table 4-3. Lift and Efficiency of a Draft Tube Air Lift System

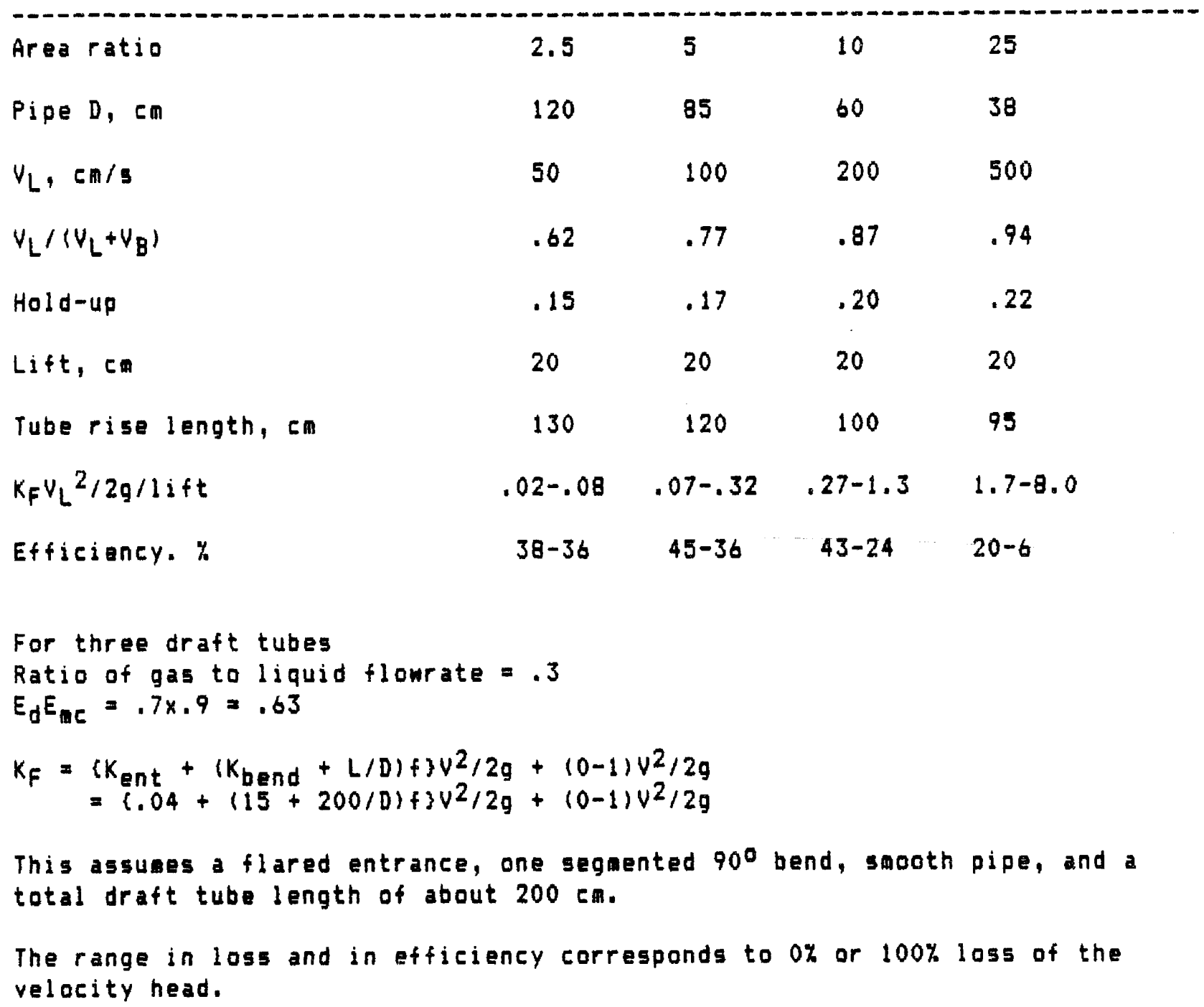




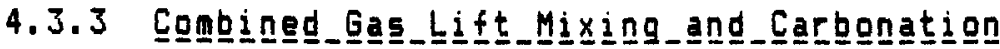

The combination of gas lift mixing and carbonation requires watching the mixing system performance to the constraints set by the carbonation. As shown above, the air lift efficiency increases with increases in liquid velocity. However, the injection efficiency of $\mathrm{CO}_{2}$ increases only with gas bubble rise time which decreases as liquid velocity increases unless the height of rise is ade greater. As an example consider narrow, long draft tubes into which the channel flow has been directed. The liquid flow rate increases in proportion to the area contraction ratio. This increase leads to a shortening of the time a gas bubble stays in contact with the liquid and thus a decrease in the overall transfer efficiency, unless the tube length is appropriatley lengthened. The degree of difficulty encountered in trying to optimize a combined gas lift and carbonation systea, depends on the distance which must be bridged between the initial configurations and requirements of each. With pure $\mathrm{CO}_{2}$ the lift attainable was much lower than required to aix the pond while with flue the lift was much greater than necessary. When carbon is recycled from digester flue gases mixed with pure $\mathrm{CO}_{2}$, a good match is achieved between transfer and mixing needs during times of maximal carbon demand.

When purified $\mathrm{CO}_{2}$ is used as the gas for mixing, the total flow rate of gas is restricted to that required to carbonate the pond. It was concluded in. Section 3.0 that even for an 8 hectare pond with $43 \mathrm{~m}$ wide channels, the gas flow rate would be low enough to attain a transfer rate of $25 \% / s$ and a gas to liquid flowrate ratio of about .02 for sumps without recycle and .056 for shallower sumps with recycle. The former sumps were 4.2 m deep the latter only 1.5 m deep. The lift provided by these configurations was only $4 \mathrm{~cm}$. Only by increasing the pond size dramatically (and also increasing the carbon storage capacity of the mediun) can the lift attainable be increased faster than the lift required. That is, if the pond area is increased $x$ fold, maintaining the same length to width ratio, the ratio of gas flow to liquid flow increases by $x^{1 / 2}$. This increases the lift. The lift is also increased by increasing the liquid velocity, accomplished by adjusting the baffle placement. Many workable configurations are possible. For example, a 40 hectare hectare pond could be mixed at $20 \mathrm{~cm} / \mathrm{s}$ by pure $\mathrm{CO}_{2}$ sparged into a 5.5 a deep sump, when $\mathrm{CO}_{2}$ demand is highest. At other times, air would be needed to dilute the $\mathrm{CO}_{2}$. Since the efficiency of such a setup would be $35-40 \%$ and air would be required about $75 \%$ of the time, the overall power requirement would be about the same as with a paddlewheel mixing system. For 5 aller pond sizes the mismatch between lift needed and pure $\mathrm{CO}_{2}$ required for carbonation is too great. If long oraft tubes are used, the rise tine of the bubbles still needs to be 125 for $95 \%$ stripping efficiency. The tubes would need to be 20 deep (long) and have an area of one tenth of the channel cross section to provide a lift of $20 \mathrm{~cm}$. 
With flue gas, as with dilution of the $\mathrm{CO}_{2}$ by air, the lift increases due to the increased flow. It can be assumed that the increase in gas flow rate would lead to an increase in average bubble size and hence an increase in. the depth needed to strip $\mathrm{CO}_{2}$ efficiently. For flue gas, at a maximal average carbon demand of $8 \mathrm{gm} / \mathrm{m}^{2} / \mathrm{hr}$, the lift attainable in a 6.2 a deep sump $180 \%$ injection efficiencyl is over $74 \mathrm{~cm}$. The gas flow could be lowered by carbonating 18-24 hours a day into a medium containing sufficient alkalinity to minimize $p H$ fluctuations in the upward direction during the day and downward during the night. This lowers the lift to 39 ch, about twice that needed. The most pronising possibility for combined processes would be to supply the carbon as flue gas over 24 hours during the high productivity months but only over 12 hours when productivity is lower. During these times air would substitute for the flue gas at night, when aixing speeds could be lower, reducing the power input. Since the cost of transporting the flue gas to the site includes the cost of pressurization sufficient for injection the overall power costs would be low. In order to reduce the lift enough, the baffling would need to be arranged to lower the liquid velocity in the supp to, say, $10 \mathrm{~cm} / \mathrm{s}$. Then, an eight hectare pond could be $\mathrm{mixed}$ at $20 \mathrm{~cm} / \mathrm{s}$ by flue gas in a 5 m deep sump when demand for $\mathrm{CO}_{2}$ is (averaged over 24 hours) $2 \mathrm{ga} / \mathrm{m}^{2} / \mathrm{hr}$. The aiflift efficiency would be low, about $15-20 \%$ and the deep sump required would be a substantial capital cost and in increased maintenance cost, but no additional cost would be incurred for mixing power. of course the power plant needs to be very close to the pond systen to transport it unpurified.

Given the uncertainties in the parameters for both carbonation and gas lift taken alone, design and cost estimation of a combined systen must await the results of the experiments proposed. A configuration which allows economic use of $\mathrm{CO}_{2}$ for gas lift may be possible, but it aust be kept in mind that carbon is the most expensive input into an algal bionass production systen. Any system for combining air lift and carbonation must use the $\mathrm{CO}_{2}$ with the highest efficiency, essentially as high an efficiency as carbonation alone would achieve.

\subsection{MIXING SYSTEM SPECIFICATION}

For the 1000 acre systen, both paddlewheel and airlift mixing systems were designed. The former requires twice the capital to construct as the latter, but there is more experience on which to base its efficiency. As discussed in Section 11.0, the inpact of this cost difference on production costs is small. The airlift system is comprised of three draft tubes, each 2 m long, as described in Table 4-3. The calculated efficiency for this configuration was the same as for the paddlewheel syster, about $40 \%$. However, confirmation of this estimate, from the experimantal system, is necessary.

No specific design is specified for a combined gas lift mixing- carbonation system. The gas transfer parameters are not known well enough to formulate a meaningful design at this tiae. Again, the impact of capital cost savings is minimal. 
SEETION 5.0

ANALYSIS OF HARVESTING SYSTEMS

\subsection{INTRODUCTION}

Harvesting algal biomass from dilute suspension (.05-.1\%) is ususally a two step process: a primary concentration step which reouces the volume of water 20-50 fold and a secondary step. usuallv centrifuoation. which further reduces the volume 5-10 fold. The capital and operating costs of industral centrifuges are so high that it precludes their use without the initial concentrating step. In special circumstances, as in the harvestina of SqI value of the algal biomass in thas case, as well as to the large size of the filaments and the manner in which they pack on screens which allows high flow rates of water. An inclined screen or vibrainng screen is used. Generally. however, a harvesting process must be able to concentrate varied types of cells, especially when the harvester effluents are to be returned to the growth ponds. Any organjsms which the harvesting process fajls to remove from the recycle stream, will be given a potentially significant competitive advantage in the growth pond [11]. Only in rare cjrcumstances ds the growth medium so selective for a chosen organism that this advantage will not result in dominance of an unwanted species. Thus, the harvesting process must not only remove the desired organism, but also any potential contaminants.

Four primary harvesting methods were examined: microstraining, belt filtering, flotation with float collection. and sedimentation in two stages. Each of these methods djscriminates on a size and/or density basis in perforaing the bionass separation. The strainer and filter are, of course, size discriminators, with performance characteristjcs that improve as the algal particle size increases. However, the filter is also more efficient for oraganisms which form a mat, thus decreasing the effective pore size.

Sedimentation and flotation devices collect biomass on the basis of both size and density. Since the operation of each of these devices becomes tenuous for small cells (66-8 microns), and since the harvester must, in a strict sense be universal in its removal capabilitiv, some universally effective method is required to transform all cells into a form which can be removed by the chosen collection device. As will be shown, the major cost of a harvesting system lies in this transformation process.

\subsection{CAPITAL COSTS OF PRIMARY HARUESTING DEVICES}

The four types of primary harvesting devices vary considerably in their installed capital costs. Conventional dissolved gas flotation units cost about. 25 million dollars per million qallons per day of suspension. The costs of microstrainers, belt filters, and settling ponds, on the same basis are .09, .12, and .05 million dollars. Nevertheless, it no pretreatment of the cells were required to 1) make each device work efficiently. and 21 make 
each work universally, the capital cost differences would not translate to large differences in annualized production cost. The most expensive device. the dissolved 0 as flotation unit. would add $50 \%$ to the capital costs of the system, but these only contribute 10-25\% of the annual production. The important point is that none of the collectors functions ejther wel] or. more lmportantly, universaily on its own. A rough calculation shows that if conditioner 15 added to the suspension orior to orimary harvestina. for each cent of conditioner added per $\mathrm{kg}$ of biomass harvested, the production cost increases by about 10\%. The conclusion is that while cost difterences do exist among various primary harvesting devices. the impact of these differences 15 small compared to the potential impact of the cost of pretreating the biomass 50 that any or all of the devices are, in fact, useable.

\subsection{PRETREATMENT OPTIONS}

There is ample experience with chemical flocculation of suspended solids to improve the separation characteristics. The thrust of recent work with chemical flocculants is to manufacture new chemicals, or devise new combinations of known chemicals. Which reduce the dose and cost of the Hocculation step. This subject will not be reviewed here, except to say that work on the use of flocculants is advancing due to the recently acquired eapability of manufacturing very high molecular weight polymers. If enough flocculant is added, the desired characteristics can be induced. At present, the use ot standard chemicals, like iron chloride, would require about. $75-1 a m$ per gin biomass, or about 4-6 ents per kg biomass. Thus an alternative to conventional floceulants is required.

One alternative is to condition the aloae without addina flocculants. Nitrogen deprivation is generally recognized to enhance the sedimenting characteristics of algae, although data in the literature is not applicable to the situation here. Sedinentation rates were generally not measured and the algae were usually starved for prolonged periods of times, well past any active growth. A report, by one of the authors, on the other hand presents data supporting the hypothesis that normally non-settling, unicellular, flagellated organisms (Dunaliella) can be made to settle at rates hiqh enough for collection in settling ponds, by short term nitrogen deprivation [4]. This process was found to work with all but the smallest oraanisms (2-5 micronl and even with an lggchrysis_sg. containing $60 \%$ lipid. But the question of universality of the process still poses a proolem.

Another alternative is to utilize the supersaturated oxygen to float the cells to the surface of the pond, to a foan collector. The advantage of tis over sedimentation lises in the fast rate of rise due to the dissolved qas coming out of solution. However, the universality of this approach is, again, open to question. 
Prelimanarv experiments have been pertormed. at Microbial froducts. Inc.. using high charae denstiy. hioh molecular weight polymers to flocculate a test organism in saline medium. A Chlorell la se. was used to demonstrate that even 5 mall cells (3-5u) can be clarified by simple sedimentation when first pretreated with the polvmer. The media used to grow the alga, to a density of 500 pom orqanic dry weight, contained 32 pot TDS, mostly as NaCl. Alkalinity was $30 \mathrm{mM}$. pH was 8.45 , and hardness was $5 \mathrm{mM}$. The cells were nitrogen sutficient. The dose of Dolymer necessary to effect comolete claritication with an adequate sedimentation rate of the flocs (>50 cm/hr) was lppm polymer per suv opm biomass. Ihis is the basis tor the desian assumption used in this report. The experiments were of a verv prelimanary nature, and not necessarliv ootimized. However. nor have they oeen validated on a laroe 5cale. naving deen Dertormed in jar tests with $250 \mathrm{ml}$ of suspension. The universality of the approach has also not been demonstrated, but the tvpe of orqanisif used provided a stringent test. It is the opinion of the authors that such an approach is highly promisina. out use on a large scale must be accompanied by continual monitoring of the effectiveness of the flocculation as oond conditions change. The type and mixtures of polymer used may nave to be changed on an ongoino basis to avoid selecting for organisms which elude entrapment by a particular flocculant.

The orimary method of harvesting the biomass produced in the larae scale and experimental systems is specified as pretreatment with polymer followed by sedimentation in a deep pond. The nutrogen depleted condition of the biomass should. in the experience of the authors, promote flocculation and sedimentation. The slurry from this pond is then further concentrated in thickening tanks of much reduced volume.

The budget for the proposed experiment has funds specificallv for testing and monitoring polymer induced harvesting. 
SECTION 6.0

SUMMARY OF ANALYSIS AND IMPLICATIONS FOR SYSTEM DESIGN

\section{I WATER CHEMISTRY}

The characteristics which are desirable in a water resource are low hardness, an excess of alkalinity over hardness, and low TDS lout still too salty for conventional agriculture). Any hardness which cannot be reaoved by the already present alkalinity (by equilibration with the atmosphere) costs $\$ .005$ per $\mathrm{kg}$ al gae produced per $100 \mathrm{ppm}$ hardness to be renoved. Lower TDS results in lower net water usage, al though the difference becomes less as the blowdown ratio (= recipricol of salts concentration factor) decreases. Considering a TDS of $40 \mathrm{ppt}$ as the practical upper limit for productive cultivation, a seawater system uses 4.5 times as much water as a system with

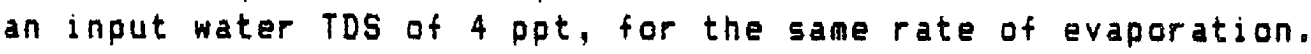

The water chemistry determines the carbonation system specifications and the $\mathrm{pH}$ range of operations. The lower limit of pH is determined by outgassing of $\mathrm{CO}_{2}$. Since $\mathrm{CO}_{2}$ is the single most costly input to the system, outgassing must be mininized. With low to moderate mixing velocities $(15-20 \mathrm{~cm} / \mathrm{s})$ and proper specification of the low pH limit, overall loss of carbon due to outgassing can be kept to less than $5 \%$ of the carbon incorporated into biomass. The upper lifit of $\mathrm{pH}$, for properly conditioned waters, is determined by the physiological response of the algae to dissolved $\mathrm{CO}_{2}$ concentration. This is unknown, but a safe level cone that should not lead to substantial loss of productivityl is 3-6 times air saturation or 30-60um. The carbon storage capacity of the medium depends on the alkalinity and the pH range of operation. It determines the number of carbonation stations required for a pond of specified size, depth, and liquid velocity, or alternatively, the maximun pond size serviceable with one $\mathrm{CO}_{2}$ station. The details of interaction between alkalinity, $\mathrm{pH}$, and $\mathrm{CO}_{2}$ concentration are discussed in Section 2.0 .

All of these considerations combine to determine water resource requirenents and $\mathrm{pH}$ of operation. The conbination used for the 1000 acre design are the following: water resource is Type II at 4 ppt TDS with excess alkalinity of 4 meq/1, no water conditioning chemical costs, and eight fold evaporative concentration resulting in a medium with TDS $=32 \mathrm{ppt}$, alkalinity of 32 meq/l, and a pH range for operation not to exceed 8.0-9.0. Water usage calculates to (assuming an average evaporation rate of $.01 \mathrm{~m} / \mathrm{m}^{2} / \mathrm{day}$ ) 11.5 liters/m2/day or $16.5 \times 10^{6} \mathrm{~m} / 400 \mathrm{ha} / \mathrm{yr}$. When this water is obtained from wells of 50 m pumping depth, the electrical energy cost $(\$ .065 / \mathrm{KW}-\mathrm{hr})$ is $\$ 220,000$ or $\$ 16 / a c r e-f t$.

In the operation of the experimental system, the large scale water specification will be simulated by a mixture of the two types of waters that are plentiful on the proposed site: $5 \%$ Salton Sea water, preconditioned by 
adding sodium carbonate at a cost of $\$ 300$ per acre per year or $\$ 450 / a c r e-f t$ used and $95 \%$ well water available at $1700 \mathrm{gpm}$. The composition of these water resources is tabulated in section 10.0 .

\subsection{CARBONATION}

The $\mathrm{CO}_{2}$ required to produce algal bionass with $50 \%$ lipid is $2.2 \mathrm{~kg} / \mathrm{kg}$ bionass. Even at the lowest extrapolated cost of $\mathrm{CO}_{2}$ [9], the cost of this input comprises over $50 \%$ of the annual production cost. Thus the most important aspect of the design is the efficient use of carbon. In this subsection, the methods of transferring $\mathrm{CO}_{2}$ into the ponds are sumarized. Recycle of carbon in particular, and all nutrients in general, is discussod in subsection 6.3 below.

Two types of carbonators ware onalyzed covered area carbonators and carbonation sumps. The former type may be feasible when pure $\mathrm{CO}_{2}$ is used, the latter is feasible for both pure $\mathrm{CO}_{2}$ and flue gases. The practical efficiency approaches $95 \%$ for stripping a pure $\mathrm{CO}_{2}$ input gas and $80 \%$ for a flue gas input.

Gas-liquid mass transfer was analyzed from first principles and evaluated in light of the large body of biochenical engineering data that has been accunulated. Nonetheless, a great uncertajnty reaains in the transfer rate that is to be expected in large scale algal systens. In the sump carbonation problea, the transfer rates were shown to depend on the average rate of rise of bubble swarms, which depends on the distribution of bubble sizes. This is determined by sparger orjfice, gas flow rate, and bubble coalescence factors (salinity, surfactants, turbulence). The rate of removal per unit length of sump depth can be much faster than would be expected if the bubble swarms travel through a considerable per cent of the sump depth before the equilibriur size distribution is attained and/or if the equilibrium bubble size is small due to anti-coalescence factors. Although the empirical data from $\mathrm{CO}_{2}$ transfer into algal ponds is sparse, and based on small systems, it has been found generally that transfer is faster than an equilibrium analysis would predict in the absence of some of the accelerating factors. The covered area carbonator was analyzed in terms of surface renewal theories of gas-liquid transfer with paraneters determined using empirical correlations developed for stream and channel aeration. Again, however, experiments on transfer through the surface of algal ponds, yielded rates significantly faster than were predicted. Thus with either carbonation method, the design specifications cannot be fixed with great precision until results from carefully designed experiments are obtained. At present the following options are specified for the 1000 acre system. 
1. "Ripple" covered area carbonator covering $2 \%$ of the pond area for pure $\mathrm{CO}_{2}, 90-95 \%$ efficiency.

2. 1.5 deep carbonation sunp for pure $\mathrm{CO}_{2}$, $95 \%$ efficiency.

3. 2-3 in deep sump for flue gas, with carbonator gas recycle flow of

$100-200 \%, 80 \%$ efficiency.

4. 2-3 deep sump for the mixture of pure $\mathrm{CO}_{2}$ with digester flue gas, no recycle, $90 \%$ efficiency.

Option 2 is used in the Base Case economic analysis, but option 4 has the most potential for reducing lipid production costs.

The experimental system will be used to determine the carbonation parameters. Both covered and sump carbonators will be tested. In addition, the effect of oxygen desorption, during carbonation, on the efficiency of $\mathrm{CO}_{2}$ input will be determined. These tests will also serve as the basis for the decision as to whether is ts feasible to remove dissolved oxygen from solution, and thereby relieve its potentially inhibitory affect on photosynthesis.

\subsection{NUTRIENT RECYCLE}

Since carbon is such a significant input into the systen, recycle of the carbon left in the residue from the lipid extraction process was considered. It was concluded that anaerobic digestion of these residues in a covered lagoon would allow recycling of $34 \%$ of the algal carbon, reducing carbon input from $2.2 \mathrm{~kg} / \mathrm{kg}$ algal biomass produced to $1.45 \mathrm{~kg} / \mathrm{kg}$. This recycled carbon is considered available at no cost, in terms of operations, due to the electrical energy derived from the methane gas produced which is used to pressurize the recovered $\mathrm{CO}_{2}$ for injection into the ponds. The capital cost of the digestor-generator systen is included in the economic ovaluation of this option. The flue gas obtained fron the combustion of the digester gases is $14 \% \mathrm{CO}_{2}$. Wnen combined in the required volumetric proportion with purified $\mathrm{CO}_{2}$, the resultant nixture is $35 \% \mathrm{CO}_{2}$. This will be more expensive than pure $\mathrm{CO}_{2}$ to inject into the ponds but less expensive than flue gas. The extra expense cones as a capital cost of constructing deeper carbonation sumps, and possibly use of recycle. Since operating costs, especially the cost of carbon, will be shown to dominate annual costs, these increased capital expenditures have little impact on production costs. The 30\% savings in $\mathrm{CO}_{2}$ input has significant impact.

In addition to carbon, much of the nitrogen and phosphorus remaining in the extract residues can be recycled. The potential for recycle is even greater than for carbon. Table b-1 summarizes the elemental balance for $C, N$, and $P$ in the anaerobic digestion process. The partition of the elements in the 1 iquid portions of the digester can only be roughly estimated at the present time, but it is evident that the potential exists for these elements to be recovered to a significant extent. 
Table b-1. Nutrient Partitioning in an Anaerobic Lagoon

$\begin{array}{lccc}\text { Digester Compartment } & \text { \% of Total } C & \% \text { of Total } & \text { \% of Total P } \\ \text { Gas Phase } & 65 & 0 & 0 \\ \text { Liquid Effluent } & 18 & 75 & 50 \\ \text { Sludge } & 17 & 25 & 50\end{array}$

In constructing Table $6-1$, it is assumed that $65 \%$ of the carbon entering the digester is gasified $\left(39 \%\right.$ to methane, $26 \%$ to $\left.\mathrm{CO}_{2}\right)$, that the nitrogen is predominantly solubolized to ammonium, and that the phosphorus partitions evenly between the liquid and sludge fractions. The gas and liquid effluent fractions are recyclable. Table b-2 gives the recycled nutrients as a per cent of the total, using the assuaptions that the algae is $60 \%$ carbon, lipid is $70 \%$ carbon, soluble nutrients are recycled with $100 \%$ efficiency and the gaseous carbon is utilized with $90 \%$ efficiency due to losses upon injection into the pond.

Table 6-2. Recycle of Nutrients

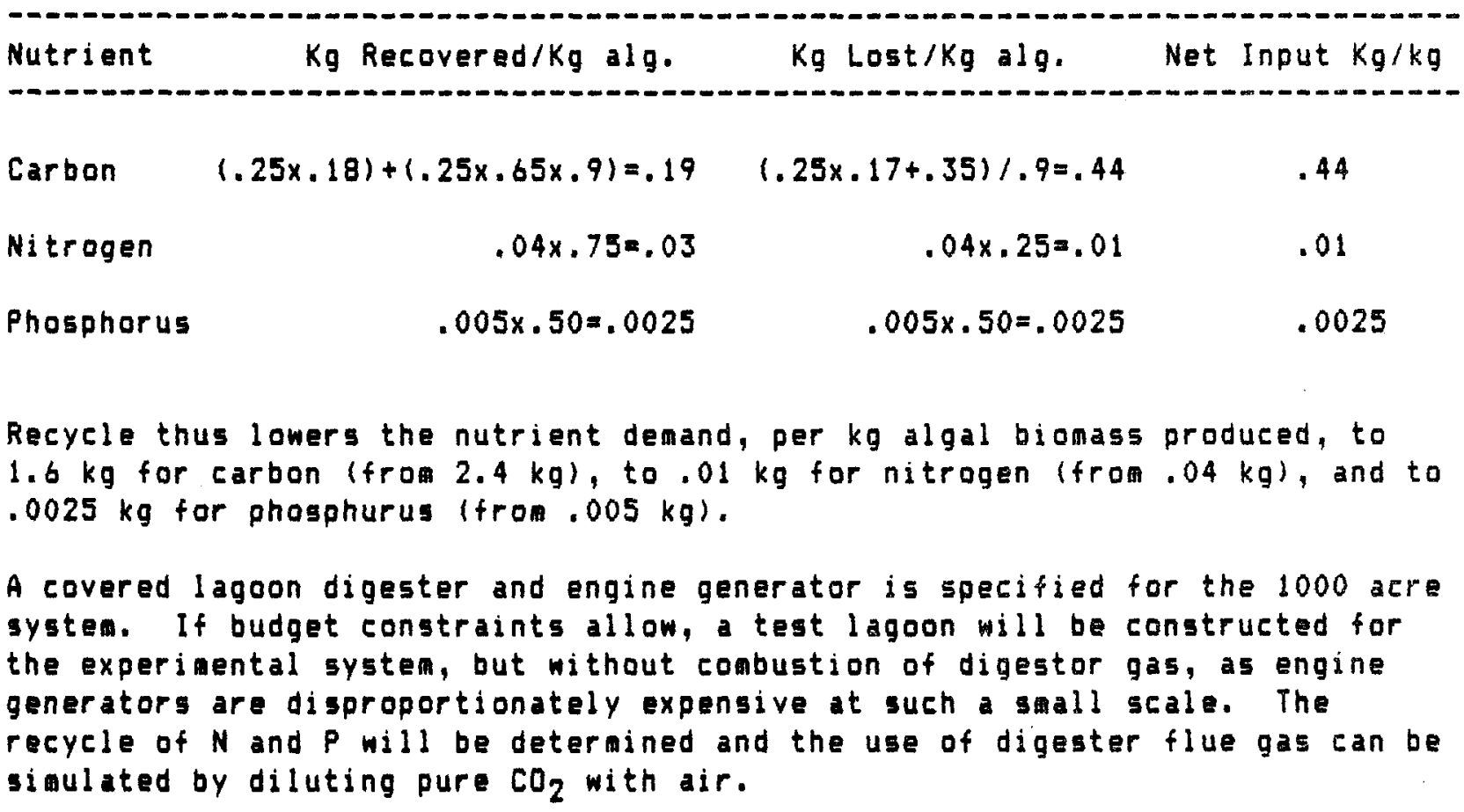




\subsection{NUTRIENT LOSSES}

The loss of nutrients from the svsten is a potentialiv sianificant oroblem unless care is taken in the desion and operation of the system to prevent such 10sses. The 1055 of carbon. primarldy as $C_{2}$ to the atmosphere, has been discussed extensively in Sections 2.0 and 3.0 . In the base liase desian, to be specitied in detail in section 10.0, the pond depth 1520 ch and the nixing velocity is $20 \mathrm{~cm} / \mathrm{s}$. Shallower depth and hioher mixino velocity both act to agọravate $\mathrm{LO}_{2}$ outgassing, which becomes about 2.5 times qreater if depth is halved and mixinq velocity increased to $50 \mathrm{~cm} / \mathrm{s}$. In addition, carbon storage in the medium. on an areal basis, decreases with decreases in depth. For media of the same alkalinity and the same range of dissolved $\mathrm{CO}_{2}$ concentration, the shallower, taster mixed pond must be operated in a narrower pH range to achieve the same efficlency of use ot carbon. lhis means that more carbonation stations are required per unit area of arowth pond.

Ammonia is another volatile species when present in unjonized form. In tresh water. the ok of the ammonium-ammonia acid-base system 159.5 . Activitv coefficients decrease as ionjc of the medium iuncreases. In the mixed acidity constant convention corotons expressed in activity. other species expressed in concentrationl the pK for the ionzation of ammonium increases. In the approximation that the activity coefficient for ammonium is the same as for bucarbonate, the ok in a medium with the jonic strength of $5 e a w a t e r$ is 9.85. If all of the nitrogen demand of the aloae is introduced as ammonia at the beginnning of each batch cycle (a worst case scenario) then the concentration of total ammonia-nitrooen would be about $2.5 \mathrm{~mm}$. At $\mathrm{pH} 8.5$ and 9.0 . the fraction of this total that is present as ammonia is. respectively.04 and 12. With a mass transfer coefficiet of .06 m/hr for transter through the surface, the loss of ammonis is, at the two oH's, .03mM/L/hr and.09mM/L/hr. This is low comoared to the rate of nitrogen uptake by alaae. However. if again the pond depth is halved and the mixinq velocity is increased to 30 $\mathrm{cm} / \mathrm{s}$, the rate of outaassing is five times as high (the volumetric rate of uptake by algae is also twice as qreat). So the outgassing losses of carbon at low pH combined with the outgassing losses of amania at high oH act to squeeze the pH of operation down, and more severly so with shallower, faster mixed pond designs. In the Base Case, nitrogen losses were specified at $30 \%$. which should be amply conservative even when the outgassing during carbonation and airlift is included.

\subsection{MIXING SYSTEM}

Three options were analvzed for mixing the ponds: paddlewheels, airlift, and combined carbonation and wixing in sumps. The overall efficiency of the three methods are. respectivelv $40 \%, 40 \%$, and $20 \%$. The lower efficiency of the combined system is due to the need to optinize for efficient transfer of $\mathrm{CO}_{2}$. However, the net power consumed in this option is only $35 \%$ higher than the other two because the $\mathrm{CO}_{2}$ cost includes power for compression. and air use is only supplementary. The paddlewheel system is twice as capital intensive as the airlift system. The combined carbonation-mixing systen costs 
a most as much as the paddlwwhel svstem because the sump used must be deep to insure efticient carbon utilization.

The decjsion on which svstem. paddlewheels or ajrlift, is best sujted for mixing algal arowth ponds. must await the results ot experiments in which an optimal desion for each has been tested. They are not actually beino compared on an equal basis in thas report. The practical efficiency of the paddiewneel systen is much better known. I.e., the dvnamis losses are more easily factored into the analysis. Thus the $40 \%$ efficlency is most likelv achievable. The alrlitt svstem. on the other hand, was evaluated from first principles, with an ac hoe factor inserted for dynamic losses. No airlift has been desioned, to the authors knowledge, which both tits the application here and ls scalable to large systems. The engineering experience with airlitts is based on much hiaher lifts used in conjunction with difficult to handle materials or in air lift fermenters. The efficiency achievable in a ponding apllication 15 yet to be determined.

Based on the literature, consultant input, and previous experience, a paddlewheel system thought to be structurally sound and efficient has been designed. Several confiqurations of airlift, and combined aaslift-carbonatorg. are presented in section 4.0. These confiqurations are merelv plausible at this point. since the behavior of bubble swarms in relatively shallow sumps in saline water which may contain surfactants, needs to be empirically determined. Thus the proposed experimental system has been designed for the measurement of the relevant oarameters.

A novel type of wixing system, applicable to very large systems, has been analyzed based on the desion specifications of a hydraulic consultant. The tan pump has potentially very high efficiency when pushing large tlows, at low velocity a ainst relatively low head la meter or more). Although this alternative has not been ancluded in the 1000 acre design, nor the experimental system. it does open up the possibility of operatinq much laroer ponds than has been considered practical up to now.

\subsection{MIXING VELOCITY AND DEPTH}

The fixing velocity and depth specified for the 1000 acre design are 20 cin/s and $20 \mathrm{~cm}$. These are considered sufficient to serve the respective purposes of keeping algal soljds suspended and providing carbon storage in the medium. Although there is some evidence for enhanced productivity at increased miximg velocity and lower depth when devices are installed in the ponds to induce organized mixing reqimes [3], the evidence is not conclusive. This specification increases capital costs. steming from anufacturing the ajrfojls used to establish the organized mixing and from the increase in both mixing system costs (due to the higher fixing velocity) and carbonation station requirements (due to the lower areal carbon storage capacity). In addition. the operating costs increase due to the increased power input for mixing. Which 
Increases as the velocity to the $2.5-3$ power and depth to the negative $1 / 3$ power. $\mathrm{CO}_{2}$ utilization efficiency also can be expected to decrease as the mass transter coefficient for outqassing increases with mixing velocity increments and depth decrements (the surface turnover rate increases). The potential impracticality of installina airfoils at reasonable cost makes basing the entire systen design on this tenuous.

The experimental system is also designed for 20 ch depth and 20 chis mixina velocity, although the system will be constructed with the flexibility to vary both.

\subsection{POND LINING}

Some form of pond linina is required to eliminate loss of water due to percolation. In the large scale design. the lining soecified ls crushed rock over a clay sealer. This combination 15 inexpensive when the materials are not too distant form the site. The major questions to be investialed durina the proposed experiment are the degree of sealing that is achievable with this lining and the effect on mixino power input and $\mathrm{CO}_{2}$ outassed. Both are expected to be somewhat oreater than with a plastic liner oue to tne increased roughness of the pond bottom. Since the rock is graded and rolled. the anticipated roughness coefficient is .018 compared to very smoothly applied plastic lining of roughness .012.

Plastic liners were considered but not chosen as a priary desian specification due to initial cost, installation difficulty, maintenance problens, and questions as to whether linings would perform as well as expected. The least expensive plastic lining would cost between $\$ 1.5-2.0$ per $a^{2}$ installed. However, these liners would need to be constantly under water to avoid photodeoradation. In addition, the very small thickness (10 ail) predisposes such a lining to developing small holes which leak. Rodents may also wreak havoc by chewing through the liner. The high quality plastic liners cost $\$ 5.5$ per $\mathrm{m}^{2}$. Although performance goals would be much easier to achieve with expensive liners, problems with rodent damage could be serious. The high capital cost of these liners, \$23 million per 1000 acres. makes the economics of their use marginal. It doubles the depreciable capital investment, but DCJ only contributes 10-20\% to the annualized production costs. If a olastic liner were required, tew experts recommend the cheaper liner over the expensive one.

High quality plastic liners are specified for all ponds in the proposed experimental systen except for the laraest ponds. In one af these. 4 hectare ponds. Clay sealer with a erushed rock overburden will be tested. The other will be plastic lined (hypalon). Thus the performance of both options will be evaluated. 


\subsection{HARVESTING SYSTEM}

Primary harvesting was evaluated in terms of devices for concentrating the aloal biomass and in terms of the reliability and universality ot each method. Microstraining and air plus 00 flotation proved to be more expensive than using a belt filter, which was analvzed as more expensive than simple sedimentation. It was noted, however, that the differences in costs, both capital and operating. would not translate into a large difference in the overall cost of producing alqal biomass (see section 11.0). The most important conclusion is that none of the devices, in and of themselves, could be expected to be very reliable in the longterm. Each discriminates on the basis of size and/or density. which would eventually lead to a situation where organisms that eluded the primary collection would be given a competitive advantage in the arowth ponds.

It is necessary to develop a means of pretreating the biomass, With flocculants. so that all biomass 19 collected by whatever device is used. Recent work with very high molecular weight, highly charged polymers appears to be a promising method of accomplishing this. A given polvmer floceulates a wide variety of organisms from a given medium. In addition, a repetoire of similar polvmer can be tailored. on site, to deal with changes in pond flora or simply changes in conditions that result in different flocculant needs. The conclusion is that harvestina microalgae appears feasible but will require constant monitoring. There does not appear to be one single answer, in terms of chemical additives, unless pond conditions are extremely constant.

Final concentration of the biomass is accomplished by centrifugation. The cost of this step does depend on the device used in the orimary concentration. Flows from microstrainers are expected to be five times those from settlino ponds and flotation collectors. A belt filter concentrates. or ls expected to concentrate somewhat more than the other methods.

\subsection{PRODUCTIVITY ENHANCEMENT AND SPECIES CONTROL}

Dissolved oxygen accumulates to hiqh concentration in moderate to large ponds during active growth of algae. Recent experiments [1] as well as a wealth of laboratory and limological data ioplicate oxygen as an inhibitor of photosynthesis. The desorption of oxyoen is a problen which is not anenable to analytic solution in all but highly specified cases. It is a non-equilibrium. nueleation process which is specific to both the chemical and hydraulic characteristics of each particular situation. Thus the feasibility of intentionally restricting 00 levels to within prescribed limits will be tested empirically in the proposed experiment. The results will be evaluated so as to suggest large scale approaches. It will also be necessarv to measure biomass productivity as a function of Do in order to determine the need for Do removal and the cost effectiveness of lowering it to a given level. 
Another possible productivity enhancement method involves creating conditions of orqanized mixina in the ponds. Several means of accomplishina this were analyzed, including contouring the pond botton to include flow obstacles. laying rows of obstacles on the bottom. and using airtoils. None were determined to be attractive in terms of effectiveness of pronoting the desired flow patterns and/or in terms of cost. Until evidence to the contrary is firmly established, the assumption used in this report is that productivity is determined by climate. medium, and especially strain cultivated. Certainly the affect of recveling the medium on longterm productivity will be monitored in the experiment.

Longterm species control is related to productivity. Strains used must be highly productive and competitive as well. Up to now. except in extreme conditions of medium composition (which results in low productivity) natural strains have dominated all outdoor pondina systems. One advantage of producing carbohydrates instead of lipids is that all of these dominant organisms observed to date, accumulate the former under nitrogen limitino conditions. A comprehensive survey of strains which accumulate lipid and are highly competitive as well 15. however, just underway.

\subsection{EFFLUENT DISPOSAL.}

Of the many technical. resource, and logistic obstacles which must be overcome for the proposed process to be successtul, one has not received enough attention. The blow down water represents a significant disposal problem. With the specified blowdown ratio of $1 / 8$ of the inflow. or $1 / 7$ of the eyaporative losses, the volume of water per hectare per year is over 5000 3 . The mass of salts (predominantly NaCl) is over $150 \mathrm{Mt}$, or about $1.5 \mathrm{Mt}$ salt per Mt dry biomass. This water mass can be evaporated in ponds with an area of .1 .4 hectare per hectare of growth ponds. These ponds need not be lined, since the precipitates will quickly seal then. Even so they must be dredged, forming salt "mountains" in short order. Either this salt must be stored as such indefinitely, or it must be transported to a disposal site, i.e., the nearest gulf or ocean. Thus an operating cost should be included for the transport of this material. The only way to reduce the amount of salt produced, from open systens, is to utilize less saline water resources and/or to decrease the blowdown ratio. Assuming that seepage and percolation losses are not persistent, the lower limit on blow down is set by the secondary concentration. If 10-20\% solids is the final concentration betore processing, and .005-.1\% solids are in the pond effluent the minimu blow down is $2 \%$ of evaporation. Unless fresh water is used, this minimum is unrealistic. For practical purposes, if a water resource containing 2 ppt IDS is used and the blowdown ratio is .04, then the volume of water and mass of salt coming out of the system per hectare per year become $1600 \mathrm{~m}^{3}$ and $80 \mathrm{Mt}$ or $.75 \mathrm{Mt} / \mathrm{Mt}$ bionass. These are still large numbers. A cost of $\$ .0067$ per $k g$ of $5 a j t$ is assumed for the large scale system to transport the salts to a disposal site.

The organic matter that is not either a product stream or recycled back to the growth ponds, must be dredged from the bottom of the anaerobic lagoon

periodically. This sludge can be dried and disposed of on site. 
SECTION 7.0

POND CONSTRUCTION

This section examines the basis for shoosing a particular pond design, and presents specific details relating to its construction. Section 7.1

discusses the various factors which influence growth pond size and geometry. Section 7.2 specifies the particular configuration chosen, and lists the design parameters of iaportance to pond construction. Section 7.3 presents the specific design options and their costs for each major element of pond construction. The high-rate pond concept, consisting of open, shallow channels in which the culture circulates, is used as the basis of pond design in this report. This chioce is based on both experience lof the authors and others), and on an analysis of alternative designs within the context of fuels production, where the cost constraints are extreme. It should be noted that within the basic high-rate pond framework, there is still ample room for innovation and cost optinization, as the analysis in this section will show.

\subsection{POND SIZE AND GEOMETRY}

The basic geometric parameters in high-rate pond design are pond size, number of channels, and length to width (L/W) ratio. The latter is defined in this report as the lenth of the center divider wall (i.e. the length of a single channel without bends) divided by the single channel width. In general, a single loop (two channels) is preferred from a hydraulic standpoint. If the pond is large enough, this configuration can take full advantage of a paddle wheal mixer [12]. The choice of pond size and shape is driven by economic factors and the effect on other system elements, such as mixing and carbonation. A siaple geometric optinization indicates that a large pono with a low L/W ratio gives the most pond area for the least wall length, as illustrated in Figure 7-1, for the case of twelve ponds in a side-by-gide (shared walls) configuration. Since the walls are a significant cost item, and since other pond elements also show economies of scale, ponds need to be made as large as practical. The choice of $L / W$ ratio aust take into account the trade-off between miniaizing wall length and other factors which affect costs. At low L/W ratios, the channel width increases, as does the cost of those elements related to channel width, such as ixing stations, carbonation sumps, etc. Once a tentative size and L/W ratio is chosen, the head 1055 (which depends also on velocity and roughness) can be calculated by Manning's formula, and evaluated relative to the proposed mixing system. The channel length may then need to be adjusted to fully utilize the capabilities of the mixing systen.

Figure 7-2 shows the cost of the growth ponds as a funtion of pond size for the range of 2-10 hectares. For each point, the number of ponds is adjusted to maintain a total system area of about 200 hectares, so the econonies of scale indicated in the figure are a result of geonetric factors rather than 
declining unit costs. Cone exception is for laser grading, which has a slight scale economy built into unit cost function, since the cost depends somewhat on the channel width). The figure shows a marked increase in cost below 4 hectares, with diminshing returns above 10 hectares. Both the cost figures and shape of the cost curve are unique to the specific design presented in this section, and may not apply to other designs. A further point with regard to figure 7-2 is that it includes only the cost of pond construction, mixing, and carbonation, and does not include harvesting, water or carbon supply, engineering, etc.

An alternative to the conventional "racetrack" configuration described above was suggested by Dr. James Harder of the U.C. Berkeley, as a method of generating circular flow patterns (secondary flows), for cycling the culture in and out of the light with a minimum of head loss. A low mound with sloping sides would be constructed using conventional earthmoving equipaent. The channel would then be built in a spiral pattern on the mound. This would produce a continuously sloped bottom, 25 required for shallow, mixed ponds. (Each ehannel would be later be graded flat across its width if necessary). The inner and outer channels would be joined by an inverted siphon, with the mixing head provided by an large diameter, low speed axial flow pump ("fan pump"), custon designed for the head requirements of the pond. The spiral configuration may have distinct advantages in the construction of very large ponds (>20 hectares), al though the secondary flows are mininal at large radii of curvature. It replaces the abrupt channel bends with a continuous gradual bend, eliminating the need for flow deflectors, and providing a ore uniform mixing regine. Since its shape is more compact than a long narrow pond, it may better conform to a given terrain and reduce the initial rough grading costs. However, the fine grading will likely be more difficult than with straight channels). Although the spiral configuration was not employed in the baseline design, it does degerve consideration, especially in the context of very large ponds.

\subsection{POND AND SYSTEM CONFIGURATION}

For the large-scale systen a pond size of 8 hectares (19.8 acres), with a L/H ratio of $20 / 1$ was chosen. Key design parameters are listed in Tabla 7.1 for the individual pond, and in Table 7.2 for the 192 hectare pond system, consisting of 24 ponds as shown in Figure 7-3. Figure 7-4 shows plan view of a single pond. The time required to complete one loop around the pond at $20 \mathrm{ca} / \mathrm{sec}$ is about 2.6 hours. A single carbonation station will satisfy the carbon storage requirements, given the assumptions about water chenistry outlined in Section 2. Referring back to Figure 7-3, the 8 hectare pond takes full advantage of the economies of scale, without pushing the size into a region of dimishing returns, some of which are not readily quantifiable (e.g. loss of operational flexibility, problens of solids deposition, etc). 


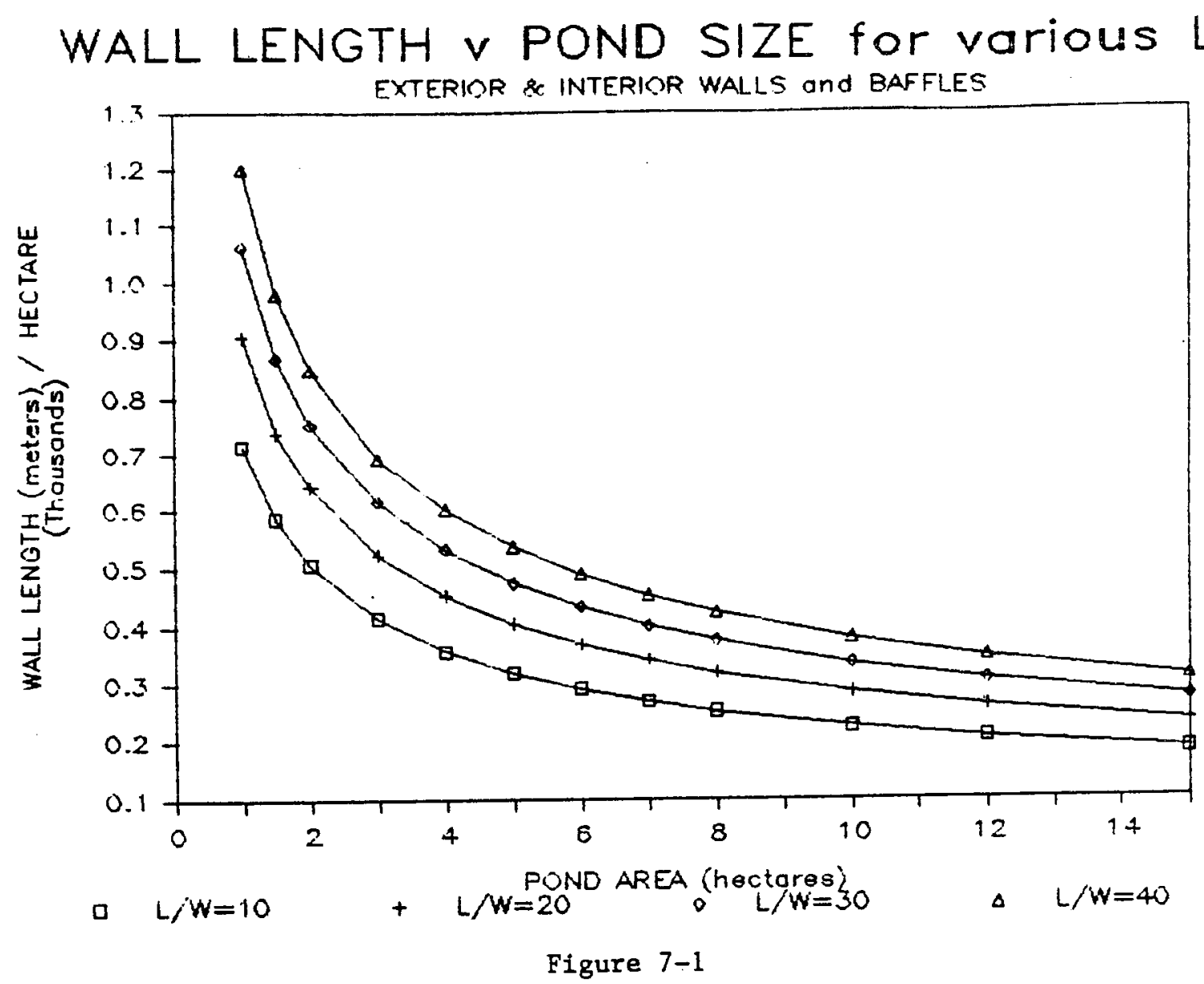

GROWTH POND CAPITAL COST

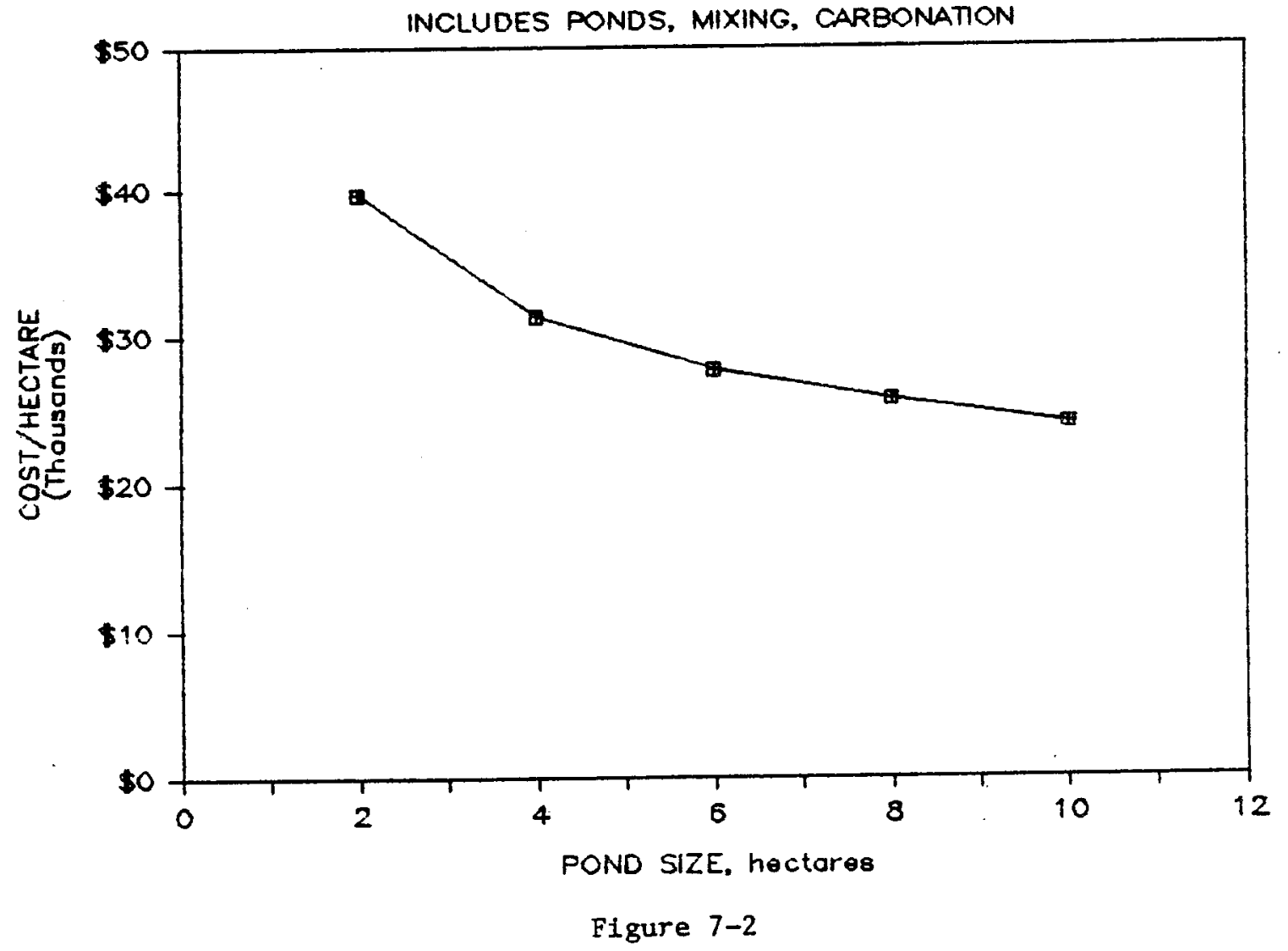




\section{Table 7-1 Pond Design Calculations - Single Pond}

*INPUTS*

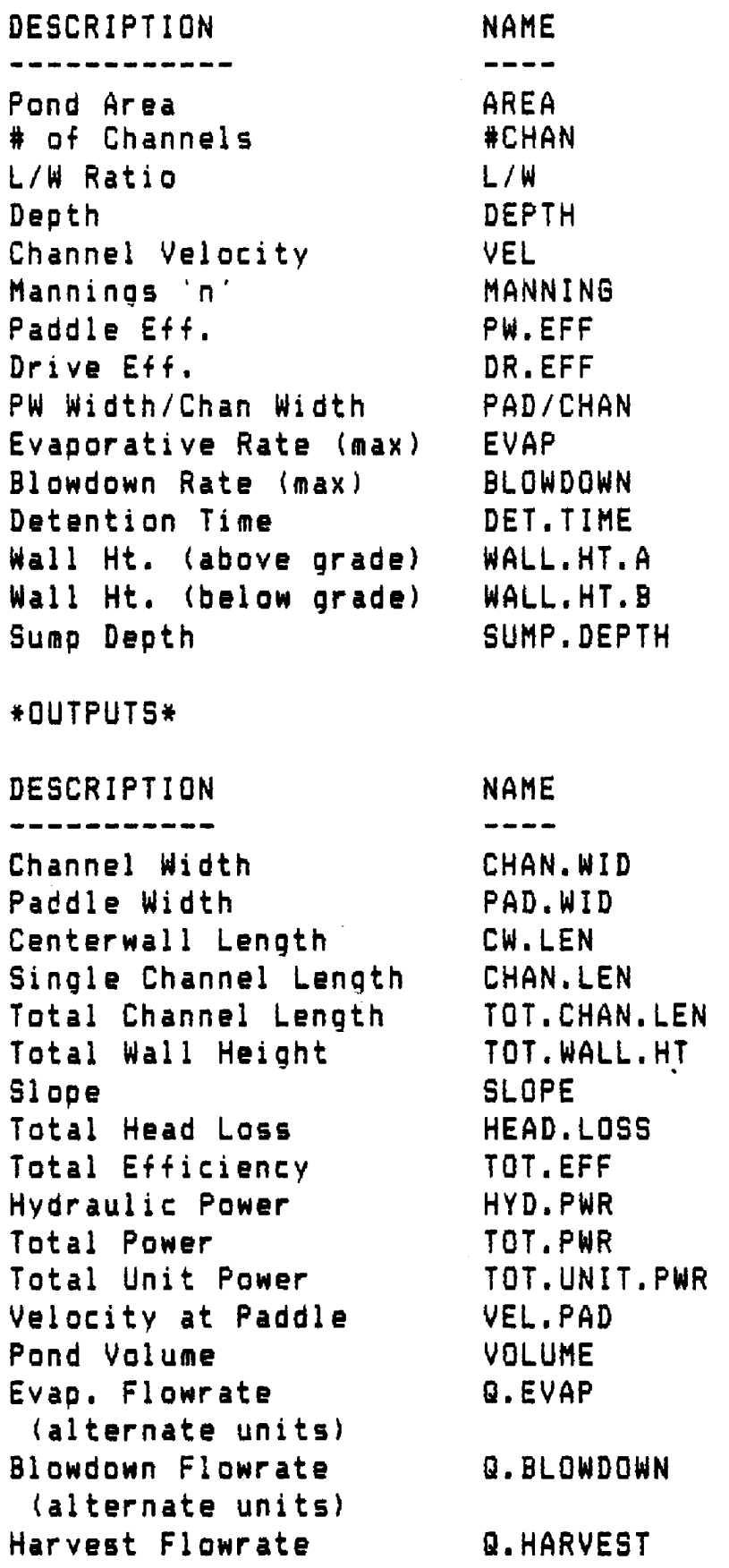

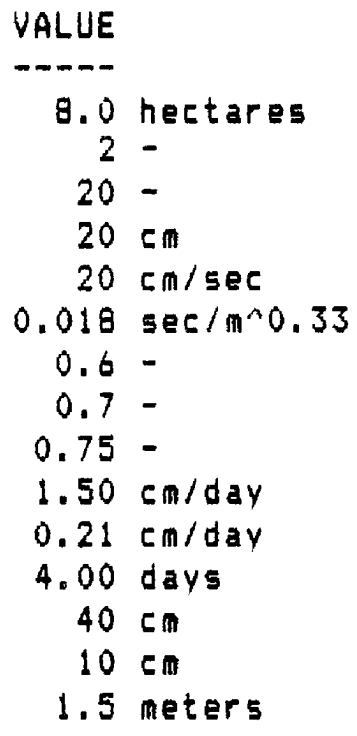

S.I. UNITS ENGLISH UNITS

43.06 meters

861.25 meters 928.89 meters 1857.78 meters

0.50 meters

$1.107 \times 10^{n}-4$

$20.98 \mathrm{~cm}$ $42 \%$

3477 watts

8278 watts

$0.10 \mathrm{watts} / \mathrm{sq} \mathrm{m}$

$26.7 \mathrm{~cm} / \mathrm{sec}$

16000 cu meters

$1200 \mathrm{cu}$ m/day

833 liters/min

$168 \mathrm{cu} \mathrm{m} / \mathrm{day}$

117 liters/min

$4000 \mathrm{cu}$ m/day

2778 liters/min

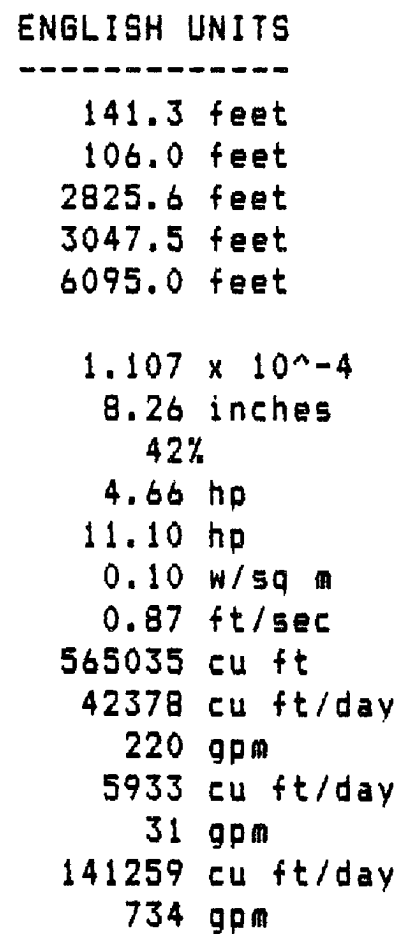


Table 7-2 Fond Design Calculations - Pond Svstem

Uses input from table above, as well as the following:

* I NPUTS*

\begin{tabular}{llr} 
DESCRIPTION & NAME & VALUE \\
\hline \# of Adjacent Ponds & \#ADJ.PONDS & - \\
Sets of Adj. Ponds & \#SETS & 12
\end{tabular}

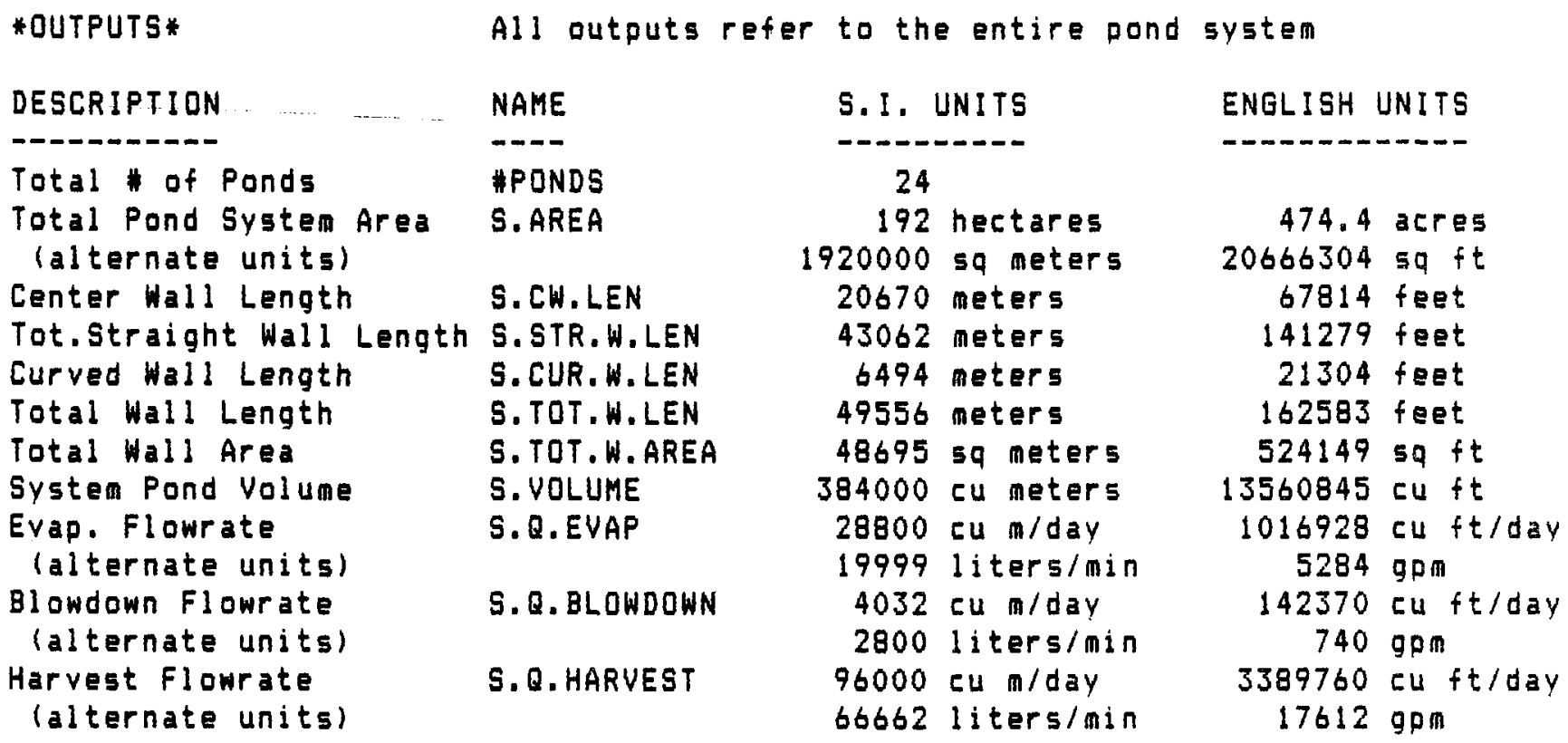


Table 7-3 Growth Pond Cost Summary - 192 Hectare System

INSTALLED COST FOR 192 HECTARE SYSTEM
24 PONDS

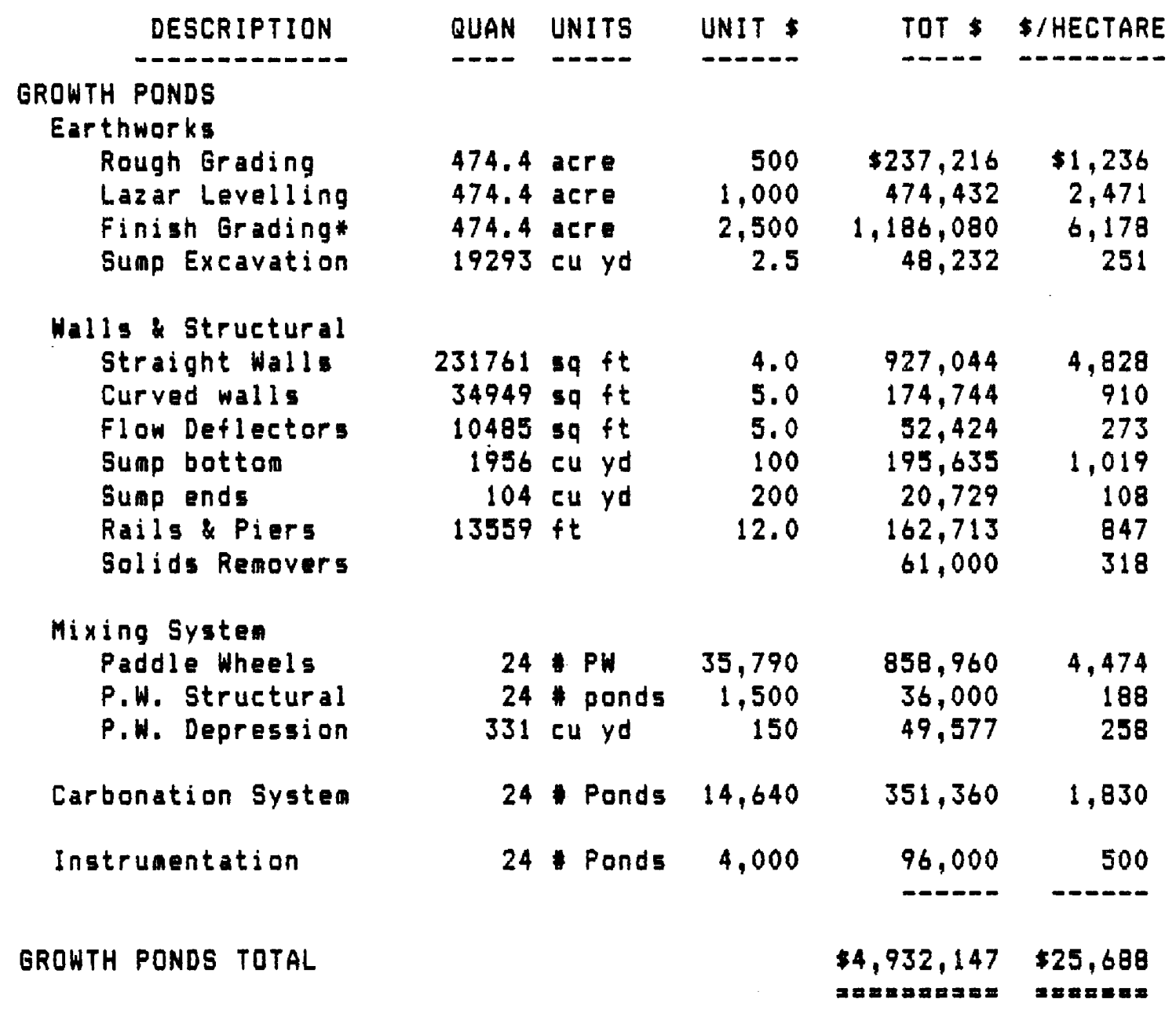

* Includes crushed rock liner 


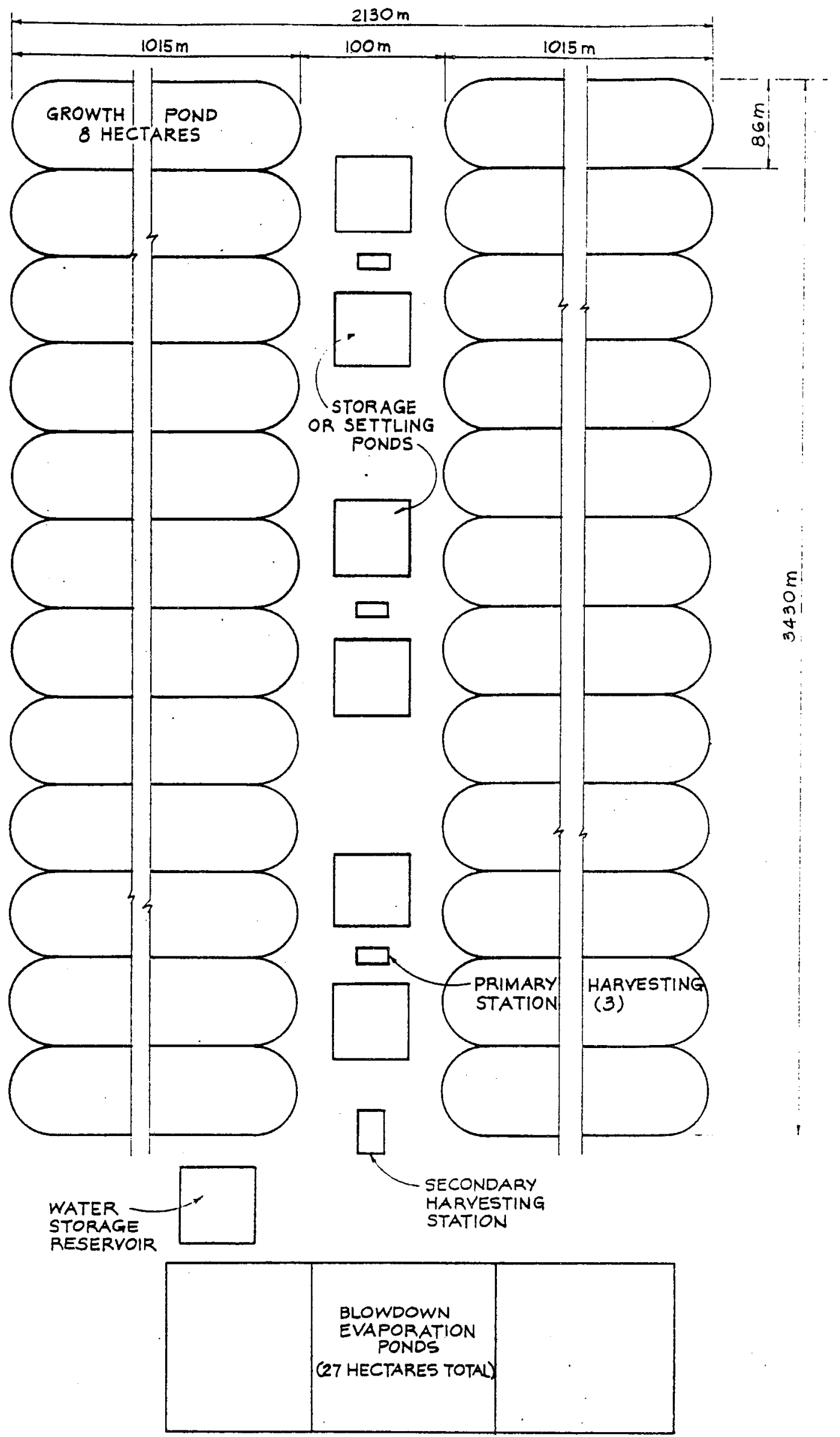

Figure 7-3 Pond System Layout 


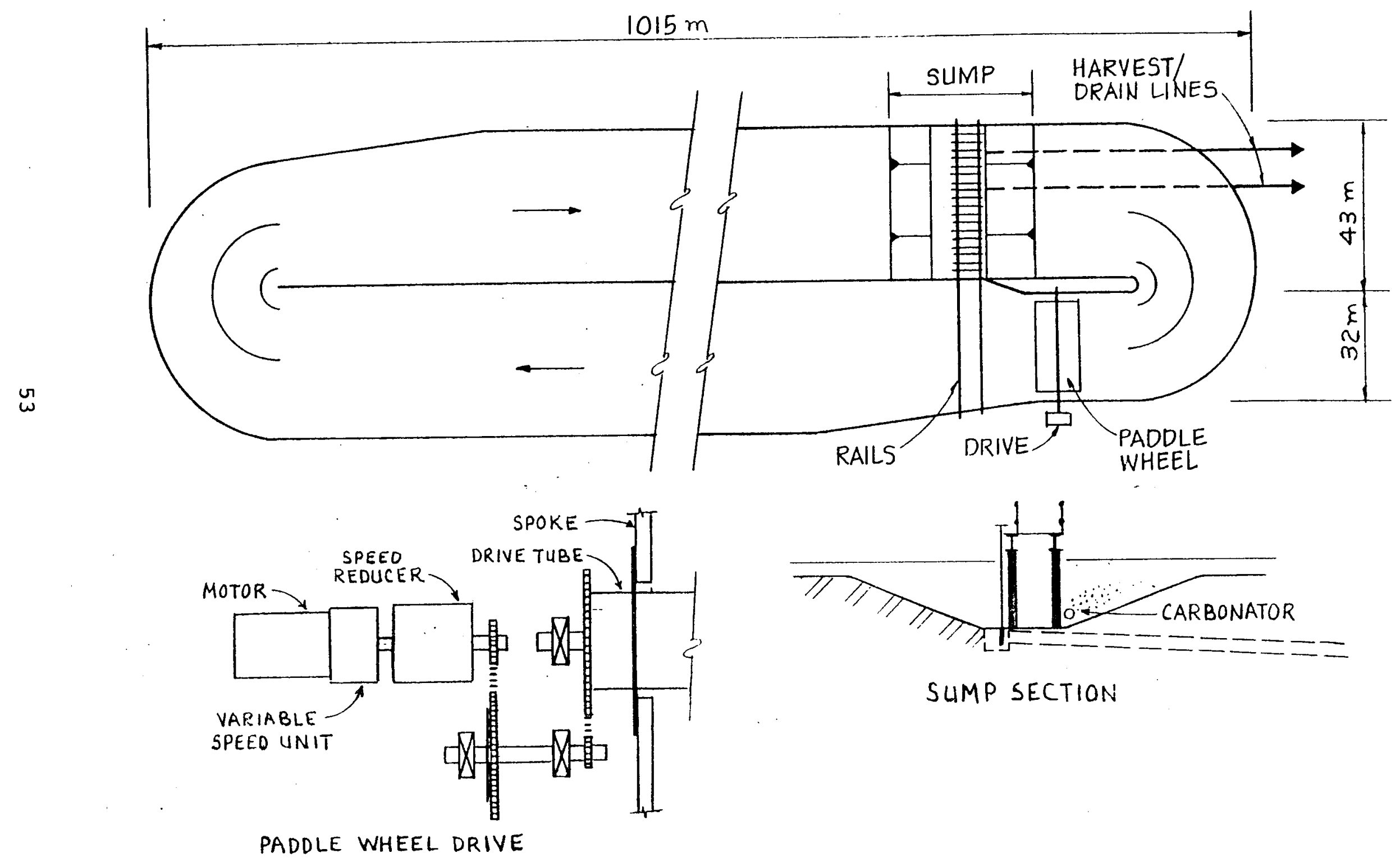

Figure 7-4 Single Pond Layout 


\subsection{POND DESIGN ALTERNATIVES AND COSTS}

\subsubsection{Introductign}

This section presents the actual designs of the various growth pond elenents, along with an estimate of their costs. In some cases, a brief analysis is included, and alternative designs are explored. Sections 7.3 .1 through 7.3 .8 treat earthworks, walls and dividers, sumps, solids romoval, carbonation, and mixing respectively. In section 7.3 .9 a summary of costs, based on the chosen alternatives is presented. Harvesting is treated in section 8.

\subsubsection{Earthworks}

\section{Rough_Grading}

- As a preparation for laser levelling, the pond grade is established roughly with conventional earthmoving equipment. The amount of rough grading will vary fron almost nil on flat terrain to major quantities of cut and fill where the terrain is rough or sloping, requiring terracing to establish the pond grade. Compaction of fills is essential to prevent settlement and can be a significant cost. Presence of rocks, roots, and other material can add appreciably to rough grading costs. Dikes or orains to control surface drainage may also be required. Earthworks for access rads, storage reservoirs, etc., is not included. For favorable terrain, rough grading costs can vary from 0 to $\$ 4000 /$ hectare. A value of $\$ 1200 /$ hectare is used in the cost estimate.

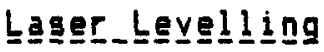

Laser levelling is needed to achieve the tolerances required for hallow pond operation, and to establish the very flat channel slopes to meet hydraulic requirenents. It has become a widely used technique in agriculture, where the cost can be as low as $\$ 900 /$ hectare for large fields. For pond construction, the cost will be greater, since the slope must be set separately for each channel, and tolerances will be quite rigorous. A value of $\$ 2500 /$ hectare is used in the cost estimate.

\section{Finished_Grading_and_Crughed_Rosk_Linger}

The cost constraints of fuel production may prohibit the use of synthetic pond liners, which alone would cost $\$ 38,000-58,000 /$ hectare depending on the quality of liner used. In the cost estimate, it is assuned that the ponds will be built on tight soil, which is sufficiently iapermeable to control sopage. Seepage rates generally decline with time as a result of clogging by organic atter and inorganic precipitates. In some cases, a clay liner $(15-30 \mathrm{~cm})$ 
may be necessary. Often, the clay is available on-site, as in the case of the experimental facility described in Section 12. If not, finished grading costs could be substantially higher, if long haul distances were involved. However, even a doubling or tripling of finished grading costs would have a minor affect on overall pond construction costs. Finish grading is usually required on clay soils due to 1055 of grade fron construction activites such 25 trenching, etc. The soil will be overlain with a minimum thickness blanket $(3-5 \mathrm{CA})$ of crushed rock or other coarse granular material to control suspension of fines. The particle size distribution and degree of compaction of this rock overburden will determine the channel poughness. Transport costs for imported granular material can be appreciable if local material is unavailable. The total cost for finish grading and crushed rock liner will likely cost between $\$ 4000-8,000 /$ hectare. A design value of $\$ 6200 /$ hectare is used in the cost estinate.

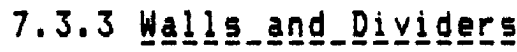

A variety of wall construction techniques are conceivable, ranging from earthen berms to slipfor concrete. This section will examine five options, cite their pros and cons, and give cost estimates for each. Four of these options are illustrated in Figure 7-5. In general, walls need to be about 0.4 meters high, except in areas where wave action would require aore freeboard (e.g. downstrean of paddle wheels), or where water accunulates under quiescent conditions. Very large ponds would probably require higher walls since larger wind induced waves could occur. In general, the center wall which divides the two channels can be of identical construction as the exterior walls. In small ponds with low head losses it may be possible to use a less expensive method for the dividers (e.g. menbrane dividers).

\section{Earthen_Berms}

Earth beras must be constructed of compacted fill by over-building, trimmed to give smooth side slopes, and then protected against erosion. A minimum top width before trimaing is about 2 meters, for conventional compaction equipment. Slope protection material would have to be several times the thickness of the bottom blanket, because of more difficult construction and greater erosion potential. Even so, there is likely to be high maintanence costs associated with slope protection. Extra protection, e.g. gunnite, will be required where wave action tends to concentrate. Weed growth on the top and sides of earth berms is also a potentially costly maitanence problea. More land is required as compared to narrow walls. Although it may be possible to construct beras for as little as \$16/linear weter with special equipment, the O\&M disadvantages weigh heavily against earth berms. Earth berms ay be appropriate for those walls which form the perimeter of the pond system, since an access road will be needed around the perimeter, and drainage considerations ay require it to be elevated. 


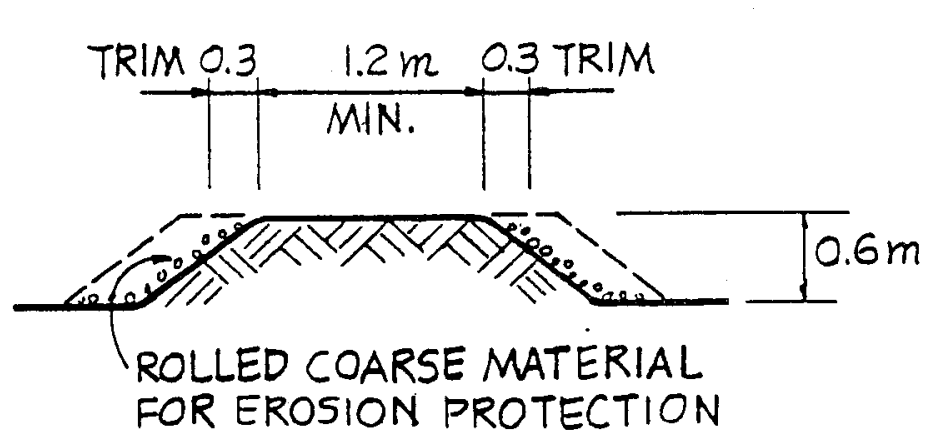

EARTH BERMS

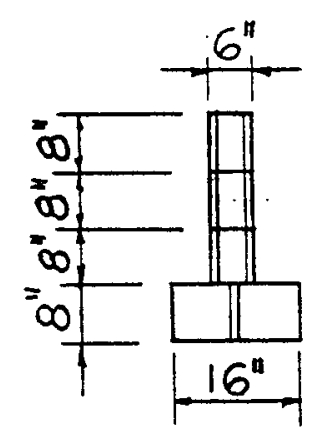

CONCRETE BLOCK

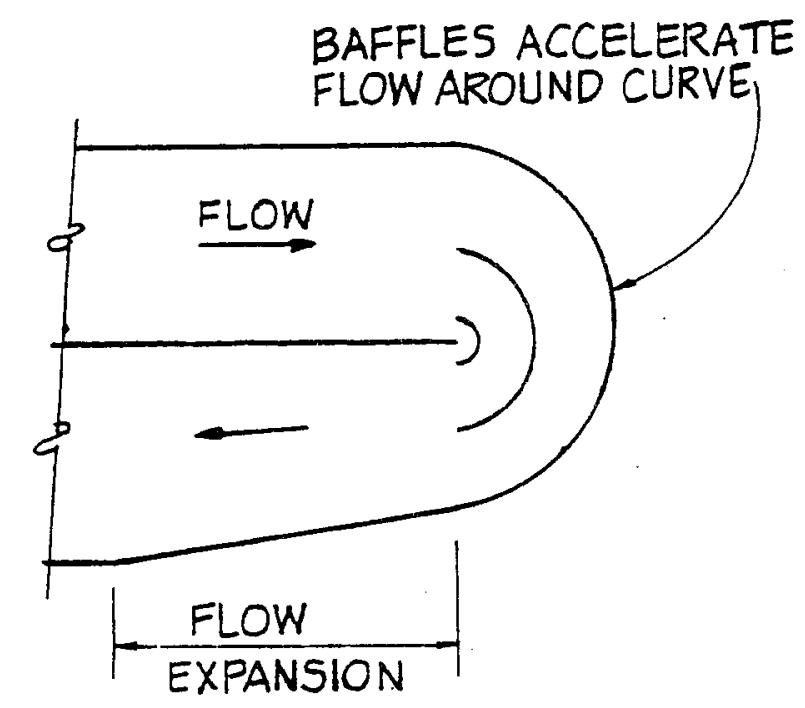

CURVED END WALLS

AND FLOW DEFLECTORS

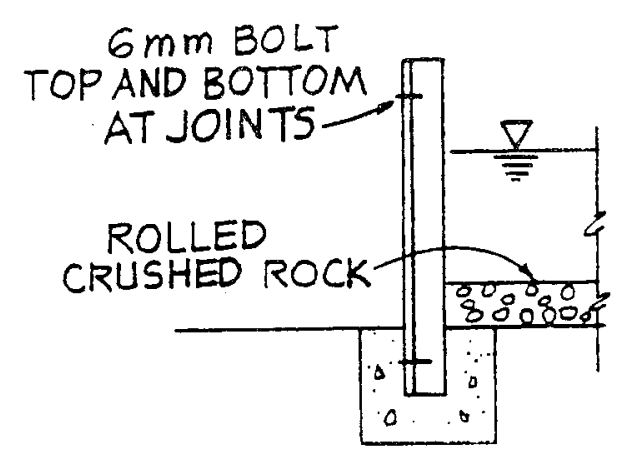

CORRUGATED ASBESTOSCEMENT WALLS

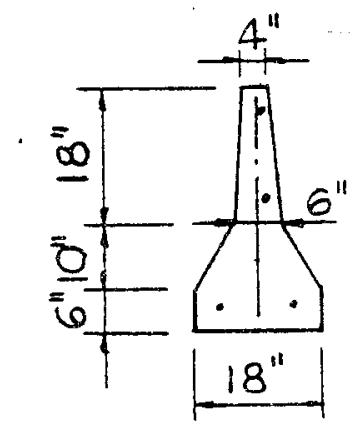

CONCRETE T

(POSSIBLY SLIPFORMED)

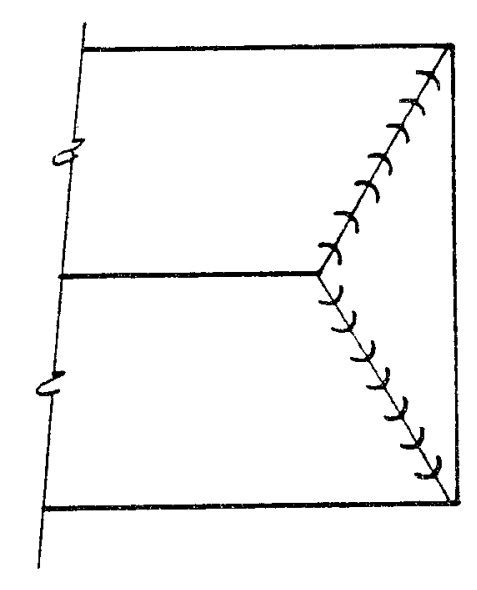

SQUARE END WALLS

AND TURNING. VANES

FIGURE 7-5 POND WALL AND FLOW DEFLECTOR OPTIONS. 


\section{Corrugategd_Ha $\underline{\underline{1}} \underline{\underline{s}}$}

A novel technique, used by Dodd in Singapore, employs corrugated asbestos-cement roofing sheets embedded in a shallow concrete-filled trench. The sheets are cut and drilled off-site, then installed with the corrugations running vertically. Adjacent pieces are caulked and bolted together, forming a free standing, waterproof wall which can expand and contract with changes in temperature. Material costs are about $\$ 9 /$ meter, with total installed costs estimated at about $\$ 24.50$ /meter. OtM costs are likely to ae quite low.

\section{Megbrane_Ha 1 l 5}

The membrane wall consists of a Hypalon membrane supported on a framework of 2"x2" redwood posts spaced 1.2 meters (4 feet) on center. The posts are set in 15 ca ( 6 inch) dianeter holes filled with concrete for anchoring and stability. The top of the membrane is anchored between two railings again made of $2 \times 2$ redwood. The bottom of the membrane is anchored in a $30 \mathrm{~cm}(12$ inchl deep trench backfilled with earth which also prevents seepage under the wall. This estimated cost of this method is $\$ 18.07 /$ meter $1 \$ 5.51 / \mathrm{ft}$, see Appendix III). Although this wakes it one of the lowest cost options, it is also the least durable, so that $0 \& M$ costs would probably offact initial cost savings. However, experimental ponds are often membrane-1ined, go this method, or some variation, would be appropriate. The experimental ponds at Vacaville, CA used solid wood walls and a membrane liner.

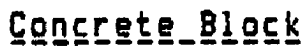

The concrete block wall consists of a poured concrete footing $15 \mathrm{~cm} x$ $30 \mathrm{c} / \mathrm{f}\left(6^{\prime \prime} \times 12^{\prime \prime}\right)$ with 2 courses of $4^{\prime \prime} \times 81 \times 16^{\prime \prime}$ blocks set on top. The block cells would be filled with pea gravel concrete and a single 4 reinforcing bar set in the top block to give the wall adequate longitudinal strength. The footing would be set below grade for stability and to prevent seepage under the wall. The estimated cost of this option is $\$ 23.35 /$ n $(\$ 7.12 / 4 t)$.

\section{Poured_Concretete.}

The poured concrete divider wall is set on a $15 \mathrm{~cm} \times 30 \mathrm{~cm}$ footing, is 10 ch (4") thick and $40 \mathrm{~cm}\left(16^{\prime \prime}\right)$ high. Custom made reusuable form are proposed that are free-standing to reduce installation and relocation labor. One 4 reinforcing bar would be set along the upper part of the wall to hold the wall together and minimize cracking. Cracking would be controlled by joints every 6.1 meters $(20 \mathrm{ft})$ and sealed with silicon to minima seepage through cracks in the control joints. The cost of this option is about $\$ 17.50 /$ meter $(\$ 5.34 / f t)$. Given the large quantity of walls to be constructed for the large scale system, it should be possible to employ slip-forning techniques at about the same cost. The key concern with concrete walls is 
seepage. Shrinkage cracks will definitely occur, but there was a lack of agreement among consultants as to their effect. One felt that the control joints plus the tendency for cracks to clog would aitigate the problem, while another felt that the need to make control joints waterproof would greatly increase the cost of concrete construction. The author experience with experimental $\left(1000{ }^{2}\right)$ high rate ponds tends to support the former, but the problen is certain to be more pronounced in large ponds. Although most seepage will be contained within the pond systen by virtue of the side-by-side layout, excessive seepage would result in short circuiting within the pond. If seepage is not a serious problen, then the concrete walls are the preferred method of construction, possibly in combination with corrugated walls for the curved portions. Such a combination was used in the cost estimate. The difference in cost between the two alternatives $1 \$ 24.50 / \mathrm{a}$ for the corrugated vs $\$ 17.50 /$ for the concretel is not enough to have a major impact on the system capital cost.

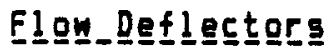

The curved flow deflectors aid in minimizing the extent of eddy formation and the associated stagnant zone downstream of the bend. Again, these can normally be built in the same manner as the straight walls, al though some of the wall options outlined above are more easily adapted to curves (e.g. corrugated walls). The situation is improved if the boffles and ond walls are placed eccentrically, and the channel width decreased through the bend, as shown in Figure 7-5. The acceleration of flow is sufficient to reduce eddy formation and eliainate most of the solids deposition. The channel constriction technique is also used at the other end of the pond, which allows access to the paddle wheel [12]. An alternative to curved deflectors are turning vanes, also shown in Figure 7-5. Turning vanes are widely used in analogous fluid systems, (e.g. air ducts), although Dainippon Ink \& Cheaical, Inc. apparently holds an application patent for their use in algae production ponds. If closely spaced, (i.e. at intervals equal to the pond depth), the vanes are quite efficient, and virtually eliainate problems of eddy formation and solids deposition. They also allow the ends of the pond to be square, which simplifies construction. The quanitity of material required for both curved deflectors and vanes is about the same, but the latter require more elabarate support and would be nore expensive to install. Curved deflectorg were used in the design, priced at $\$ 25 /$ meter (\$273/hectare). Vanes would cost about twice this amount.

\section{3 .4 Sugegs}

Sumps are necessary in order to provide a deepened area for $\mathrm{CO}_{2}$ additions so that high absorbtion is acheived, and to provide a collection point for draining the pond. The sump may also provide an area of peduced velocity where inert solids and settleable organic matter can accumulate and be removed. The analysis of $\mathrm{CO}_{2}$ absorption presented in section 3.0 concluded 
that for an for an 9 hectare pond, a sump depth of about 1.5 meters will result in $95 \%$ absorption of $\mathrm{CO}_{2}$, if the diffusers produce bubbles about 1 man inameter. This depth is also sufficient to prevent vortexing and air entrainment in the drain pipe. The sump crosg-section is shown in Figure 7-4. In order to facilitate drainage, insure uniform carbonation, and expedite excavation, a single sump is constructed across the entire width of the channel. The transition into the sunp is gradual to minimize turbulence and avoid the need for concrete formwork. The length (in the direction of flow) is related to the issue of solids removal, as discussed in the following section. In the baseline design, the length is kept to a miniaum (1 meter). The distribution pipe for $\mathrm{CO}_{2}$ is located at the downstrean end of the sump, so as not to interfere with any solids deposition that may occur. $\mathrm{CO}_{2}$ absorption actually takes place in the downstream transition section. The harvesting/drain piping originate from small "sub-sumps" located in the botton of the sump, so that a submergence of 1.5 meters is maintained.

\section{3 .5 Sol 1 ds Rengyal}

The accumulation of both inert and organic solids, which by virtue of their density or tendancy to aglomerate into flocs and settle, is inevitable after a period of pond operation. This material tends to settle in "dead spots" (i.e. stagnant areas) within the pond, and will eventually lead to operational problens. Since a sump is to be included for the reasons outlined above, the question arises whether it could also serve as sedimentation basin for removal of settleable solids. If, for instance, the sump were made 5 meters long (botton length), the detention time of fluid passing through the sump would be about 300 seconds. A geometric analysis indicates that only very rapidly settling particles ( $\left.V_{p} \geq 30 \mathrm{~cm} / \mathrm{min}\right)$ will be renoved completely, with the remainder being removed in proportion to their settling rate divided by $30 \mathrm{~cm} / \mathrm{min}$. Since most of the solids settle at rates well below this, the efficiency of the sump for solids removal is likely to be quite low. Although the efficiency could be improved by increasing the length of the sump ( $V_{p}$ varies as $\left.1 / L\right)$, the marginal increase in performance would not justify the expense. The problem is that both low velocities and long detention tines are necessary. Thus it may be necessary to design stagnant zones, similar to those ereated by an unbaffled turn, in which solids can accumulate and be removed, but in such a way so as not to disrupt the mixing regime over a large area of the pond. It may be possible to do this in a portion of the carbonation sump, or perhaps in a smaller sump right after the bend before the paddle wheel. The whole issue of solids accumulation needs to be assessed at the pilot scale, since most of the current information comes from observations of waste treatment ponds, which are subjected to high organic loadings, and in which a large accumulation of solids would be expected. A method for removing solids from the nain sump, which uses a suction device mounted on a travelling bridge, has been developed [12], and is described in Appendix II]. For an 8 hectare pond, this method would cost about $\$ 1300 /$ hectare, most of which is for the piers 
and rails on which the bridge travels. Regardless of whether the sump will accumulate sufficient solids to justify the expense of the travelling bridge, the $\$ 1300 /$ hectare has been included in the cost estimate, since it will allow access to the sump for servicing the carbonation system and effluent drain valves. Also described in Appendix III is a mechanical method for dredging the pond channels, which is estimated to cost $\$ 310 / h e c t a r e$. The final decision on the best approach to solids removal must await pilot scale studies which will define the severity of the problem and the effectiveness of the variuos alternatives.

\section{3 .6 Carbonatign}

The analysis in Section 3 concluded that a single carbonation station per pond would be sufficient to maintain an adequate level of dissolved carbon in the culture. The carbonation system is designed to supply the peak demand of $7.2 \mathrm{gn} \mathrm{CO} / \mathrm{m} / \mathrm{hr}$, which corresponds to about 4800 liters/min $(170$ efm) at the assumed delivery temperature of $27^{\circ} \mathrm{C}\left(80^{\circ} \mathrm{F}\right)$. A $100 \mathrm{~mm}\left(4^{\mathrm{n}}\right)$. distribution pipe spans the channel on the downstrea side of the sump, with spargers spaced along its length. The effect of sump depth and bubule size on $\mathrm{CO}_{2}$ transfer efficiency was also described in Section 3 . The analysis concluded that very fine bubbles (1 ma) were necessary for lateral flow carbonation in shallow sumps, and that the sump depth increased rapidly for larger bubbles. While it is a fairly simple matter to generate bubbles of 2-3 ma diameter with porous diffusers, to produce 1 m bubbles the flowrate per diffuser nust be quite low (bubble size is more sensitive to flowrate than to pore sizel. The manufacturers contacted could provide only cautious estimates of flowrates for this application, so that the actual type and number of diffusers will have to be deternined by pilot scale tests. For purposes of cost estimation, a relatively conservative approach was taken, based on information supplied by Cardox Co., a manufacturer of porous tube diffusers. The total cost of $\$ 18,800$ ( $\$ 2350 /$ hectare) includes the $p H$ controller, control valve, $\mathrm{CO}_{2}$ flowmeter, and associated piping. Since experjence has shown that the rates of $\mathrm{CO}_{2}$ absorption are often better than those predicted by the methods of section 3 , significant cost reductions are possible in this category.

\section{3 .7 Mix $\underline{\underline{i}} \mathrm{ng}$}

For an 8 hectare pond mixed at $20 \mathrm{~cm} / \mathrm{sec}$, the Manning's formula pradicts a head loss of $21 \mathrm{~cm}\left(8.3^{\prime \prime}\right)$, for an assuned roughness factor of $n=0.018$. The corresponding hydraulic power is 3480 watts $(4.67 \mathrm{hp})$. Paddle wheels are chosen for aixing, for reasons outlined in section 4-2. The constriction in channel width (see section 7-3-3) allows the paddle whel to be $25 \% 5$ aller than the channel width, and allows access to the drive. Even 50 , the width is 32.3 meters $(106 \mathrm{ft})$, so the paddle wheel is broken into three sections, separated by flexible couplings that allow some vertical and angular aisallignment. Design of the paddle wheels is based on a stress and 
deflection analysis of the paddles, the drive tube, and of each paddle wheel section. Although the low rotational speed means that torques are very high, it is the deflection of the paddle wheel under itg own weight land that of attached growth, which can be significant) that governs design of the tube. The design is similar to the small paddle wheels used in the Vacaville, $C A$ experimental ponds shown in Figure 7-6, with some notable changes. Many of these changes are based on improvements made by Dodd in the course of designing several "generations" of paddle wheels. The number of blades is increased from six to eight, and adjacent sections are offset by $22.5^{\circ}$, both of which reduce pulsations on the drive train and in the flow of the water. A solid baffle between sections also blocks flow across the channel. A small clearance between the paddle tip and the shallow (5em) curved depression below it makes the paddle wheel in effect a large positive displacement pump, with a minimum of backflow. The drive shaft is a steel pipe with solid stainless steel stub shafts at the bearings. The drive consists of a 15 hp electric motor, a variable speed unit, an in-line speed reducer, and two-stage chain and sprocket reduction. The final driven sprocket is inboard of the bearing, so that the stub shaft merely supports the paddle wheel weight, and does not transmit the drive torque. The various components (and their cost) are listed in Appendix III. The drive tube and hubs are epoxy coated steel, while the spokes and paddles are fiberglass, for corrosion resistance. In order to have the necessary rigidity in bending, the paddles must either be supported with a structural member (if $\$$ lat), or be formed into a structural shape themselves. The large quantity of paddles required for the large scale system allows the use of custom designed shapes, at very little cost over that of flat sheets. Thus a curved shape paddle was designed that has sufficient rigidity to span the 2.43 meters $(8 \mathrm{ft})$ between hubs without structural backing. The paddle is $0.64 \mathrm{~cm}$ thick, $57 \mathrm{~cm}$ high, and has a $61 \mathrm{~cm}$ radius of curvature. (The paddle height must accomodate the nominal depth, lift, depression, and wave action generated by the paddle whel itself). The curved shape also sheds water efficiently as it leaves the water. With each pair of ponds laid out as a mirror image, the two drives are elose together, minimizing wiring costs.

The paddle wheels are a major cost component of the growth pond system, each one costing about $\$ 37,500$, including structural supports, concrete depression, and installation. This is almost $20 \%$ of the growth pond cost.

\section{3 .8 Instrungentatíng}

Instrumentation to measure teeperature and dissolved oxygen will be provided for each pond, and this information, along with $\mathrm{pH}, \mathrm{CO}_{2}$ flowrate, and make-up water flowrate will be transmitted to a microcomputer-based data acquisition unit which records the data and prepares sumary reports. Given the relatively low price of such systems, one will be installed at each harvesting station, (i.e. for each eight growth ponds), eliminating the long data transmission lines that would be necessary in a totally centralized system. Allowing $\$ 2000 / p o n d$ for the measuring and transmitting equipment, 


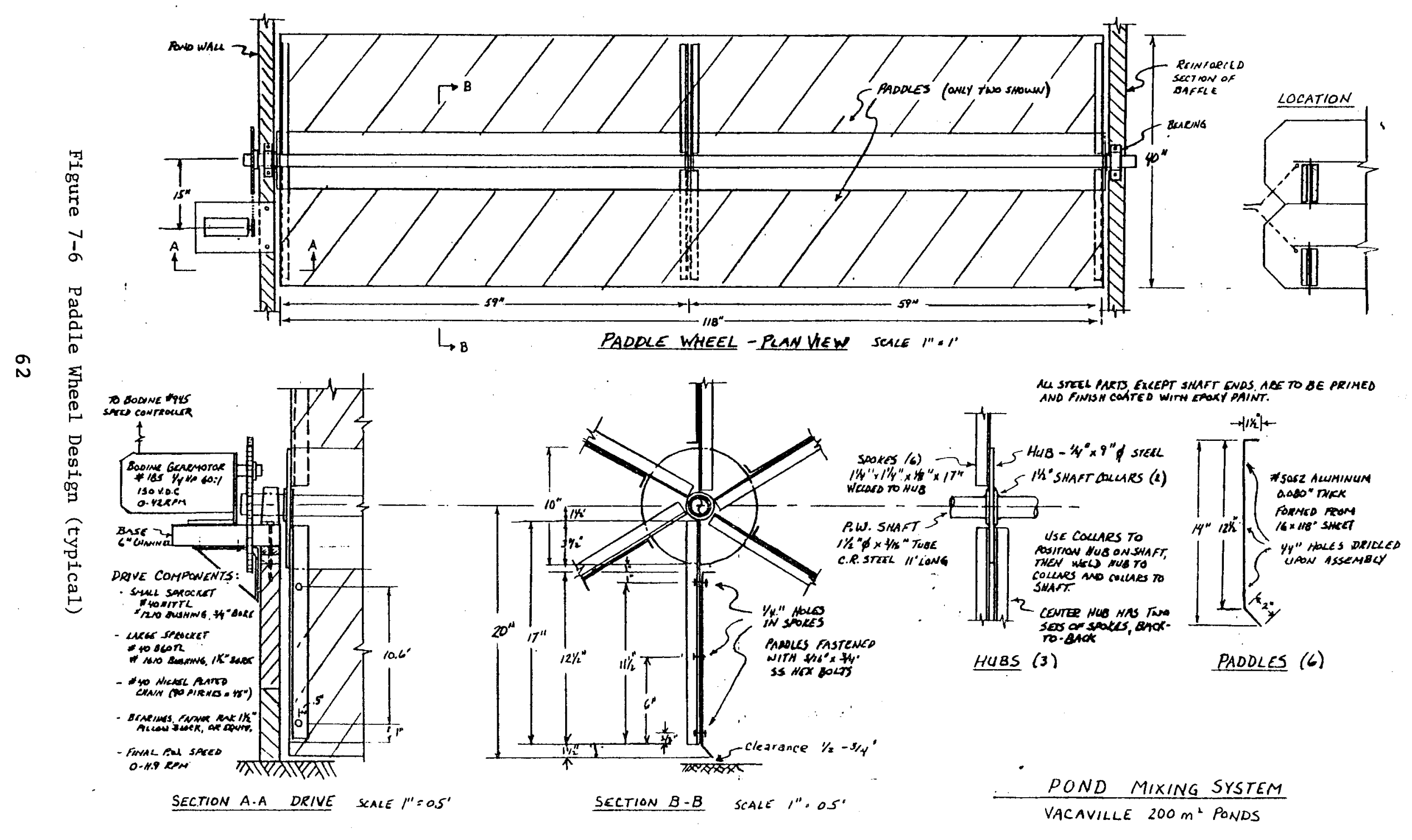


and $\$ 16,000$ per harvesting station for the data acquisition system linstalled costs), the overall cost is $\$ 96,000$, or $\$ 500 /$ hectare. A system of this type could later be expanded to automate harvesting operations, an option not provided for in the cost estimates.

\section{3 .9 Pond_Cost_Summary}

A sumary of costs for the 24 eight hectare ponds is given in Table 7-3. The table was developed on a spreadsheet, so that the sensitivity to changes in design or costs could be examined with relative ease. The quantity of material in each category is an equation based on the Pond Design Calculations, samples of which were listed in Tables 7-1 \& 7-2. In most cases the unit costs were fixed, although in some cases le.g. carbonation, mixing), they were represented by an equation, or reference to a look-up table. For this reason, the range of the program is limited to ponds of about 2-10 hectares, although the quantities colum is accurate over a much wider range. The mixing systen costs were generated from a separate program. 
SECTION 8.0

HARVESTING SYSTEM DESIGN

This section presents three alternative designs for harvesting, inluding ( 1 ) Microstraining; (2) Belt Filtration; (3) Settling. (Air/do floatation, mentioned in Sections 5 and 12 , is not analyzed in this section). In each of the three cases, further concentration is acheived through centrifugation, in order to bring the solids content of the slurry up to $10 \%$ VS. However, the costs of centrifugation vary widely according to the level of concentration achieved in the primary harvesting step. The harvesting operations are based on the analysis of Section 6 , which concluded that an induction phase would be necessary to achieve high lipid levels in the cells. This in turn iaplies batch, as opposed to continuous, harvesting. The harvest flowrates are based on a four day (systen average) detention time,although the growth/induction cycle will most likely be longer, especially in the winter months.

\section{Q. 1 MICROSTRAINING}

Microstrainers are an attractive harvesting method because of their mechanical simplicity and availability in large unit sizes. The recent availability of very fine mesh polyester screens has revived interest in their use for microalgae harvesting. Fabrics as fine as one nicron (nominal) have been successfully employed for algae renoval from lagoon effluents. However, attempts to harvest small unicellular algae with the one micron fabric have yeilded disappointing results, in spite of the fact that the cells were larger than one micron in size [13]. (The lack of success in straining small algae with the one aicron weave can be attributed to the fact that the actual openings in this fabric are rectangular, with dimensions of approximately one by six microns). Subsequent studies concluded that it would be necessary to flocculate the cells prior to microstraining. Current research is aimed at determining the types and amounts of flocculant necessary for various species. The use of flocculants in harvesting can have a significant iapact on operating costs, depending on the dose required. Under certain conditions, it may be possible to use microstrainers without adding flocculants, as in the case of large unicellular (e.g. Platymonas) or colonial algae, or with culturing techniques that induce "autoflocculation."

The design assumptions for the microstrainer based harvesting system are listed in Table 8-1, and are discussed below. The critical design parameters are hydraulic loading (flowrate/net effective subaerged area), solids removal efficiency (linfluent TSS-effluent TSS)/influent TSS), and concentration ratio (concentrate TSS/influent TSS). Although accurate prediction of these paraneters requires pilot scale tests with the particular spocies, some reasonable estimates can be made fros existing information. The hydraulic loading deteraines the size and number of microstrainers required, and so has 
TABLE 8-1. Microstrainer-Based Harvesting Svstem

\section{Design Parameters}

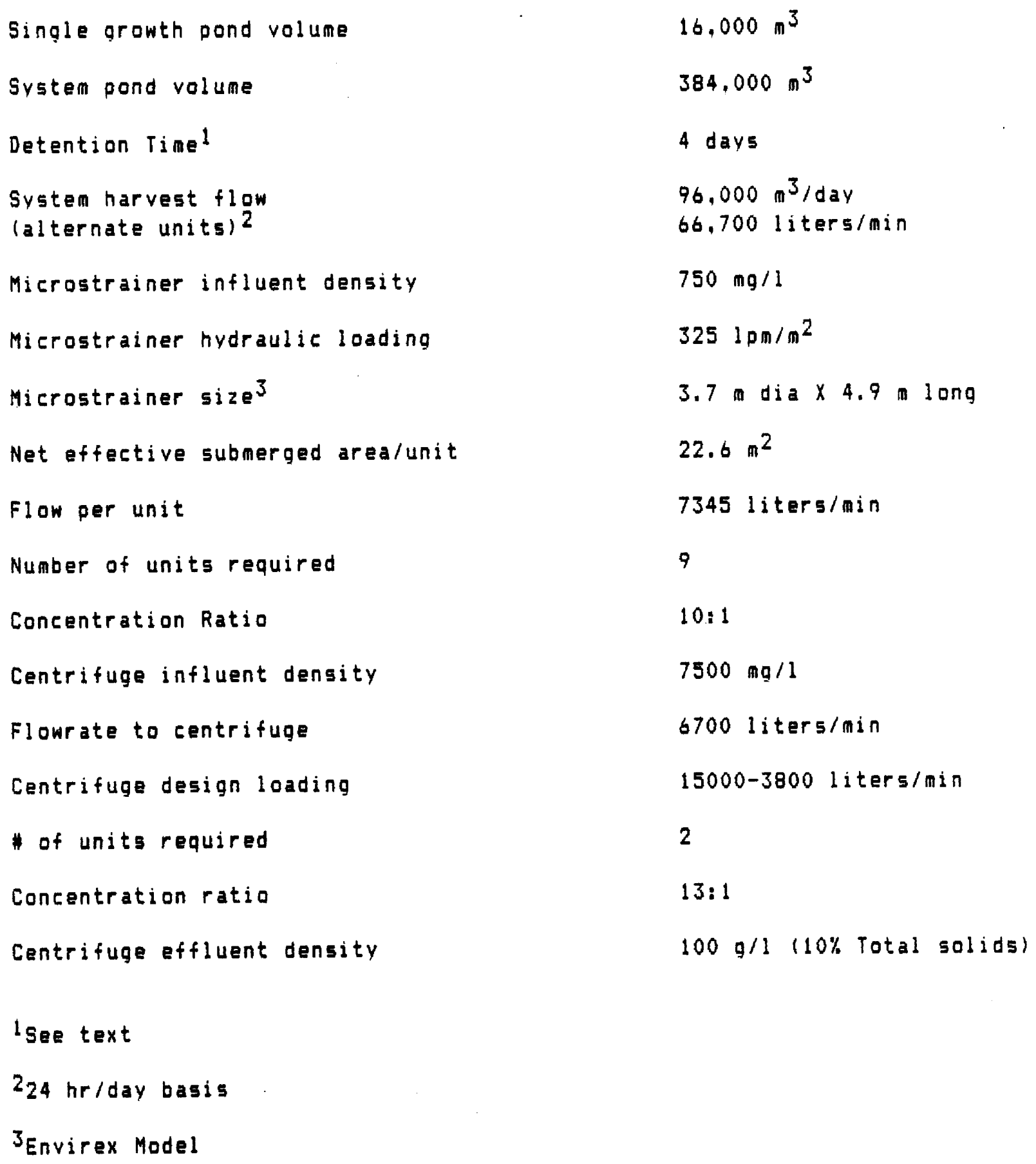


a strong impact on capjtal costs. Its value depends primarily upon the influent solids concentration, the size of the screening media, and the characteristic size of the algae. The "one micron" sereen imposes too severe a penalty on hydraulic loading to be a practical alternative. since this analysis presupposes large, colonial, or flocculated algae, the required mesh size will fall in the range of six to twenty microns. The hydraulic loading is assumed to be $325 \mathrm{lpm} / \mathrm{m}^{2}\left(8 \mathrm{gpm} / \mathrm{ft}^{2}\right)$, a reasonable value for the mesh range specified. The importance of solids removal efficiency depends on the mode of operation, ranging from critical for "once-through" systens le.g. seawater), to moderate for recycle systems, wherein unharvested cells are returned to the ponds in the harvest return strean. On the other hand, the microstrainer must produce a significant increase in solids density to justify its relatively high cost. For lagoon effluent polishing, a concentration ratio of $b: 1$ is typical. However, these systeas are operated to produce the lowest possible effluent density, not to concentrate algae. When optimized for the latter, a tenfold concentration should be attainable. This corresponds to a tenfold reduction in flow to the secondary harvester. since centrifuge capacity is largly flowrate dependent, the concentration ratio is of major importance.

In order to reduce large dianeter piping runs, the primary harvesting is decentralized into three harvesting stations, each containing three nierostrainers, and each serving eight growth ponds. An alternative would be to use slightly smaller microstrainers (increasing the number to twelve) and building six stations, each serving four ponds. This would further reduce piping runs, but the savings would be offset by higher microstrainer and facilities costs. This trade-off is not considered in the cost analysis. A schematic of the harvesting system is shown in Figure $8-1$. An entire pond volume is harvested on the fifth day of the growth/induction cycle, so the system average detention time is actually five rather than four days, and harvesting could be spread over 1.2 days per pond. However, a one day per pond timetable is more practical and allows some flexibjlity in o\&M.

An unfortunate consequence of batch harvesting is the need to store the clarified effluent until harvesting is completed. In a continuous process, it is returned immediately to the pond, but in a batch process this would dilute the culture along an exponential curve. Since the microstrainers are likely to be limited by solids, rather than hydraulic loadings, it way be possible to return the effluent, while gradually increasing the harvest flowrate to compensate. Obviously there are practical linits to this, as flowrates would have to increase indefinitely in order to harvest all of the cells, so in fact some algae would always go unharvested. With careful controls, the correct amount of seed algae could be left in the pond for the next batch. However, given the uncertainties involved, it is prudent to include storage ponds in the design, which hold the clarified effluent until harvesting is complete. If located entirely above grade, the effluents can be returned to the growth pond by gravity. If harvesting begins after dark on the fourth day and is finished $24 \mathrm{hrs}$ later, the entire night is available to drain the effluents from the storage pond back into the growth pond. 


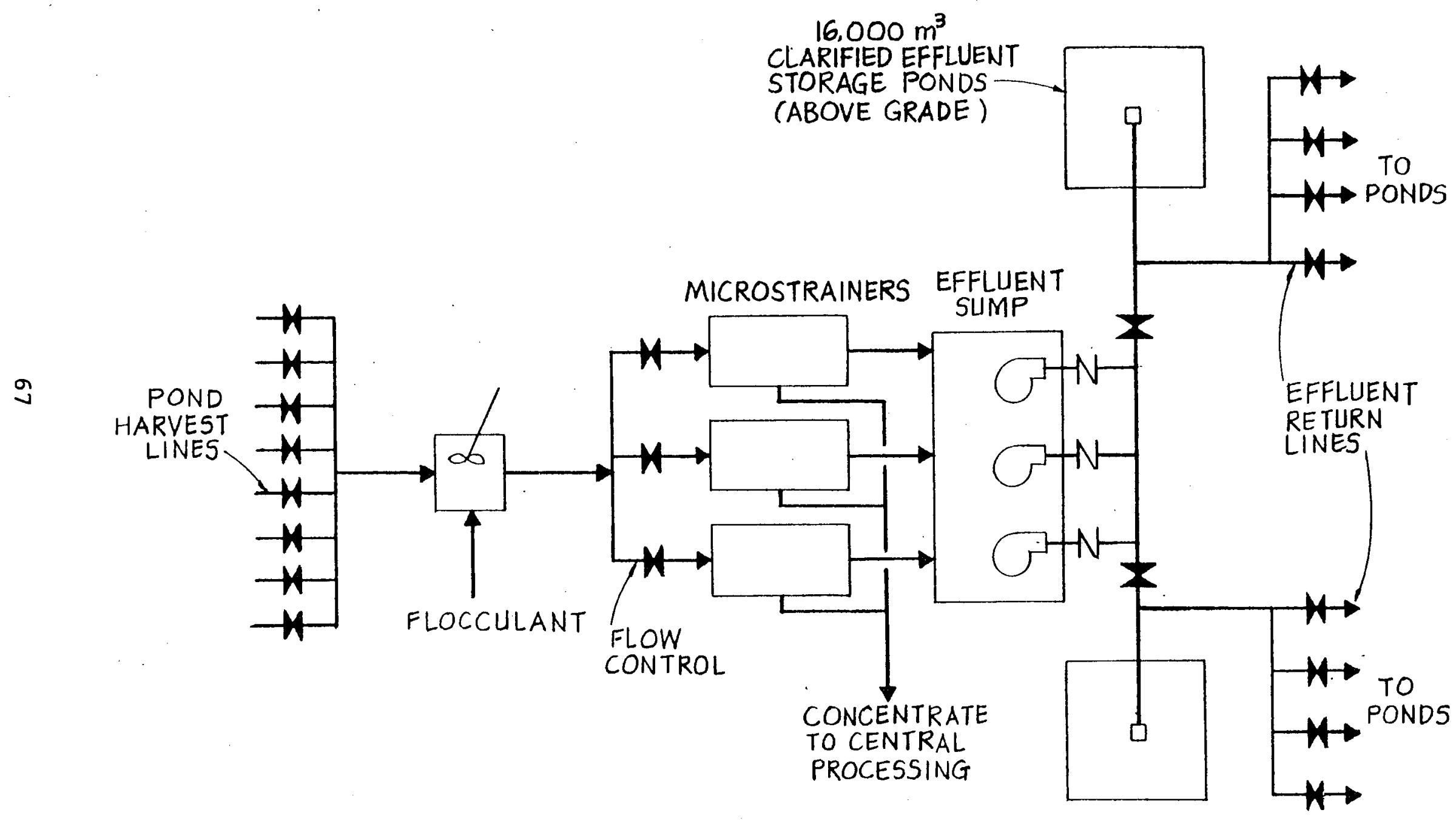

Figure 8-1 Microstrainer-Based Harvesting System 
The concentrated harvest streac from all microstrainers is pumped to a centralized secondary harvesting facility. The total flowrate to this facility, assuming $24 \mathrm{hr} /$ day operation, is 6670 l/ain (1760 op 1 ). Three large horizontal solid bowl decanter centrifuges, constructed with corrosion resistant aterials, are required. These are rated at 1510-3960 1pn (400-1000 gpa) each, depending on feed characteristics, flocculant dosage, and degree of concentration required. Although the use of disk nozle centrifuges might reduce capital costs, the savings would most likely be offset by higher operating costs [12]. The centrifuges concentrate the solids by a factor of 10-13, producing the required 10\% slurry. The solids are discharged continuously by eans of an internal screw conveyor. The clarified effluent from the centrifuges is returned to the ponds via the nakeup water network, elininating the need for separate return piping.

Capital costs for the microstrainer-centrifuge harvesting option are shown in Table 8-2. The total harvesting cost is $\$ 21,800 /$ hectare. If the centrifuges could be operated at $3700 \mathrm{lom}$ (very close to their maximum rated capacity), then only two units are required, and the total harvesting costs are reduced to $\$ 18,700 /$ hectare. Estimated annual operating costs are shown in Table 8-6, for an assumed flocculant cost of $\$ .01 / \mathrm{kg}$ dry algae. The sensitivity of operating costs to flocculant dose is discussed in section 11 . Although one would intuitively expect a trade-off between the quantity of flocculant used and the microstrainer design paraneters (which would effect capital costs), there is not sufficient data at this time to evaluate this trade-off, other than to say that certain species simply cannot be harvested without flocculants.

\subsection{BELT FILTRATION}

A vaccuun belt filter for algae harvesting, developed by Dodd in 1972, used a fine mesh stainless steel screen with aper precoat. The concept was later refined, with the sreen and precoat being replaced by a polyester fabric similar to those used in microstrainers. A pilot scale unit operated in singapore was very successful in harvesting Micractiniun and other large species, somewhat less 50 with small algae such as Chloredla. In general, the floccuant dose should be less than in the case of microstrainers, since the algae mat aids in filtration. Although the belt filter has a relatively high capital cost, it can concentrate solids much wore effectively than a microstrainer, by a factor of about $70: 1$ as opposed to 10:1. Since the product is more concentrated, flow to the secondary harvester is reduced substantially, resulting in lower secondary harvesting cost and reduced energy consumption. For the entire 192 hectare system, the secondary harvester flow is about $950 \mathrm{lp}(250 \mathrm{gpa})$. The layout of a belt filter systen would be very similar to the microstrainer systen shown in figure 8-1. The capital cost of the belt filter option is shown in Table 8-3, based on estinates supplied by Dodd. (The belt filter was assuaed to cost 50\% moro than a microstrainer of equal capacityl. Storage ponds are again necessary. 
TABLE 8-2. MICROSTRAINER BASED HARVESTING OPTION

CAPITAL COSTS

PRIMARY HARVESTING

9 Microstrainers (3.7 m dia $\times 4.9 \mathrm{~m})$ stainless steel construction, includes motor \& controls @ $\$ 160,000$ ea.

$\$ 1,440,000$

3 Housings, with concrete pit \& sumps (a) $\$ 50,000$

150,000

3 Pumps stations, including all valves \& Piping 300,000

6 Storage ponds 300,000

TOTAL

$\$ 2,190,000$

TOTAL/hectare

$\$ 11,400$

SECONDARY HARVESTING

2 Sharples PM95000 centrifuges, complete with motor \& control \& $\$ 650,000$

1 Housing \& concrete pad (4000 ft)

1 Pumps \& piping

TOTAL

TOTAL/hectare

$\$ 1,300,000$

100,000

150,000

$\$ 1,550,000$

$\$ 8,070$

TOTAL HARVESTING

$\$ 3,740,000$

TOTAL/HECTARE

$\$ 19,480$ 
PRIMARY HARVESTING

Belt Filters ( $1.5 \times$ Microstrainer Costs)

3 Housing, with concrete pad \& sumps

6 Effluent Storage Ponds

3 Pump Stations, including a-1 harvest/return piping, valves, etc.

$$
\begin{array}{r}
\$ 2,160,000 \\
150,000 \\
300,000 \\
300,000 \\
\hline \$ 2,910,000 \\
\$ \quad 15,200
\end{array}
$$

Total

SECONDARY HARVESTING

2 Sharples PM60000 Centrifuges @ $\$ 275,000$

1 Housing + concrete pad (2000 $\mathrm{ft}^{2}$ )

1 Pump/piping system

$\$ 550,000$ 50,000 50,000

Total

Total/hectare

$\$ 650,000$

$\$ 3,390$

TOTAL HARVESTING

TOTAL/HECTARE

$\$ 3,560,000$

$\$ 18,600$ 
The centrifuge cost is based on two units, each soller than those used with the microstrainers. The choice of two smaller, rather than a single larger unit reflects the O\&M realities of the need for more than a single centrifuge. Since the solids concentration going into the centrifuge is so auch higher than in the case of the aicrostrainers, a more conservative

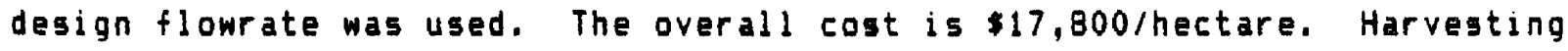
cost is not nearly as sensitive to centrifuge flowrates as in the cases of microstrainers. Operating cost estimates for the belt filter option are shown in Table 8-6. Note the significant reduction in energy cost associated with this option.

A comparison of Tables $8-2$ and $8-3$ shows that the two options presented thus far have capital costs very nearly the same, if the favorable assumption regarding centrifuge flowrate is made for the microstrainer option. operating costs for the belt filter option are significantly less. However, any comparison should be made with some caution, since large microstrainers are commercially available and their costs are known, whereas the belt filter represents new technology, for which costs are necessarily more uncertain.

\subsection{SETTLING}

The use of settling for aicroalgae harvesting is based on the observation that nitrogen-starved cultures will settle at rates of $30 \mathrm{~cm} / \mathrm{hr}$ or greater without adding flocculants. (The addition of 5 mall amounts of polymer can increase this rate and produce a more compact concentratel. The same phenomenon has been observed in non-nitrogen starved cultures, but in a less consistant, and more species and media dependent fashion.

A settling rate of $30 \mathrm{~cm} / \mathrm{hr}$ is still relatively low, and requires long detention times in the settling device, whether it be batch or continuous. The latter would not apply in this case, given that the growth/induction process is inherently batch. The major engineering problem in a large scale batch settling process is to devise an effective, inexpensive solids removal schene. The major drawback of batch settling is the large piping systems that are needed to transfer the fluids in ralatively short periods of tine, so that more time is available for quescient settling. This is partially overcome by the use of shared settling ponds and pump stations, which service a number of ponds in sucession. Other questions raised in connection with large scale settling ponds include the effect of wind nixing on settling rates and the possible degredation of the lipid fraction during the process. The wind mixing problen can be aitigated through the use of berms. Degredation is not likely to be a problem in the time period lapproximately 24 hoursl involved in the proposed design.

The layout of the settling pond system is shown in Figure 8.2. A two stage process is proposed, consisting of a large ( 0.5 hectare) settling pond, which concentrates the algae by a factor of 20 , followed by a second gravity thickening stage, which concentrates by an additional factor of 2.5 , for an 


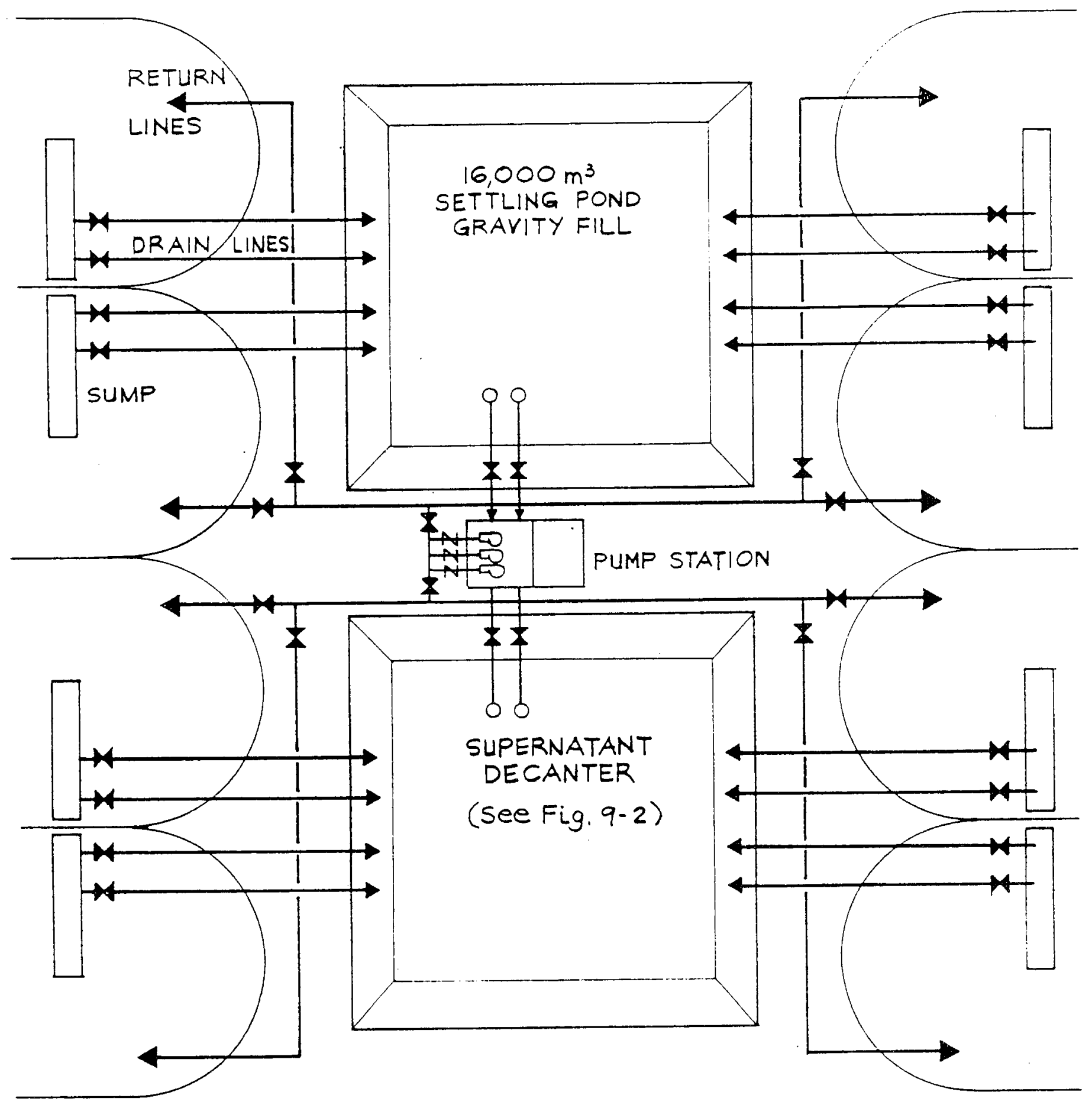

Figure 8-2 Settling Pond System Layout 
overall concentration factor of 50 . The choice of a two stage process is based on experience in operating the 40,000 liter batch settling pond in Vacaville. CA. This approach greatly reduces the need for precise discrimination between the concentrated bottom fraction and the less concentrated layer that forms above it, albiet at a greater cost. The large settling pond is sized to hold one pond volume $\left(16,000\right.$ meter ${ }^{3}$ ) in a 3 meter depth. The working volume is all below grade, so the ponds can be orained by gravity. It is a conventional sloped-sidewall basin, with 2i1 sideslopes. The dimensions are shown in Figure 8.3, along with other relevent details. The pond is lined with Hypalon ${ }^{1}$ or CPE 2 . The pond botto slopes towards a central alley on $2 \%$ grade. Both supernatant and concentrate piping go to an external pumping station that is shared by two settling ponds. The following summarizes the harvest sequencel (1) The contents of the growth pond are drained to the settling pond. The drain lines are sized to complete this in four hours. (2) The contents settle for a period of eight hours. (3) The supernatant is decanted off over a period of ten hours, and is returned to the growth pond (see figure 8-3 for draw-off details). Since liquid is removed from the top of the pond, settling continues in the lower layers. When the liquid level reaches the break in the slope, decanting is complete. Approximately $5 \%$ of the contents remain in the gettling pond. (4) The remaining concentrate is pumped to the secondary thickener. At various intervals, the concentrate stream (or stored secondary supernatant) is diverted into the flushing system, washing down solids that have have settled on the bottom of the pond into the collection alley, which leads to the concentrate sump. The concentrate removal process takes about two hours. The settling pond is now ayailable for the next growth pond. (5) The concentrate reaains in the thickener for about eight hours. The secondary supernatant is returned to the growth ponds, while the secondary concentrate is pumped to a centralized facility for centrifugation to $10 \%$ solids, as in the other harvesting schenes.

The sequence as described above is based on a four day cycle time, which is the shortest conceivable period for growth and induction. Actual cycle times will probably be five days or longer, depending on the time of the year, so that settling and decanting times may actually be longer than described above. The flowrates of the various fractions are listed in Table 8-4, for the four day cycle. Additional harvesting details are given below.

The pump station is a wet pit design, and is divided into two sections for supernatant and concentrate. Three vertical mixed flow pumps, each sized at $50 \%$ of the required flowrate, are provided. The pump station operates

1 A synthetic rubber liner manufactured by DuPont

2 Chiorinated polyethylene liner 

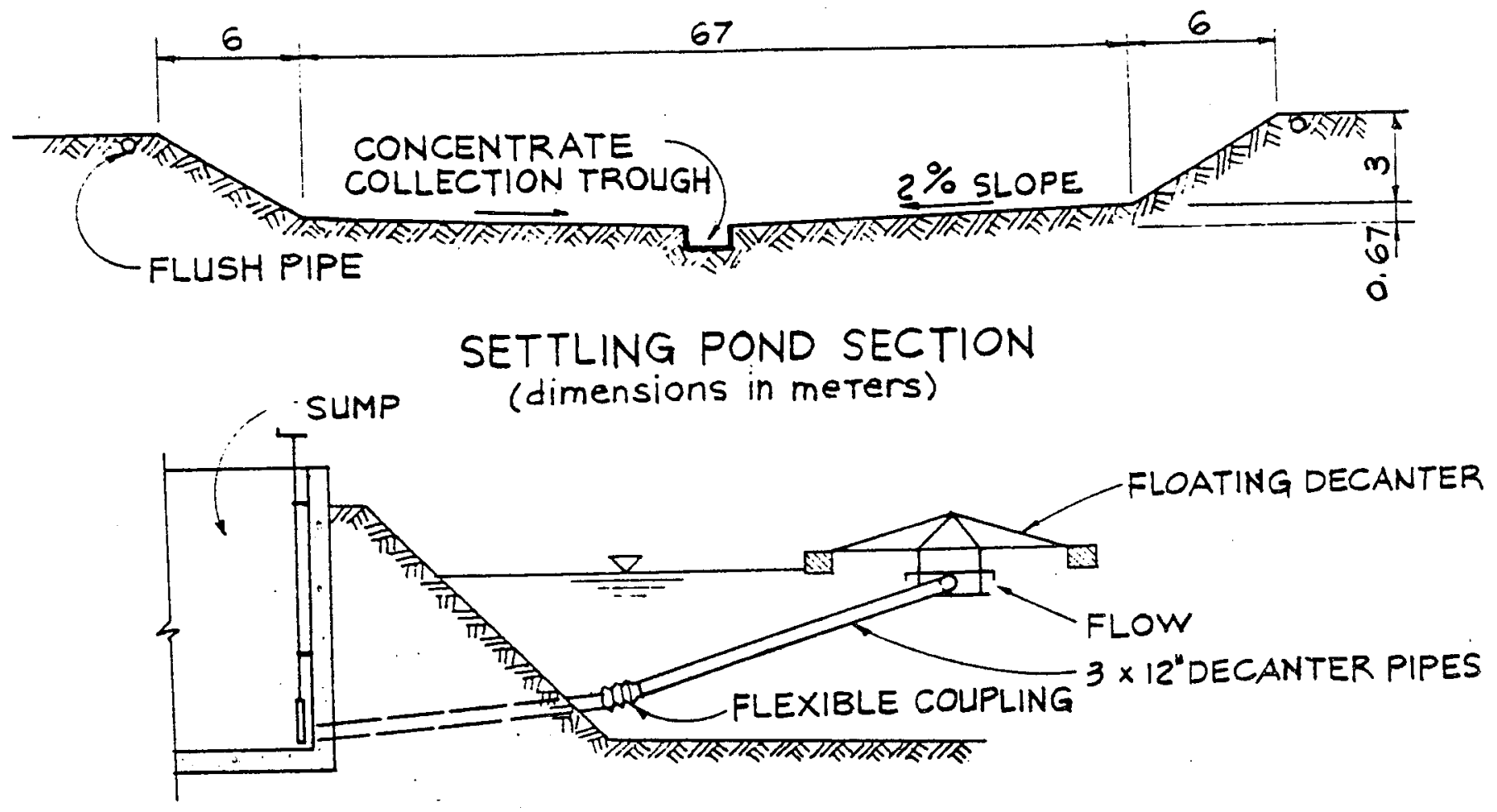

SUPERNATANT DECANTER

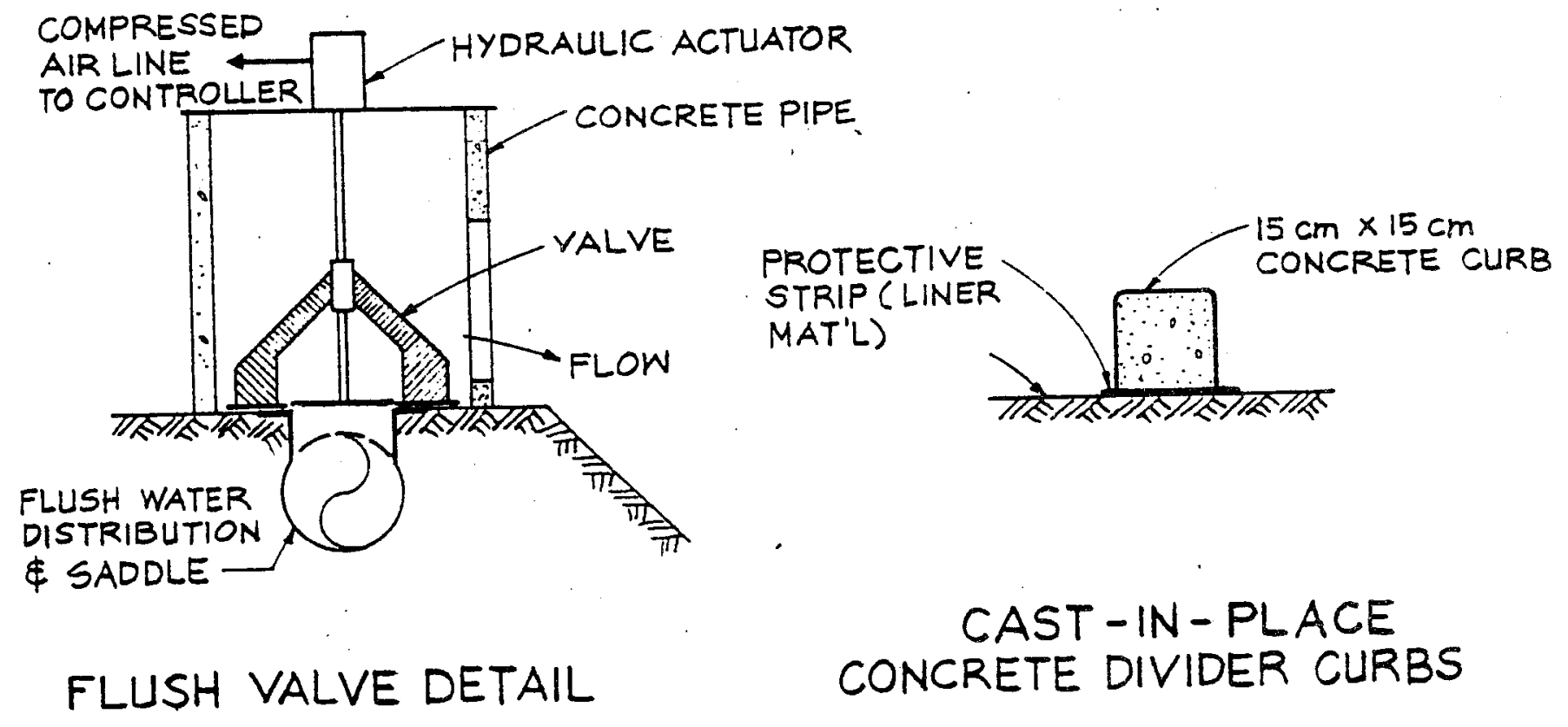

Figure 8-3 Settling Pond Details 
almost continuously when the cycle tine is four days. Two screw pumps are used to pump the primary concentrate into the secondary thickener. (Low shear solids handling pumps are required for handling all concentrate fractions). The flush system is very similar to those used in dairies for aanure collection, and is designed to provide flushing velocities of about 1 meters/sec ( $3 \mathrm{ft} / \mathrm{sec}$ ), which should be sufficient to resuspend and transport solids accumulated on the bottom of the pond. The channels are divided by 0.10 meter $(4$ inch) concrete curbs which are either poured directly on the liner or precast and set in place. In the figure, the concentrate itself is diverted into the flush network, consisting of a distribution pipe which sequentially feeds the flush water into 16 channels, 8 on either side of a concrete collection alley isee details in Figure 8-4). It may be necessary to divert some of the initial concentrate (which will have the least amount of solids) into a small storage pond, and use this liquid for flushing, or build two smaller secondary thickeners and $f$ lush with recyled secondary supernatant. Since good distribution of the flush water over the width of the channel is essential, optimization of the geonetry may also be necessary, (i.e.a larger number of channels, or a change in pond geometry to longer, narrow channels). None of these options would have a major impact on costs. These and other issues, such as the optimal duration and frequency of flushing, must be resolved in pilot studies.

After settling in the secondary thickener for about a hours, the secondary supernatant is decanted in the same fashion as before, and pumped into the return flow network. Secondary concentrate is punped to the central facility for centrifugation. The average flowrate is $40 \%$ greater than in

Table 8-4 Settling Pond Systen Flowrates

SINGLE POND:

\begin{tabular}{|c|c|c|c|c|c|}
\hline \multirow[b]{2}{*}{ Fraction } & \multicolumn{2}{|c|}{ Volume } & \multirow{2}{*}{$\begin{array}{l}\text { Time } \\
\text { hrs. }\end{array}$} & \multicolumn{2}{|c|}{ Flowrate } \\
\hline & $n^{3}$ & gallons & & lp & $g p n$ \\
\hline ond Volume & 16,000 & $4.23\left(10^{6}\right)$ & 4 & 66700 & 17612 \\
\hline 10 Supernatant & 15,200 & $4.02\left(10^{6}\right)$ & 10 & 25300 & 6690 \\
\hline $1^{0}$ Concentrate & 800 & $2.11\left(10^{5}\right)$ & $1.2 *$ & 11400 & 3000 \\
\hline $2^{\circ}$ Supernatant & 480 & $1.27\left(10^{5}\right)$ & 2 & 4000 & 1057 \\
\hline $2^{\circ}$ Concentrate & 320 & $8.45\left(10^{4}\right)$ & 2 & 2670 & 705 \\
\hline
\end{tabular}

SYSTEM (centrifuge flowrate):

$2^{\circ}$ Concentrate $320 \mathrm{~m}^{3} / 4$ days $\times 24$ ponds $=1330 \quad 352$

* Total removal time is longer because of recyle to flush system. 


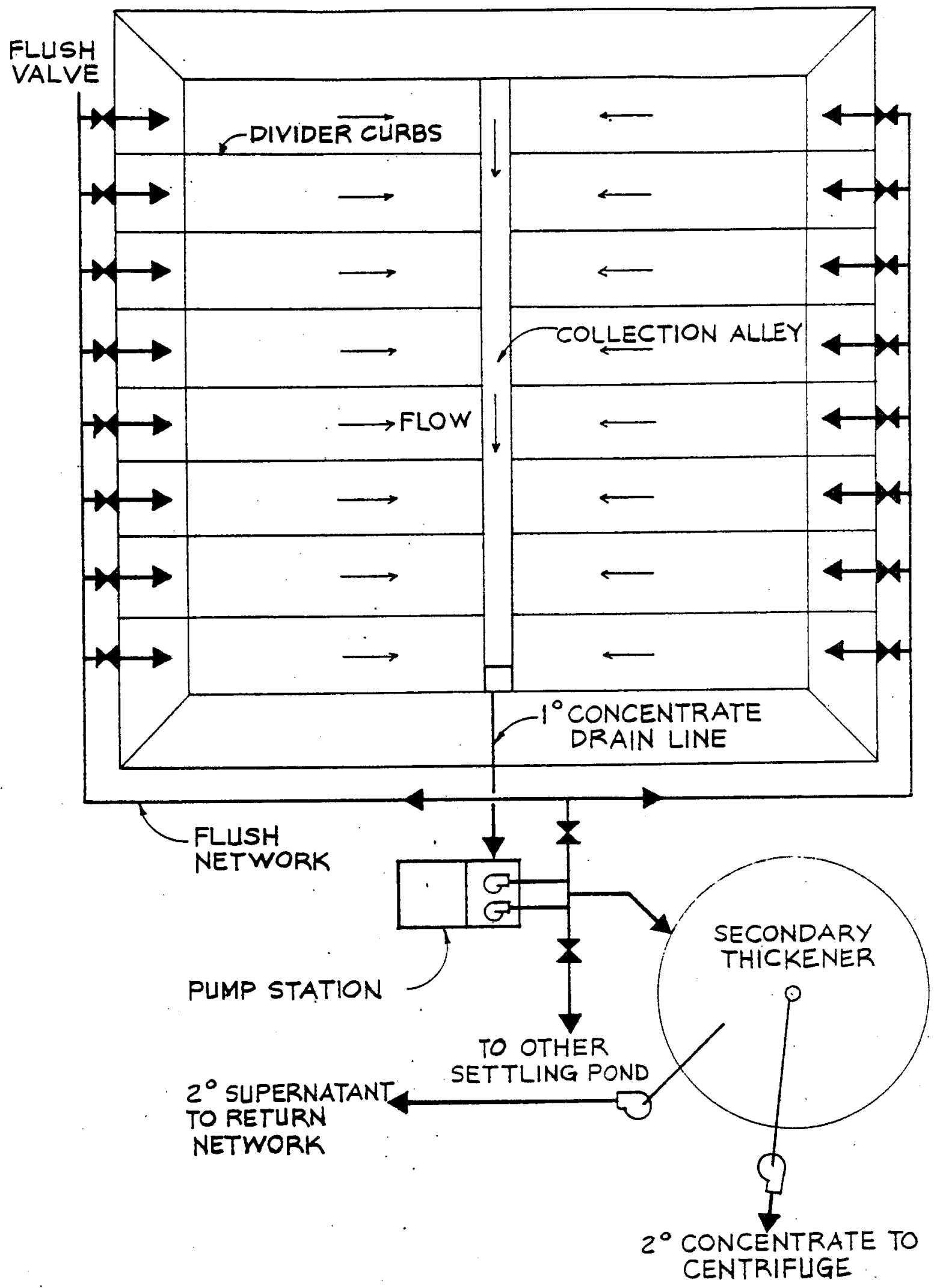

Figure 8-4 Settling Pond Flush System and Secondary Thickening 
the case of the belt filter, but a factor of five less than in the case of microstrainers. Capital costs for the settling option are shown in Table 8-5. At $\$ 11,260 /$ hectare, cost of this option is substantially less than for either microstrainers or belt filters. Estimated operating costs are shown in Table 8-6.

Table 8.5 Settling Pond Harvesting Option

Capital Costs

PRIMARY HARVESTING (2 stage)

Each harvesting station consists of 2 settling ponds (below grade), one pump station, and 1 secondary thickener. Each station serves 8 growth ponds.

\begin{tabular}{|c|c|c|}
\hline & Station & Systen \\
\hline Excavation \& shaping: $25,000 \mathrm{yd}^{3}=\$ 2.50 / \mathrm{yd}^{3} \times 2=$ & $\$ 125,000$ & $\$ 375,000$ \\
\hline Liners: $71630 \mathrm{ft}^{2}-\$ 0.60 / \mathrm{ft}^{2} \times 2=$ & 86,000 & 258,000 \\
\hline Piping, Valves, sumps, punps (see Table AIV-l) & 156,000 & 468,000 \\
\hline Secondary thickening (see Table AIV-2) & 107,000 & 321,000 \\
\hline $\begin{array}{l}\text { Primary Harvesting Subtotal } \\
\text { Primary Harvesting Subtotal /hectare }\end{array}$ & 474,000 & $\begin{array}{r}1,422,000 \\
\$ 7,360\end{array}$ \\
\hline
\end{tabular}

SECONDARY HARUESTING:

2 Sharples PM75000 centrifuges $\$ 330,000$

660,000

Housing \& concrete pad

50,000

Punps piping

50,000

Secondary Harvesting Subtotal

Secondary Harvesting Subtotal/hectare

750,000

$\$ 3,900$

TOTAL HARVESTING

$\$ 2,172,000$

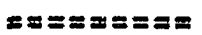

TOTAL HARVESTING/HECTARE

$\$ 11,300$

$== \pm \approx=$ = 
Table 8-b Estimated Operating Costs of Harvest Options

MICROSTRAINER BELT FILTER SETTLING PONDS

\section{ELECTRICAL}

Primary, kwh/yr

Secondary, kwh/yr

Total, kwh/yr

Total, $\$$ yr

FLOCCULANTS

MAINTANENCE

TOTAL
174,000

$2,578,000$

$0 .-2 .-1$

$2,752,000$

$\$ 178,900$

$\$ 216,000$

$\$ 112,200$

-.--.---

$\$ 507,100$

$\mathrm{z}=\mathrm{z}=\mathrm{z}=\mathrm{m}=$
348,000

967,000

$-2-0--$

$1,315,000$

$\$ 85,500$

$\$ 216,000$

$\$ 106,800$

$-.-2$.

$\$ 407,500$

$=\mathrm{z}=\mathrm{a}=\mathrm{a}=$
343,000

$1,096,000$

$1,439,000$

$\$ 93,500$

$\$ 216,000$

$\$ 81,000$

-.--.--

$\$ 390,500$

$\mathbf{z = \boldsymbol { z }} \mathbf{z = \mathbf { z }}$

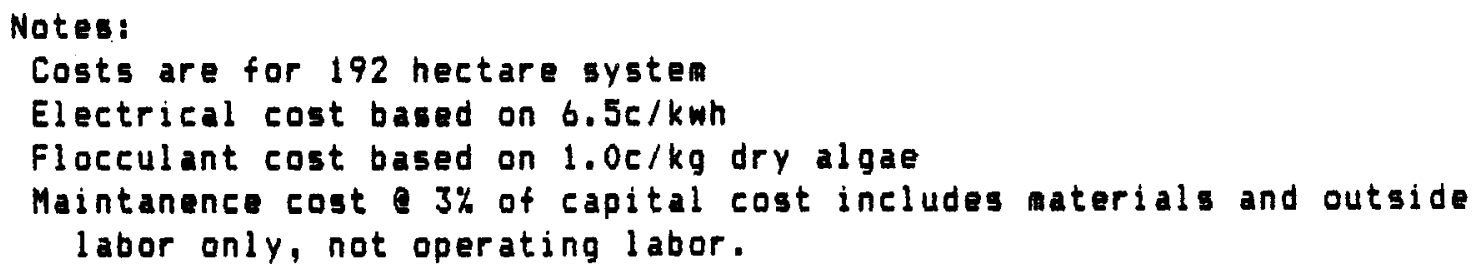


Section 9

\section{SYSTEM-WIDE COSTS}

System-wide costs include the water, carbon, nutrient, power, and blowdown systems, as well as roads and buildings. In the case of carbon and power, the emphasis is on the distribution rather than on the source, since SERI has has examined the resource issues in far greater. depth than would be possible in this report. An exception is the issue of nutrient recycle within the system, which is examined in Section 6. Table 9-1 lists the system wide costs, and also sumarizes the total cost for the 192 hectare system. Table 9-2 1ists the electrical and maintanence costs for the system. Both tables are based on the use of settling ponds for harvesting. Total operating costs are presented in Section 10.

\subsection{WATER SUPPLY AND DISTRIBUTION}

The capacity of the water supply systen is based on a maximum evaporative rate of $1.5 \mathrm{~cm} / \mathrm{day}$ and blowdown rate of $0.2 \mathrm{~cm} / \mathrm{day}$. Maximum, rather than the average rates nust be used because such rates are likely to persist for a period of months during the sumer. Additional water is required for initial filling of ponds, but this is assuned to take place during the non-sumer months, when excess capacity is avallable. The required volumes and flowrates were listed in Table 7-2. On a continuous basis, the combined flowrate is $22,700 \mathrm{lpm}(6000 \mathrm{gpm})$. Both the supply and distribution system will be sized on this basis, although puping costs are based on yearly averages of 15,200 lpa $(4000 \mathrm{gpm})$, which reflects both reduced evaparation and some contribution from rainfall. The authors believe that the SERI estimates for water consumption were too low, while estinates for the cost/unit delivered were high. This analysis assumes a separate nell field for each 192 hectare module, which differs from the approach taken in the SERI resource studies.

The well field is assumed to be off-site, to avoid 0\&M interference and possible subsidence problems. Eight $30 \mathrm{~cm}$ (12") wells, each rated at 2840 lpm (750 gpa), are set in a grid pattern with a spacing of 1600 meters 10.5 mile). The wells are assumed to be 122 meters $(400 \mathrm{ft})$ deep, with a static 1 ift of 46 meters $(150 \mathrm{ft})$. A water storage reservoir $\left(16,000 \mathrm{~m}^{3}\right)$ is included as part of the supply systea. If necessary, water conditioning facilities would be located at the reservoir (see section 2).

A cost estimate of the water supply system is presented in Table 9-3. The cost of wells is based on information supplied by well drillers in the Salton Sea area. The cost of the piping network is based on the assumption that inexpensive "100 ft head" PVC is used. While heavier, ore expensive pipe is always used in municipal water systeas, the $100 \mathrm{ft}$ head pipe is widely used in low pressure agricultural applications, especially when large dianeters are required. All large diameter pipes specified throughout this report are of this type. The unit costs in all cases includes installation, which runs 


\section{Table 9-1 192 Hectare System Capital Cost Sumary

$$
\text { Base Case: } \quad 112 \mathrm{mt} \text { algae/ha/yr }
$$

\begin{tabular}{|c|c|c|}
\hline GROWTH PONDS & TOTAL $\$$ & $\$$ / HECTARE \\
\hline Earthworks* & $\$ 1,945,960$ & $\$ 10.135$ \\
\hline Walls struetural & $1,594,290$ & 8.304 \\
\hline Mixing System & 944,537 & 4,919 \\
\hline Carbonation Systen & 351.360 & 1.830 \\
\hline Instrumentation not included elsewhere & 96,000 & 500 \\
\hline HARVESTING - Settling Pond Option & & \\
\hline Primary** & $1,436,000$ & 7.479 \\
\hline Secondary (centrifugation) & 760,000 & 3,958 \\
\hline SYSTEM-WIDE COSTS & & \\
\hline Water Supply & 660,000 & 3,438 \\
\hline Water Distribution & 189,000 & 984 \\
\hline CO2 Distribution & 50,000 & 260 \\
\hline Nutrient Supply Systen. & 150,000 & 781 \\
\hline Blowdown Disposal System* & 160,000 & 833 \\
\hline Euildings (harv. blds. not included) & 110,000 & 573 \\
\hline Roads \& drainage* & 100,000 & 521 \\
\hline Electrical Distribution (3\% of above) & 256,414 & 1,335 \\
\hline Electrical Supply & 113,000 & 58 \\
\hline Machinery & 80,000 & 417 \\
\hline ENGINEERING (10\% of above)* & 899,656 & 4.686 \\
\hline CONTINGENCY (15\% of above)* & $1,484,433$ & 7.731 \\
\hline LAND COSTS ( $\$ 1250 /$ hectare)* & 480,000 & 2,500 \\
\hline & $\ldots-\cdots$ & 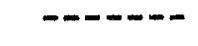 \\
\hline TOTAL CAPITAL COST. & $\$ 11,860,650$ & $\$ 61,774$ \\
\hline DEPRECIABLE PORTION & $\$ 6,415,601$ & $\$ 33,415$ \\
\hline NON DEPRECIABLE PORTION & $\$ 5,445,049$ & $\$ 28,360$ \\
\hline
\end{tabular}

Notes:

* non-depreciable item

** patrially non-depr. $(\$ 375,000)$

$112 \mathrm{mt} / \mathrm{ha} / \mathrm{yr}=30 \mathrm{~g} / \mathrm{m} 2 / \mathrm{day}$

Land area $=2 \times$ growth pond area 
Taole 9-2 Electrical \& Maintanence Operating Cost Sumary - 192 Hectare Svstem

GROWTH PONDS

Earthworks

Walls \& Structural

Mixing System

Carbonation System

HARVESTING - Settline Pond Option

Primary

Secondary (centrifugation)

SYSTEM-WIDE COSTS

Water Supply

Water Distribution

CO2 Distribution

Nutrient Supply System

Blowdown Disposal System

Buildings harv. blds. not

Roads \& drainage

Electrical Distribution

Electrical Supply

Machinery

TOTAL

IOTAL/HECTARE

* Assumes electricity costs

* Majntanence materials only

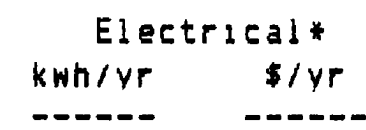

2060000

133,900

343000

22,295

71,240

1555000

101,075

121000

7,865

104000

6,760

200000

13,000

5479000

$\$ 356,135$

$\$ 1,855$

$z=m=m=2=$

$\$ 0.065 / \mathrm{kw}-\mathrm{hr}$

\begin{tabular}{rr}
\multicolumn{3}{c}{ Malntanence* } \\
$\%$ of Cap & $\$ / y r$ \\
\hline $1 \%$ & $\$ 19,460$ \\
$3 \%$ & 47.829 \\
$3 \%$ & 28.336 \\
$3 \%$ & 10.541 \\
$3 \%$ & 2.880
\end{tabular}

$3 \% \quad 43.080$

$5 \% \quad 38,000$

$3 \% \quad 19,800$

$3 \% \quad 5.670$

$3 \% \quad 1,500$

$3 \% \quad 4,500$

$3 \% \quad 4,800$

$3 \% \quad 3,300$

$1 \% \quad 1,000$

$1 \% \quad 2,564$

$1 \% \quad 1,130$

$10 \% \quad 8,000$

$\$ 242,389$

$\$ 1,262$

$=x=x=x=3$ 
about $\$ 10-26 /$ meter $(\$ 3-8 / f t)$, depending on size.

The water distribution system includes eveything beyond the storage reservoir and water conditioning systen. Three vertical propeller punps feed into a piping network that supplies akeup water to the growth ponds. The system schematic is shown in Figure 9-1, along with pipe sizes, flowrates, and pressure losses. The flows are for evaporative makeup only, the blowdown make-up is added when the pond is refilled after harvesting. In a systen using settling ponds, the central corridor is fairly wide, (about 110 meters), 30 it is ore practical two use two distribution ains which run down either side of the central corridor. A pump station is located at the storage reservoir. Pressure requirements are assumed to equal the dynamic imainly pipe friction) losses, since some static head is available at the reservoir. The water distribution system could conceivably operate by gravity flow, but this assumption was not made.

Table 9-3 Water Supply System Cost

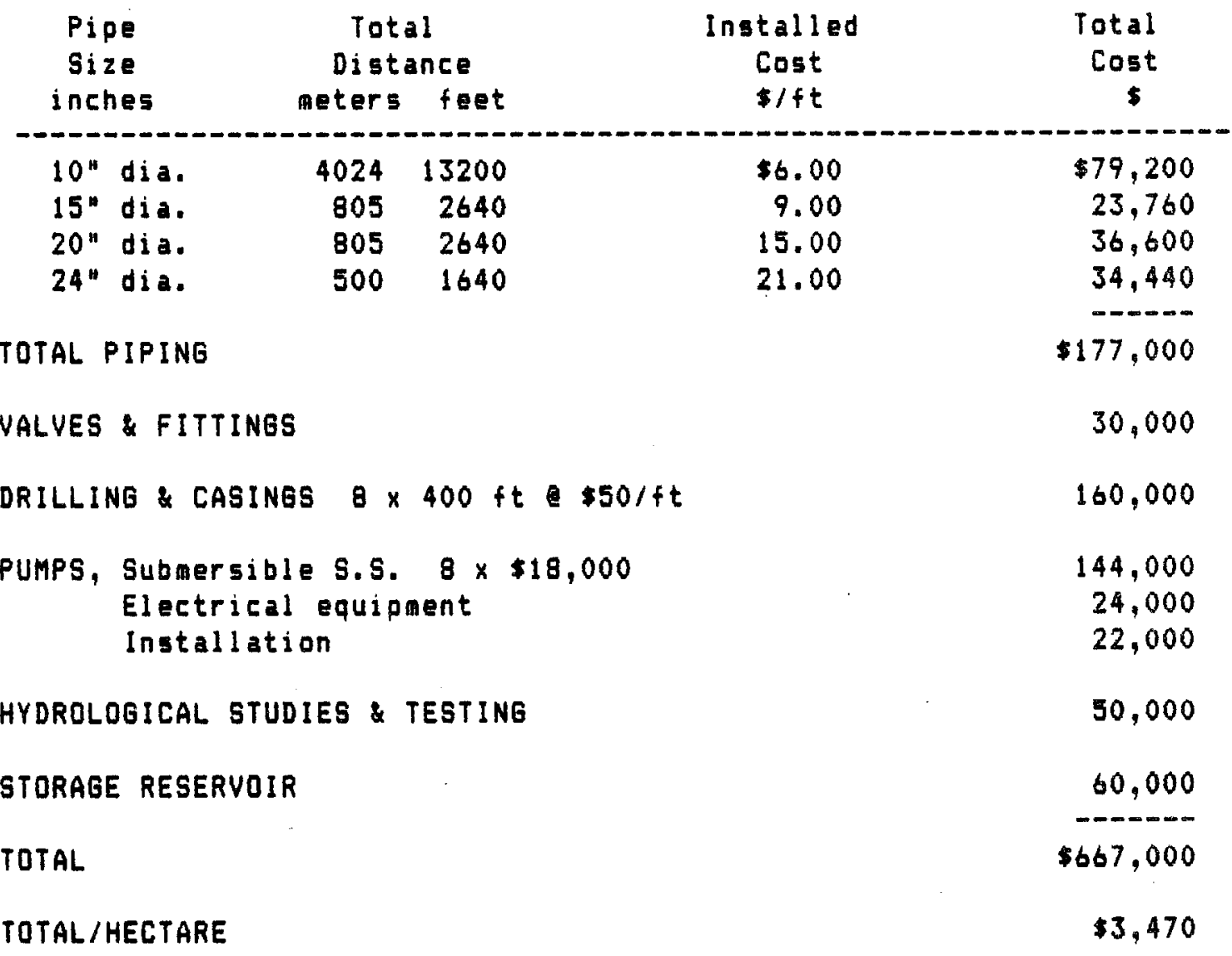




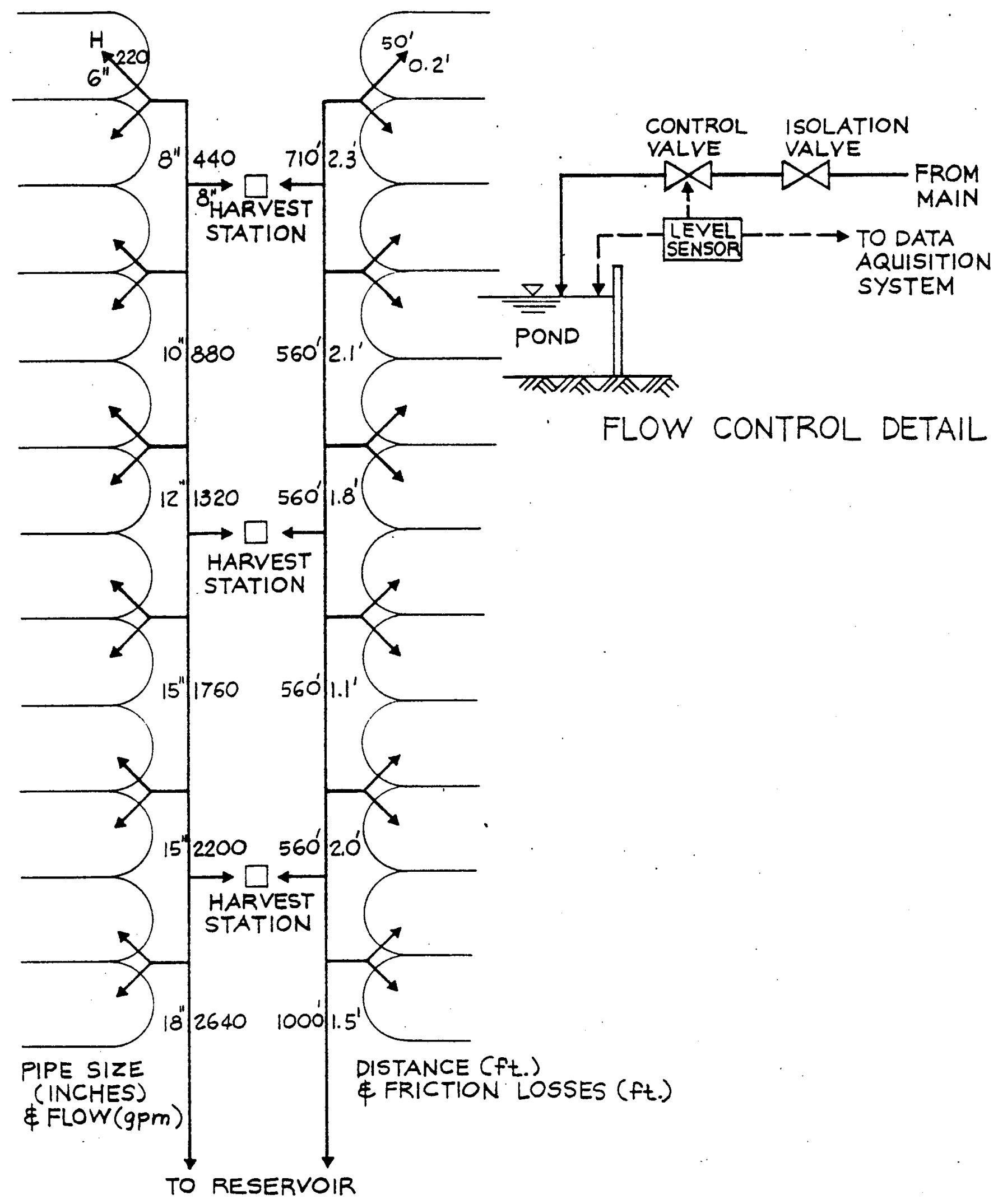

Figure 9-1 Water Distribution System 


\section{$9.2 \mathrm{CO}_{2}$ SUPPLY AND DISTRIBUTION}

The source of $\mathrm{CO}_{2}$ for microalgae production has been examined in some detail [9]. It was concluded that $\mathrm{CO}_{2}$ could be acquired fron existing or proposed power plants and the competition from enhance oil recover (EOR) would not pose a serious problem. The cost of $\mathrm{CO}_{2}$ derived in thig fashion depended on a number of assumptions regarding scale, location, ownership of the power plant, etc., and ranged from $\$ 0.07-\$ 0.21 / \mathrm{m}^{3}$. This report does not attempt to refine the SERI estimates. Instead, the $\mathrm{CO}_{2}$ cast is treated as a variable, and subjected to a sensitivity analysis in section 11.

The design of the distribution system depends upon the pressure at which $\mathrm{CO}_{2}$ is delivered to the site, assuming that about $2.5 \mathrm{p}$ i is required at the pond to satisfy the static head and sparger losses (1.5, 1 psi respectively). If this pressure is high ( $>50 \mathrm{psi}$, then the distribution network can consist of very sabll (6" and less) pipe sizes. For medius pressures (e.g. 10 psi), pipe sizes would range fron $8^{\prime \prime}$ to $3 "$. For very low pressures (3.5 psi, or a 1 psi drop through the distribution systen), sizes would range from 12" to 4". The latter might apply to a systen which recovered unpurified flue gas at atmospheric pressure. In such a case, a trade-off exists between compressing to aedium pressure (lawer capital cost, higher operating costs) versus low pressure (higher capital cost, lower operating cost). A high pressure distribution systen is not practical, since the conpressors required are very expensive compared to the high volume turboblowers that would be used for low or mediun pressures. The low va. nediu pressure trade-off was not evaluated, because the impact on overall costs is very small. The medium pressure case was used to size the $\mathrm{CO}_{2}$ distribution network. The cost of $\mathrm{CO}_{2}$ is assumed to include delivery at 10 psi, except in the nutrient recyele seenario, where compression costs for the anaerobic lagoon flue gas are included (see sections $b$ \& 11 ).

Since the supply costs are included in the delivered unit $\mathrm{CO}_{2}$ cost, and the flow metering and control systens were included under growth pond carbonation (Section 7.3.6), the costs shown in Table 9-1 consist solely of the piping network, which is itemized in Table 9-4. Except for the pipe sizes, the network is identical to that of the makeup water distribution system, and therefore is not shown.

\subsection{NUTRIENTS}

The types of nutrient required and their source is discussed in section 10. Liquid ammonia is used for nitrogen requirements. All other nutrients are purchased as salts. Since all of the nutrients are added at the beginning of the batch, with the possible exception of some additional ammonia during the first two days, the facilities can be located at the harvesting stations, with nutrients being added into the return flow network. If necessary, an amonia tank can be located at each set of ponds for supplemental nitrogen. In general, a batch growth cycle greatly siaplifies the process of nutrient 
additions.

Since the cost of adding nutrients (other than $\mathrm{CO}_{2}$ ) is minor, a detailed design was not performed. An estimate of $\$ 40,000$ per harvesting station plus $\$ 2500$ per set of ponds, for a total of $\$ 150,000$ was included in Table 9-1.

TABLE 9-4 $\mathrm{CO}_{2}$ DISTRIBUTION NETWORK CAPITAL COSTS

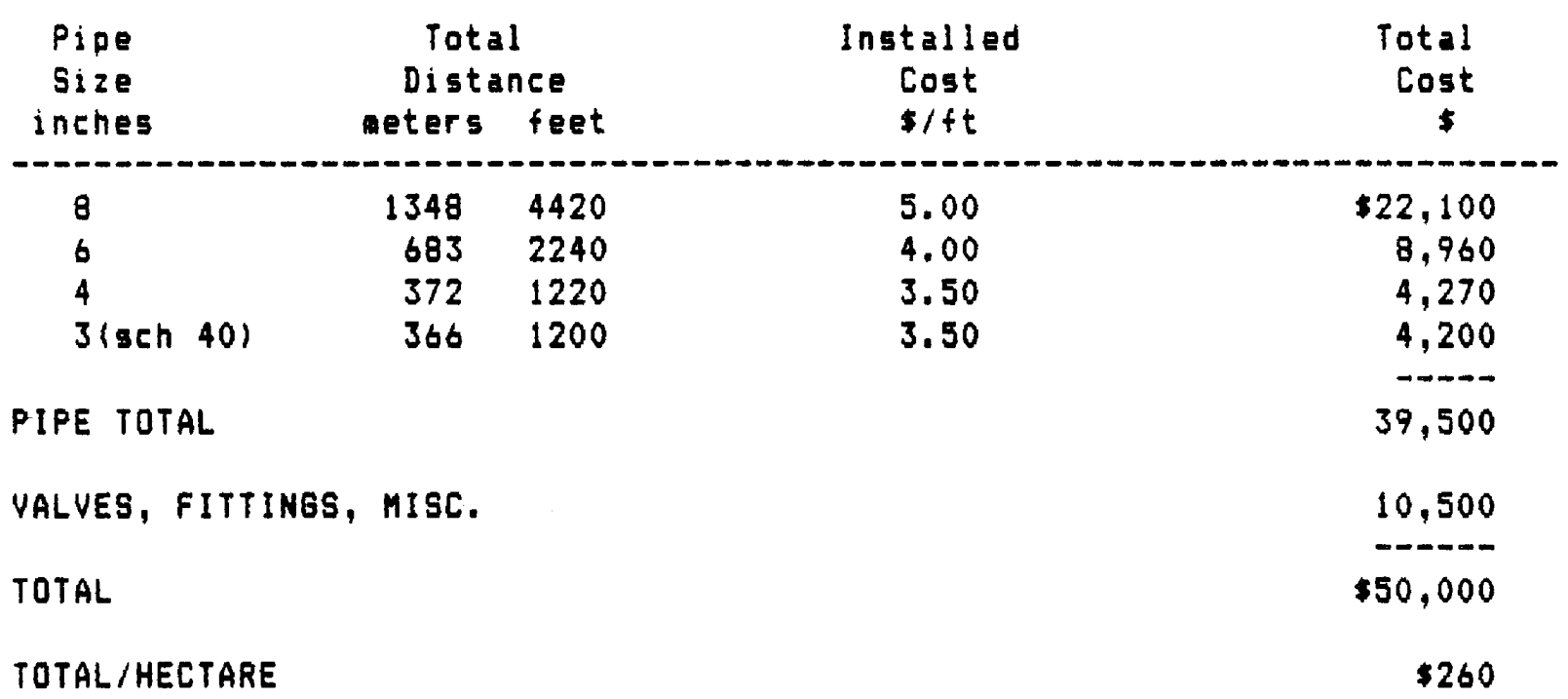

\subsection{BLOWDOWN DISPOSAL SYSTEM}

The issue of blowdown was discussed in Section 2. A blowdown rate equivalent to $14 \%$ of the evaporative rate is specified. For an average evaporation of 1 cof/day, the blowdown $f 10 w r a t e$ is $2700 \mathrm{~m}^{3} / \mathrm{day}(95,000 \mathrm{ft} / \mathrm{day})$. The blowdown is taken from the centrifuge effluent stream, and pumped to evaporation ponds, where it is concentrated back to solid form. Ultimate disposal is by trucking the salt to suitable landfill. The evaporation ponds cover 27 hectares (14\% of the growth pond area), and consist of shallow, unlined earthen ponds. These ponds cost about $\$ 110,000$ to construct, with another $\$ 50,000$ budgeted for puaps, piping and misc., for a total of $\$ 160,000$. A cost of $1 \mathrm{e} / \mathrm{kg}$ algae $10.67 \mathrm{c} / \mathrm{kg} \mathrm{salt)}$ is included in the operating cost for ultimate salt disposal.

\subsection{BUILDINGS}

Buildings include an office, lab, shop, and storage sheds for nutrients and machinery. The cost of buildings for harvesting machinery was included in the harvesting cost estimates. The offices, lab, and culture rooms can be large permanent trailers. The shop has a concrete floor and utilities. The sheds have concrete floors, are open on one side, and have a minioum of 
utilities. A rough estimate of the building costs is given in Table 9-5.

\section{Table 9-5 Building Costs}

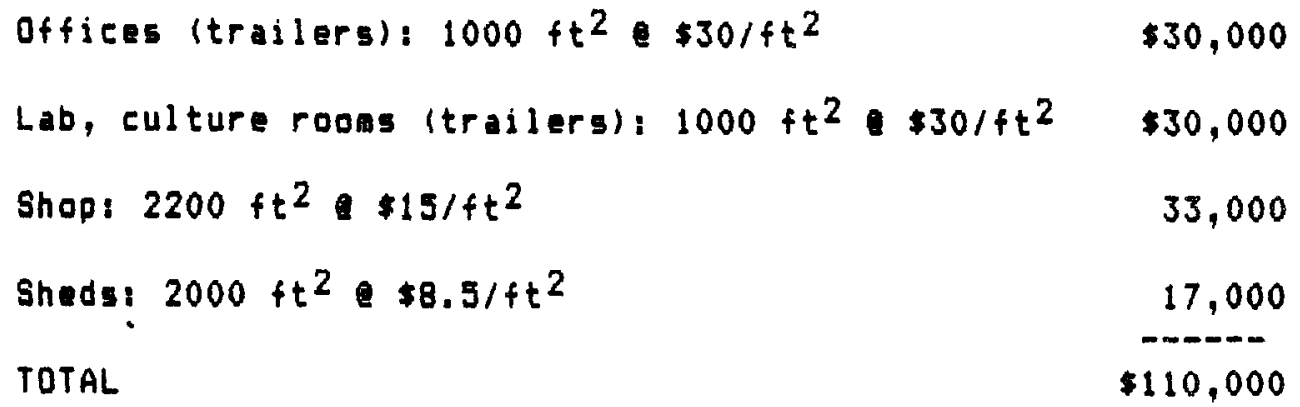

\subsection{ROADS AND DRAINAGE}

Roads and drainage are difficult to estimate in the absence of a specific site. If the perimeter walls of the pond system are earth berms, then the cost of upgrading the to roads (unpaved) is minor, since large acounts of crushed rock is already being imported for pond lining. Drainage would involve construction of diversion channels (if necessary), placing of culverts, etc, and would be integrated into grow pond earthworks. A figure of $\$ 100,000$ is assigned to roads and drainage.

\subsection{ELECTRICAL SUPPLY AND DISTRIBUTION}

Electrical distribution includes the cost of all on-site power distribution and wiring, exclusive of the utility service, substation, and motor starters and controljers (the latter were included in the individual cost estimates). Power distribution systems are normally estimated in terms of total facility cost, taking both complexity and scale into account. Given the size and relative simplicity of the system, a factor of $3 \%$ is used. Considering that so much of the facilities cost is for earthworks and pond walls, which have no electrical power requirements, this estimate is quite reasonable.

In order to arrive at a figure for electrical supply, it was arbitrarily assumed that 5 miles of transmission lines would be required. A recent estimate for from the Imperial Irrigation District of $\$ 3 / f t$ (essentially independent of load) was used for transaission line costs $(\$ 80,000)$. An additional $\$ 43,000$ (again IID estimate) was allocated for the substation cost (1000 kVA), for a total of $\$ 113,000$ for electrical supply. 


\subsection{MACHINERY}

A budget of $\$ 80,000$ is included for vehicles and machinery. Typical requirenents would be two pick-up trucks, one flatbed truck, a bachhoe-loader, and misc. shop machinery.

\subsection{OTHER COSTS SHOWN IN TABLE 9-1}

The remaining costs shown in Table 9-1 (engineering, contingency, 1 and), are taken fron the SERI economic model. The land cost is based on a total land requirement of two times the growth pond area. Actual land requirements are quite sensitive to the well spacing, which is difficult to estimate. However, the contribution of land cost to total cost is minor, 50 that an error will have very little effect, especially on an annualized basis. 
SECTION 10.0

LARGE SCALE SYSTEM OPERATIONS AND OPERATING COSTS

\subsection{OPERATIONS OVERVIEH}

The operations described below form the Base Case that serves as the reference for cost sensitity analyses in section 11.0. Deviations from this case are so labeled.

The basjc operation of the conceptual large scale systen consists of batch growth followed by batch accumulation of 1 ipids (to $50 \%$ of the ash free dry weight) induced by nitrogen limitation. Both processes are invisioned to take place in the same pond. Recent results of Laws [3] indicate that high productivity of nitrogen sufficient biomass is attainable in batch culture. The biomass productivity after nitrogen depletion from the medium, in bateh operation, has been shown [1,10] to be nearly equal to that of nitrogen sufficient batch growth when carbohydrate is accumulated. For lipid accumulation, a higher heating value must be ascribed to the biomass so that, on a dry weight basis some decrease in biomass productivity must be expected. There is little or no evidence that algae have a high enough lipid content during active growth. Since nitrogen sufficient batch growth appears to be productive, and lipid accumulation must be done in batch, there is no real reason to operate any of the system continuously. Cells would accumulate storage products under nitrogen depleted continuous dilution, but much of the biomass harvested would not be induced, or only paptially so.

The average productivity of the system is postulated to be $30 \mathrm{gm} / \mathrm{m}^{2} / \mathrm{day}$ averaged over a 360 day year. This is equal to a photosynthetic efficiency of $7.5 \%$ of visible light. Productivity is expected to be lower during the late fall, winter, and early spring and higher at other times. The density of cultures reflects this, being lower during cooler, less sunny times of the year. Since productivity is not a linear function of temperature and insolation, bateh density would be lower when productivity is lower, even though detention times are longer. At times of high productivity, nitrogen sufficient batch growth would last from 1.5 to 2 days followed by $2-3$ day induction period. At tines of low to moderate productivity, these perjods would be, on average, 2-3 days and 3-4 days. The density achieved when nitrogen first becones depleted from the mediuc are, for the two cases respectively, 400-500 ppa and 250-300 ppm. This would increase under induction conditions by a factor of about two to 800-1000 ppa and 500-600 ppm 
for the two average cases. Thus, at the time of harvest the density of the cultures would range between 500 and $1000 \mathrm{ppm}$ with a lipid content of about $50 \%$ and a nitrogen content of about $4 \%$, with 20-25\% protein 15-20\% carbohydrate and a balance of $10 \%$ other chemicals.

The induced biomass is to be harvested either by a two-stage settling process or by flotation followed by foa collection. Either process would be followed by centrifuging material concentrated by a factor of 50 . The primary harvesting processes are not expected to be $100 \%$ efficient. This is not a problen since an inoculum nust be left for start of the succeeding batch. A harvesting efficiency of $90 \%$ is postulated for the Base Case. The centrifugation of the 2-5\% slurry increases the density to 10-20\% ash free solids.

Since substantial performance is being expected of the primary harvesting process, it may become necessary to use chemical flocculants to aid clarification rate and efficiency. The dose of chenical is postulated to be low (<\$.02/kg biomass). In the Base Case, the cost of polymer addition is set at $\$ .01 / \mathrm{kg}$ harvested biomass.

The organism required to function in this system must possess several important characteristics. It must be competitive, productive, induce lipid prolifically, not be subject to inhibition by light, oxygen or fluctuations in temperature, and it must be able to recover from depignentation quickly and become highly productive soon after nitrogen is replenished in the medium. Each of these characteristics has been observed in at least some organism, but not all in any one organism. However, a concerted effort to find such an organisa has just recently begun at SERI. Probably the nost severe criterion of those listed is the ability to store large amounts of lipid quickly. A recently isolated chrysophyte, called Chryso/El, is tentatively chosen as a test organism. It accululates lipids prolifically (personal communication, B. Barclay of SERI), has a broad salinity tolerance, but must be tested for its tolerance to high temperature. The Platymonas.se.grown in Hawaii, although not a lipid producer, will be used as a productivity standard, since it is, as of now, the most productive organisin grown in intensive, outdoor culture. 
Carbon is to be supplied as purified $\mathrm{CO}_{2}$, introduced into the ponds via sumps $1.5 \mathrm{~m}$ deep. The source of carbon, at a 400 hectare scale must either be commercial or, in the best of circumstances a $\mathrm{CO}_{2}$ well near the site. Power plant carbon containing gases are not a feasible source at this relatively small scale. The algal biomass, after extraction of the lipid component, will be anaerobically decomposed in a covered lagoon from which the liberated gases are recovered. The methane energy is to be converted to heat and electricty with the $\mathrm{CO}_{2}$ remaining recycled for the growth of nore algal bioass. 34\% of the carbon needed for new growth can be provided in this manner, reducing the denand of new carbon to algae ratio fron $1: 1.7$ to 1:2.4. The recycle of nutrients from the anaerobic digester is not included in the Base Case.

The water resource specified for use in this systen is similar to the Type II water described by SERl. This water has a TDS of 4 ppt, an alkalinty of 13-15 meq/l and a Ca concentration of 10 aM. The water needs to be conditioned by equilibration, in holding ponds, with the atmosphere to induce precipitation of the calcium as calciun carbonate. The precipitate will be removed by alum or lime floceulation, if necessary, and sedimentation. The resulting water is low in calcium 11 m is the practical lower liait) and still contains about 4 meq/l alkalinity. An eight-fold average concentration of solutes is achieved when an average amount of water is blowndown which equals $1 / 7$ of the average evaporation. Since the system is to be operated in batch, the salinity will fluctuate somewhat, but this is a secondary effect. Thus the pond mediun will avarage 32 ppt TDS.

The approximately 1.5 nt of salts produced per at of algal bionass will be transported to a large body of salt water, or other disposal site, at a cost of .67 cents per $\mathrm{kg}$. The sludge from the lagoon will be dried in sludge drying beds and plowed in on site. 
10.2 OPERATIONAL COSTS OF A 1000 ACRE SYSTEM

The parameters of the Base case desion of the larae scale system are summarized in Table 10-1. This design is used in section 11.0 as the reterence case for cost sensitivity analysis.

\section{Table 10-1. Base Case Design Parameters}

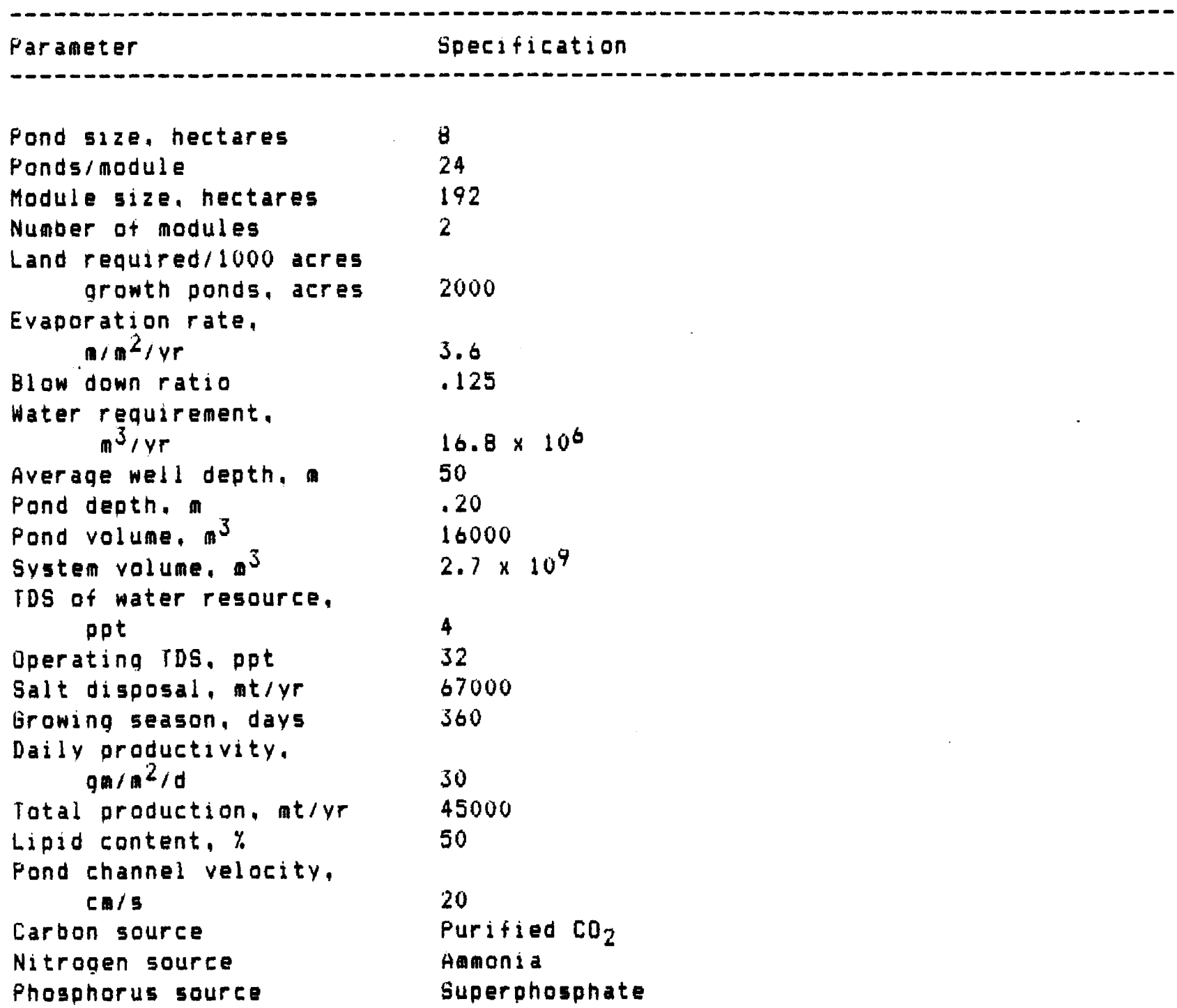


The operating costs of the Base Case desian are summarized in Table 10-2. All costs are given on a per hectare per year basis, a per module (192 ha) per year basis, and on a total cost per 1000 acre per year. For the chemical inputs, the unit requirement and the unit cost are given as well. Power unit cost is taken at 6.5 cents per kilwatt hour. Disposal of salts contained in the blowdown (evaporated and transported to a disposal site) is taken as .b7 cents per kg salt produced. The breakdown of the maintanance and labor costs are given in Table 9-2 and 10-3 respectively.

The carbon source is purified $\mathrm{CO}_{2}$, at a low cost of $\$ 35 /$ at. This value is varied in the sensitivity analysis presented later. $2.2 \mathrm{~kg} \mathrm{CO}_{2}$ is required to produce a kg of alaal biomass at $50 \%$ lipid. Losses are assumed to be less than $5 \%$. Nitrogen, at $\$ 250 /$ mt is derived from ammonia, and used with a $75 \%$ efficiency to cover losses. The phosphorus, at $\$ 900 / \mathrm{mt}$ is derived from superphosphate. Iron is added as ferrous sulfate and costs $\$ 500 /$ int Fe. All other nutrients are assumed to be present in the water resource, or as a trace contaminant of the above nutrients. Even with the low price of $\mathrm{CO}_{2}$ assumed, this one input alone dominates the production price of the aloal biomass.

A high molecular weight polymer is included to flocculate the alqal biomass prior to primary concentration in a settling pond. It is assumed that 1 ppm of polymer is required for each 500 ppm biomass. The cost of the polymer is $\$ 5.00 / \mathrm{kg}$.

The only operating cost associated with the water resource is the cost of pumping from a 50 deep well and transport to the holding ponds. Water conditioning is presumed to occur during the eight day holding time, and is due to the precipitation of calciun carbonate by the alkalinity in the water upon equilibration with the atmosphere. Power costs are included for mixing, harvesting (dominated by centrituge power), nutrient supply pumping, and buliding utilities.

The maintenance operating costs are for materials only, as detalled in Table 9-2 of 5ection 9.0. The labor for maintenance is included in the personnel breakdown listed in Table 10-3 Estimates are based on five shifts per week, 360 days per operation, and rough judoenent of people needed on hand.

For this base case, the total, non-annualized operating costs are $\$ 0.2$ million for the 45.450 at of algal biomass produced. At $50 \%$ lipid and a conversion of 7.14 bbl lipid per at lipid, the "lipid oil" produced equals 160,000 bbl/yr. The capital cost summary was given in Section 9.0. Together with the operating cost sumary Table 10-2, the total annualized production cost will be calculated in the next section using the SERI economic nodel. 


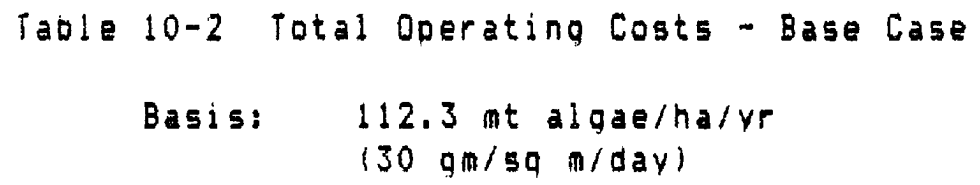

NUTRIENTS ( 1$)$

$\mathrm{CO} 2$

$\mathrm{N}$, as NHJ

P. as Superphosphate

Fe. as FesO4

QUAN UNIT

REQ'D COST

-.- YEARLY COST, Thousands -..-

$192 \mathrm{ha} \quad 1000$ ac

$\mathrm{kg} / \mathrm{kg} \quad \$ / \mathrm{mt}$

$\$$ halyr

$\$ /$ yr

$\$ /$ yr

$-\cdots$

35

0.053

250

0.005

900

0.005

500

Total

$\$ 8.65$

1.47

0.51

$\$ 1.660$

-...-.

0.28

283

$\$ 3,501$

597

97

205

$-----$

54

114

$\$ 10.91$

$\$ 2,094$

$\$ 4,416$

FLOCCULANT

$0.002 \quad 5000$

$\$ 1.12$

$\$ 216$

$\$ 455$

POWER

Mixing

1 Harvesting

2 Harvesting

Water Supply

Nutrient Supply

Builatings

Total

SALT DISPOSAL

MAINTANENCE (matl's)

LABOR

TOTAL

$$
106 \mathrm{kwh} / v r^{*} \mathrm{e} / \mathrm{kwh}
$$

- $2.06 \quad---5$

$0.34 \quad 6.5$

$1.10 \quad 6.5$

1.68

0.10

0.20

6.5

6.5

6.5

5.48
0.70

0.12

0.37

0.57

0.04

0.07

$-\ldots . .-$

$\$ 1.85$

c/kg

0.67

(2)

(3)

(3)
1.13

1.26

1.39

$\$ 16.54$

$\mathrm{m}=\mathrm{m}=\mathrm{m}$

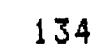

22

71

109

7

13

-...-

$\$ 356.14$

$\$ 750.93$
282

47

150

230

14

27

-.-.-

(1) $\mathrm{kg} / \mathrm{kg}$ - $\mathrm{kg}$ required / $\mathrm{kg}$ algae produced

(2) See Table 9-2

(3) See Table 10-3

* 192 ha basis 
rable 10-3. Labor Required for 1000 Acre Systen

$\begin{array}{llccc}\text { Plant Manager } & 1 & 2080 & 25 & 52000 \\ \text { Shift Supervisors } & 4 & 2080 & 17 & 141.440 \\ \text { Pond Operators } & 10 & 2080 & 10 & 166,400 \\ \text { Centrifuge Operators } & 5 & 2080 & 12 & 124.800 \\ \text { Laboratorv Manager } & 1 & 2080 & 17 & 35.360 \\ \text { Laboratory Technicians } & 2 & 2080 & 10 & 41.600 \\ & & & \text { TOTAL } & 561.600\end{array}$


SECTION 11.0

ECONOMIC ANALYSIS OF A 1000 ACRE ALGAL PRODUCTION SYSTEM

\subsection{BASE CASE}

The capital cost of the Base Case design was presented in Table 9-1, the operating costs in Table 10-2. Appendix VI contains these tables again as well as the capital and operating costs for all of the sensitivity analyses. In the Base Case the biomass productivity is $45.5 \times 10^{3}$ mtiyr at a lipid content of 50\%. This is well in excess of any currently achievable lipid oroductivity. The biomass production value has been achieved, on a year round basis [3], but under conditions of nutrient sufficiency and at 15-20\% 1ipid content. The orice of $\mathrm{CO}_{2}$ used in the Base case is $\$ 35 / m$ t which is about as much as a very large scale user would be charged for comercial $\mathrm{CO}_{2}$ if transportation distance were less than 200 miles. The installed system cost $15 \$ 76,600$ per hectare using a low cost system design and favorable assumptions concerning the suitability of land and other resources needed for systen construction. The total capital cost of construction is 525 million dollars. Thus the Base Case must be considered very optimistic in terms of lipio productivity, nutrient costs, and attainfent of capital cost goals. In this section. the sensitivity of the production cost of alaal bionass and lipid oil (unextracted), to these assumptions will be analyzed to determine where the future work must be concentrated.

rable 11-1 shows the input and output data of the Base Case using the SERI economic model. The parameters of this model are given in Taule 11-2. A quick qlance at the economic fiqures reveals that even at $\$ 35 / \mathrm{nt}, \mathrm{CO}_{2} \mathrm{Cost5}$ dominate the Base case economics. Half of the annualized production costs come trom this. Unless the price, or quantity of $\mathrm{Ca}_{2}$ is reduced, the economics of producing low value products from alade cannot improve significantly. In addition. increases in productivity have relatively little effect on final costs when $\mathrm{CO}_{2}$ is 50 dominant a factor. Thus only some initial sensitivity is presented with the Base Case as the reference level. The cost of the carbon input is significantly reduced by the addition of an anaerobic lagoon, in which extraction residues containing about half of the algal caroon, are degraded to volatile carbon gases which are recycled to the growth ponds. The design of an efficient, low cost recvcling system, is an important feature of the large scale design and experimental system tests.

\subsection{SENSITIVITY OF BASE CASE TO PRODUCTIVITY CHANGES}

Table 11-3 shows the effect of varying the system biomass productivity on the annualized production costs. Capital costs of some itens, like centrifuges, were increased using a scale factor of .7 . However, no increases in capital costs were assumed necessary to achieve the two and three fold increases in productivity analyzed. The major increases come in operating costs, particularly in proportional increases in the $\mathrm{CO}_{2}$ required. Doubling the 
Table 11-1 Base Case Economic Analysis

INPUTS

BASE CASE

Depreciable capital investment

$\$ 13,940,000$

Non-Deprec capital investment

$11,060,000$

Annual operating costs

Annual maintenance costs

Systen algal yield nt/yr

System Lipid yield bbls/yr

Carbohydrate yield mityr

Protein yield int/yr

$6,180,000$

510,000

45450

150000

9100

9100

CALCULATED VALUES

Cost of capital

0.0475

Cap Recov Factor (book life)

0.0692

Cap Recov Factor (depr life)

0.0947

Fixed Charge Rate

0.0951

PV of Capital Investment

$\$ 17,349,560$

PV of Nondeprec Investment

$13,765,150$

PV of Operating costs

$123,965,000$

PV of Maintenance costs

$10,930,980$

TOTAL PV OF FACILITY

$\$ 166,010,700$

Annualized Cost Algae Plant

LIPID only price \$/bb]

$\$ 11,934,510$

79.56

262.59

Lipid price by weight \$/ it

304.68

Lipid price by value $\$ / \mathrm{mt}$

284.56

304.68

Protein price by weight \$/mt

Protein price by value $\$ / m t$

327.87

304.68

Carbohyd price by weight $\$ / m$ t

327.87

Carbohyd orice by value \$/at

Annualized Capital Cost DCI

Annualized Capital Cost NCDI

Annualized Operating cost OPP

Annualized Mainten. Cost MNT

Annualized Cost Total AAP

$\$ 1,650,002$

952,285

$8,576,007$

756,215

$11,934,508$

Annualized Capital Cost DCI

Annualized Capital Cost NCDI

Annualized Operating cost OPP

Annualized Mainten. Cost MNT

Annualized Cost Total AAP

$13.8 \%$

$8.0 \%$

$71.9 \%$

$6.3 \%$

$100.0 \%$ 
Table 11-2 Econonic Model Input Parameters

FINANCIAL PARAMETERS

$\begin{array}{lr}\text { Base year for constant dollars } & 1984 \\ \text { Year for investaent outlay } & 1992 \\ \text { Year for cost information } & 1985 \\ \text { Year first commercial oper } & 1996 \\ \text { System oper life (book life) } & 25 \\ \text { Tax life for depreciation } & 15 \\ \text { Annual other taxes fn of CI } & 0.01 \\ \text { Annual ins preniun fn of CI } & 0.01 \\ \text { Effective income tax rate } & 0.46 \\ \text { Investment tax eredit } & 0.09 \\ \text { Debtitotal capitalization } & 0.3 \\ \text { Connon Stkitot capitalization } & 0.5 \\ \text { Prefer Stkitot capitalization } & 0.2 \\ \text { Ann rate return on debt } & 0.037 \\ \text { Ann rate return comon stk } & 0.065 \\ \text { Ann rate return prefer stk } & 0.045 \\ \text { Rate of general inflation } & 0 \\ \text { Escalation capital costs } & 0.01 \\ \text { Escalation operating costs } & 0.015 \\ \text { Escalation maintenance costs } & 0.018 \\ \text { Cost capital loptional) } & 0 \\ \text { Cap Recovery factor (optional) } & 0 \\ \text { Fixed Charge Rate (optional) } & 0 \\ \text { Lipid credit } \$ \text { mt } & 200 \\ \text { Protein credit } \$ \text { /mt } & 100 \\ \text { Carbohydrate credit } \$ / \text { at } & 100\end{array}$


productivity only decreases unit production costs by $20 \%$. Tripling productivity only leads to a further decrease of less than $5 \%$. or $23 \%$ reduction from the Base case. Thus productivity enhancenent will only be meaningful if the amount or cost of $\mathrm{CO}_{2}$ is decreased. The cost was already assumed to be quite low. The recycling of carbon will be seen to dramatically affect the sensitivity of production costs to productivity increases.

Table 11-3. Base Case: Sensitivity to Productivity

\begin{tabular}{|c|c|c|c|}
\hline $\cos t$ & BASE & 2XPROD. & $3 \times$ XROD. \\
\hline $\begin{array}{l}\text { LIPID onlv price.\$.bbl } \\
\text { ALGAE price } \$ / m t\end{array}$ & $\begin{array}{r}79.56 \\
262.59\end{array}$ & $\begin{array}{r}63.79 \\
210.30\end{array}$ & $\begin{array}{r}81.52 \\
202.83\end{array}$ \\
\hline $\begin{array}{l}\text { Lipid price by weight } \$ / \text { at } \\
\text { Lipid price by value } \$ / \text { mt } \\
\text { Protein price by weight } \$ / \text { mt } \\
\text { Protein price by value } \$ / \text { mt } \\
\text { CHO price by weight } \$ / \text { mt } \\
\text { CHO price by value } \$ / \text { mt }\end{array}$ & $\begin{array}{l}304.68 \\
284.56 \\
304.68 \\
327.87 \\
304.68 \\
327.87\end{array}$ & $\begin{array}{l}244.28 \\
228.15 \\
244.28 \\
262.88 \\
244.28 \\
262.88\end{array}$ & $\begin{array}{l}235.60 \\
220.04 \\
235.60 \\
253.53 \\
235.60 \\
253.53\end{array}$ \\
\hline $\begin{array}{l}\text { DCI, \% total } \\
\text { NDCI, \% total } \\
\text { OPP, \% total } \\
\text { MNT, \%total } \\
\text { AAP, \% }\end{array}$ & $\begin{array}{r}13.8 \\
8.0 \\
71.9 \\
6.3 \\
100.0\end{array}$ & $\begin{array}{r}10.3 \\
5.4 \\
79.4 \\
4.9 \\
100.0\end{array}$ & $\begin{array}{r}7.8 \\
3.9 \\
82.9 \\
5.4 \\
100.0\end{array}$ \\
\hline
\end{tabular}

\subsection{SENSITIVITY OF THE BASE CASE TO CARBON RECYCLE}

The low cost anaerobic digester is a major proposed innovation in that recovery of the input nutrients for return to the algal growth ponds has not been atterpted on large scale. The efficiency of the recovery and reuse of nutrients from biomass degraded in a low cost, covered lagoon is a factor that nust be empirically determined in the proposed experimental system. The lagoon not only allows recycle of carbon $(33 \%)$ but also up to $75 \%$ of the nitrogen and $50 \%$ of the phosphorus. In addition, the methane produced is combusted to produce electrical power, at about 25-30\% efficiency. This electricity can be used on site, for mixing power, etc. In some of the cases analyzed, the electrical output of the digestion system exceeds the needs of the system. In these cases, the surplus value of the power produced, calculated at 6.5 cents/Kw.hr, is added as a negative number to operating costs.

The recycle of carbon reduces the denand of new input carbon, per kg algal biomass, from $2.2 \mathrm{~kg}$ to $1.6 \mathrm{~kg}$. Table 11-4 shows the effect of the gavings in $\mathrm{CO}_{2}$ quantities on the annualized production costs of bionass and 1 ipid. The capital costs of the Base case were oodified to include the costs of the covered lagoon and engine generator. Maintanance costs increased. but operating costs decreased due to the lower quantity of $\mathrm{CO}_{2}$ used and the power generated. Since all of the unextracted biomass goes into the lagoon 
Table 11-4 Economic Analysis: Base Case + Recycle

\begin{tabular}{|c|c|c|}
\hline INPUTS & BASE CASE & RECYCLE \\
\hline $\begin{array}{l}\text { Depreciable capital investment } \\
\text { Non-Deprec capital investment } \\
\text { Annual operating costs } \\
\text { Annual maintenance costs } \\
\text { System algal yield mt/yr } \\
\text { System Lipid yield bbls/yr } \\
\text { Carbohydrate yield mt/yr } \\
\text { Protein yield mt/yr }\end{array}$ & $\begin{array}{r}\$ 13,940,000 \\
11,060,000 \\
6,180,000 \\
510,000 \\
45450 \\
150000 \\
9100 \\
9100\end{array}$ & $\begin{array}{r}\$ 17,620,000 \\
11,430,000 \\
3,640,000 \\
800,000 \\
45450 \\
150000\end{array}$ \\
\hline ALCULATED VALUES & & \\
\hline $\begin{array}{l}\text { Cost of capital } \\
\text { Cap Recov Factor (book life) } \\
\text { Cap Recoy Factor (depr life) } \\
\text { Fixed Charge Rate }\end{array}$ & $\begin{array}{l}0.0475 \\
0.0692 \\
0.0947 \\
0.0951\end{array}$ & $\begin{array}{l}0.0475 \\
0.0692 \\
0.0947 \\
0.0951\end{array}$ \\
\hline $\begin{array}{l}\text { PV of Capjtal Investment } \\
\text { PV of NonDeprec Investment } \\
\text { PV of Operating costs } \\
\text { PV of Maintenance costs }\end{array}$ & $\begin{array}{r}\$ 17,349,560 \\
13,765,150 \\
123,965,000 \\
10,930,980\end{array}$ & $\begin{array}{r}\$ 21,929,650 \\
14,225,640 \\
73,014,990 \\
17,146,630\end{array}$ \\
\hline TOTAL PV OF FACILITY & $\$ 166,010,700$ & $\$ 126,316,900$ \\
\hline $\begin{array}{l}\text { Annualized Cost Algae Plant } \\
\text { LIPID only price } \$ / b b \text { l } \\
\text { ALGAE price } \$ / m t\end{array}$ & $\begin{array}{r}\$ 11,934,510 \\
79.56 \\
262.59\end{array}$ & $\begin{array}{r}\$ 9,307,186 \\
62.05 \\
204.78\end{array}$ \\
\hline $\begin{array}{l}\text { Lipid price by weight } \$ / m t \\
\text { Lipid price by value } \$ / m t \\
\text { Protein price by weight } \$ / m t \\
\text { Protein price by value } \$ / m t \\
\text { Carbohyd price by weight } \$ / m t \\
\text { Carbohyd price by value } \$ / m t\end{array}$ & $\begin{array}{l}304.68 \\
284.56 \\
304.68 \\
327.87 \\
304.68 \\
327.87\end{array}$ & $\begin{array}{l}443.82 \\
221.91 \\
443.82 \\
443.82\end{array}$ \\
\hline $\begin{array}{ll}\text { Annualized Capital Cost } & \text { OCI } \\
\text { Annualized Capital Cost } & \text { NCDI } \\
\text { Annualized Operating cost OPP } \\
\text { Annualized Mainten. Cost } \\
\text { Annualized Cost Total }\end{array}$ & $\begin{array}{r}\$ 1,650,002 \\
952,285 \\
9,576,007 \\
756,215 \\
11,934,508\end{array}$ & $\begin{array}{r}\$ 2,085,584 \\
984,142 \\
5,051,241 \\
1,186,219 \\
9,307,186\end{array}$ \\
\hline $\begin{array}{ll}\text { Annualized Capital Cost } & \text { DCI } \\
\text { Annualized Capital Cost } & \text { NCDI } \\
\text { Annualized Operating cost OPP } \\
\text { Annualized Mainten. Cost } \\
\text { Annualized Cost Total }\end{array}$ & $\begin{array}{r}13.8 \% \\
8.0 \% \\
71.9 \% \\
6.3 \% \\
100.0 \%\end{array}$ & $\begin{array}{l}22.4 \% \\
10.6 \% \\
54.3 \% \\
12.7 \% \\
100.0 \%\end{array}$ \\
\hline
\end{tabular}


for digestion. there are no carbohydrate or protein by products. Although not included in the model, the lagoon sludae is a potential fertillzer product. The production cost of bionass orops $22 \%$ compared to the base case. from $\$ 263 / \mathrm{mt}$ to $\$ 205 / \mathrm{mt}$. The lipid only price drops from $\$ 79.6 / b b 1$ to $\$ 62 / b b 1$. This is as much a decrease, relative to the Base Case, as tripling the productivity provided. More imoortantly. it will be shown below that now productivity increases have much more impact on final cost than they did without carbon recycle. This is due to the decrease, in terms of per cent of total annualized cost, of operating relative to capital outlays. In the Base Case operating costs contributed over $70 \%$ of the total, capital only $22 \%$. With nutrient recycle and power generation, operating drops to $54 \%$ of the total and capital rises to one third.

\subsection{RECYCLE CASE: PRODUCTIVITY SENSITIVITY}

The results of variations in assumed biomass productivity, with $50 \%$ lipid, on the annualized production costs, are presented in Table $11-5$. The $1.0 x$ productivitv case reters to the nutrient recycle case discussed above. Doubling productivity now reduces production cost $30 \%$, whereas without recycle the reduction was $20 \%$. Biomass production cost in \$144/mt, lipid price 15 $\$ 44 /$ bbl. If productivity is only increased by $50 \%, 20 \%$ sayings is still achieved in production costs. When processing of the biomass is included, i.e., extraction and conversion to useable fuel, the impact of productivity increases is likely to be reduced. The production costs are sensitive to reductions in productivity, with a $30 \%$ reduction leading to almost a $30 \%$ zncrease in cost. Thus, a productivity of $30 \mathrm{gm} / \mathrm{m}^{2} / \mathrm{day}$ on average with a $50 \%$ lipid content, appears to be a high but economically reasonable goal. Decreases in productivity have substantial impact, but increases above 1.5 fold begin to have diminishing returns as well as being unrealistic. This is shown in Fiqure 11-1 as a decrease in the slope of the graph of lipid price versus productivity.

\subsection{RECYCLE CASE: SENSITIVITY TO CO2 PRICE}

Although the price of $\mathrm{CO}_{2}$ used in all of the preceding analvses is not inconsistent with commercial $\mathrm{CO}_{2}$ cost under favorable circumstances, the quantities needed for very large scale systems, and the remote siting of these systems, may preclude the use of commercial $\mathrm{CO}_{2}$. In this case, the $\$ 35 /$ ht price is a low one, as purification of $\mathrm{CO}_{2}$ from power plant atack qases is more expensive than from refinery off gases. To demonstrate the exensitivity of the design to variation of the assumed price of $\mathrm{CO}_{2}$, two cases were analyzed: free $\mathrm{CO}_{2}$ and $\$ 70 /$ mt $\mathrm{CO}_{2}$. The results are shown in Table $11-6$. Doubling the cost of carbon increases annualized production costs about $40 \%$. When $\mathrm{CO}_{2}$ is free (an exceptional case only applicable to small systems located near an existing well) the costs are reduced $40 \%$. Thus again, the Base Case assumption on carbon price appears to be an economically reasonable one that must be achieved. The addition of nutrient recvele to this cost is one of the most necessary features to successfully develop. Carbon is too costly, in general, to allow half of it to escape from the system without being incorporated into product. 
Table 11-5 Recrele Case: Productivity Sensitivity

\begin{tabular}{lrrr} 
INPUTS & $R, 0.5 \times P$ & $R, 0.67 \times P$ & $R, 1.0 \times P$ \\
\hline Depreciable capital investment & $\$ 14,570,000$ & $\$ 15,290,000$ & $\$ 17,620,000$ \\
Non-Deprec capital investment & $10,820,000$ & $11,030,000$ & $11,430,000$ \\
Annual operating costs & $2,650,000$ & $2,990,000$ & $3,640,000$ \\
Annual maintenance costs & 660,000 & 690,000 & 800,000 \\
System algal yield mt/yr & 22725 & 30315 & 45450 \\
System Lipid yield bbls/yr & 75000 & 100000 & 150000
\end{tabular}

Carbohydrate yield mt/yr

Protein yield $m t / y r$

CALCULATED VALUES

Cost of capital

Cap Recov Factor (book life)

Cap Recov Factor (depr life)

Fixed Charge Rate

PV of Capital Investment.

PV of NonDeprec Investment

PV of Operating costs

PV of Maintenance costs

TOTAL PV DF FACILITY

Annualized Cost Algae Plant

LIPID only price $\$ / b b l$

ALGAE price \$/mt

Lipid price by weight $\$ /$ at

Lipid orice by value $\$ /$ int

Protein price by weight $\$ /$ at

Protein price by value $\$ /$ mt

Carbohyd price by weight $\$ / m t$

Carbohyd price by value $\$ /$ int
0.0475

0.0692

0.0947

0.0951

$\$ 18,133,650$

$13,466,450$

$53,156,520$

$14,145,970$

$\$ 98,902,580$

$\$ 7,312,236$

97.50

321.77

697.38

348.70

697.38

697.38

$\$ 19,029,750$

$13,727,810$

$59,976,600$

$14,788,970$

0.0475
0.0692

0.0947

0.0951

$\$ 107,523,100$

$\$ 7,931,843$

79.32

261.65

567.36

283.68

567.36

567.36

$\$ 21,929,650$

$14,225,640$

$73,014,990$

$17,146,630$

$\$ 126,316,900$

$\$ 9,307,186$

62.05

204.78

443.82

221.91

443.82

443.82

$\begin{array}{lrrrr}\text { Annualized Capital Cost } & \text { DCI } & \$ 1,724,572 & \$ 1,809,794 & \$ 2,085,584 \\ \text { Annualized Capital Cost } & \text { NCDI } & 931,621 & 949,702 & 984,142 \\ \text { Annualized Operating Cost } & \text { OPP } & 3,677,414 & 4,149,233 & 5,051,241 \\ \text { Annualized Mainten. Cost } & \text { MNT } & 978,631 & 1,023,114 & 1,186,219 \\ \text { Annualized Cost Total } & \text { AAP } & 7,312,237 & 7,931,843 & 9,307,186 \\ & & & & \\ \text { Annualized Capital Cost } & \text { DCI } & 23.6 \% & 22.8 \% & 22.4 \% \\ \text { Annualized Capital Cost } & \text { NCDI } & 12.7 \% & 12.0 \% & 10.6 \% \\ \text { Annualized Operating Cost } \text { OPP } & 50.3 \% & 52.3 \% & 54.3 \% \\ \text { Annualized Mainten. Cost } & \text { MNT } & 13.4 \% & 12.9 \% & 12.7 \% \\ \text { Annualized Cost Total } & \text { AAP } & 100.0 \% & 100.0 \% & 100.0 \%\end{array}$


Table 11-5 Recyele Case: Productivity Sensitivity (continued)

\begin{tabular}{|c|c|c|}
\hline INPUTS & $R, 1.5 \times P$ & $R, 2 \times F$ \\
\hline $\begin{array}{l}\text { Depreciable capital investment } \\
\text { Non-Deprec capital investment } \\
\text { Annual operating costs } \\
\text { Annual maintenance costs } \\
\text { Systen algal yield mt/yr } \\
\text { Systen Lipid yield bbls/yr } \\
\text { Carbohydrate yield mt/yr } \\
\text { Protein yield mt/yr }\end{array}$ & $\begin{array}{r}\$ 19,640,000 \\
12,000,000 \\
4,630,000 \\
1,000,000 \\
68175 \\
225000\end{array}$ & $\begin{array}{r}\$ 21,900,000 \\
12,550,000 \\
5,620,000 \\
1,120,000 \\
90900 \\
300000\end{array}$ \\
\hline \multicolumn{3}{|l|}{ CALCULATED VALUES } \\
\hline $\begin{array}{l}\text { Cost of capital } \\
\text { Cap Recov Factor (book life) } \\
\text { Cap Recov Factor (depr life) } \\
\text { Fixed Charge Rate }\end{array}$ & $\begin{array}{l}0.0475 \\
0.0692 \\
0.0947 \\
0.0951\end{array}$ & $\begin{array}{l}0.0475 \\
0.0692 \\
0.0947 \\
0.0951\end{array}$ \\
\hline $\begin{array}{l}\text { PV of Capital Investment } \\
\text { PV of NonDeprec Investaent } \\
\text { PV of Operating costs } \\
\text { PV of Maintenance costs }\end{array}$ & $\begin{array}{r}\$ 24,443,710 \\
14,935,060 \\
92,873,460 \\
21,433,290\end{array}$ & $\begin{array}{r}\$ 27,256,480 \\
15,619,580 \\
112,731,900 \\
24,005,290\end{array}$ \\
\hline TOTAL PV OF FACILITY & $\$ 153,685,500$ & $\$ 179,613,300$ \\
\hline $\begin{array}{l}\text { Annualized Cost Algae Plant } \\
\text { LIPID only price } / / \text { bbl } \\
\text { ALGAE price } \$ / \text { mt }\end{array}$ & $\begin{array}{r}\$ 11,265,740 \\
50.07 \\
165.25\end{array}$ & $\begin{array}{r}\$ 13,132,360 \\
43.77 \\
144.47\end{array}$ \\
\hline $\begin{array}{l}\text { Lipid price by weight } \$ / m t \\
\text { Lipid price by value } \$ / m t \\
\text { Protein price by weight } \$ / m t \\
\text { Protein price by value } \$ / m t\end{array}$ & $\begin{array}{l}358.15 \\
179.08 \\
358.15\end{array}$ & $\begin{array}{l}313.12 \\
156.56 \\
313.12\end{array}$ \\
\hline $\begin{array}{l}\text { Carbohyd price by weight } \$ \text { /at } \\
\text { Carbohyd price by value } \$ / \text { mt }\end{array}$ & 358.15 & 313.12 \\
\hline
\end{tabular}

$\begin{array}{lrrr}\text { Annualized Capital Cost } & \text { DCI } & \$ 2,324,680 & \$ 2,592,184 \\ \text { Annualized Capital Cost } & \text { NCDI } & 1,033,220 & 1,080,576 \\ \text { Annualized Operating cost } & \text { OPP } & 6,425,067 & 7,798,891 \\ \text { Annualized Mainten. Cost } & \text { MNT } & 1,482,774 & 1,660,707 \\ \text { Annualized Cost Total } & \text { AAP } & 11,265,741 & 13,132,358 \\ & & & \\ \text { Annualized Capital Cost } & \text { DCI } & 20.6 \% & 19.7 \% \\ \text { Annualized Capital Cost } & \text { NCDI } & 9.2 \% & 8.2 \% \\ \text { Annualized Operating Cost } & \text { OPP } & 57.0 \% & 59.4 \% \\ \text { Annualized Mainten. Cost } & \text { MNT } & 13.2 \% & 12.6 \% \\ \text { Annualized Cost Total } & \text { AAP } & 100.0 \% & 100.0 \%\end{array}$




\section{Figure 11-1 Productivity Sensitivity}

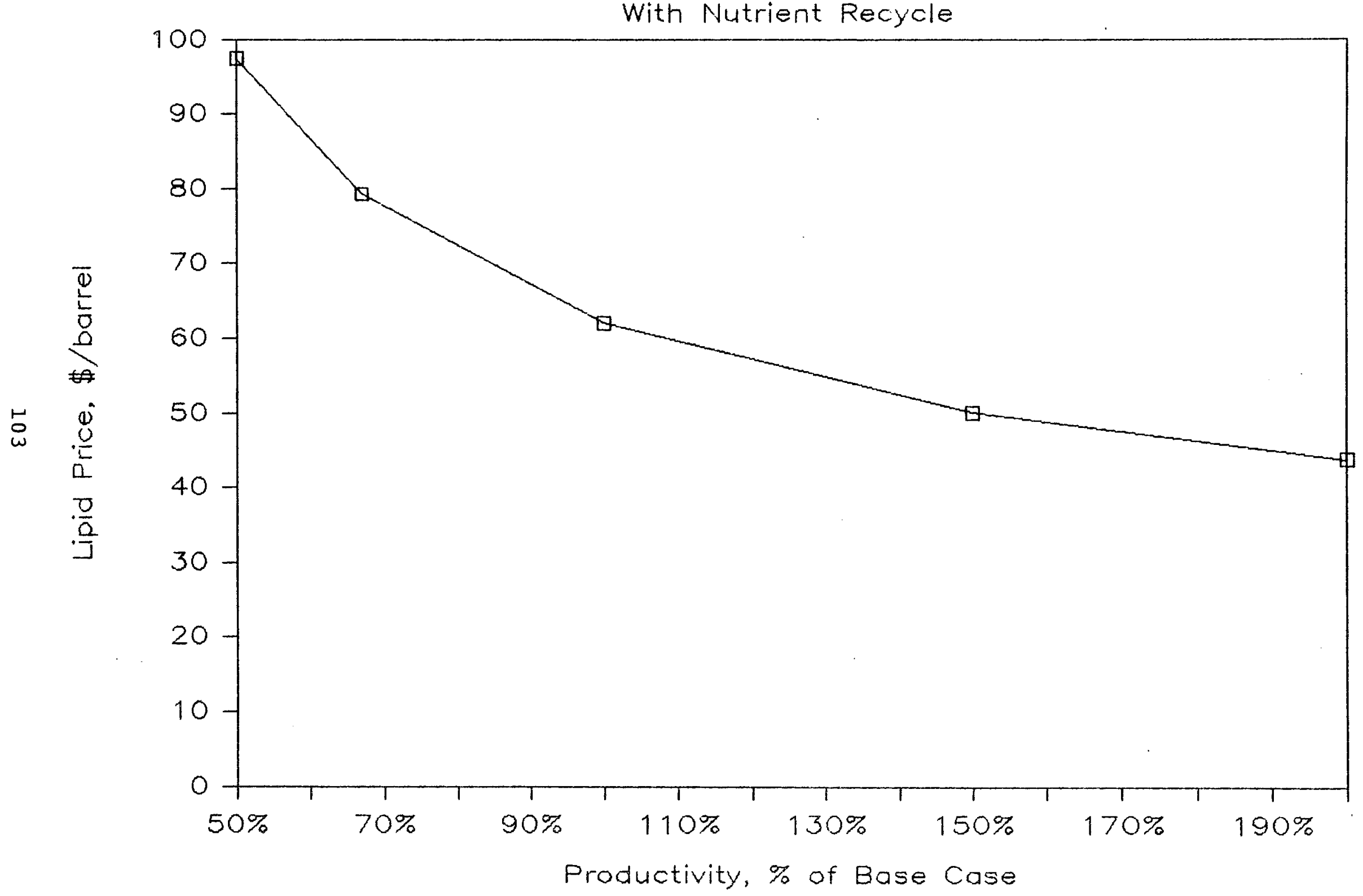


Table 11-6 Recycle Case: Sensitivity to CO2 Price

\begin{tabular}{|c|c|c|c|}
\hline INPUTS & R, Free & $R, \$ 35 /$ mt & $R, \$ 70 / m t$ \\
\hline $\begin{array}{l}\text { Depreciable capital investment } \\
\text { Non-Deprec capital investment } \\
\text { Annual operating costs } \\
\text { Annual maintenance costs } \\
\text { Systen algal yield mt/yr } \\
\text { systed Lipid yield bbls/yr } \\
\text { Carbohydrate yield mt/yr } \\
\text { Protein yield mt/yr }\end{array}$ & $\begin{array}{r}\$ 17,300,000 \\
11,420,000 \\
1,100,000 \\
800,000 \\
45450 \\
150000\end{array}$ & $\begin{array}{r}\$ 17,620,000 \\
11,430,000 \\
3,640,000 \\
800,000 \\
45450 \\
150000\end{array}$ & $\begin{array}{r}\$ 17,300,000 \\
11,420,000 \\
6,180,000 \\
800,000 \\
45450 \\
150000\end{array}$ \\
\hline CALCULATED VALUES & & & \\
\hline $\begin{array}{l}\text { Cost of capital } \\
\text { Cap Recor Factor (book life) } \\
\text { Cap Recov Factor (depr life) } \\
\text { Fixed Charge Rate }\end{array}$ & $\begin{array}{l}0.0475 \\
0.0692 \\
0.0947 \\
0.0951\end{array}$ & $\begin{array}{l}0.0475 \\
0.0692 \\
0.0947 \\
0.0951\end{array}$ & $\begin{array}{l}0.0475 \\
0.0692 \\
0.0947 \\
0.0951\end{array}$ \\
\hline $\begin{array}{l}\text { PV of Capital Investment } \\
\text { PV of NonDeprec Investment } \\
\text { PV of Operating costs } \\
\text { PV of Maintenance costs }\end{array}$ & $\begin{array}{r}\$ 21,531,380 \\
14,213,200 \\
22,064,970 \\
17,146,630\end{array}$ & $\begin{array}{r}\$ 21,929,650 \\
14,225,640 \\
73,014,990 \\
17,146,630\end{array}$ & $\begin{array}{r}\$ 21,531,380 \\
14,213,200 \\
123,965,000 \\
17,146,630\end{array}$ \\
\hline TOTAL PV OF FACILITY & $\$ 74,956,180$ & $\$ 126,316,900$ & $\$ 176,856,200$ \\
\hline $\begin{array}{l}\text { Annualized Cost Algae Plant } \\
\text { LIPID only price } \$ / b b l \\
\text { ALGAE price } \$ / m t\end{array}$ & $\begin{array}{r}\$ 5,743,681 \\
38.29 \\
126.37\end{array}$ & $\begin{array}{r}\$ 9,307,186 \\
62.05 \\
204.78\end{array}$ & $\begin{array}{r}\$ 12,793,210 \\
85.29 \\
281.48\end{array}$ \\
\hline $\begin{array}{l}\text { Lipid price by weight } \$ / \text { mt } \\
\text { Lipid price by value } \$ / m t \\
\text { Protein price by weight } \$ / \text { at } \\
\text { Protein price by value } \$ / \text { mt } \\
\text { Carbohyd price by weight } \$ / \text { at } \\
\text { Carbohyd price by value } \$ / \text { at }\end{array}$ & $\begin{array}{l}273.89 \\
136.95 \\
273.89\end{array}$ & $\begin{array}{l}443.82 \\
221.91 \\
443.82\end{array}$ & $\begin{array}{l}610.06 \\
305.03 \\
610.06\end{array}$ \\
\hline
\end{tabular}

$\begin{array}{lrrrr}\text { Annualized Capital Cost } & \text { DCI } & \$ 2,047,707 & \$ 2,085,584 & \$ 2,047,707 \\ \text { Annualized Capital Cost } & \text { NCDI } & 983,282 & 984,142 & 983,292 \\ \text { Annualized Operating Cost } \text { OPP } & 1,526,474 & 5,051,241 & 8,576,007 \\ \text { Annualized Mainten. Cost } & \text { MNT } & 1,186,219 & 1,186,219 & 1,186,219 \\ \text { Annualized Cost Total } & \text { AAP } & 5,743,682 & 9,307,186 & 12,793,214 \\ & & & & \\ \text { Annualized Capital Cost } & \text { DCI } & 35.7 \% & 22.4 \% & 16.0 \% \\ \text { Annualized Capital Cost NCDI } & 17.1 \% & 10.6 \% & 7.7 \% \\ \text { Annualized Operating Cost } \text { OPP } & 26.6 \% & 54.3 \% & 67.0 \% \\ \text { Annualized Mainten. Cost } & \text { MNT } & 20.7 \% & 12.7 \% & 9.3 \% \\ \text { Annualized Cost Total } & \text { AAP } & 100.0 \% & 100.0 \% & 100.0 \%\end{array}$




\subsection{RECYCLE CASE: SENSITIVITY TO LIPID CONTENT}

Lipid content of the biomass produced (at $30 \mathrm{gm} / \mathrm{m}^{2} / d$ ) was varied from $20 \%$ to $50 \%$ (the Base Case value) to determine the effect on lipid price. As shown in Table 11-7, reduced lipid dramatically increases lipid price. Thus the Base Case assumption of $50 \%$ lipid content needs to be achieved when lipid oil is the desired product. Recycle of carbon was assumed in this analysis and had the effect of causing a decrease in biomass production cost as lipid content was decreased. This analysis could be adapted to the case of methane fuel production if the non-lipid fraction is assumed accessible to degradation and If the amount of carbon recvele is corrected for removal of carbon as the methane product. No such analvais was done in detail as lipid production is the primary goal. The system would have to produce biomass at $\$ 75 / m$ t to provide methane at \$5/MBTU. The svstem designed is effectve in producing methane gas if the covered lagoon dagester performs as well as assumed. This will be studied in the proposed experimental system.

\subsection{RECYCLE CASE: SENSITIVITY TO DEPRECIABLE CAPITAL INVESTMENT}

The capital investment does not appear to significantly affect the annualized production costs until it qets large. Three variations in DCI were analyzed for their impact. The first, 1.5 times the DCI of the recycle case would apply if the primary harvesting device were auch more expensive than the proposed sedimentation systen. An example of a device that would fall into this range of DCl increase is an engineered dissolved gas flotation reactor, costing about $\$ 12$ million per 1000 acre system. The secand change in DCl, to twice the baseline level, corresponds to lining the ponds with a high quality synthetic material costing $\$ 5.00 / \mathrm{m}^{2}$, or about $\$ 22$ million dollars per 1000 acres of growth pond area. This type of liner would be used if ponds lined with less expensive earthen materials proved to lose too much water. The five fold increase in DCI would correspond to lining and covering a pond system. This is very costly and as yet there is no evidence that, on a large scale, this concept is at all workable. As shown in Table 11-8, the 50\% increase in DCI leads to a $15 \%$ increase in product cost which implies that it is affordable if it is necessary for good performance of the harvesting system. The $100 \%$ increase in DCI, for a liner, increases cost of lipia oroduct by $30 \%$. This is affordable only if the increase is offset by some other savings or by productivity increases. Thus use of a liner is marginal. The $400 \%$ increase. for a covered svstem, results in 2.25 fold increase in production costs. Which is by all means too much even if the covered system somehow made all other performance goals achievable. It must be kept in mind that synthetic materials used for lining and covering will likelv inflate with crude oil prices, so that hoping for oramatic oil price increases to make such systems affordable is not warranted. 
Table 11-7 Recycle Case: Sensitivity to Lipid Content

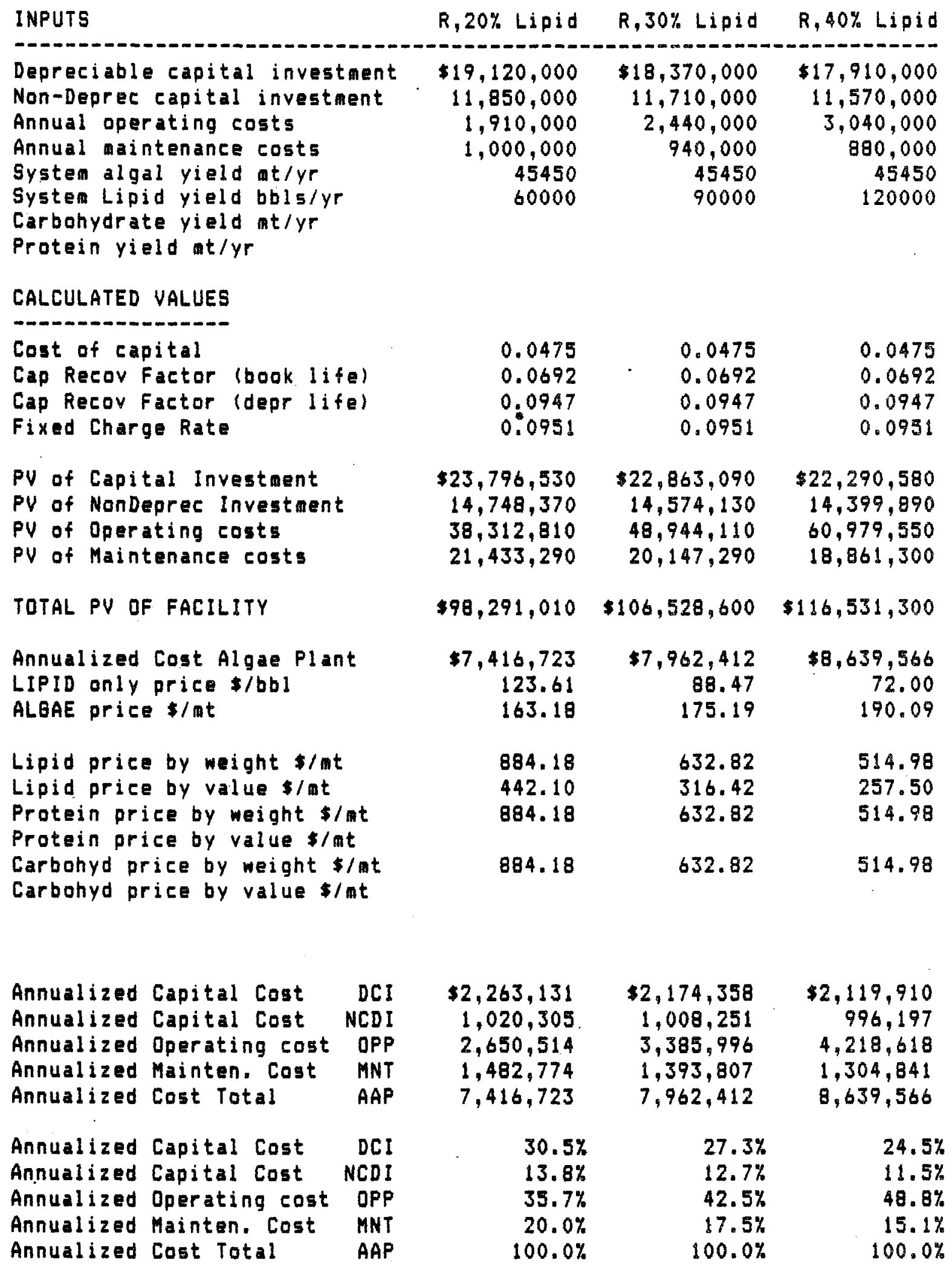


Table 11-8 Recycle Case: Sensitivity to DCI

\begin{tabular}{lrrr} 
INPUTS & $R, 1.5 \times D C I$ & $R, 2 \times D C I$ & $R, 5 \times D C I$ \\
\hline Depreciable capital investment & $\$ 26,430,000$ & $\$ 35,240,000$ & $\$ 88,100,000$ \\
Non-Deprec capital investment & $11,430,000$ & $11,430,000$ & $11,430,000$ \\
Annual operating costs & $3,640,000$ & $3,640,000$ & $3,640,000$ \\
Annual maintenance costs & $1,060,000$ & $1,320,000$ & $2,910,000$ \\
System algal yield mt/yr & 45450 & 45450 & 45450 \\
System Lipid yield bbls/yr & 150000 & 150000 & 150000 \\
Carbohydrate yield mt/yr & & &
\end{tabular}

Protein yield mt/yr

CALCULATED VALUES

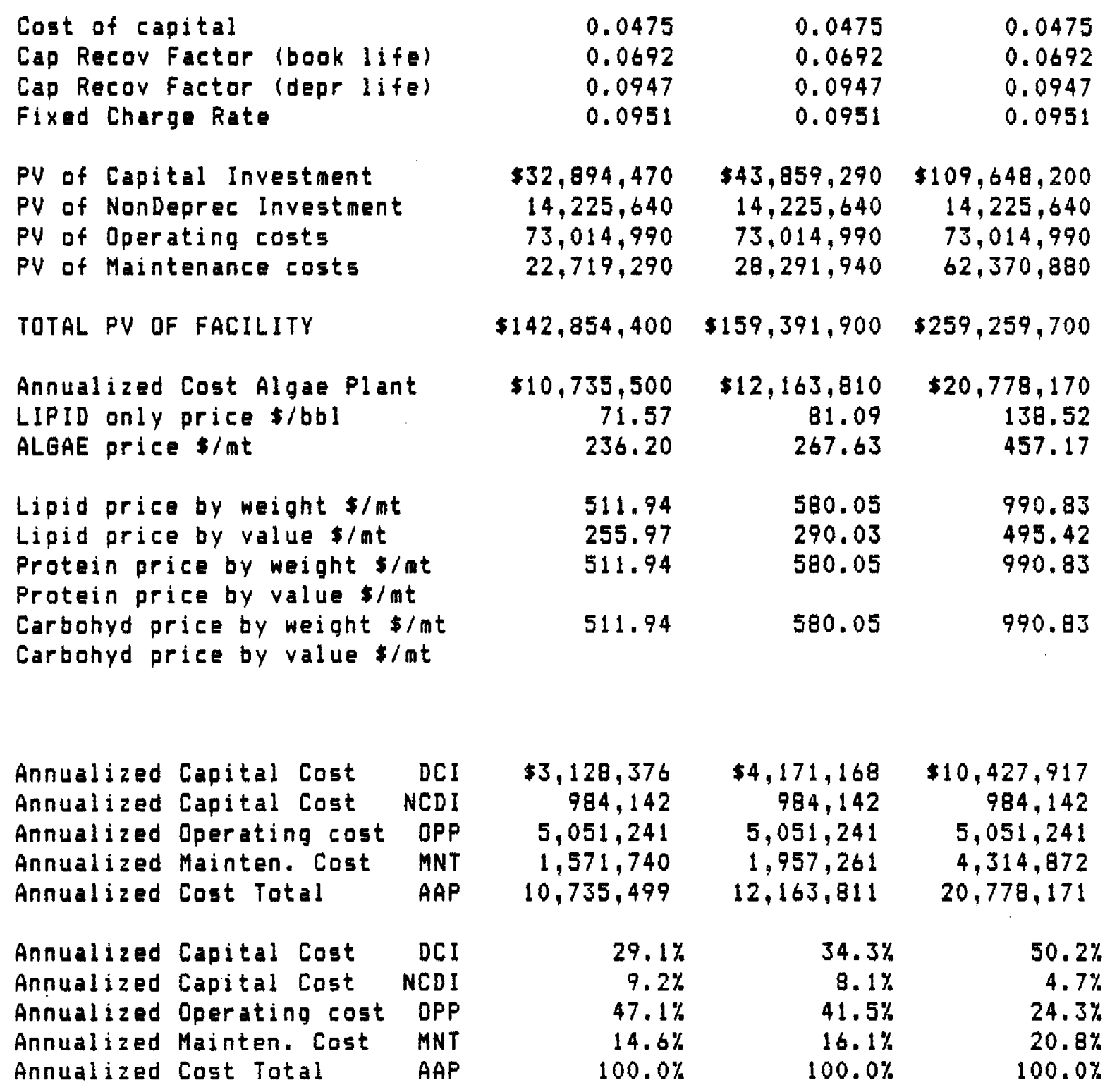




\subsection{RECYCLE CASE: SENSITIVITY TO COST OF CAPITAL}

All of the modeling done so far is based on assumptions which lead to a cost of cadital of about $5 \%$. While this may be reasonable in some circumstances. many orivate investors will want to see a areater return for risking capital or for investina in a capital intensive business. Using the recycle case. three cost of capital tactors were used to test sensitivity to this parameter. each with the original DCI and with the $100 \%$ increased DCl. The results are given in Tables $11-9$ and $11-10$.

As expected, the cost of capital has qreat impact on tinal product costs and this impact increases as capital costs increase. The contribution of annualized capital cost to total annualized cost increases from $33 \%$ at the lowest rate and lowest level of capital requirement to $60 \%$ at the highest of each. This means that, except at the most favorable borrowing rate, the capital intensity of a system is an important factor. Very expensive systems must be justified in terms of very great increases in productivity. However productivity has an upper limit which is less two than times the base case value, i.e.. it is doubtful that a lipid accumulating alga could ever be expected to be $15 \%$ efficient in converting solar energy. For these reasons, the design criteria used in this report, lowest cogt with highest effect, appears to be justified.

\subsection{RECYCLE CASE: SENSITIVITY TO POLYMER DOSE}

Harvesting is one of the steps in the overall process that must be highly reliable. In the basic design of the systen, it was assumed that a high molecular weight polymer would have to be added to the aloal suspension to aid in flocculating the biomass prior to primary concentration. The dose of polymer used. 1 pom per 500 ppm of biomass. is a low one. The results of the sensitivity analysis shown in Table 11-11 indicate that this dose could be doubled without increasing product cost more than $7 \%$, and even a five fold higher polymer dose would only lead to a $20 \%$ increase. A low dose, 1-3 ppm/ ppm. is becoming state of the art due to the capability of tailoring polymers to specific applications.

\subsection{CONCLUSIONS}

The sensitivity analyses performed confirm that the optimistic assumptions used in setting the large scale system performance standards are necessary to produce fuel products fron algae economically. The analyses also indicate that a low cost. carbon efficient system has the best opportunity of achieving these standards. Productivity increases, which appear necessary despite the high lipid productivity assumed here, will have the most impact on final product cost when achieved within the framework of the systen specified here. The questions of resource availability were not, of course, solved by these analyses. However, the system designed is very efficient in its utilization of resources. 
Table 11-9 Recycle Case: Sensitivity to Cost of Capital (k)

\begin{tabular}{|c|c|c|c|}
\hline INPUTS & $R, k=.047$ & $R, k=.07$ & $R, k=.10$ \\
\hline $\begin{array}{l}\text { Depreciable capital investment } \\
\text { Non-Deprec capital investment } \\
\text { Annual operating costs } \\
\text { Annual maintenance costs } \\
\text { System algal yield mt/yr } \\
\text { System Lipid yield bbls/yr } \\
\text { Carbohydate yield mt/yr } \\
\text { Protein yield mt/yr }\end{array}$ & $\begin{array}{r}\$ 17,620,000 \\
11,430,000 \\
3,640,000 \\
800,000 \\
45450 \\
150000\end{array}$ & $\begin{array}{r}\$ 17,620,000 \\
11,430,000 \\
3,640,000 \\
800,000 \\
45450 \\
150000\end{array}$ & $\begin{array}{r}\$ 17,620,000 \\
11,430,000 \\
3,640,000 \\
800,000 \\
45450 \\
150000\end{array}$ \\
\hline ALCULATED VALUES & & & \\
\hline $\begin{array}{l}\text { Cost of capital } \\
\text { Cap Recov Factor (book life) } \\
\text { Cap Recov Factor (depr life) } \\
\text { Fixed Charge Rate }\end{array}$ & $\begin{array}{l}0.0475 \\
0.0692 \\
0.0947 \\
0.0951\end{array}$ & $\begin{array}{l}0.0700 \\
0.0858 \\
0.1098 \\
0.1202\end{array}$ & $\begin{array}{l}0.1000 \\
0.1102 \\
0.1315 \\
0.1581\end{array}$ \\
\hline $\begin{array}{l}\text { PV of Capital Investment } \\
\text { PV of NonDeprec Investment } \\
\text { PV of Operating costs } \\
\text { PV of Maintenance costs }\end{array}$ & $\begin{array}{r}\$ 21,929,650 \\
14,225,640 \\
73,014,990 \\
17,146,630\end{array}$ & $\begin{array}{r}\$ 23,373,740 \\
15,162,420 \\
57,974,420 \\
13,572,460\end{array}$ & $\begin{array}{r}\$ 25,395,390 \\
16,473,860 \\
44,343,990 \\
10,342,760\end{array}$ \\
\hline TOTAL PV OF FACILITY & $\$ 126,316,900$ & $\$ 110,083,000$ & $\$ 96,556,000$ \\
\hline $\begin{array}{l}\text { Annualized Cost Algae Plant } \\
\text { LIPID only price } \$ / \text { bbl } \\
\text { ALGAE price } \$ / m t\end{array}$ & $\begin{array}{r}\$ 9,307,186 \\
62.05 \\
204.78\end{array}$ & $\begin{array}{r}\$ 10,250,610 \\
68.34 \\
225.54\end{array}$ & $\begin{array}{r}\$ 11,853,790 \\
79.03 \\
260.81\end{array}$ \\
\hline $\begin{array}{l}\text { Lipid price by weight } \$ / m t \\
\text { Lipid price by value } \$ / m t \\
\text { Protein price by weight } \$ / m t \\
\text { Protein price by value } \$ / m t \\
\text { Carbohyd price by weight } \$ / m t\end{array}$ & $\begin{array}{l}443.82 \\
221.91 \\
443.82\end{array}$ & $\begin{array}{l}488.81 \\
244.41 \\
488.81\end{array}$ & $\begin{array}{l}565.26 \\
282.63 \\
565.26\end{array}$ \\
\hline
\end{tabular}

$\begin{array}{lrrrr}\text { Annualized Capital Cost } & \text { OCI } & \$ 2,085,584 & \$ 2,810,038 & \$ 4,014,160 \\ \text { Annualized Capital Cost } & \text { NCDI } & 984,142 & 1,301,095 & 1,814,894 \\ \text { Annualized Dperating cost } & \text { OPP } & 5,051,241 & 4,974,813 & 4,885,293 \\ \text { Annualized Mainten. Cost } & \text { MNT } & 1,186,219 & 1,164,659 & 1,139,442 \\ \text { Annualized Cost Total } & \text { AAP } & 9,307,186 & 10,250,605 & 11,853,790 \\ & & & & \\ \text { Annualized Capital Cost } & \text { DCI } & 22.4 \% & 27.4 \% & 33.9 \% \\ \text { Annualized Capital Cost } & \text { NCDI } & 10.6 \% & 12.7 \% & 15.3 \% \\ \text { Annualized Operating Cost } \text { OPP } & 54.3 \% & 48.5 \% & 41.2 \% \\ \text { Annualized Mainten. Cost } & \text { MNT } & 12.7 \% & 11.4 \% & 9.6 \% \\ \text { Annualized Cost Total } & \text { AAP } & 100.0 \% & 100.0 \% & 100.0 \%\end{array}$


Table 11-10 Recycle Case: Sensitivity to Cost of Capital at 2x DCI

\begin{tabular}{|c|c|c|c|}
\hline INPUTS & $\begin{array}{c}2 \times \text { DCI } \\
R, k=.047\end{array}$ & $\begin{array}{l}2 \times D C I \\
R, k=.07\end{array}$ & $\begin{array}{l}2 \times D C I \\
R, k=.10\end{array}$ \\
\hline $\begin{array}{l}\text { Depreciable capital investment } \\
\text { Non-Deprec capital investment } \\
\text { Annual operating costs } \\
\text { Annual maintenance costs } \\
\text { System algal yield mt/yr } \\
\text { Systen Lipid yield bbls/yr } \\
\text { Carbohydrate yield nt/yr } \\
\text { Protein yield mt/yr }\end{array}$ & $\begin{array}{r}\$ 35,240,000 \\
11,430,000 \\
3,640,000 \\
1,320,000 \\
45450 \\
150000\end{array}$ & $\begin{array}{r}\$ 35,240,000 \\
11,430,000 \\
3,640,000 \\
1,320,000 \\
45450 \\
150000\end{array}$ & $\begin{array}{r}\$ 35,240,000 \\
11,430,000 \\
3,640,000 \\
1,320,000 \\
45450 \\
150000\end{array}$ \\
\hline \multicolumn{4}{|l|}{ CALCULATED VALUES } \\
\hline $\begin{array}{l}\text { Cost of capital } \\
\text { Cap Recov Factor (book life) } \\
\text { Cap Recov Factor (depr life) } \\
\text { Fixed Charge Rate }\end{array}$ & $\begin{array}{l}0.0475 \\
0.0692 \\
0.0947 \\
0.0951\end{array}$ & $\begin{array}{l}0.0700 \\
0.0858 \\
0.1098 \\
0.1202\end{array}$ & $\begin{array}{l}0.1000 \\
0.1102 \\
0.1315 \\
0.1581\end{array}$ \\
\hline $\begin{array}{l}\text { PV of Capital Investment } \\
\text { PV of NonDeprec Investment } \\
\text { PV of Operating costs } \\
\text { PV of Maintenance costs }\end{array}$ & $\begin{array}{r}\$ 43,859,290 \\
14,225,640 \\
73,014,990 \\
28,291,940\end{array}$ & $\begin{array}{r}\$ 46,747,480 \\
15,162,420 \\
57,974,420 \\
22,394,550\end{array}$ & $\begin{array}{r}\$ 50,790,780 \\
16,473,860 \\
44,343,990 \\
17,065,560\end{array}$ \\
\hline TOTAL PV OF FACILITY & $\$ 159,391,900$ & $\$ 142,278,900$ & $\$ 128,674,200$ \\
\hline $\begin{array}{l}\text { Annualized Cost Algae Plant } \\
\text { LIPID only price } \$ / b b l \\
\text { ALGAE price } \$ / m t\end{array}$ & $\begin{array}{r}\$ 12,163,810 \\
81.09 \\
267.63\end{array}$ & $\begin{array}{r}\$ 13,817,670 \\
92.12 \\
304.02\end{array}$ & $\begin{array}{r}\$ 16,608,590 \\
110.72 \\
365.43\end{array}$ \\
\hline $\begin{array}{l}\text { Lipid price by weight } \$ / \text { mt } \\
\text { Lipid price by value } \$ / m t \\
\text { Protein price by weight } \$ / m t \\
\text { Protein price by value } \$ / m t\end{array}$ & $\begin{array}{l}580.05 \\
290.03 \\
580.05\end{array}$ & $\begin{array}{l}658.91 \\
329.46 \\
658.91\end{array}$ & $\begin{array}{l}792.00 \\
396.00 \\
792.00\end{array}$ \\
\hline $\begin{array}{l}\text { Carbohyd price by weight } \$ / \text { at } \\
\text { Carbohyd price by value } \$ / \text { at }\end{array}$ & 580.05 & 658.91 & 792.00 \\
\hline
\end{tabular}

$\begin{array}{lrrrr}\text { Annualized Capital Cost } & \text { DCI } & \$ 4,171,168 & \$ 5,620,076 & \$ 8,028,321 \\ \text { Annualized Capital Cost } & \text { NCDI } & 984,142 & 1,301,095 & 1,814,894 \\ \text { Annualized Operating cost } \text { OPP } & 5,051,241 & 4,974,813 & 4,885,293 \\ \text { Annualized Mainten. Cost } & \text { MNT } & 1,957,261 & 1,921,687 & 1,880,080 \\ \text { Annualized Cost Total } & \text { AAP } & 12,163,811 & 13,817,671 & 16,608,588 \\ & & & & \\ \text { Annualized Capital Cost } & \text { DCI } & 34,3 \% & 40.7 \% & 48.3 \% \\ \text { Annualized Capital Cost NCDI } & 8.1 \% & 9.4 \% & 10.9 \% \\ \text { Annualized Operating cost } \text { OPP } & 41.5 \% & 36.0 \% & 29,4 \% \\ \text { Annualized Mainten. Cost } & \text { MNT } & 16.1 \% & 13.9 \% & 11.3 \% \\ \text { Annualized Cost Total } & \text { AAP } & 100.0 \% & 100.0 \% & 100.0 \%\end{array}$


Table 11-11 Recycle Case: Sensitiyity to Polymer Dose

\begin{tabular}{|c|c|c|c|}
\hline INPUTS & $R, 1 \times$ Poly. & R, $2 \times$ Poly. & R. 5xPoly. \\
\hline $\begin{array}{l}\text { Depreciable capital investment } \\
\text { Non-Deprec capital investment } \\
\text { Annual operating costs } \\
\text { Annual maintenance casts } \\
\text { Systen algal yield mt/yr } \\
\text { Systen Lipid yield bbls/yr } \\
\text { Carbohydrate yield mt/yr } \\
\text { Protein yield at/yr }\end{array}$ & $\begin{array}{r}\$ 17,620,000 \\
11,430,000 \\
3,640,000 \\
800,000 \\
45450 \\
150000\end{array}$ & $\begin{array}{r}\$ 17,620,000 \\
11,430,000 \\
4,094,000 \\
820,000 \\
45450 \\
150000\end{array}$ & $\begin{array}{r}\$ 17,620,000 \\
11,430,000 \\
5,456,000 \\
920,000 \\
45450 \\
150000\end{array}$ \\
\hline \multicolumn{4}{|l|}{ CALCULATED VALUES } \\
\hline $\begin{array}{l}\text { Cost of capital } \\
\text { Cap Recov Factor (book life) } \\
\text { Cap Recov Factor (depr life) } \\
\text { Fixed Charge Rate }\end{array}$ & $\begin{array}{l}0.0475 \\
0.0692 \\
0.0947 \\
0.0951\end{array}$ & $\begin{array}{l}0.0475 \\
0.0692 \\
0.0947 \\
0.0951\end{array}$ & $\begin{array}{l}0.0475 \\
0.0692 \\
0.0947 \\
0.095\end{array}$ \\
\hline $\begin{array}{l}\text { PV of Capital Investment } \\
\text { PV of NonDeprec Investment } \\
\text { PV of Operating costs } \\
\text { PV of Maintenance costs }\end{array}$ & $\begin{array}{l}21,929,650 \\
14,225,640 \\
73,014,990 \\
17,146,630\end{array}$ & $\begin{array}{l}\$ 21,929,650 \\
14,225,640 \\
82,121,800 \\
17,575,300\end{array}$ & $\begin{array}{r}\$ 21,929,650 \\
14,225,640 \\
109,442,200 \\
17,575,300\end{array}$ \\
\hline TOTAL PV OF FACILITY & $\$ 126,316,900$ & $\$ 135,852,400$ & $\$ 163,172,80$ \\
\hline $\begin{array}{l}\text { Annualized Cost Algae Plant } \\
\text { LIPID only price } \$ / \text { bul } \\
\text { ALGAE price } \$ / m t\end{array}$ & $\begin{array}{r}\$ 9,307,186 \\
62.05 \\
204.78\end{array}$ & $\begin{array}{r}\$ 9,966,858 \\
66.45 \\
219.29\end{array}$ & $\begin{array}{r}\$ 11,856,910 \\
79.05 \\
260.88\end{array}$ \\
\hline $\begin{array}{l}\text { Lipid price by weight } \$ / m t \\
\text { Lipid price by value } \$ / m t \\
\text { Protein price by weight } \$ / \text { at } \\
\text { Protein price by value } \$ / m t\end{array}$ & $\begin{array}{l}443.82 \\
221.91 \\
443.82\end{array}$ & $\begin{array}{l}475.28 \\
237.64 \\
475.28\end{array}$ & $\begin{array}{l}565.4 \\
282.7 \\
565.4\end{array}$ \\
\hline arbohyd price by weight $\$ / m t$ & 443.82 & 475.28 & 565.4 \\
\hline
\end{tabular}

$\begin{array}{lrrrr}\text { Annualized Capital Cost } & \text { DCI } & \$ 2,085,584 & \$ 2,085,584 & \$ 2,085,584 \\ \text { Annualized Capital Cost } & \text { NCDI } & 984,142 & 984,142 & 984,142 \\ \text { Annualized Operating cost } & \text { OPP } & 5,051,241 & 5,681,258 & 7,571,307 \\ \text { Annualized Mainten. Cost } & \text { MNT } & 1,186,219 & 1,215,875 & 1,215,875 \\ \text { Annualized Cost Total } & \text { AAP } & 9,307,186 & 9,966,859 & 11,856,908 \\ & & & & \\ \text { Annualized Capital Cost } & \text { DCI } & 22.4 \% & 20.9 \% & 17.6 \% \\ \text { Annualized Capital Cost NCDI } & 10.6 \% & 9.9 \% & 8.3 \% \\ \text { Annualized Operating cost OPP } & 54.3 \% & 37.0 \% & 63.9 \% \\ \text { Annualized Mainten. Cost } & \text { MNT } & 12.7 \% & 12.2 \% & 10.3 \% \\ \text { Annualized Cost Total } & \text { AAP } & 100.0 \% & 100.0 \% & 100.0 \%\end{array}$


SECTION 12.0

EXPERIMENTAL SYSTEM DESIGN AND CONSTRUCTION COSTS

\subsection{SITE DESCRIPTION}

The site chosen for the experimental system is in Brawley, California in the Inperial Valley on a two thousand acre asparagus farm. Over one thousand acres of land are at present not cultivated. The location of the pond system is on land that borders the southwest side of the salton Sea, makino that water resource available by pipeline or shallow well. The land is substantially flat. With sandy ano clay soils and sparse vegetation. Fiqures 12-1 and 2 show the qeneral location of the site and the specific location of the pond construction area.

The climate in the Imperial Valley is representative of the warmer. orjer areas of the American Southwest. The annual rainfall averages $7 \mathrm{~cm}$, the net pan $A$ eyaporation averages $240 \mathrm{~cm}$, and the mean insolation is 480 Lanqleys/day total. Table 12-1 summarizes the mean monthly and yearly climatic data.

Table 12-1. Climatic Conditions at the Proposed Experimental Site

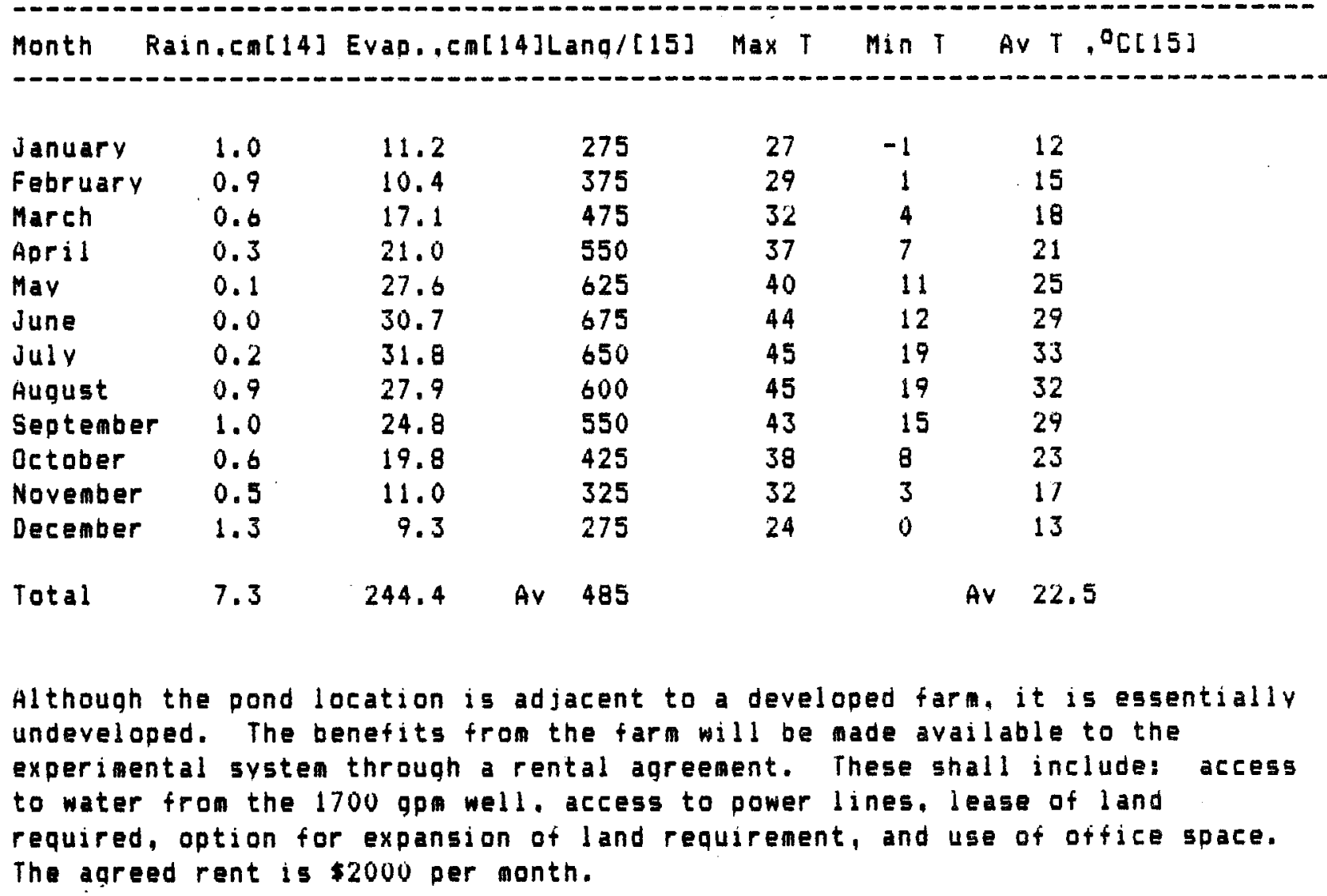




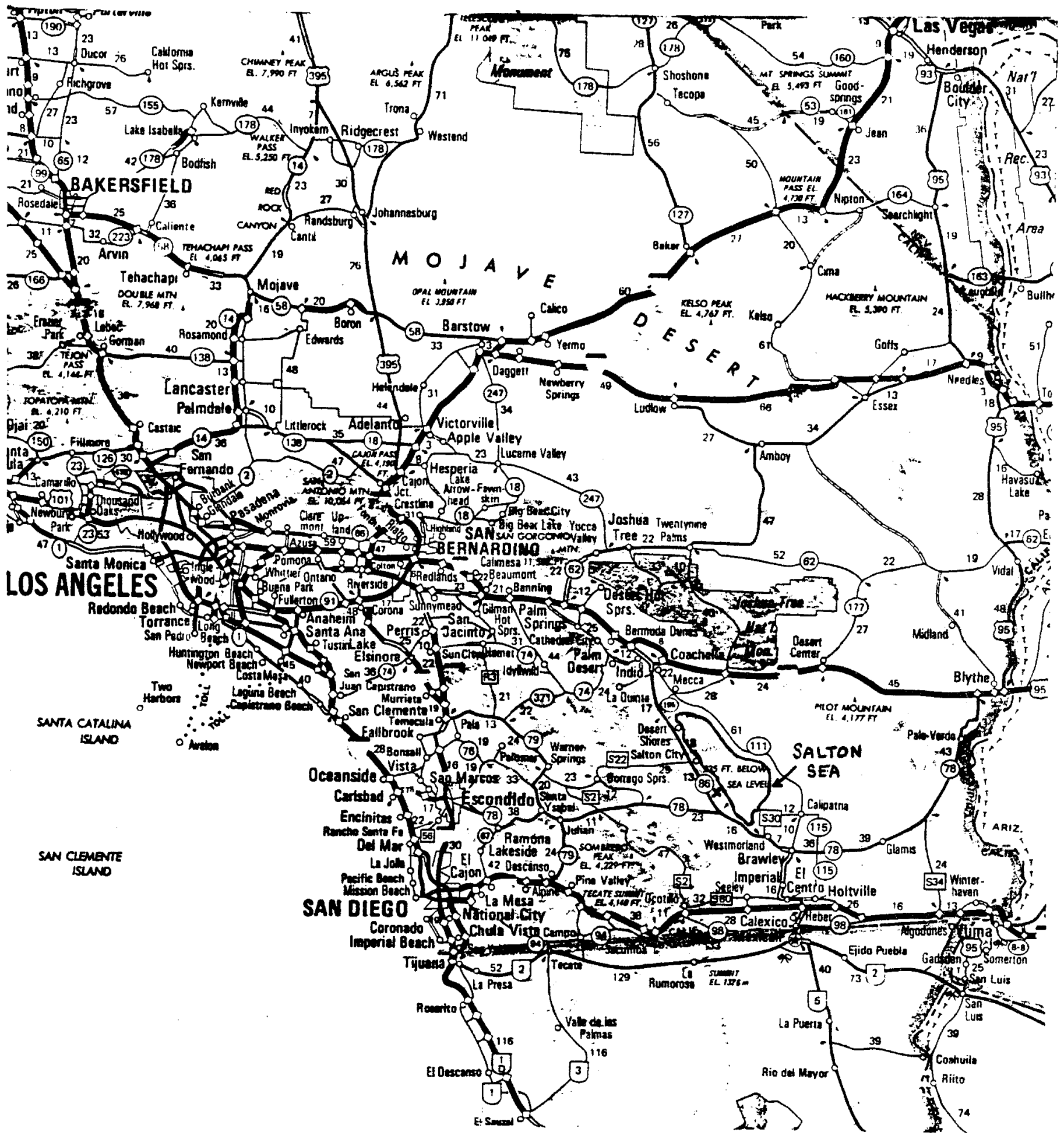

Figure 12-1 Location of Experimental System 


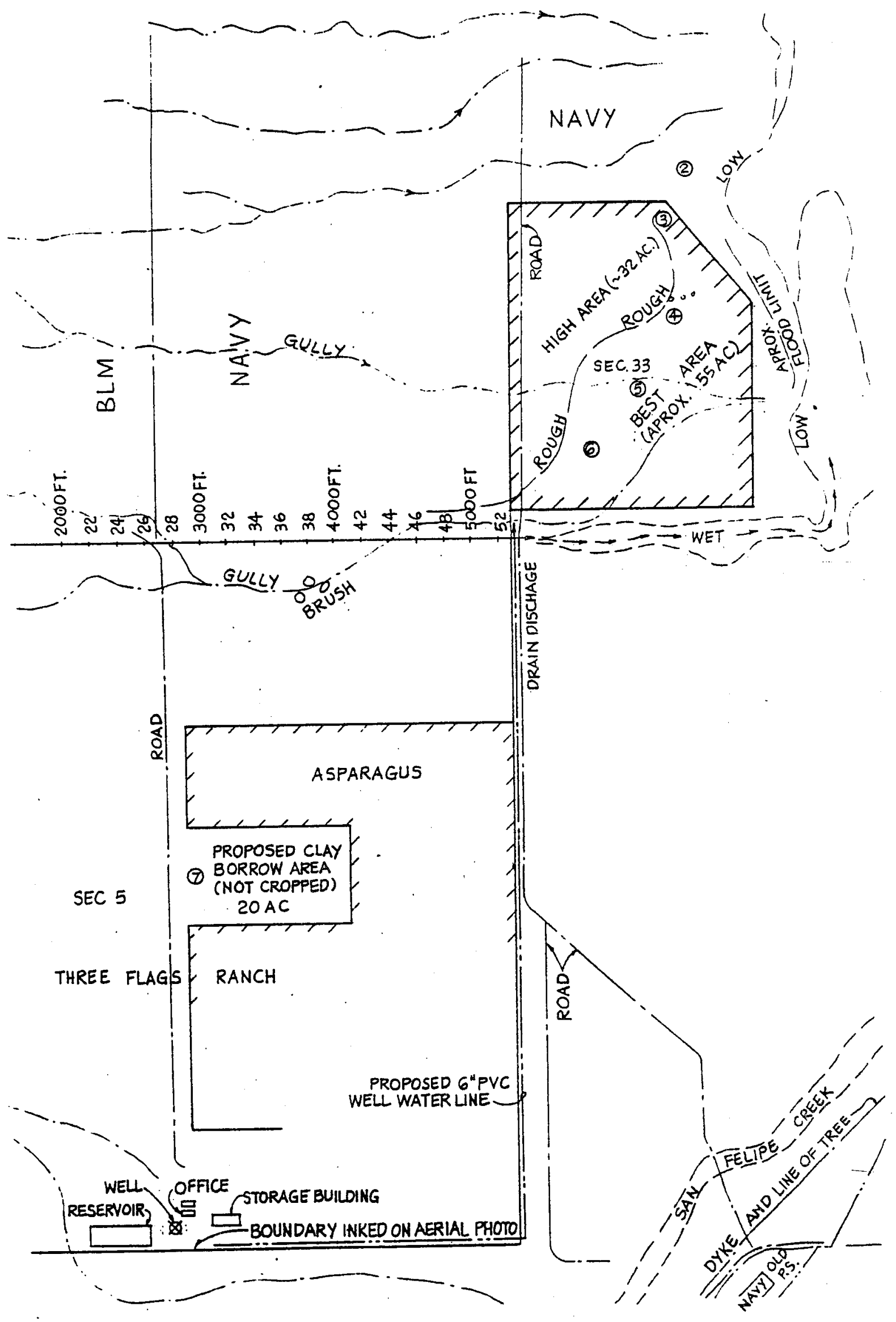

Figure 12-2 Experimental Site 
The characteristics of the well water and of Salton Sea water are qiven in Table 12-2. Both waters are known to support the growth of pnotosynthetic organisms. The high calcium level in the Salton Sea water necessitates some form of water conditioning. After conditioning, this water can be mixed with the well water to obtain a resource with almost any salinity. The two starting salinities of 1 interest are 4 and 8 pot, allowing experimental blowdown ratios of, 125 and .25 respectively, to attain a medium salinity of 32 ppt. The mixture ratios required to yield the two salinities are, well. water to Salton Sea water, 19 to 1 and 4 to 1 , In addition, the Saltion Sea water can be used to approximate ocean water.

rable 12-2. Chemical Composition of Experimental Site Water Resources

Salton Sea[16]

$\mathrm{pH}$

TDS, ppt

Alkalinity, meq/1

Ca, pon

Ma, ppm

K. $P$ P

Na, $P D \cap$

Cl, $P$ OM

$\mathrm{SO}_{4}$. $\mathrm{PP}$ ก
8.6

34.8

2.2

1089

1220

75

970

14700

7800
Groundwater

8.55

2.5

3.2

40

50

20

800

1200

100

\subsection{EXPERIMENTAL SYSTEM DESCRIPTION AND JUSTIFICATION}

Aside from laboratory and other support systems, the experimental system consists of six $1.5 \mathrm{~m}^{2}$ ponds, three $50 \mathrm{~m}^{2}$ pands, two $4000 \mathrm{~m}^{2}$ ponds cone acre each) and, 1 f budget allows, one 4 hectare pond (10 acres). The goal of the experimental systen is to demonstrate, on a scale that can be extrapolated with a large degree of confidence to a full scale systen, the designs and operational performance goals of the full scale system. The 4 hectare pond is the minimum size that is still close enough to full module size to allow a direct transfer of results to a laraer systen. In that sense it is the optimal choice for this project. It is, however, costly. Thus the experimental system. Without the 4 hectare pond, has been desiqned to test all of the full scale systea paraneters. A greater degree of extrapolation is needed, of course, to transfer the results. Especially in the cases of mixing and carbonation, the larger pond is desirable. However, the 4 hectare ponds can be operated to simulate, in head loss and carbon storage time, the larger ponds. All of the final engineering results must be obtained from the .4 or 4 hectare ponds. 
It is not the goal of this experiment to encompass the activities of the other work carried on in the ASP. Species screening in general, biological adaptation studies, and development of resource analyses are all functions that are bevond the scope of this experiment. However. Whenever an outdoor system is operated there is an abundance of laboratory culture work and small scale test work that must accompany the demonstration experiments. Each site has its own environmental input parameters which must be studied. Each or ganism obtained from a screening program responds differently to these specific site inputs. The $1.5 \mathrm{~m}^{2}$ and $50 \mathrm{~m}^{2}$ ponds specified are for use in these support studies. A large number of the former are included because they are easy to operate and manipulate, and also inexpensive. Being outdoors they are more realistic a test system that lab cultures. The 50 in ponds oridge the qap between the small ponds and the real demonstration ponds. They do this literally by oroviding an intermediate volume for inoculum buidd-up. In addition. less expensive mock-ups of engineering designs can be tested in these ponds, vielding results which serve in the evaluation of the overall feasibility of a desiqn and thus input into the decision whether to go ahead and test at the larger scale. Two of the $50 \mathrm{~m}^{2}$ ponds are for testing basic design parameters, two being the inimur number required for controlled, simultaneous experimentation. The third is to be used to vary subsviten designs, e.g., airlift vs. paddlewhel mixing. More detail is given in Section 13 on the use of each of the pond systems.

\subsection{ALTERNATIVE SITES}

Two back up sites have been identified for the proposed experiment. Neither is as optimal. overall, as the primary site in Brawley, Ca., but each has specific advantages. One of the sites is also located in the laperial Valley, at Salton City. It borders the Salton Sea as well. The advantages of this site are that it has more presently constructed laboratory and shop space and. most importantly, an inexpensive source of $\mathrm{CO}_{2}$ fron a well. The disadvantages are that the supply of low TDS water is significantly more expensive and that the expansion potential is linited to under 8 hectares. Microbial Products. Ine. has an informal option to use this site. The second back up site is located in the area of Roswell. New Mexico. No specifie site has been selected, however conversations with personnel at the New Mexico Solar Energy Institute indicate that many sites are available. The Institute and other state agencies, as well as private concerns are potentially interested in co-funding an algae based experimental andor demonstration system. This is one of the primary advantages of this site. Water, of varying salinity is plentiful, laboratory and culture facilities are avallable for lease, and $\mathrm{CO}_{2}$ pipelines are nearby. Thus this site would appear to be the least expensive at wich to construct facility. However, the elimate is not as warm, especially in late fall and early spring, as the I pperial Valley of California. This could liait the length of the growing season. Although this may be a realistic condition for much of the southwest, an experimental facility produces data more cost-effectively when the growing season is long. In any case, the design of the proposed systen could be easily adapted to either of the alternative sites. 


\subsection{EXPERIMENTAL SYSTEM DESIGN}

Since a primary goal of the experimental system is to validate the design concepts of the large scale system, its design will closely parallel that of the ponds and harvesting systems presented in Sections \& \& 9 . Obviously, only a limited number of the more promising and important design options outlined in those chapters will be constructed, and the operation of the experimental system will focus on resolving the most important technical issues.

The proposed experimental site was described in the previous section. A nore detailed view of the actual pond site is shown in Figure 12-3. The large ponds (5 \& 10 acres) shown are for reference only, and are not included in the baseline experimental proposal. The proposed two 0.4 hectare ponds would be located in the lower middle portion of the site, as indicated on the figure. A section view of the site is shown in Figure 12-4, with approximate elevations above the Salton Sea.

In the sub-sections which follow, each element of the experimental systen is described, along with its cost, starting with the two 0.4 hectare growth ponds. In most cases, the unit costs are significantly higher than in the 192 hectare system, reflecting the 240-fold difference in total systen size. Design parameters for the single pond and the two pond system are listed in Tables 12-3*12-4.

\subsubsection{4_Hectare_Growth_Ponds: Design_and_Cost}

\section{Earthworkㅗ}

Rough grading costs were estimated conservatively pending a more detailed survey of the pond site. A local earthworks contractor quoted a price of $\$ .55 / y d^{3}$ for cutting and filling. An allowance was also made for possible diversion of the shallow gulley shown on the botton of Figure 12-3, as well as for initial site clearing. A total of $\$ 5000$ was budgeted for this category. This should also cover the additional area required for the site buildings and the settling pond. Lazar levelling will cost about $\$ 3000$ total. The $\$ 2000$ finish grading cost is actually less than in the large scale design because the liner costs (one membrane lined, one crushed rock) are listed separately. $\$ 900$ is budgeted for sump excavation.

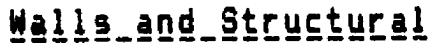

The cracking/seepage issue discussed in Section 7.3.3. Will be examined by building the divider wall and a portion of the outside wall in the unlined pond out of poured concrete. The outside wall, which has the full 20 cm of head across, it is more likely to indicate a problen, if any exists. If so, remedies, are available (e.g. covering the inside of the wall with a membrane) 


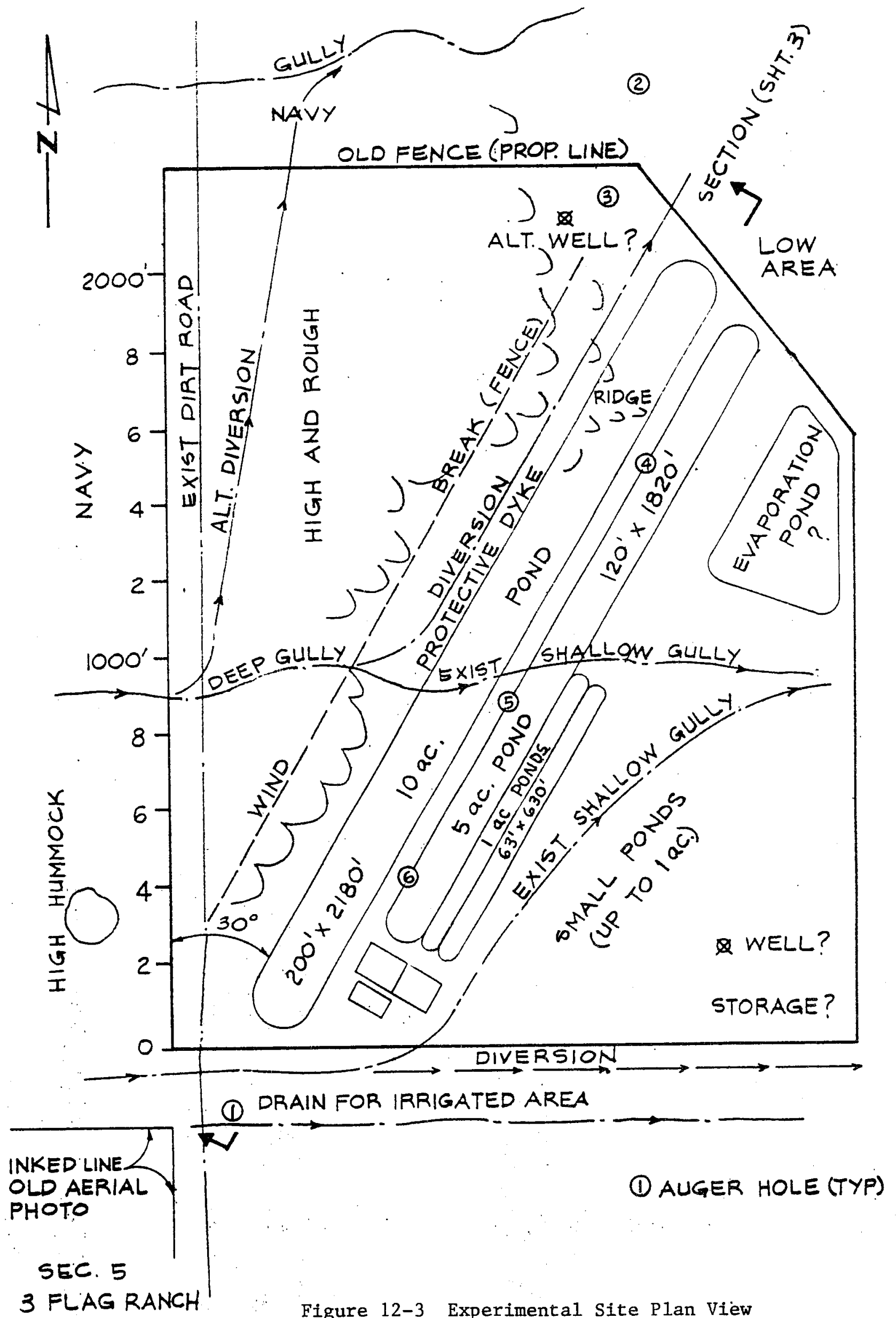




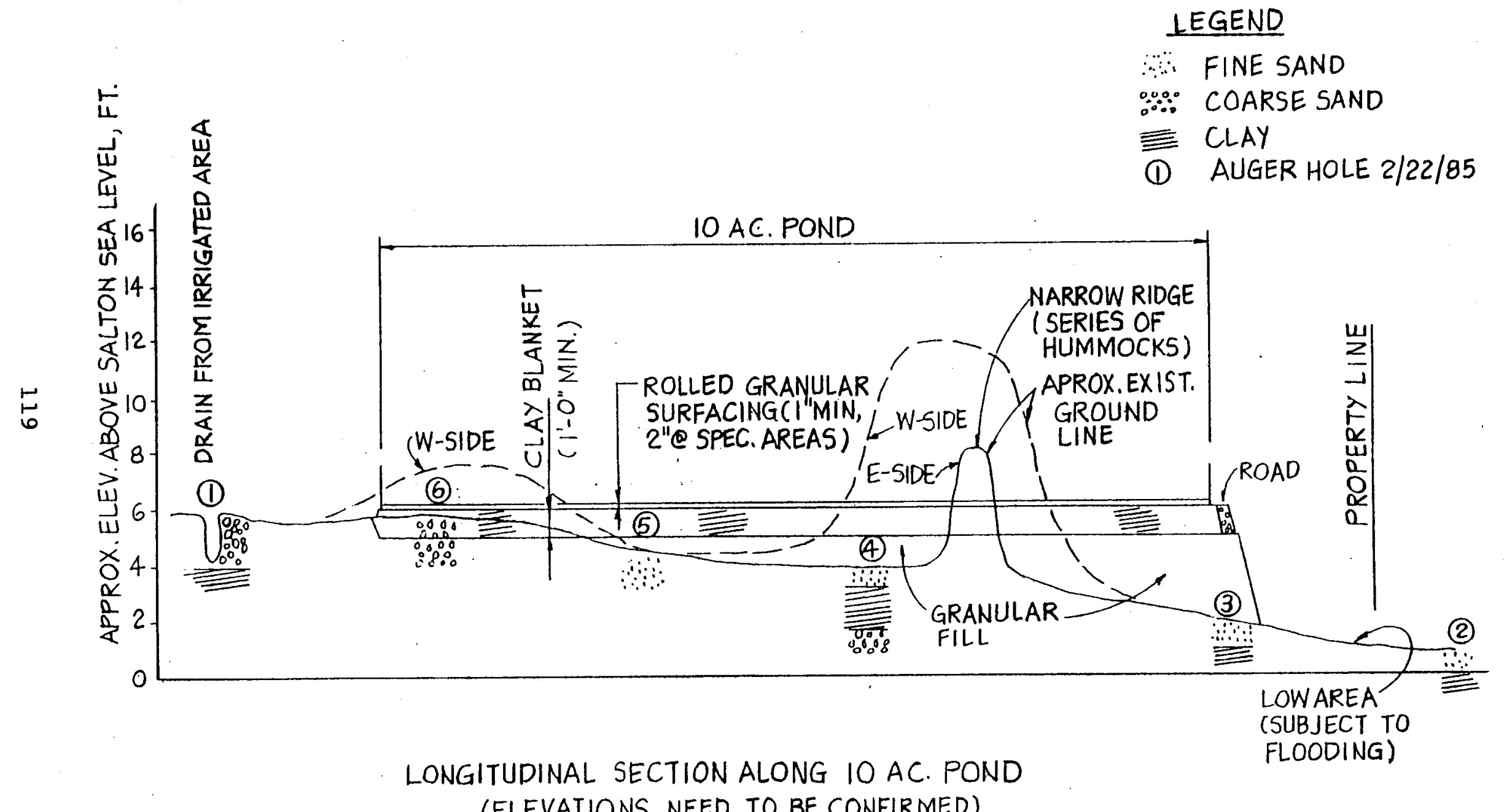

(ELEVATIONS NEED TO BE CONFIRMED) 
* INPUTS*

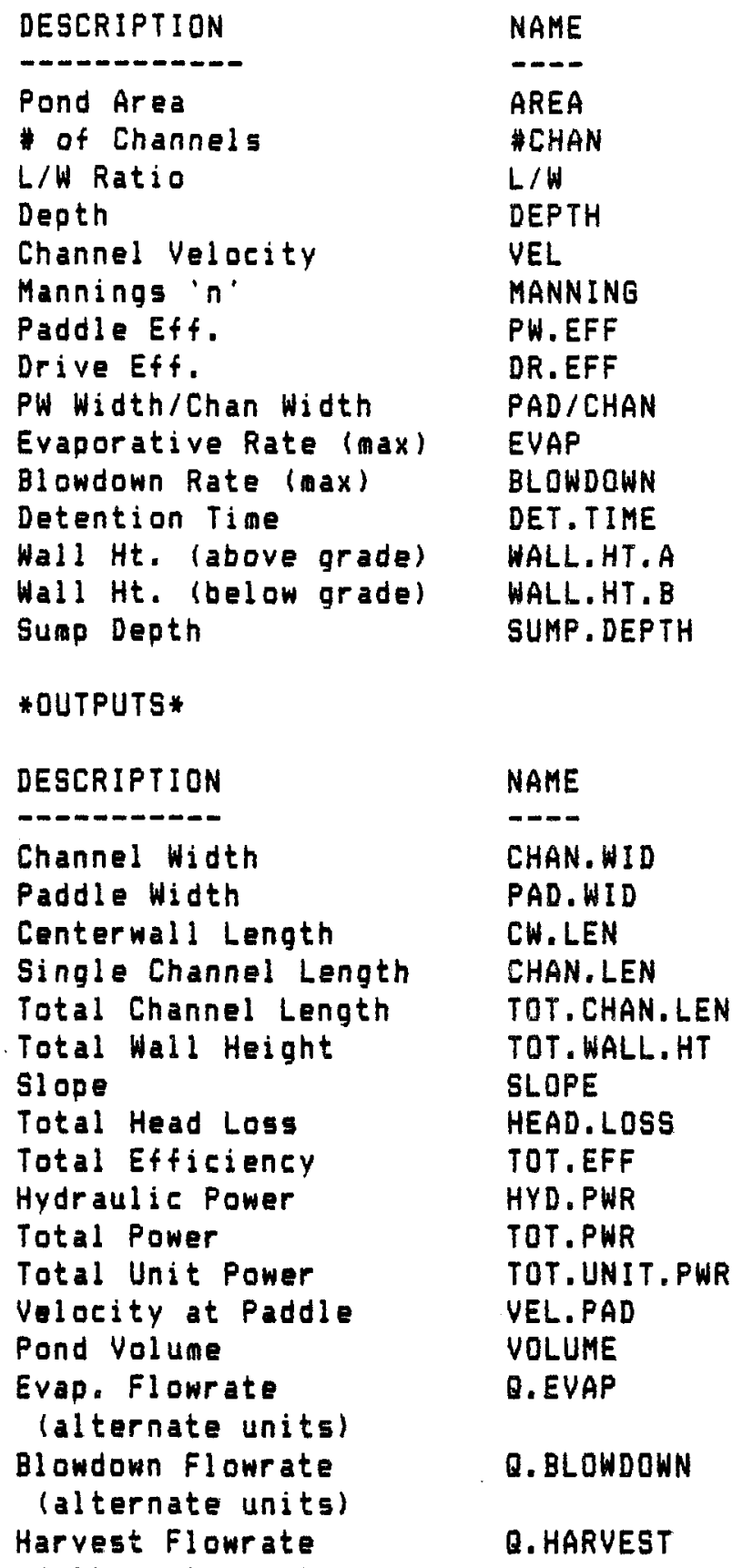

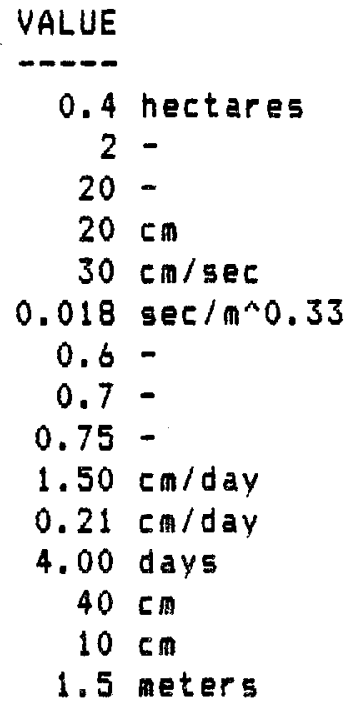

5. I. UNITS ENGLISH UNITS

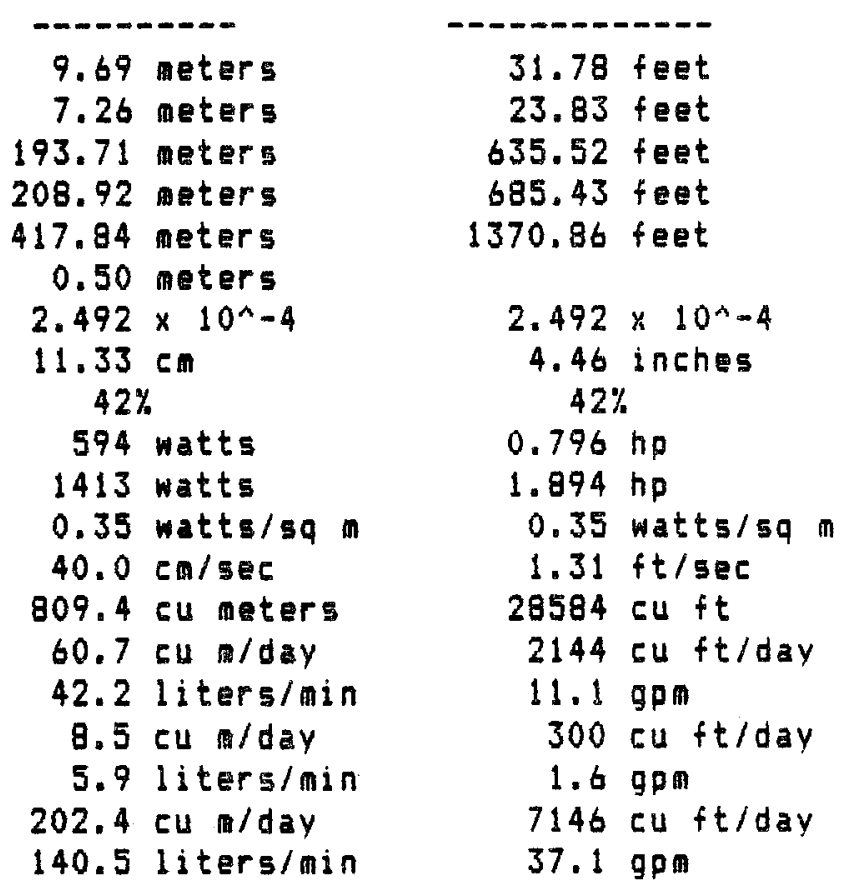




\section{Table 12-4 0.8 Hectare Fond System Desig̨n Calculations}

$$
\text { (uses input from above, as well as the following) }
$$

*INPUTS*

DESCRIPTION
Sets of Adjacent Ponds
Sonds

*OUTPUTS*

DESCRIPTION

Thand

Total \# of Ponds

Total Pond System Area

(alternate units)

Center Wall Length

Tot.Straight Wall Length

Curved Wall Length

Total Wall Length

Total Wall Area

System Pond Volume

Evap. Flowrate

(alternate units)

Blowdown Flowrate

(alternate units)

Harvest Flowrate

(alternate units)

\begin{tabular}{lr} 
NAME & VALUE \\
\hdashline$-\bar{r}$ & $-P$ \\
\#ADJ.PONDS & 2 \\
"SETS & 1
\end{tabular}

All outputs refer to the entire pond system

NAME

\#PONDS

S. AREA

S. CW.LEN

S.STR.W.LEN

S. CUR. H. LEN

S.TOT.W.LEN

S. TOT.W.AREA

S. VOLUME

S.Q.EVAP

S. Q. BLOWDOWN

S.Q. HARVEST
5.1. UNITS

- -

2

0.8094 hectares
8094 sq meters
387 meters
969 meters
122 meters
1090 meters
545 sq meters
1619 cu meters
121.4 cu m/day
84.3 liters/min
17.0 cu m/day
11.8 liters/min
404.7 cu m/day
281.0 liters/min

ENGLISH UNITS

$\begin{array}{ll}2.000027 & \text { acres } \\ 87121.38 & 5 q \mathrm{ft} \\ 1271 & \mathrm{feet} \\ 3178 & \mathrm{feet} \\ 399 & \mathrm{feet} \\ 3577 & \mathrm{feet} \\ 5868 & \mathrm{sq} \mathrm{ft} \\ 57167 & \mathrm{cu} \mathrm{ft} \\ 428 \mathrm{cu} \mathrm{ft} / \mathrm{day} \\ 22.3 \mathrm{gpm} \\ 600 \mathrm{cu} \mathrm{ft} / \mathrm{day} \\ 3.1 \mathrm{gpm} \\ 14292 \mathrm{cu} \mathrm{ft} / \mathrm{day} \\ 74.2 \mathrm{gpm}\end{array}$


to keep the pond operational. The issue is moot for the membrane lined pond since the meabrane will extend up to the top of the wall. The curved walls will be built using Dodd's corrugated panel technique. The issue of existing patents on the flow deflector vanes will be examined, and if favorably resolved, vanes will be installed at one end of the ponds. The total cost of walls and flow deflectors is $\$ 25,100$.

The sumps are identical to those described for the large scale systen in section 7.3.4. Rajls and piers will be installed installed $(\$ 3400)$, and $\$ 5000$ is budgeted for solids removal equipment, which will not be built until the severity of the problem is evaluated.

\section{Mixing Systeten}

Paddle wheels will be built, incorporating the features discussed in section 7.3.6. The paddle wheel design specifications and costs are included in Appendix III. Simce these are experimental ponds, the design is based on a maximum velocity of $30 \mathrm{~cm} / \mathrm{sec}$. The cost is $\$ 24,400$ for the two mixing systens.

\section{Carbonatatign}

Carbonation efficiency is a key technical issue to be studied in the experimental system. The 0.4 hectare ponds, with their full-scale sized sumps, will provide data which can be extrapolated to larger ponds with confidence. The cost of the two carbonation systems is $\$ 7000$, which includes the $\mathrm{pH}$ controller and associated instrumentation.

\section{Ling 1 g}

One of the ponds will be lined with a good quality membrane liner (Hypalon or CPE), while the other will be lined with a 0.3 meter $(1 \mathrm{ft})$ clay base topped with a thin layer of crushed rock, rolled to a smooth finish. The clay is necessary because of the sandy soil at the pond site, and is available on-site for the cost of hauling. The crushed rock liner is an important cost saving feature of the large scale systen which needs to be evaluated. The relatively long channels will allow accurate head losg measurenents to be made, from which roughness coefficients can be determined.

\section{Summaay}

A sumary of the construction costs for the two 0.4 hectare experimental ponds is presented in Table 12-5. 
Table 12-5 0.8 Hectare Experimental System Pond Costs

\begin{tabular}{cc} 
INSTALLED COST FOR & 0.8 HECTARE SYSTEM \\
\hline PONDS & 0.4 HECTARES EACH
\end{tabular}

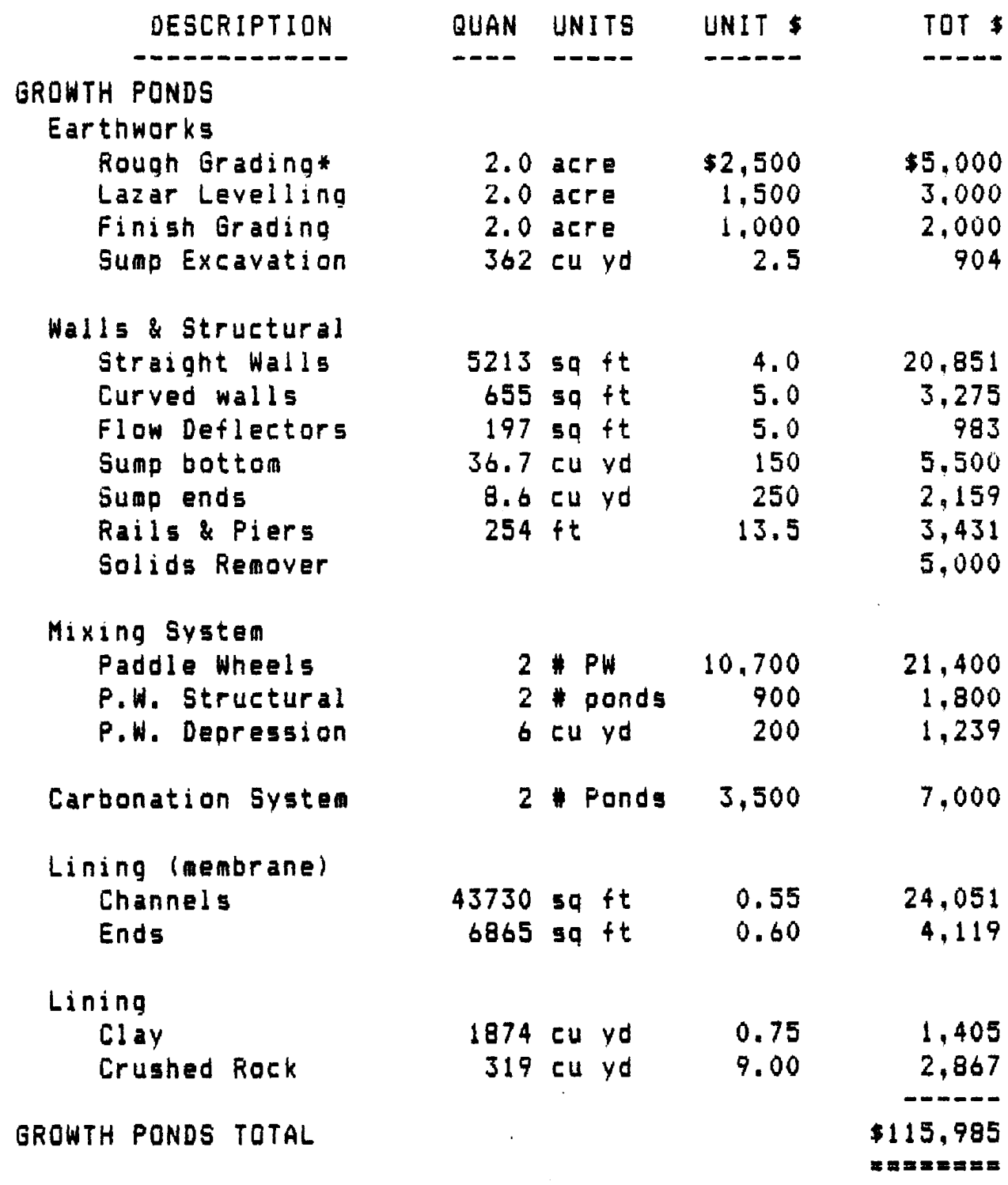

* Includes drainage diversion site clearing 


\subsection{2_ 50_59_meter_E_Exerimental___Ponds}

Three $50 \mathrm{~m}^{2}$ experimental growth ponds will be constructed for biological and small scale engineering studies. Two of these will be aixed with paddle wheels, one with an air lift. All three ponds will be lined. The cost breakdown for these ponds is shown in Table 12-b.

\section{Table 12-6 $50 \mathrm{~m}^{2}$ Pand Costs}

Site Peparation (levelling, etc):

Walls: $430 \mathrm{ft} \$ 8 / \mathrm{ft}$

Sumps: $3 \times \$ 500$

Mixing Systems (2 P.W., 1 air $1 i f t)$ :

Carbonation: $3 \times \$ 2000$

Submersible Pumps: $2 \times \$ 300$

Drains, piping: $3 \times \$ 800$

Misci:

TOTAL, 3 Ponds
$\$ 1000$

3440

1500

5250

6000

600

2400

1500

$-2--$

$\$ 23,040$

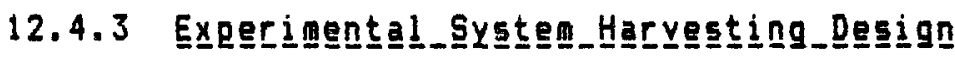

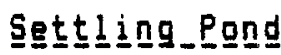

In order to validate the settling pond concept, a settling pond sized for the volume of a 0.4 hectare growth pond will be constructed. Rather than building a scaled down version of the large settling ponds of section 8 , the experimental settling pond will be an almost full scale version of one of the channels in the larger pond. The depth, width, and length will be approximately $80 \%$ of full size. An identical $2 \%$ botton slope will be used. This pond will allow meaningful evaluation of settling characteristics and proposed concentrate collection system of the large pond. The side walls will be made as steep as possible (possibly lined with gunnite instead of a membranel in order to reduce "edge effects." Two 20,000 liter tanks, with sloped bottoms, will be used for secondary settling, flush storage, and for primary settling tests with the $50 \mathrm{~m}^{2}$ ponds. Figure $12-5$ shows the proposed settling pond systen, while Table 12-7 lists its cost. 


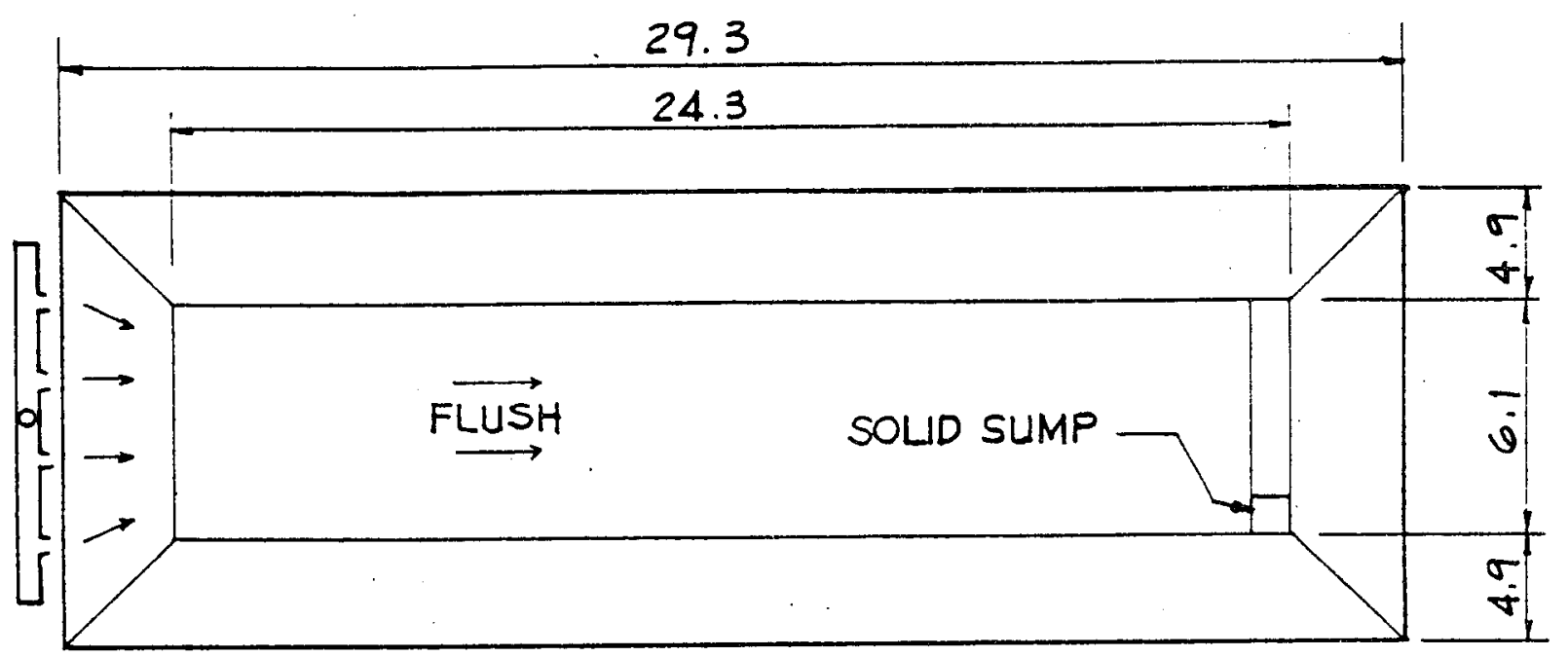

PLAN VIEW

(Dimension in meters)

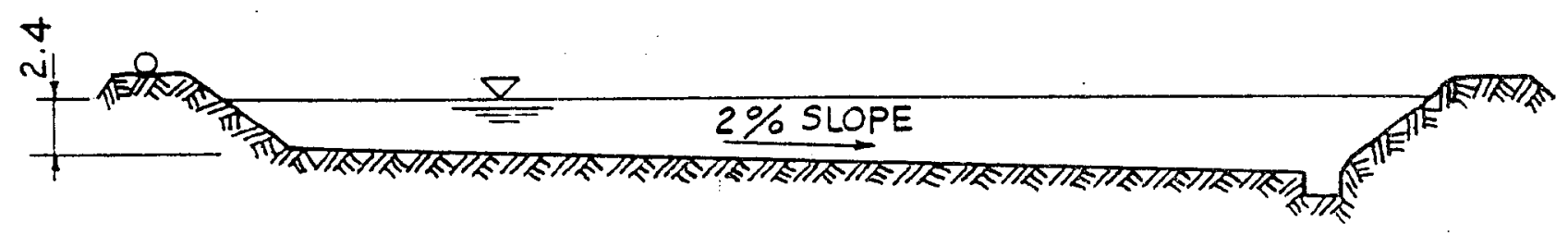

SECTION VIEW

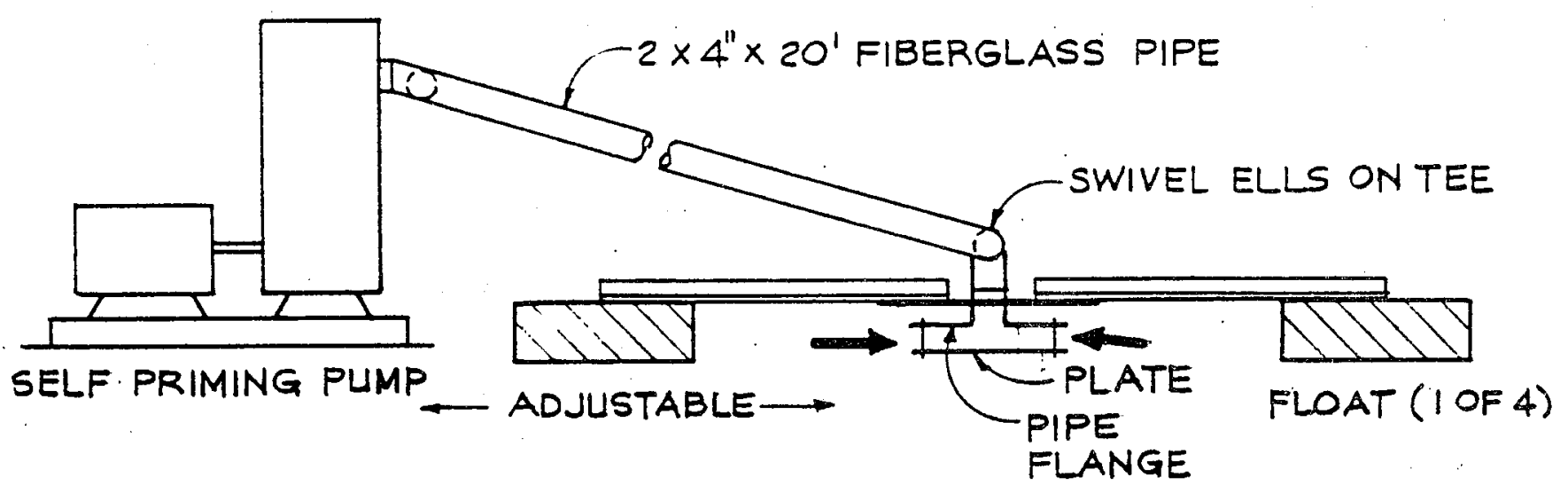

SUPERNATANT DECANTER DETAILS

Figure 12-5 Experimental System Sett1ing Pond 
Table 12-7 Experinental Systea Settling Pond Cost

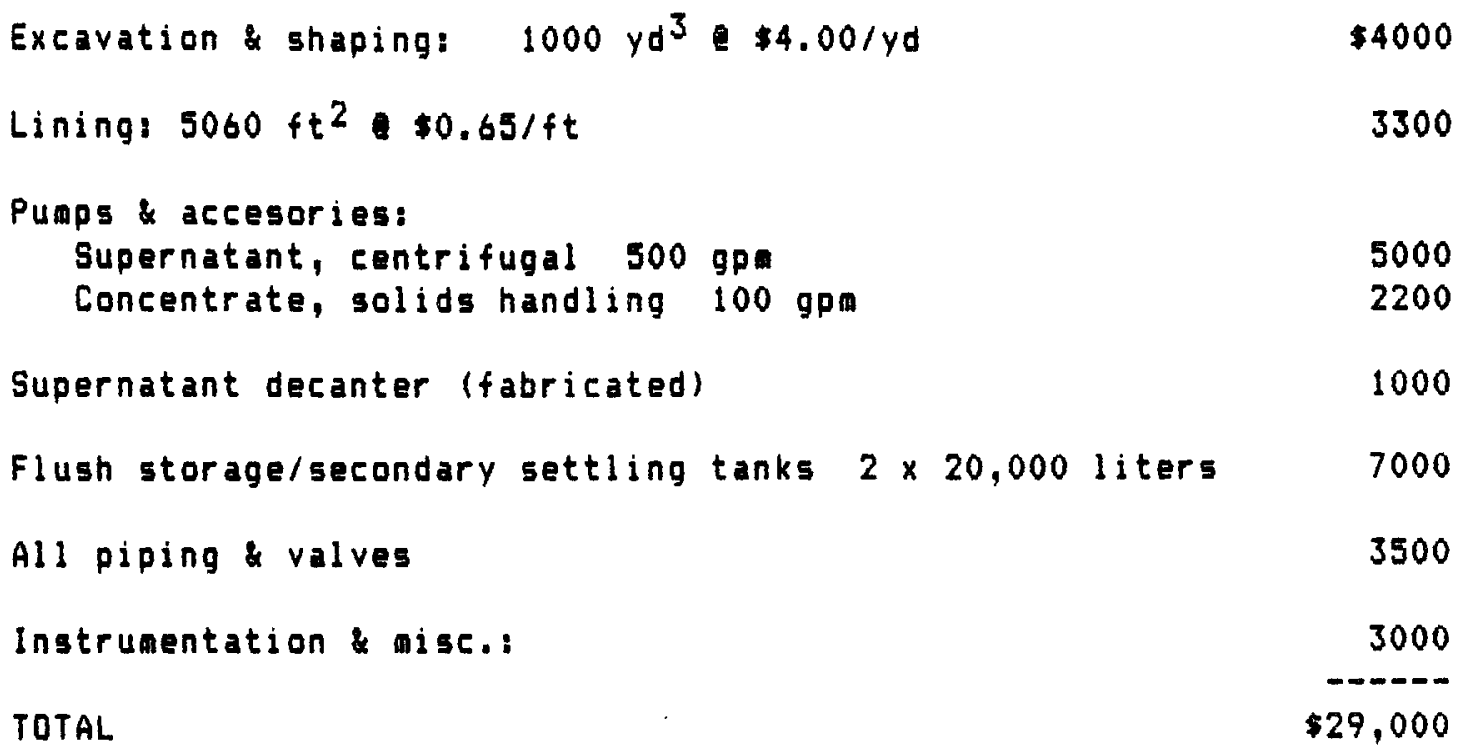

\section{Altternative_Harvesting_Design}

A total of $\$ 30,000$ has been budgeted for the development of an alternative harvesting method, which would be either belt filtration or air/Do

floatation. The belt filter was discussed in Section 8 . Although a pilot scale unit would probably cost more than $\$ 30,000$, there a possibility of purchasing the unit built by Dodd in singapore. The other alternative is to develop a air/DO floatation separator, which operates in much the same fashion as a dissolved air floatation, but uses fine bubble spargers in conjunction with the release of dissolve oxygen to float the algae to the surface. Low doses of polymer are used to enhance coagulation. A budjet of $\$ 30,000$ should be sufficient to develop a reasonable sized experimental unit.

\section{Center $\underline{\text { f }}$ ugge}

An additional $\$ 30,000$ is budgeted for the purchase of pilot scale centrifuge, since centrifugation is likely to follow any primary harvesting process. A small horizontal solid bowl unit can be purchased for this amount, from which the necessary scale-up data data can be compiled. Alternatively, a larger unit, many of which are available on the used equipment market, could be purchased. 


\subsection{Systen-wide Costs}

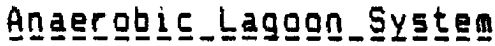

An covered anaerobic lagoon will be constructed to test the feasibility of nutrient recycling, and to stabilize algal solids before disposal. The lagoon will significantly reduce the quantity of solids to be dried and disposed of. Although there are no plans for utilization of the methane produced (since suitable engine-generators are quite expensive), the lagoon's performance will be monitored. A rough estimate of $\$ 20,000$ was provided by the consultant who designed the anaerobic lagoon system for the large scale system, for a lagoon sized to handle the thickened effluent from the 0.4 hectare ponds.

\section{Water_-Sugely}

An existing well at the proposed site has ample capacity to provide groundwater to the pond system. The cost of piping this water from the well to the pond site was estinated at $\$ 23,500$. An additional $\$ 10,000$ is budgeted to construct a shallow well near the Salton Sea as a source of highly saline water. With these two sources, a wide range of salinities can be formulated.

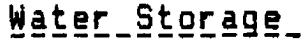

A lined water storage pond will be constructed as part of the water supply system. The pond will also serve as a settling pond for water treatment. The design and dimensions of the water storage pond is shown in Table 12-8.

\section{Water_and_Carbon_Díx}

Most of the piping for the experimental system is contained within a small area at the head of the growth ponds. \$1500 is budgeted for water distribution to the experinental ponds and settling pond. The $\mathrm{CO}_{2}$ will come from a rented storage tank. The carbonation system itself is included in the pond cost (Table 12-5). Most nutrients are added in salt form directly into the pands, or in some cases, are dissolved in a small mix tank and pumped. Nitrogen will be added as aqua-ammonia from a storage tank (these are normally rented). A total of $\$ 3500$ is budgeted for mix tanks, piping and valves associated with $\mathrm{CO}_{2}$ distribution and nutrient additions.

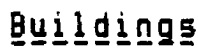

The offices, lab, and culture rooms will be located in rented trailers, with the exception of a small "lab annex", which contains balances and other 


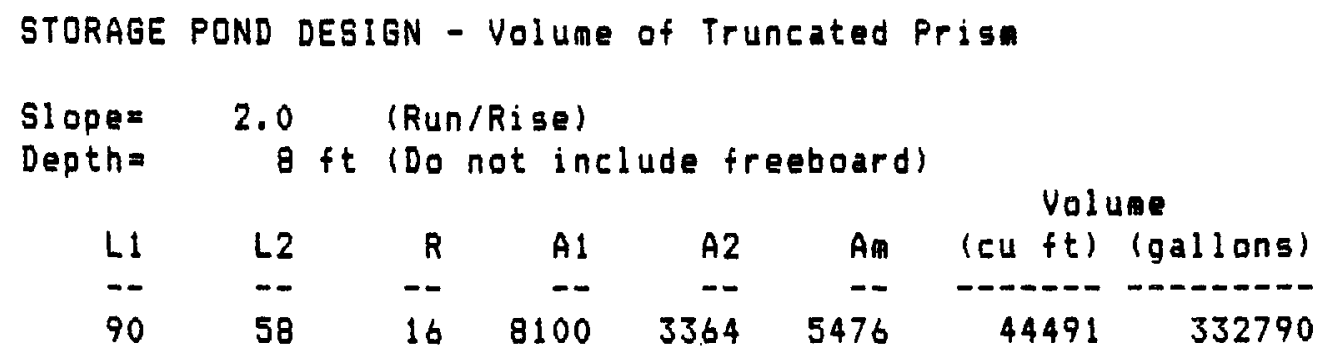

Fron table above:

$\begin{array}{ll}\text { Slopes } & 2 \text { (run/rise) } \\ \text { Depth } & =8 \mathrm{ft} \\ \text { LI } & =90 \mathrm{ft}\end{array}$

Computations:

Length at top of berm

Length of botton

Area of bottom

Area of botton liner

Side panel height, to waterline =

side panel height, total =

Side panel area (based on total) =

Area of all four side panels =

Total liner area
Additional design parameters:

Desired freeboard $=1 \mathrm{ft}$

Addl. liner beyond

top of berm $=2 \mathrm{ft}$

COST:

Excavation berms: $\quad 862$ cu yd $\$ 3 / c u$ yd $=$

Liner:

$9444 s q \mathrm{ft} \quad \$ .60 / 89 \mathrm{ft}=$

5666

Misc.:

TOTAL 
instruments that must be on more solid ground. Additional buildings include a shop and centrifuge/chemical storage shed at the pond site. The cost of buildings is shown in Table 12-9.

Table 12-9 Experimental System Buildings Cost

Lab annex: concrete floor, air conditioned, $350+t^{2} \$ \$ 30 / f t^{2} \$ 10,500$

Shop: concrete $f 100 r, 1000 f t^{2} \$ 15 / f t^{2} \quad 15,000$

Centrifuge shed, concrete $f 100 r$, one side open, $500 \mathrm{ft}^{2} \mathrm{\$} \$ \mathrm{ft} \mathrm{t}^{2} 4,000$

TOTAL

$\$ 29,500$

\section{Rog $\underline{\underline{B} \mathrm{~d}} \mathbf{5}$}

A small amount ( $\$ 2500)$ is budgeted to extend an existing dirt road to the proposed pond site.

\section{Instrumentatiggn}

This category covers the cost of instrumentation not already included in other categories, (e.g. solar monitor, pond temperature and level sensors, power measuring equipnent, etel and for a microconputer-based data aquisition system. Ultimately, the system could be used to automate various pond operations, as most of the package data aquisition systems have digital output lines that can be used to open valves, turn on pumps, etc. A total of $\$ 15,000$ is budgeted for this category.

\section{El}

The cost of electrical distribution and wiring is normally estimated as a percentage of total capital costs. For a relatively small project such as the proposed experimental system, $5 \%$ is typical.

\section{Machingery}

A total of $\$ 15,000$ is budgeted for machinery, to cover the cost of a pick-up truek, shop tools and equipment. 


\section{Engínęering}

The engineering budget, $5 \%$ of capital costs, or about $\$ 20,000$ is to cover the cost of any outside engineering (e.g. surveying, drafting, soils analysis) required for the construction of the ponds. Most of the engineering will be done in-house, and is included in the operating cost budget in the following section.

\section{Gontinggency}

A 10\% contingency is included to cover unforseen costs and unusual circumstances.

\subsubsection{Summary_of_Const_ructign__Costs}

A summary of all construction costs for the proposed experimental facility is given in Table 12-10 The two 0.4 hectare growth ponds account for about 25\% of the total, the 5 mall ponds about $7 \%$, the harvesting systens about $20 \%$, systen-wide costs about $33 \%$, engineering $5 \%$, and contingency $10 \%$ 
Table 12-10 Experimental Facility Construction Cost Summary

Earthworks*

Walls \& Structural

Mixing System

Lining (1 membrane, 1 crushed rock)

GROWTH PONDS - $3 \times 50$ sq meter

$-6 \times 1.5$ sq meter

HARVESTING

Settling Pond System

Air/Do Floatation

Centrifuge

SYSTEM-WIDE COSTS
GROWTH PONDS: $2 \times 1$ acre

Carbonation System

TOTAL \$

- - - - -

$\$ 10,904$

41,199

24,439

7,000

32,443

23,000

9,000

29,000

30,000

30,000

20,000

23,500

10,000

8,600

1,500

3,500

29,500

2,500

15,000

17,554

15,000

19,182

ENGINEERING (5\% of above)

40,282

- - - -

$\$ 443,103$

$\mathrm{x}=\mathrm{x}=\mathrm{z}=\mathrm{z}$ 
SECTION 13.0

EXPERIMENTAL SYSTEM OPERATION AND COSTS

\subsection{INTRODUCTION}

The work plan and work schedule are presented below for the construction and operation of the experimental system. The plan is broken down into individual tasks, each describing an essential aspect of construction or operation. The schedule follows, with each task assigned a time span for completion. The cost of labor, equipment, supplies, and overhead is then delineated. The final budget, including construction and operating costs, follows this section

\subsection{SYSTEM CONSTRUCTION}

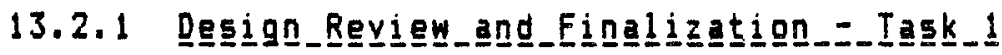

The design, and any changes made during the review process, must undergo a final review for insertion of detail and finalization of the construction schedule. This work would actually be done primarily before a contract start date and continue during the first month.

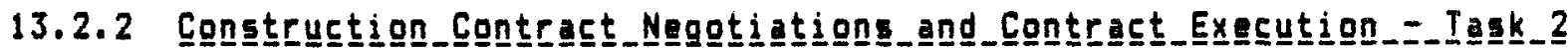

Concurrent with Task 1, during the first month of the project, construction contractors will be sought and interviewed. After the solicitation of bids and negotiations, a final construction schedule will be drawn up and any variation from the initial budget reviewed.

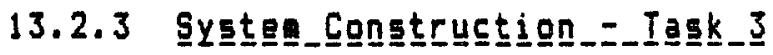

Contingent on the weather, the construction of the entire proposed systen would take four months. The acquisition of trailors for office space, the construction of storage and utility buildings, and earthworks will be done during the first of these four months. After laying water and power lines, the systen itself will be constructed. 


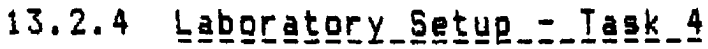

During the eighteen month contract period, the laboratory will be set up primarily in trailors. Acquisition of trailors and installation of laboratory equipment will begin once the site utilities are in place and the earthwork completed. Some of the laboratory equipment will have to be housed in a small pre-fabricated building on a concrete slab for stability. As soon as possible thereafter, a laboratory technician will be hired to initiate the algal culture collection and prepare for growth of inoculum. The $1.5 \mathrm{~m}^{2}$ ponds will be operational at this time.

\subsection{EXPERIMENTAL PLAN}

\subsubsection{Water_Resgurce﹎Experiments - Iask_ 5}

The water resource is an important paraneter of the overall systen. Since it is yet of rather undefined composition, the experimental system nust be flexible enough to test a wide variety of water resources. The two water resources available at the proposed site provide this flexibility when combined with water conditioning. The salton Sea provides the sodium chloride needed to achieve any conceivably useful TDS. It can be diluted with the well water to achieve any intermediate salinity allowing the systen to be operated at almost any blow down ratio. The calcium concentration is very high in the salton sea, so that some water softening is required. The magnesium level is also high. Conditioning will be done with soda ash for calcium removal, and with lime and soda ash for removal of both. input stream splitting will allow adjustment of both to different degrees. Still, the waters composed in this anner may only approximate specified water resource characteristics. It should be noted that these specifications are only averages so that precise duplication is not realistic. However, the small ponds, $1.5 \mathrm{~m}^{2}$, and laboratory cultures can be used to formulate and test any given water coaposition. As of now, the water resources of interest are Type Il concentrated eight fold and seawater. The following experiments will be performed regarding water chemistry and algal growth on these naters.

A. Water Conditioning

1. Cost of conditioning vs aount renoved and efficiency

2. Precipitate removal by settling

3. Precipitate formation, after initial conditioning, upon additional concentration 


\section{B. Water Chenistry}

1. Identification of species precipitating and remaining ion composition, by outside analytic laboratory

2. Approximate determination of inorganic carbon reaction equilibriua constants by inflection points in titrations. Determination of carbon storage capacity as a function of $\mathrm{pH}$ change.

C. Controlled Tests of Algal Growth on Waters Used

1. Bottle tests in laboratory, with Type II water as control for the growth of the lipid containing strains like Chryso/fl and Cheatoceros

2. Growth tests in $1.5 \mathrm{~m}^{2}$ ponds with Type II water as control for Chryso/fl (or other promising lipid producer) and seawater as control for growth of Platymonas.

D. Media Recycle

1. Prelininary media recycle experiments will be conducted in the 1.5 and $50 \mathrm{~m}^{2}$ ponds to determine the minimum blow down ratio that is feasible. These experiments will be done for one month at a timne, which is short in terms of what must be actually practiced in a real system, but long enough to assess feasibility.

2. All experiments in ponds of 44 hectare size will be performed with media recycling. This is necessary for minimizing the operational cost of these experiments and crucial for assessment of the utiliization of saline groundwaters in any practical system which is to be operated in the arid areas of the U.S. Southwest. Productivity and species dominance as a function of the duration of cultivation on recycled mediun are the main factors to be analyzed.

\section{3 .2 Carbonation_Systega_Iestg_=_Iask_b}

Although in-pond sump were specified for carbonation in the large $5 c a l e$ design, both sumps and covered area carbonators will be tested in the experimental system. Sumps, however, will be provided in the larger experimental ponds, being the primary method. Covers will be added later if the results from $50 \mathrm{~m}^{2}$ ponds are positive. The carbonation tests will be extensive and will be done prior to inoculation in both freshwater and media. The specific tests follow.

A. Sump Carbonation

1. Stripping rate per unit depth of sump

a. versus sump liquid depth

b. versus the ratio of gas flowrate to liquid flowrate

c. versus sparger type (initial bubble size) and gas flowrate 
2. Overall transfer efficiency in 1.5 an deep sump

a. versus sparger type

b. for co-current, lateral, and counter-curpent flow

3. Performance of gas recycle, if necassary

8. Covered area carbonator

1. Overall transfer efficiency for given area of cover

2. Effect of water velocity under cover

3. Efficiency of ripole cover

C. Effect of algae and supersaturated oxygen on trangfer efficiancy

1. Measure $\mathrm{CO}_{2}$ transfer and $\mathrm{O}_{2}$ out

2. Determine if algae excretion products enhance transfer

Dissolved oxygen can be measured using an Orion Do probe and checked with the Winkler method. Carbon uptake can be measured by calculating the change in total inorganic carbon from pH change and the carbon equilibrium equations.

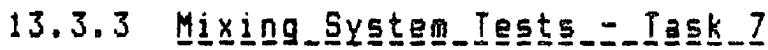

Although many paddlewhel systems are now used for fixing algal cultures, there is little data on the actual efficiency obtained in large ponds. Less data is available concerning airlift mixing systems for low head, low velocity systens. Thus it will be important to determine just how well these different options perform. Since the primary syster to be installed in the experimental ponds is the paddlewheel, airlift aixing will be tested initially by sparging air into the carbonation sumps adapted for the purpoge by installation of a baffle. Measurenents will include head loss and various power numbers as a function of water velocity. In addition, $\mathrm{CO}_{2}$ outgassing will be neasured as a function of mixing speed. If the parameters determined for airlift nixing are favorable, a oraft tube system for ajrlift will be designed and installed in a $50 \mathrm{~m}^{2}$ pond for testing. Scale-up to it ha will depend an the evaluation of results and budget constraints.

The parameters determined from the capbonation tests and the airlift mixing tests will be used to evaluate and design a combined gaslift and carbonation system. The calculations will be performed for a flue gas system thigh gas flow rates), a diluted $\mathrm{CO}_{2}$ gas phase $\left(35 \% \mathrm{CO}_{2}\right.$, at three times the $\$ 10$ w rate of a pure $\mathrm{CO}_{2}$ systen), and for pure $\mathrm{CO}_{2}$ (low gas flow case).

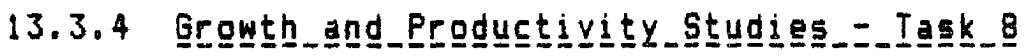

Studies on the growth and productivity of the algae will be performed in the $1.5 \mathrm{~m}^{2}$ and $50 \mathrm{~m}^{2}$ ponds. The best conditions will be scaled up to the .4 ha ponds for validation of the full scale design. Both indoor bottle cultures and the $1.5 \mathrm{~m}^{2}$ cultures provide a convenient means to test quickly a moderate number of factors and values. Initial work indoors usually indicates whether a factor is important or not, except for those that depend 
on high light intensity. For these the outdoor small ponds work well. Thus media optimization studies can be performed indoors, while pH and DO work is best done outdoors. Since the mixing regime in small pond does not simulate that in a larger one, the initial results obtajned at the small scale need to be tested, in the short and long term, at the $50 \mathrm{~m}^{2}$ and.4 size. Factors to be tested for affect on productivity include $p H, D O$, alkalinity, temperature, batch detention time, continuous vs batch operation, and nitrogen depleted productivity and storage product accunulation. Routine measurements include $\mathrm{pH}$, temperature, $\mathrm{DO}$, insolation, $\mathrm{CO}_{2}$ input and biomass density. Chenical composition is measured as required to determine lipid productivity. Since correlation of productivity with various parameters is often a useful evaluative tool, much data needs to be taken and stored in an organized manner. A computer automated data acquisition system will be installed for this. In addition, with this in place, the status of productivity in a pond can be determined approximately on-line, without having to wait for cell density measurements, by monitoring the $\mathrm{CO}_{2}$ input and the $\mathrm{pH}$. When corrected for injection and outgassing losses, $\mathrm{CO}_{2}$ input is proportional to productivity.

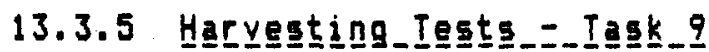

Two harvesting aethods will be tested in the operation of the experimental systen: flotation followed by foam collection and slow primary settling in large settling ponds followed by secondary settling in saall tanks. Both aethods will be followed by centrifugation to provide a final product at 10\%-20\% volatile 50lids. The biomass to be separated will be nitrogen starved and flocculated with small doses of high olecular weight polymers. Polymer flocculation is an important feature of the harvesting process. On site polymer flocculation tests will be conducted with the aid of

consultants. The hypothesis being tested is that polymers can be tailored to the specific needs, i.e., chemical medium and algal type, while still naintaining enough versatility to function as univerally effective flocculant. The collection method, sedimentation or flotation, will be evaluated in terms of flocculant type and dose required to achieve efficient and reliabe separation and concentration. The dose of flocculant must not exceed the equivalent of $\$ .02$ per $\mathrm{kg}$ dry biomass, and preferably half that. For gas flotation studies, some testing will be done right in the ponds. The density of biomass leaving the flotation station will be used to calcualte the harvesting efficiency. This will be measured as a function of pond $D O$, biomass density (since several passes through the harvester will be made; each with lower inconing biomass density), $\mathrm{CO}_{2}$ input, duration of nitrogen depleted growth, and flocculant dose.

Unharvested biomass will re-enter the nitrogen sufficient growth phase. Thus it will be necessary to test strains for the ability to quickly absorb newly introduced nitrogen and enter an active growth stage. 
The sedimentation tests will be performed in two phases: cell settling and sedimented slurry removal. The settling rates of the biomass will be measured as detailed previously [1] in indoor tests, with and without flocculant. When the velocity for most of the biomass exceeds $30 \mathrm{~cm} / \mathrm{hr}$, the pond will be fed flocculant and pumped into the settling basin.

Sedimentation time will be determined on the basis of equivalency to settling $3 \mathrm{~m}$ in 10-15 hrs. After decanting the supernatent, the slurry recovery system will be tested for efficiency and rate of slurry removal. Then the rate of thickening in tanks will be determined.

Centrifugation tests are important at this point to determine the throughput and hence the size and number of centrifuges needed at the large scale. Centrifuge vendors are available to test the characteristics of the biomass slurry and consult on centrifuge selection and operation.

Once the harvesting parameters have been determined with biomass from $50 \mathrm{~m}^{2}$ ponds, the process will need to be validated using the large growth and settling ponds. The latter have been designed to equlate directly the solids removal system specified for the full scale design. The experimental settling pond is a "slice" of the full scale settling pond, having the same characteristic dimension for solids flushing.

13.3 .6 Digestign_of_Bionass_in_z_Covered_Lagogn_for_Nutrient_Recyeling_Tests_ $=-1 \mathrm{a} a \underline{k}+10$

A small, covered lagoon will be constructed to digest, anaerobiaclly, the biomass harvested from the large ponds. These tests will be somewhat artificial in that the "pretreatment" due to lipid extraction will be absent. The results will still be extremely valuable in acertaining how the biomass components, that do degrade, partition in the lagoon. This information is necessary to validate the assumption upon which the extensive recycling of carbon, nitrogen, and phosphorus was based. The lagoon has been sized to accept the total biomass harvest of a one acre pond. The tests will provide the data necessary for evaluating the system's capability of producing a methane fuel product.

\section{3 .7 Linger_Eva}

A significant capital cost savings incorporated into the large scale design is the use of clay sealer and crushed rock overburden for pond lining. One of the 4 ha ponds, and the 4 ha pond if constructed, will be lined in this manner. The liner nust be evaluated, over the longterm, for water loss and buildup of deleterious organic solids. This nust be done in a large pond in which the hydraulics are similar to a full scale pond. The other 4 ha pond will be lined with a high quality plastic liner and serve a control, as well as a test of the endurance of such a liner under field conditions. All of the $50 \mathrm{~m}^{2}$ ponds will be similarly lined. 


\subsection{OPERATIONS SUMMARY AND EXPERIMENTAL PRIORITIES}

The proposed system consists of $5 i x 1.5 \mathrm{~m}^{2}$ ponds, three $50^{2}$ ponds, and two 4 hectare ponds. A 4 hectare pond would yield results directly transferrable to large systems, but it is not cost effective research at this time. The $1.5 \mathrm{a}^{2}$ ponds are to used for initial screening of promising algal species under outdoor conditions of temperature and irradiance. Media and growth parameters will be determined in these sall ponds. The $50 \mathrm{~m}^{2}$ ponds will be used to test the various subsystem designs (carbonators, aixing systems, air flotation, sedimentation systems) at a scale which will indicate feasiblilty at lowest experimental cost. These ponds will also be used for growth studies and to provide inoculum for the 4 ha ponds. The latter will serve as the primary testing facilitiy for valjdation of the large scale design over longter operation. As far as validation of the large scale dasign, the highest priority experiments are those which determine the utilization efficiency of $\mathrm{CO}_{2}$, including mass transfer coefficients and losses throughout the system; those which test cost effectiveness of methods for primary concentration of the algal suspension, including polyaer flocculation tests and evaluation of collection device performance and cost (settling ponds, flotation devices); use of an inexpensive anaerobic lagoon for recycling nutrients (especially carbon) that would not be removed in the product stream, including the partitioning of these nutrients in recoverable fractions of the lagoon; evaluation of the pond lining alternatives, nost importantly the water losses when plastic liners are not used and the endurance of each of the liners; and the effect of longtern sedia recycling on system performance.

The bionass and lipid productivity goals will be evaulated, but attainment of these goals is substantially dependent upon provision of strains pre-screened for the ability to produce lipid. A preliminary choice of strains include the high lipid producing Chryso/fl, a productive and potentially high lipid producing strain of Chaetoceros, and the Hawaijan Platymonas for use as a biomass productivity standard. The possibility of removing photosynthetically produced oxygen from the pond mediun will be examined--no determinationn is possible prior to experimentation--and the effects of such removal on productivity will be studied.

Two important growth characteristics of the organisms will be scrutinized during this experiment. First is the ability to recover quickly fron nitrogen starvation after addition of new nitrogen into the medium. This involves resistance to photo-oxidation and photo-bleaching in already depigmented cells. Second is the ability to maintain high productivity in a mediun that has undergone extensive recycling. This usually means that the organism must not excrete organics into the mediu in significant quantity. 


\subsection{EXPERIMENTAL SCHEDULE}

Fiqure 13-1 lists the eleven tasks described above and shows the anticiapted schedule of completion. Many of the tasks are of an onooing nature, with periodic evaluation. Task 12, data evaluation and reporting, is indicated on the figure.

\subsection{BUDGET DESCRIPTION}

The complate budqet 15 given at the conclusion ot this section. The elements of the budoet are described in Tables 13-1,2.3. and 4. Table 13-1 qives the cost of pond equipment. These items were included in the total pond construction costs oiven in Section 9.0. The costs 1isted in table 13-2, are for laboratory equipment. Iwo cost colunns are included in this table. The tirst quves the cost of acquiring new equipment as specified. Those items which are owned by Microbial Froducts, Ine. or are government owned but, at present avallable for use by Microbial Products, Inc. Will be made available for use on this project. Thus the second column lists the cost of equipment which must be purchased for this project. The supplies and materials lother than those used in constructing the pond system) are detailed in Table 13-3. The costs shown are based on vendor quotes or on previous experience. At the experimental scale, nutrient costs are high because quantities are relatively small. The breakdown of direct labor costs is given in Table 13-4. The time alotments are in equivalent full months of work, not by scheduled work time. The budget form that follows at the end of this section gives the total project cost for the eighteen month effort, including overhead and fee.

\section{Table 13-1. Experimental System - Pond Equipnent}

$\begin{array}{lr}\text { Motors, speed reducers for d acre ponds } & \text { Cost } \\ \text { pH controllers, } 2 & 4800 \\ \text { Flowmeters, } 5 & 1450 \\ \text { Motors. controllers, small ponds } & 1500 \\ \text { Pumps.5 } & 8100 \\ \text { Centrituge, harvest } & 30000 \\ \text { Air/Do, harvest (partial) } & 5000 \\ \text { Computer, interfaces } & 15000 \\ & \\ \text { Total } & 67850\end{array}$




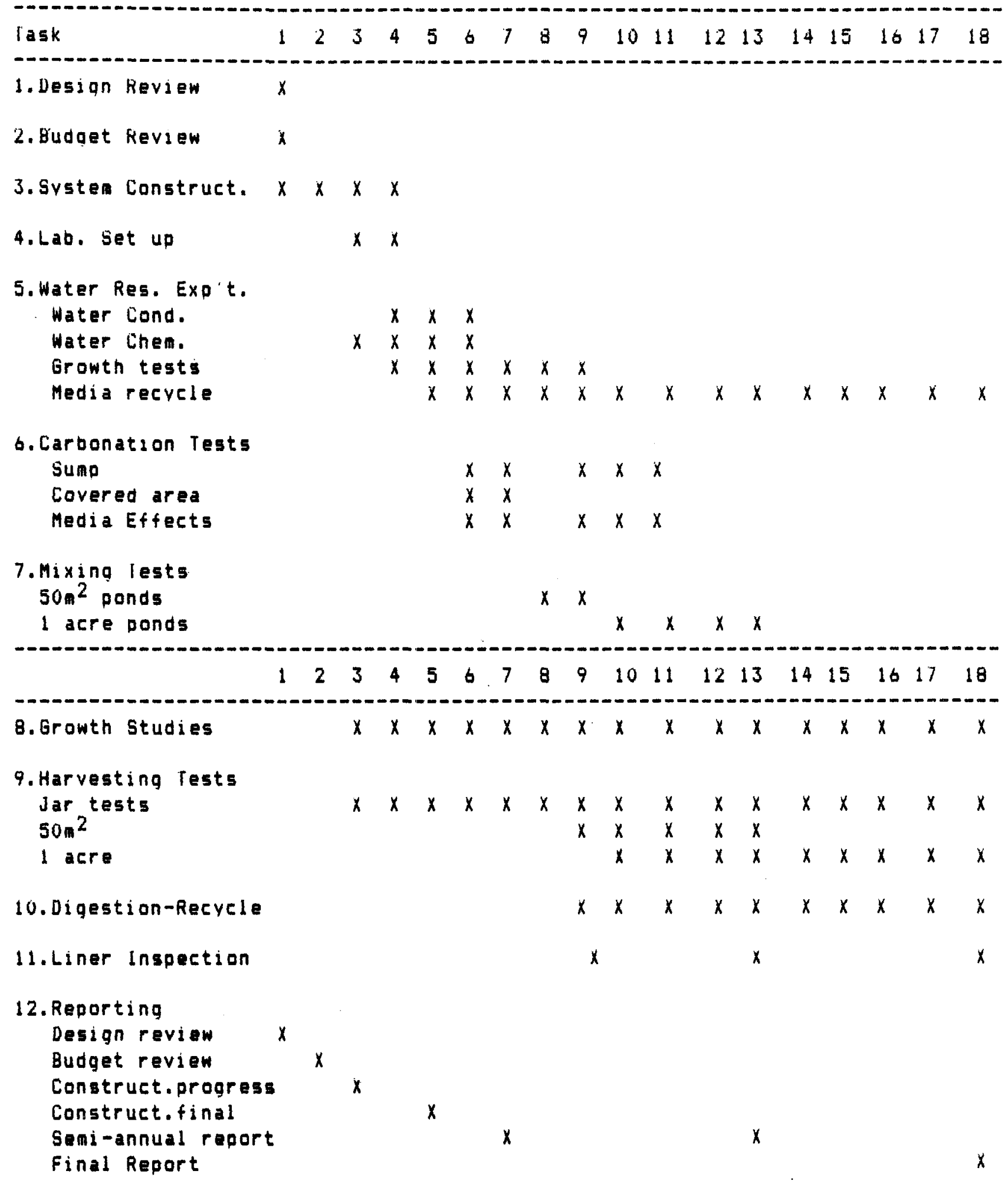

Fiqure 13-1. Experinental Schedule 
Table 13-2. Laboratory Equipment

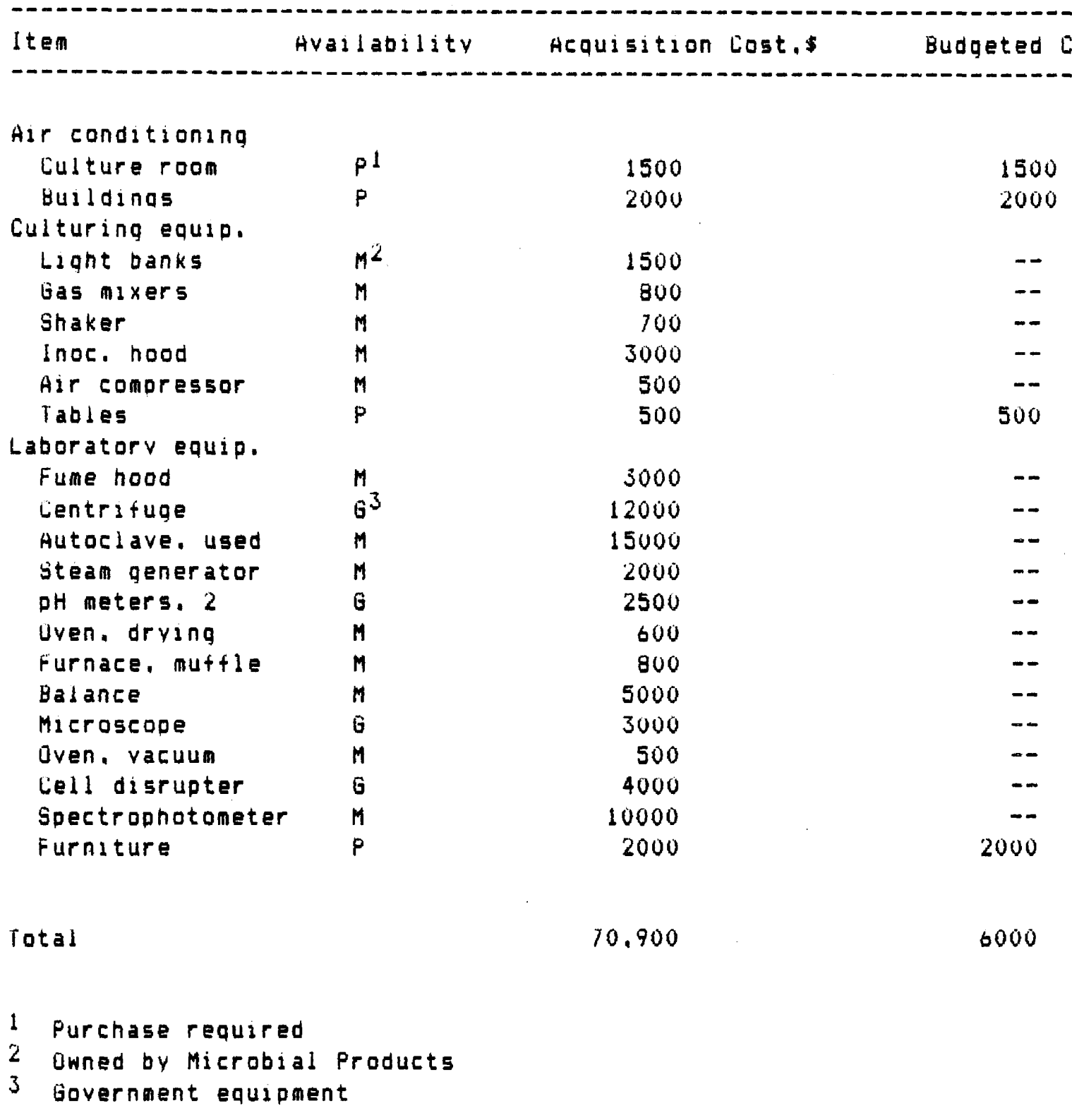


Table 13-3. Operating Materials and Supplies

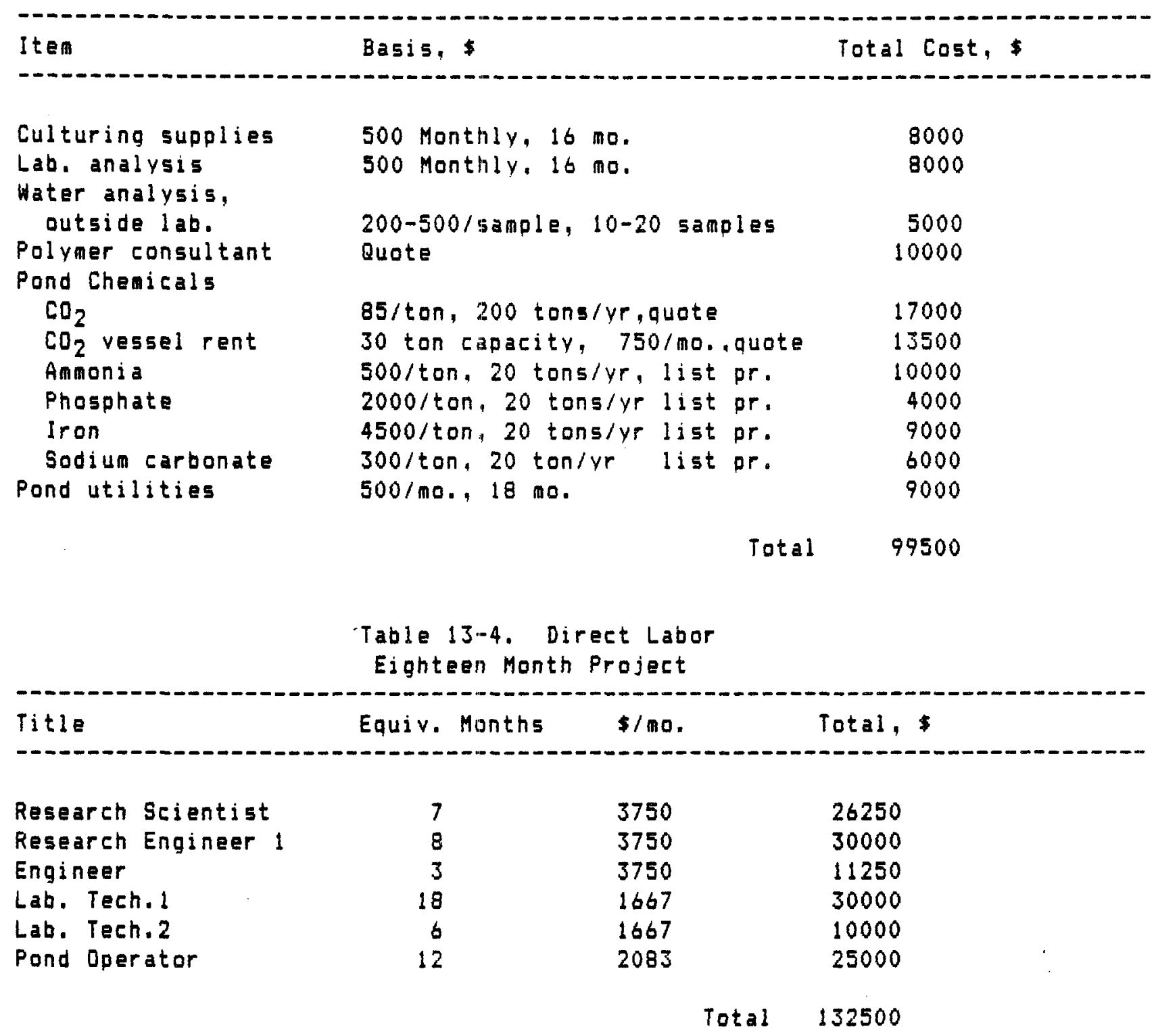


BUDGET

CATEGORY

$\cos \cos ^{2}$

Materials and Supplies

Pond construction (Table 12-9 minus $\$ 67,850$ for equipment

included below.......... ... 375,253

Operating (Table 13-3)................ 99,500

Special Equipment

Pond Equipment (Table 13-1) . . . . . . . . . . 67,850

Laboratory $(T a b l e(3-2)$. . . . . . . . . . . 6,000

Direct Labor (Table 13-4).................. 132,500

Total Direct Cost................... . 681,103

Indirect Cost (1.318 x Direct Labor) . . . . . . . . 174,635

Total Direct plus Indirect. . . . . . . . . . . . . 855,738

Fee $(7 \%$ of total direct plus indirect)............ 59,901

TOTAL Project Cost................... 915,639 


\section{REFERENCES}

1. Weissman, J.C. and R.P. Goebel, "Production of Liquid Fuels and Chemicals By Microalgae," Einal_Regort, SERI \#XK-3-030135-1, 1985.

2. Benemann,J.R., R.P. Goebel, J.C. Weissman, and D.C. Augenstein, "Microalgae as a Source of Liquid Fuels," Final_Regort, DOE DEACOS 81 ER $30014,1982$.

3. Laws, E.A., "Research and Development of Shallow Algal Mass Culture Systems for the Production of 0ils," Subegntract_Regort, SERI * $x K-3-03136$ oct. 1984.

4. Heissman, J.C. and J.R. Benemann, "Microalgae Production of Glycerol and Related Chemicals on Saline Waters," Fingl Regert, NSF, PFR-8008748, 1981 .

5. Barclay, B., Personal Coamunication of results of SERI Water Resource Project, 1985

6. Moo-Young, M., and H.W. Blanch, "Design of Biochenical Reactors: Mass Transfer Criteria for Simple and Complex Systems,"

7. Aiba, S., A.E. Humphrey, and N.F. Millis, Bigeheniegl_Enginegring, 2nd ed., Acadenic Press, New York, 1973.

8. Zlokarnik, M., "Sorption Characteristics for Gas-Liquid Contacting in

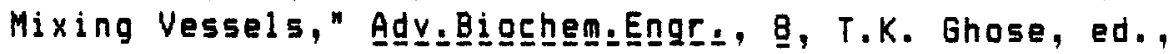

9. Hill, A., D. Feinberg, R. MeIntosh, B. Neenan, and K. Terry, "Fuels form Microalgae: Technology Status, Potential, and Research Issues," Draft_Report, SERI, 4625.20 , Dec. 1984.

10. Weissman, J.C. and J.R. Benemann, "Polysaccharide Production By Microalgae," Éinge l_Regort, NSF, PFR-7917646, April 1980.

11. Weissman, J.C. and J.R. Benemann, "Biomass Recycling and Species Competition in Continuous Cultures," Biotechnol._Bioengs, 21, 1978.

12. Dodd, J. Personal Communication.

13. Shelef, G., et al, "Microalgae Harvesting and Processing: A Literature Review," Subgontract_Regort. SERI, \#XK-3-03031-01, August, 1984.

14. Imperial Irrigation District, Annual Weather_Sugmary 1914-892. Records of the Watermaster, 1982.

15. Clinate_Atlas of the_U_s., U.S. Dept. Commerce, 1979.

16. Imperial Irrigation District, Laboratory Certificate, Nov. 7, 1983 


\author{
APPENDIX I \\ CARBON DIOXIDE TRANSFER
}

\title{
A.I INTRODUCTION
}

Transferring carbon to algae ponds is a major design problem. Unlike typical fermentations, which may have volumetric production rates of $15 \mathrm{~g}$ biomass/l-hr in deep, well-stirred tanks, algae ponds have 200-1000 times lower peak volumetric production rates in shallow, open ponds. Thus, large volumes of water must be transported to carbonation sites where $\mathrm{CO}_{2}$ is injected. In the plug-flow regime of high rate ponds, enough $\mathrm{CO}_{2}$ must be injected, and subsequently stored in the water to meet the carbon demand of the algae, as well as any $\mathrm{CO}_{2}$ losses due to outgassing as the water travels between carbonation stations. Storage capacity is a function of depth, alkalinity and pH change. The alkalinity can be supplied by the water source, and concentrated by water evaporation from the pond, to a level determined by the blow-down ratio. The allowable oH changes are determined by biological tolerance of the desired microalgae population and water resource characteristics. Many inexpensive water sources contain hardness which tends to precipitate. The extent of precipitation depends on pH and alkalinity, j.e., carbonate concentration. Thus, the variables of water chemistry, blowdown rate, depth, $P H$ changes, and $C$ storage potential are all interrelated. $\mathrm{CO}_{2}$ losses due to outgassing depend on $\mathrm{pH}$, alkalinity and carbonator spacing, as well as mixing speed.

\section{AI. 2 PHYSICAL ABSORPTION OF $\mathrm{CO}_{2}$}

Gas-liquid mass transfer is a subject which has received much attention in the chemical and biochemical engineering literature. Theories and experimental corpelations are well developed. However, they give only approximate and/or relative estimates of transfer rates. In the final analysis, rates must be empirically derived from prototypes and pilots. This is especially true of open channel carbonation, where irregular surface deformations occur due to turbulence, wind and bubbles. These disturbances way well have significant effect on gas transfer in ponds. The following analysis quantifies some of the more pertinent aspects of algal pond carbonation and evaluates. relatively, the sensitivities to depth and mixing intensity.

The theories of gas-liqujd transfer into agitated liquids all involve some simplified manner of incorporating the hydrodynanics into the basic diffusional models. The rationale is that at some scale, close to the gas-liquid interface, turbulent eddy diffusion is daaped to the extent that molecular diffusian is responsible for transfer. In the thin film model [1, 23 filn thickness paraneter, d, incorporates (in a mostly unspecified manner) all of the hydrodynamics, yielding a transfer rate equal to (D/d) (C*-Co), where $D$ is the molecular diffusion coefficient of the solute gas in $\mathrm{cm}^{2} / \mathrm{s}$, 
C* is the molar concentration of solute gas that would be in equilibrium with the partial pressure of solute in the gas phase, in moles/cm and co 15 the molar concentration of solute gas in the bulk liquid. The mass transfer coefficient, $k_{L}$ is equal to $0 / d$. $k_{L}$ is defined from the empirically observed relationship VdCo/dt $=k_{L} a(C *-C O)$. Here dCo/dt is the transfer rate, moles/cm $\mathrm{cm}^{3}$.sec, $V$ is the volume in $\mathrm{Cm}^{3}$, a is the interfacial area in $c m^{2}, K_{L}$ is in $c m / s e c$. The intensity of turbulence determines the film thickness, but the latter is difficult to infer theoretically and hard to measure.

In other models, the liquid turbulence is viewed as causing replacement of small interfacial surface areas with liquid from the uniformly mixed bulk. The type of distribution of surface ages assumed determines the quantitative prediction of these models. Hiquee's surface renewal model assumes ald elements of area have a uniform lifetime [3]. A convenient model, and the one used below, is Danckwert's renewal model [4] in which the probability of any element of surface being replaced is proportional to the age of the surface element. Then the surface renewal is a Poisson process, having manv calculational conveniences.

In this approximation, gas side resistance to diffusion is considered negligible, so that at the gas liquid interface equilibrium does exist between the bulk gas partial pressure of solute and the concentration of solute in the liquid at this interface. The relationship between gas side partial pressure and liquid side concentration is given by Henry solubility law, with Henry's constant appropriately decreased for elevated temperatures and ionic strength and composition of the liquid. Especially for anything but small gas phase partial pressures of $\mathrm{CO}_{2}$, where diffusion of solute molecules to the interface actually linit transfer, the equilibriun relationship is valid.

Once an element has been "renewed," transfer is assumed to go as in an infinitely deep, stagnant liquid. All transfer properties are determined as averages over the entire interfacial area, using the Poisson distribution as the weighting function. Purely physical transfer (without chemical reaction) goes as (DS) $1 / 2(C *-C O)$, where $S$ is the rate of surface renewal, or $1 / S$ is the average age of any surface element after formation. Several other models are available, however, there is little empirical evidence for any one in particular. In most circunstances, all models give similar quantitative predictions and, in addition, relative prediction as to the effect of chemical reactions on gas absorption. As alluded to above, in many instances, the model chosen for use depends on calculational ease in the specific case.

The renewal rate, $S$, embodies all of the effects of turbulence on gas-liquid transfer. It is not possible to measure, directly, this idealized parameter, but its value can be inferred from experiments. Flow of water in flumes, 
streams, and sewers is closely related to that in open channels. The empirical formula developed for $k_{L}$ as a function of 5 lope, velocity and depth from sewer data (5) has been found to correlate (b) with numerous sets of data taken for flumes, streams and open channels. As indicated in table Al-1. Danckwert 's model, in which $k_{L}=(D S) 1 / 2$. was used to calculates from $k_{L}$ based on purely physical absorption. Although the orioinal correlations were made for aeration, $S$ is andependent of the diffusion process and can thus be determined. The procedure is to (1) choose a channel roughness coefficient and use Manning's formula to determine slope from given depth and velocity values, (2) insert the depth, velocity, and slope values into the Parkhurst-Pomeroy (5) correlation to determine $k_{L}$, and 3 ) use Danckwert's model to determine $s$ from $K_{L}$ and $D_{2}$. Table Al-2 shows values of $k_{L}$ (for oxygen, for $\mathrm{CO}_{2}$ multiply by $(1.91 / 2.28)$ ) and renewal rate calculated according to this procedure with $n=.025$.

TABLE AI-1. MASS TRANSFER COEFFICIENTS FOR FLOWING HATER

gasis: $s_{1}=(1.49)^{-2}(d)^{-4 / 3}(n v)^{2}$

$$
\begin{aligned}
& k_{L}=\left(1.69 \times 10^{-2}\right)\left(1+0.17 v^{2} / 0 d\right)\left(s_{j} v\right) 0.375 \\
& k_{L} \propto\left(d^{-.5}\right)\left(V^{1.125}\right) \\
& S=k_{L}{ }^{2} / 00(4)
\end{aligned}
$$

$$
\text { Where: } \begin{aligned}
S_{1} & =\text { slope } \\
d & =\text { depth, } f t . \\
v & =\text { linear flow velocity, ft/sec. } \\
g & =\text { gravitational acceleration, } 32.2 \mathrm{ft} / \mathrm{sec}^{2} \\
k_{L} & =\text { transfer coefficient. cm/sec measured at } 20^{\circ} \mathrm{C} \\
D_{0} & =\text { diffusivity of oxyaen }=2.28 \times 20^{-5} \mathrm{~cm}^{2} / 5 e c \text { at } 20^{\circ} \mathrm{C} \\
S & =\text { average rate of surface renewal, } \sec ^{-1}
\end{aligned}
$$

The purpose of this procedure is to get approximate values of carbonation coefficients using data from aeration experiments and develop a means of, in theory, determining the effect of chemical reaction on carbonation relative to purely physical absorption. The first objective could be met without calculating renewal rates. The results would again depend on the particular model chosen since $k$ on where is 1 or 0.5 , or a value in between. since relative molecular diffusivities are not substantially different, 
model discrimination is not possible based on experimental determination of m (7). However, this also means that, for an approximate analysis, the result 3s substantially independent of the model basis. The second objective is conveniently attained using the renewal rate when the chenical reaction is first-order or considered pseudo-first order.

\section{Al.3 CHEMICAL ENHANCEMENT OF $\mathrm{CO}_{2}$ ABSORPTION}

The concentration gradient of a gaseous solute diffusing into a liquid can be steeper if the solute reacts with components of the liquid phase. The magnitude of this effect depends on the physical absorption time constant, the reaction rate constants, and the concentrations of reactants. Absorption of $\mathrm{CO}_{2}$ into alkaline waters may be accelerated by one of two major uncatalyzed reaction paths, the hydration of $\mathrm{CO}_{2}$ and subsequent acid-base reaction to form bicarbonate ion and the direct reaction of $\mathrm{CO}_{2}$ with the hydroxyl ion to form bicarbonate. The rate of the former reaction is faster at $\mathrm{pH}$ values below 8 , while the second dominates above $\mathrm{pH} 10$. Between 9 and 10 both can be important. Several investigators (7) have calculated the magnitude of the enhancement of $\mathrm{CO}_{2}$ absorption rates caused by these chenical reactions. Danckwert g renewal model is particularly convenient when the reaction is first order or pseudo-first order. Although the reaction of $\mathrm{CO}_{2}$ and $\mathrm{OH}$ ion is, in general, second order, under some circumstances the $O H$ ion concentration may be considered constant during that time interval between renewal of a surface element, when stagnant diffusion conditions are assuned to prevail. Thus if the rate of surface renewal is high enough, relative to the influx of $\mathrm{CO}_{2}$ and subsequent depletion of $\mathrm{OH}$ in the surface layer, so that $O H$ is not significantly depleted, the pseudo-first order conditions prevail.

When the renewal time is long, the absorption rate of $\mathrm{CO}_{2}$ is high and/or the concentration of $\mathrm{OH}$ is low the reaction proceeds quickly, depleting the $O H$ concentration just below the interface. When these conditiong prevail, the rate of absorption is nearly the same as if the reaction were instantaneous. The instantaneous reaction gives the maximal enhancenent for the given conditions. The enhancement factors are pH dependent because the concentration of reactant, $O H$, depends on $\mathrm{pH}$. The alkalinity affects $\mathrm{OH}$ concentration by buffering $\mathrm{pH}$ changes upon absorption of $\mathrm{CO}_{2}$. Thus, although the reaction rate is governed by the diffusion of $\mathrm{CO}_{2}$ down fron the interface and diffusion of dissolved $O H$ from the bulk liquid, in certain $\mathrm{pH}$ ranges the diffusion of many more molecules of $\mathrm{CO}_{2}$ (from the saturated interfacel is needed than of $O H$ from the bulk, due to the buffer action. For example, at $\mathrm{pH} 9$, over 100 molecules of $\mathrm{CO}_{2}$ must diffuse downward for each molecule of $\mathrm{OH}$ actually depleted from the reaction zone. 
TABLE AI-2. CO2 MASS TRANSFER COEFFICIENTS AS A FUNCTION OF POND HYDRAULICS

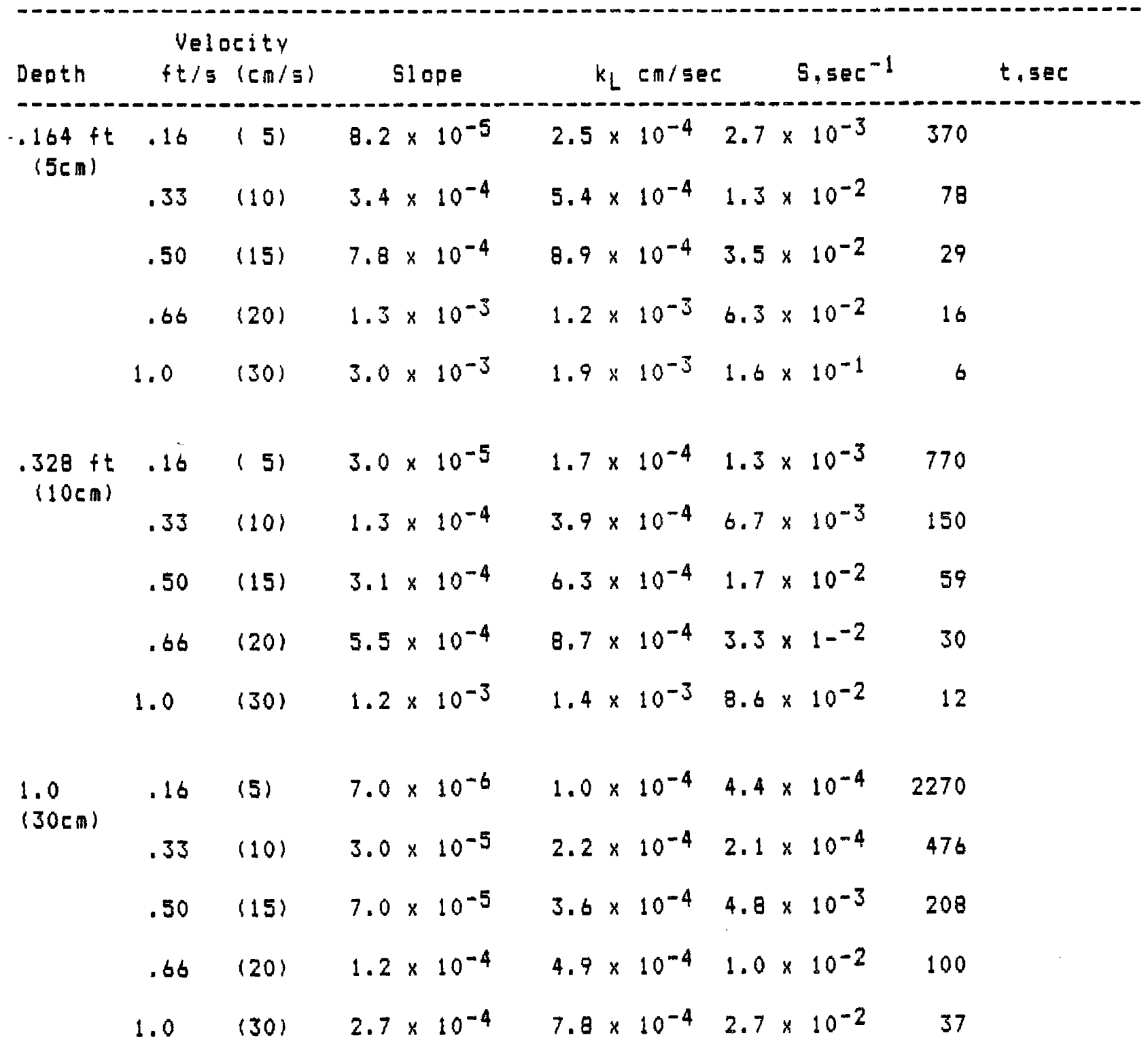

* For $\mathrm{CO}_{2}$ at $20^{\circ} \mathrm{C}$ this overestinates $k_{L}$ by $10 \%$. However, since diffusion coefficients are significantly greater at higher temperatures more accurate estimation is not called for. 
The hydration reaction, on the other hand, differs in that it is not $\mathrm{pH}$ dependent at the surface lbelow the surface it is, which limits the reverse reaction), and it is first order in $\mathrm{CO}_{2}$. Thus, enhancenent due to this reaction is essentially the same at all $\mathrm{pH}$ values between 7 and 11 . Table AI-3 gives the forward and reverse reaction rates, and Table AI-4 the concentrations of reactant, at the surface and in the bulk at oH 7.5 and 10.3. All rate constants are for $20^{\circ} \mathrm{C}$ and infinite dilution, giving lower limits to enhancement. Reverse reactions are negligible.

TABLE AI-3. CHEMICAL ENHANCEMENT FACTORS (9) AND REACTION RATE CONSTANTS

Enhancement of First Order Reactions: $(1+k / s)^{1 / 2}$

Enhancement of Instantaneous Second Order Reaction:

$1+D_{O H}(O H)_{B} / 2 D_{C O 2}\left(\mathrm{CO}_{2}\right)^{*}$

Reactions:

$$
\begin{aligned}
& \mathrm{H}_{2} \mathrm{O}+\mathrm{CO}_{2} \underset{\mathrm{k}_{2}}{\stackrel{\mathrm{k}_{1}}{\longrightarrow}} \mathrm{H}_{2} \mathrm{CO}_{3} \stackrel{\text { fast }}{\longrightarrow} \mathrm{H}^{+}+\mathrm{HCO}_{3}- \\
& \mathrm{CO}_{2}+\mathrm{OH} \underset{\mathrm{k}_{4}}{\stackrel{\mathrm{k}_{3}}{\rightleftharpoons}} \mathrm{HCO}_{3}-
\end{aligned}
$$

$k$ - 1st order reaction rate constant or pseudo first order constant

B - Bulk liquid concentration

* - Saturated surface concentration

Z - Effective staichionetric coefficients

Constants: $k_{1}=0.02 \sec ^{-1}$

$$
\begin{aligned}
& k_{2}=20 \sec ^{-1} \\
& k_{3}=10^{4} \mathrm{~L} \text { mole }-1 \sec ^{-1} \\
& k_{4}=2 \times 10^{-4} \mathrm{sec}^{-1}
\end{aligned}
$$

All $20^{\circ} \mathrm{C}$, infinite dilution 
Considering the second order reaction of $\mathrm{CO}_{2}$ and $\mathrm{OH}$ at $\mathrm{PH} 10.3$, the parameters which determine which regime is appropriatae (pseudo-first order or instantaneous), are (1) the rate of $\mathrm{CO}_{2}$ absorption, (2) the ratio of OH to dissolved $\mathrm{CO}_{2}$ at the surface, and (3) the ratio of the time any element of tluid remains at the surface (the turnover time = inverse of the renewal ratel to the maximal rate of the pseudo-first order reaction, $\mathrm{k}_{3}(\mathrm{OH})$. With 1 atm $\mathrm{CO}_{2}$ in the gas phase, the physical absorption rate $15.01 \times 10^{-3}$ moles/ch $/ 5 e c .$. or after 200 sec. of quiescence of an element of fluid. 1 ca deep, 20 moles $\mathrm{CO}_{2} / \mathrm{L}$ is absorbed. This amount of absorption overwhel ms the buffer, causing a drop in $O H$ concentrations. Thus, the pseudo-first order approximation does not apply. Similar calculations for other oH ranges Table AI-4) confirm this over the entire $\mathrm{pH}$ range of interest.

The effective stoichiometry of the reaction is $\mathrm{pH}$ dependent, as shown in rable Al-4. This stoichiometry, along with the bulk concentration of oH and the saturated level of $\mathrm{CO}_{2}$ determines the maximal enhancement of an instantaneous reaction regine. Even though the stoichiometry can become quite high, the concurrently falling oH concentration keeps the maximal ennancement from going above 1.05. Even this is not achieved due to the tinite reaction rate constant of $10^{4} \mathrm{~L} / m o l e-s e c$. Thus the direct reaction of $\mathrm{CO}_{2}$ and $\mathrm{OH}$ does not serve to enhance the reaction when the turnover time is on the order of 200 sec.

Even when the turnover time is only b 5ec., there is no appreciable chemical enhancement. Around $\mathrm{pH} 9.5$ the reaction is close to first order because the anount of $\mathrm{CO}_{2}$ absorbed during short contact time can be buffered by the solution, keeping the $O H$ concentration relatively constant. However, this concentration is low, keeping the reaction rate low relative to the rate of physical absorption. Increases in absorption rates under these conditions is due almost entirely to the hydrodynanic enhancement discussed previously.

The other reaction path, the hydration of dissolved $\mathrm{CO}_{2}$, is a first order reaction which can never be considered instantaneous. According to any of the models the enhancement factor is 2-3. Again if hydrualic conditions are chosen to incrase the renewal rate, and hence the physical absorption rate, then chemical enhancement is reduced. For example, with a 6 sec vs. a 200 sec turnover time, physical absorption rates increase b-fold, but chenical enhancenent decreases by almost the same factor, giving overall only a $12 \%$ increase in absorption rates. This is a consequence of the low value of the reaction rate constant, $0.02 \sec ^{-1}$. The entancement varies as $(1+k / 5) 1 / 2$ so at higher values of $s$, the reaction competes poorly with turnover in absorbing $\mathrm{CO}_{2}$.

Since even with 30 meq/L of alkalinity the buffer capacity is not great enough to enhance the absorption rates, the net effect of chemical reactions is the same for the low $\mathrm{pH}$, low alkalinity case. Here again, due to the first order reaction of $\mathrm{CO}_{2}$ and water, rates are enhanced 2-3 fold at a slow turnover rate (corresponding to a 1 foot deep pond mixed at $0.5 \mathrm{fps}$ ) and about 12\% at high turnover rates (a pond depth of $1 / 3 \mathrm{ft}$. and linear velocity of 1.5 fps under the coverl. 
TABLE A-I-4 CHANGES IN TOTAL CARBON CONCENTRATION IN THE SURFACE LAYER ${ }^{1}$

\begin{tabular}{|c|c|c|c|c|c|c|c|c|c|c|c|}
\hline $\mathrm{pH}$ & $\begin{array}{l}\mathrm{H}^{+} \\
\mathrm{M}\end{array}$ & $\begin{array}{l}\mathrm{OH} \\
\mathrm{M} \\
\end{array}$ & क० & d 1 & $\partial_{2}$ & $\begin{array}{l}\text { Alk } \\
\text { meq/L }\end{array}$ & $\begin{array}{l}\mathrm{C}_{\mathrm{T}} \\
\mathrm{mM} \\
\end{array}$ & $\mathrm{pH}$ Change & $\begin{array}{c}\Delta C_{T} \\
M \times 10^{3} \\
\end{array}$ & $\mathrm{OH}$ & $\frac{1}{\mathrm{Z}}-\frac{\Delta \underline{\omega}_{2}}{\Delta \mathrm{OH}}$ \\
\hline 10.3 & $5 \times 10^{-11}$ & $.2 \times 10^{-3}$ & $4.7 \times 10^{-5}$ & .472 & .528 & 30 & 19.5 & $10.3-9.3$ & 7.73 & $.18 \times 10^{-3}$ & 43 \\
\hline
\end{tabular}

$9.3 \quad 5 \times 10^{-10} \quad .2 \times 10^{-4} \quad 8.98 \times 10^{-4} \quad .899 \quad .101 \quad 30 \quad 27.2$

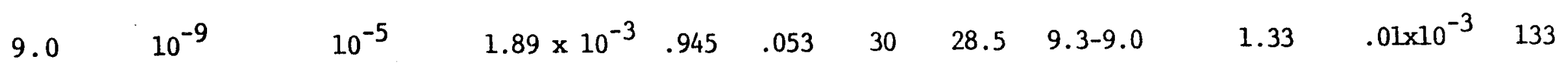

$\begin{array}{llllllllllll}8.3 & 5 \times 10^{-9} & .2 \times 10^{-5} & 9.8 \times 10^{-3} & .979 & .011 & 30 & 30.0 & 9.0-8.3 & 1.43 & .008 \times 10^{-3} & 179\end{array}$

崔

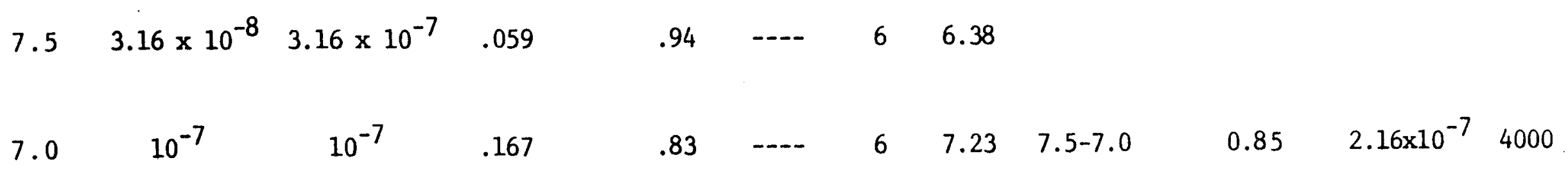

1 Surface film assumed to be $0.1 \mathrm{~cm}$

$\alpha \circ \quad \mathrm{CO}_{2} / \mathrm{C}_{\mathrm{T}}$

$\alpha_{1} \quad \mathrm{HCO}_{3} / \mathrm{C}_{\mathrm{T}}$

$\alpha_{2} \quad \mathrm{CO}_{3} / \mathrm{C}_{\mathrm{T}}$ 
Chemical enhancement can therefore be expected to lower areal carbonator coverage by 50-67\% when that coverage was initially calculated to be high. If measures are taken to increase physical absorption rates under a cover. then the $80 \%$ reduction in coverage thereby gained will not be much more affected by chemical reactions. In sumps chemical enhancement is also not effective under pond conditions, unless the reactions are catalyzed.

\section{REFERENCES}

1. Whitman, W.G., Chengand_Met__Eng:, 29, 147, 1923.

2. O'Conner, O.J. and W.E. Dobbins, "The Mechanism of Reaeration in

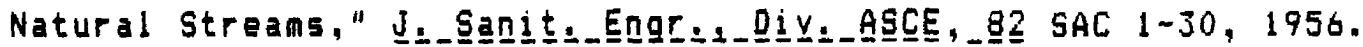

3. Higbie, R., Irans__Am.Inst__Chem._Engrse, 35,365, 1935.

4. Danckwerts, P.V., "The Significance of Liquid Film Coefficients in Gas Absorption," in Ind._Engng. Chem., 43, 1460, 1951.

5. Parkhurst, J.D. and R.D. Pomeroy, "Oxygen Absorption in Streams," J._Sangit._Engng._Di $\underline{Y}$ __ASCE, 9Q8, SAI, 101-124, 1972.

6. Wilson, G.Y. and N. MacCleod, "A Critical Appraisal of Empirical Equations and Models for the Prediction of the Coefficient of Reaeration of Deoxygenated Water," Water_Res., B, 341-366 1974.

7. Danckwerts, P.V., Gag_Liguidd_Regetigng, McGraw Hill, New York, 1970. 


\title{
APPENDIX AII
}

\author{
by D. C. Augenstein
}

GASLIFT PUMPS FOR COMBINED PUMPING AND

GAS CONTACTING IN ALGAL PRODUCTION SYSTEMS

\section{AII.I INTRODUCTION}

Gaslift pumps have been proposed to fulfill the simultaneous needs for pumping and gas transfer in microalgal growth systems. This treatment examines, first, the factors governing pumping efficiency, then factors governing the gas transfer function. Gas transfer requirements dictate the most important design parameters. Likely performance of a gaslift meeting both pumping and gas transfer requirements is then examined.

Prior to presenting detail, some important conclusions can be summarized here. With a configuration guaranteeing adequate (>80\%) fractional transfer of $\mathrm{CO}_{2}$ from stack gas, energy available to pump liquid neets or exceeds pumping needs anticipated for high rate pond systems with channel velocities in the 15-30 $\mathrm{cm} / \mathrm{sec} \mathrm{range.} \mathrm{A} \mathrm{good} \mathrm{match} \mathrm{between} \mathrm{pumping} \mathrm{capacity} \mathrm{and} \mathrm{system}$ needs seens possible with several plausible combinations of other parameters. When $\mathrm{CO}_{2}$ containing stack gas is sparged to supply $\mathrm{CO}_{2}$ needs, it seens that energy requirements will be high but probably tolerable function - 5 to $25 \%$ - of systen output. However, when transfer of pure $\mathrm{CO}_{2}$ is considered, a gaslift configuration guaranteeing adequate (>90\%) fractional $\mathrm{CO}_{2}$ transfer seems unable to meet pumping needs. Energy demand for pure $\mathrm{CO}_{2}$ sparging would be less than $3 \%$ of systen output. Representative pumping efficiencies are in the range of $20-50 \%$ and optimum sump depths range between 5-20 meters. It appears that if power plant stack gas is to be considered for $\mathrm{CO}_{2}$ source, more energy efficient transfer methods through gaslifts might be considered. Major remaining uncertainties affecting this treatment concern the channel roughness, $n$, which will acatually be encountered, and the absorption coefficient, $\mathrm{Kg}$, for $\mathrm{CO}_{2}$ in the pond liquid. Other details are presented in the report, which follows.

\section{AII.2 GENERAL DESCRIPTION OF AIRLIFT CONTACTOR/PUMP}

The schematic of an airlift systen of the type envisioned for application in an algal growth systen is shown in Figure AII-1. In the figure, a ducting system (A) brings liquid to the base of the unit. There, at the base of the vertical draft tube (B) gas is introduced through a $5 p a r g e r$ to create a dispersion of gas in liquid. Because of the lower effective density of the gas/liquid dispersion relative to the liquid, it rises through the vertical Section $B$ as shown and is discharged at an elevated head (the punping head) relative to the inlet. Necessary gas-liquid contacting (to be discussed later) is also accomplished in the vertical section B. In practice, in an algal growth systen with wide channels, the gaslift configuration would be 


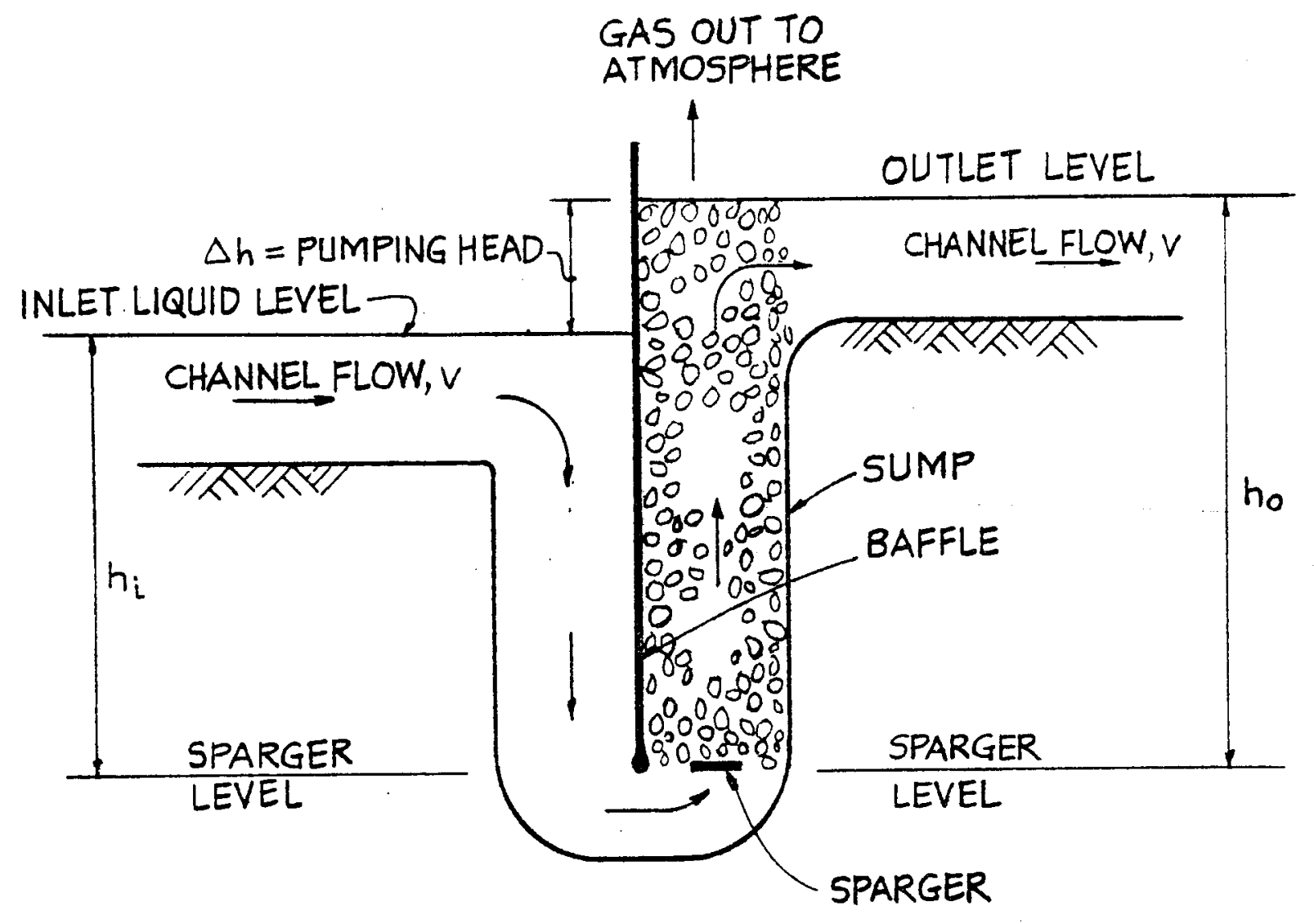

Figure AII-1 Gas Contacting Sump 
one in which the necessary number of airlift units, side by side, span the channel, or a unit with cross section of Figure All-1 (rectangular) spanning the channel, or even, just one draft tube. Analyses to follow are general to all these possible configurations. The advantage clajmed for airlift use relative to independently pumping at one location in the system and sparging gas in at another - is that it provides both pumping and gas contacting functions in one unit operation.

\section{A11.3 GENERAL BACKGROUND}

Recent chemical abstracts (1980-83) contained no relevent references on gaslift use solely for pumping liquids. Further communications with Dr. R. T. Hatch (who has extensively researched and published on airlift fermenters) resulted in the finding that the only recent use of gaslifts known to him has been in handling of liquid radioactive wastes in nuclear fuel processing plants, and in collecting ("vacuuming") manganese nodules from the sea floor. In essence, gaslift pumping has been used recently only when either its high reliability (due to no noving parts) and/or its ability to handle, unattended and remotely, very abrasive slurries such as manganese nodules at great depths is required. It seens - although no rigorous analysis is done here - that alternative pumping methods are in most cases reliable enough and more efficient and econonical than the combined cost of the compressor/draft tube required for the gaslift approach. It is worth conmenting, however, that before the development of improved materials and pumps, airlifts were used extensively in applications such as primary sewage, oilwell, and coal mine (acid water) punping. References to these applications date to the early $1900^{\prime} \mathrm{s}[2,3]$. For reasons stated, and also because optinizing gas transfer (treated later) gives operating conditions outside the range for existing correlations $[4,5]$ it will be necessary later to treat airlift pumping based on first principles.

\section{A11.4 GENERAL ASPECTS OF PAST INUESTIGATIONS: PUMPING AND CONTACTING}

Because of extensive pilot and commercial application of airlift fermenters, numerous articles are available discussing aspects of their operation - for example references $6-12$. Pumping efficiency in airlift fermenters - which determine cycle time around the flow loop consisting of the annulus and draft tube in such fermenters - is almost always adequate and hence pumping has not been a concern. It is, however, addressed in reference 8 . A major topic for analysis in the cited references $6-13$ has been the ability of the unit to transfer oxygen efficiently. This transfer capacity relates directly to the ability of the unit to transfer $\mathrm{CO}_{2}$, which is the concern with algal growth systems. Central to both gas transfer and punping is the behavior of the gas-liquid dispersion in the updraft section, and, in particular, the behavior of the bubble swarm generated within the upflow section. As bubble behavior is critical in both these respects, this topic is addressed first. 
A number of correlations have been developed to describe the behavior of swarms of bubbles which result from sparging of gas into liquid. The treatment to follow uses some simplifying assumptions which are valid for aqueous systems with low surfactant levels. Such low surfactant conditions are expected to exist in most algal growth systems.

Sparging of gas into liquid results in swarms of individual gas bubbles which rise away from the sparger. The size distribution of the bubbles leaving the sparger may initially be a strong function of the sparging method. However, as bubbles of differing size rise through the fluid at differing velocities, coalescence of the smaller bubbles occurs; on the other hand, bubbles above a certain critical diameter, about $0.5 \mathrm{~cm}$ in water, will be broken up by fluid forces. The net result of this coalescence of smaller bubbles and breakuo of larger ones is that a steady-state bubble size distribution is attained once gas has risen a certain distance above the sparger. Coalescence (and hence the height above the sparger at which equilibrium size distribution is attained) depends strongly on fluid properties, but for fluids similar to water, at gas holdups e>.01, equilibrium would appear to be attained by the time gas had risen above 1 meter [13]. This can be intuitively understood by considering velocities of bubbles of various sizes. ffor bubble diameter $D_{B}<0.2 \mathrm{~cm}$, the stoke's range, the bubble velocity $V_{B} D_{B}{ }^{2}$ ) and the fact that a larger bubble sweeps out a cylindrical locus exceeding its own diameter $\left(D_{B}\right)$. Within that cylinder it will catch up and coalesce with a smaller, slower bubble above it.

The outcome of an example calculation can illustrate the coalescence process. Consider an initial case of two bubbles with a diameter ratio of 2 $\left(D_{B, 1}=0.2\right.$ cm and $D_{B, 2}=0.1 \mathrm{~cm}$, both in stokes law range $)$ and an initial vertical separation of $15 \mathrm{~cm}$, with the smaller bubble above the larger. (This circunstance will exist on the average in the case where e = 0.011 . The larger bubble will catch up and coalesce with the smaller bubble after only a $25 \mathrm{~cm}$ rise. (Note though that higher levels of surfactants and electrolytes can hinder the coalescence process, and the analysis is done only for fluids with properties near water, for example low TDS algal growth systens.) Power dissipation can affect the equilibrium bubule size, but for power dissipations expected in airlift operation this affect has been shown (albeit in other types of fermentations systems) to be negligible [16]. Gas holdup, e, nay vary with pressure but any effect on bubble diameter from this is also expected to be negligible, both as pressure effects are negligible and as the coalescence dispersion process tends to maintain the characteristic size distribution.

Rise velocities of bubbles have been established 35 a function of bubble dianeter [15]. Bubbles may be classified into two categories, "rigid sphere" up to $D_{B} 0.2$ cm which rise according to Stokes law, at velocities up to 30 $\mathrm{cm} / \mathrm{s}$. for $D_{B}=0.2 \mathrm{~cm}$, and larger bubbles whose gas/liquid interface is fluid and which - over a wide range of sizes, $D_{B} 0.25$ to $2.0^{+} \mathrm{cm}$ - rise at about 25-32 cm/sec [15]. At an equilibrium bubble size distribution discussed most gas, $95+\%$, is in bubbles with $D_{B}>0.25 \mathrm{~cm}$ and a very important consequence of this is that the average rise velocity of gas 
through liquid, at least at gas holdups up to $E=0.25$, is about 28-32

cm/sec. An average bubble rise velocity of $30 \mathrm{~cm} / \mathrm{sec}$ relative to the liquid will be assumed for analysis to follow. Another assumption is that cross section of flowing liquid in the gaslift - hence the average liquid velocity - is constant. This assumption is to some extent artificial but introduces little error and simplifies the mathematics.

Given a net rise velocity of $30 \mathrm{~cm} / \mathrm{sec}$ of gas relative to liquid, a constant liquid velocity $V_{L}$ and a flow rate ratio of gas to liquid of $Q_{0 c} / Q_{L}$

(where Qge is the gas flow corrected for pressure. temperature and moisture effects - these corrections are treated later), the following relations hold:

$$
\begin{aligned}
& Q_{L}=A_{L} V_{L} \\
& Q_{g c}=A_{g c}\left(V_{L}+30\right)
\end{aligned}
$$

where $A_{L}$ and $A_{g c}$ are the flowing cross section of liquid and gas, respectively. Gas holdup, e, which can alternatively be defined as the void fraction of gas in the gas-liquid dispersion, is given by

$$
e_{c}=A_{g C^{\prime}}\left(A_{L}+A_{g C}\right)
$$

and, making the necessary substitutions, average holdup can be derived in terms of $Q_{g} / Q_{L}$, and $V_{L}$ as

$$
e=\frac{Q_{g} \text { Cpe }}{Q_{L}\left(1+30 / V_{L}\right)+Q_{Q} C p e}
$$

where $\theta_{g}$ is the qas flow, at STP, into the sparger and the term Cpe is a pressure correction factor. Expression (4) will be referped to later.

\section{A11.6 CORRECTION FOR PRESSURE}

As noted, pressure must be compensated for in determining. gas holdup. If gas flow through the liquid is expressed at 1 atmosphere, then the ratio of actual gas volume and volumetric flow to these values at one atmosphere can 
be easilv computed as a function of oressure and liquid head. An average correction factor, termed Cpe here, can also be computed for the gas stream between the sparger and surface in the draft tube section. This factor. Coe, can be expressed either in terms of pressure or alternatively in terms of $h_{j}$ and $h_{0}$ (refer to Fiqure AIl-1). This correction has been compiled graphically with results shown in Table AlI-l. Another assumption is that water vapor and temperature corrections ( $35 \%$ total) can be neglected. No corrections are in fact necessary if both 1) the temperature of the gaslift fluid equals compressor inlet temperature, and if 2 ) inlet air to the compressor has the same weight ratio of water to gas as the saturated gas rising through the draft tube.

\section{A11.7 PUMPING BY GASLIFT PUMPS}

Refering to Figure AII-1 it is evident that a flow equation can be developed:

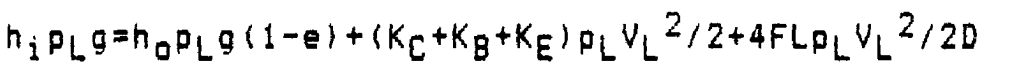

where

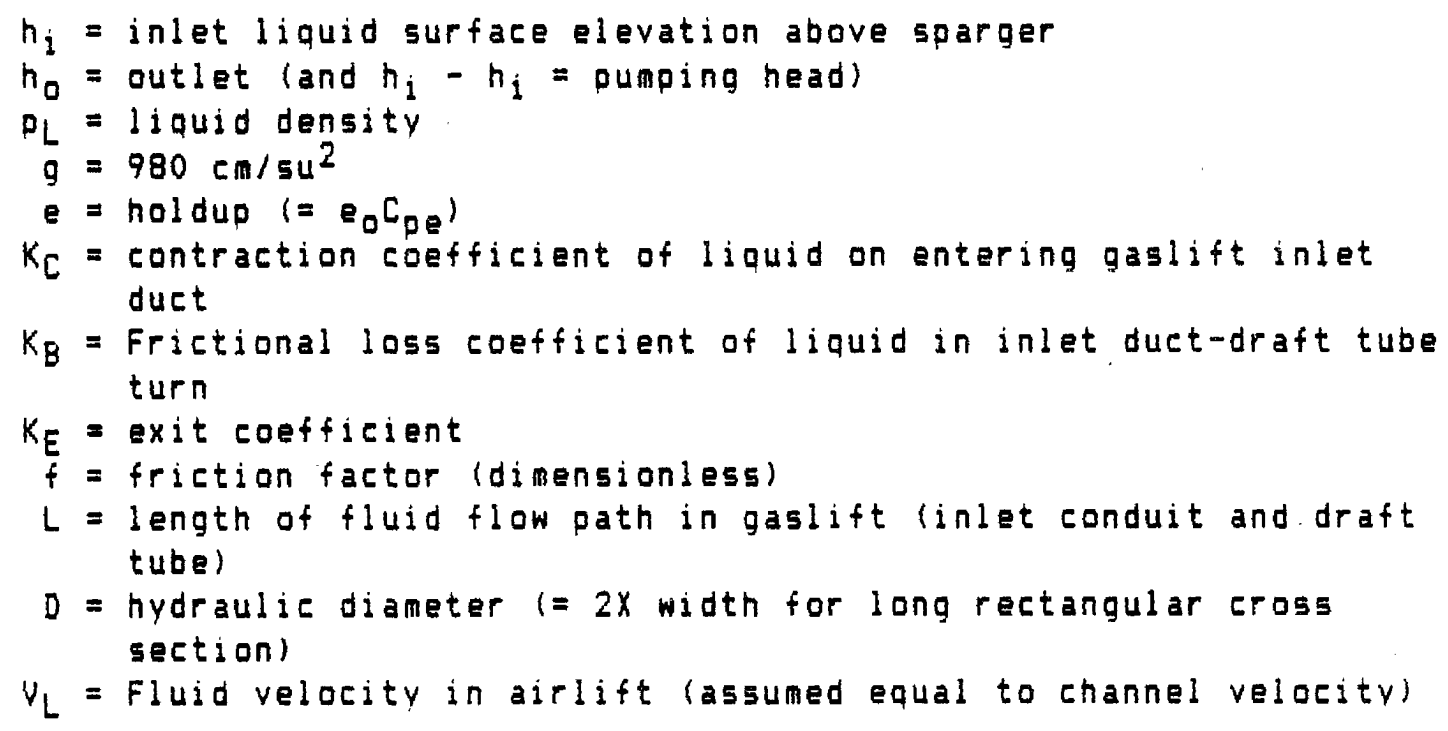

It is convenient to define the overall friction coefficient, as $K F=\left(K_{L}+\right.$ $K B+K_{C}+4 f(L / D)$. Then equation 5 becomes

$$
h_{i} g=h_{0} g(1-e)+K_{F} V_{L}^{2} / 2
$$




$\begin{array}{cc}\text { TABLE AII-1. Computed Values of CPE vs. Depth* } \\ \text { Depth, Em } & \text { C PE } \\ 100 & .96 \\ 200 & .92 \\ 300 & .89 \\ 400 & .86 \\ 500 & .823 \\ 600 & .803 \\ 700 & .775 \\ 800 & .752 \\ 1000 & .712 \\ 1200 & .676 \\ 1400 & .645 \\ 1600 & .619\end{array}$

* Gas volume correction factor for depth and pressure. See Text. 
It is evident that with values for CPE available equation 6 can be used for various predictive purposes. Discussion of the use of equation 6 will come later after it is demonstrated how gas transfer and pumping requirements $f i x$ some of the independent variables.

Before going on, it is interesting to consider likely magnitudes of frictional loss terms within the gaslift due to fluid flow, if gaslifts are applied to algal growth systems channel flow. Velocities proposed for high-rate pond systems range from 10-30 cm/sec [17]. The fluid head increment at an airlift pumping station is likelly to be in the order of 30 to $100 \mathrm{~cm}$, or even more, to provide economical pumping station soacing [17]. It is interesting to note that a $30 \mathrm{~cm}$ pumping head is equivalent to 65 velocity heads $\left(=p^{2} / 2\right)$. It can be readily calculated that if fluid flow in the gaslift is $30 \mathrm{~cm} / \mathrm{sec}$, and that if (for one "bad case" example) fluid is both drawn from and existing into stagnant liquid, in which case by Reference $20 K_{C}=0.43$ and $K_{L}=1.0$ - that the frictional entrance and exit losses are only about $2.4 \%$ of the work expended to pumping liquid through the pumping head. The balance of expected frictional losses, from a (possible) $180^{\circ}$ bend between gaslift inlet duct and draft tube, and the total frictional loss from channel flow at $L / D=20$, will total less than $3 \%$ of the pumping work. Thus for this example total frictional losses in the airlift pump are small, about $5 \%$. Because $V_{L}$ and $V_{c h}$ can be equal, and a bend configuration can be chosen to minimize frictional loss, frictional losses due to fluid flow should in fact be in the range of $1 \%$ of the pumping work expended for cases of interest.

While frictional losses are minor, relative to useful work done in pumping, other inefficiencies exist. One of these, which is major, can be understood intuitively as due to the $30 \mathrm{~cm} / \mathrm{sec} s$ lip velocity of gas relative to liquid discussed earlier. This and other factors relating to efficiency are discussed next.

\section{A11.8 EFFICIENCY CALCULATIONS}

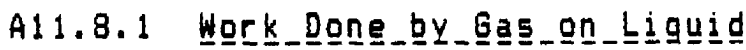

The work done by an element of gas on the liquid can be stated as (force exerted by gas on 1 iquid) $x$ (distance moved by liquid during time force is exerted). Note that the distance is not the total moved by the gas element, as the forcexdistance product of the $30 \mathrm{~cm} / \mathrm{sec}$ gas movement through the liquid is lost, i.e., dissipated as heat. (Also note here that the following analysis is in C.G.S. units, and based on $1 \mathrm{~cm}^{3}$ gas or viewed by the compressor.)

The average force exerted by $1 \mathrm{~cm}^{3}$ gas on the liquid is gCpe $\Delta p$, with Cpe as calculated earliler, for the time the gas is in the liquid. If gas rises from the sparger to the surface, the time gas is in contact with the liquid is $h_{0} /\left(V_{L}+30\right)$. Thus the work done by the $1 \mathrm{~cm}^{3}$ gas element on the liquid, $w_{g L}$ during the rise of the gas element, is 


$$
w_{g L}=g C_{p e} h_{0}\left\{V_{L} /\left(30+V_{L}\right)\right\}\left(T_{g I} / T_{C}\right)
$$

If qaslift temperature $T_{g l}$ is different from compressor inlet temperature $T_{C}$, the term $T_{q l} / T_{C}$ compensates for this. The term $\Delta p$ is assumed to be $1 \mathrm{gm} / \mathrm{cm}^{3}$ and 50 is omitted in 7 . Other terms were defined earlier.

\section{A11.8.2 Work_Exoended_to__Eomeress_Gas}

For low head compression, which is the case for algal growth systems, single stage isentropic compression will be applied, and the expression for the work done to pump $1 \mathrm{~cm}^{3} \mathrm{gas}, \mathrm{H}_{\mathrm{g}}$, is given by

$$
W_{g c}=n R T_{c}\left\{\left(p_{2} / p_{1}\right)(k-1) / k-1\right\} x
$$

where

$$
\begin{aligned}
n & =m o l s \text { gas in } 1 \mathrm{~cm}^{3} \text { at compressor inlet temperature } \\
T_{C} & =g a s \text { temperature entering compressor, ok } \\
k & =C_{p} / C_{v} \text { of } 935,=1.4 \text { for air } \\
P_{1} & =\text { compressor inlet pressure, } 1 \text { atm (or } 10^{6} \text { dyne/cm }{ }^{2} \text { ) } \\
P_{2} & =\text { compressor outlet pressure } \\
x & =p o l y t r o p i c \text { compression factor, } 3.5 \text { (dimensionless) }
\end{aligned}
$$

In CGS units, $R=8.31 \times 10^{7} \mathrm{erg} / \mathrm{mol} / 0^{\circ} \mathrm{K}$. For $1 \mathrm{~cm}^{3}$ gas entering the compressor at one atmosphere the product $n T_{C}$ is constant (whatever the temperature) at $1.218 \times \mathrm{k10}^{-2} \mathrm{~mol}{ }^{\circ} \mathrm{K}$, and with this value (8) becomes, in ergs expended to pump $1 \mathrm{~cm}^{3}$ (compressor inlet conditions)

$$
W_{g c}=3.546 \times 10^{b}\left\{\left(p_{2} / p_{1}\right)(k-1) / k\right.
$$

Isentropic compression is less efficient than isothermal compression since a portion of the isentropic compression work appears as unusable heat, but it is interesting that efficiency of isentropic compression is still high relative to isothermal at pressures likely to be needed. For example, at a compression ratio of $2 / 1$ (or ca $10 \mathrm{M}$ depth for $h_{i}$ ), isentropic compression is $91 \%$ as efficient as isothermal. 


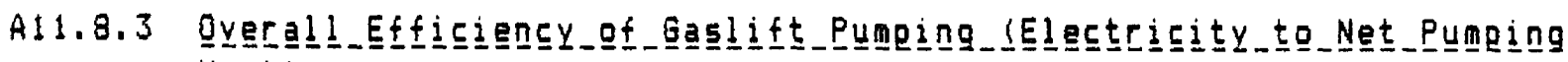
Work $)$

The work done by an element of gas on the liquid has been given previously as equation (7). Given equation ( 6 ) and if it is assumed for the moment that channel and gaslift flow velocities are equal then this energy expenditure divides between pumping head and fluid frictional losses in the ratio

$$
\frac{\left(h_{0}-h_{i}\right) g}{\left(h_{0}-h_{i}\right) g+\frac{K_{F} V^{2}}{2}}
$$

The expression for efficiency, $E_{g} / p$, defined as the ratio of pumping work accomplished to gas compression work requirement then becomes

$$
E_{g / p}=\frac{c_{p e g} h_{0}\left(\frac{V_{L}}{30+V_{L}}\right)}{3.546\left(10^{6}\right)\left(\frac{p_{2}}{p_{1}} \frac{k_{-1}}{k}-1\right)} \cdot \frac{\left(h_{0}-h_{i}\right) g}{\left(h_{0}-h_{i}\right) g+\frac{k_{F} V^{2}}{2}}
$$

The remaining factor to be considered is the motor/compressor efficiency by which 11 is multiplied to give $E_{0}$, the overall expression for efticiency:

$$
E_{0}=E_{m c} E_{g / p}
$$

It is of interest to note that overall pumping efficiency $E_{0}$ should range by equation (12) between about $25 \%$ and $50 \%$. One set of typical operating conditions (based on $80 \% \mathrm{CO}_{2}$ transfer need, computations presented later) might consist of a fluid gaslift and channel flow velocity of $15 \mathrm{~cm} / \mathrm{sec}$, draft tube height $=5.4$ meters, and a pumping head of $14.5 \mathrm{~cm}$. Efficiency under these circumstances at $\varepsilon_{\text {me }}=0.8$ would be about $29.5 \%$. If $\mathrm{CO}_{2}$ transfer efficiency rises to $95 \%$, and fluid flow velocity is increased to 30 cm/sec, the pump head needed will increase to $1.16 \mathrm{~m}$. With other parameters kept the same, the draft tube height must increase to 13.5 meters and overall efficiency would increase somewhat, to $40.8 \%$. Higher efficiencies are obtainable with higher channel and gaslift flow velocities; however, such higher velocities can result in energy consumption which is a large fraction, easily around $50 \%$, of total expected system output (see later discussion) and in addition, there is no evidence that such flow velocities are required. Such velocities might in fact be deleterious in terns of suspending solids in the types of unlined channel systems which are likely to be affordable. 
The pumping needs of a channel growth system could be met with any suitable combination of gas/liquid flow ratios $f\left(=Q_{g} / Q_{L}\right)$, and gaslift draft tube height and area. However, configurations must also be able to meet $\mathrm{CO}_{2}$ transfer needs. Because of the importance of $g a s\left(\mathrm{CO}_{2}\right)$ transfer and design constraints posed by gas transfer, this topic is addressed next.

\section{A11.9 GAS TRANGFER FROM BUBBLE SWARMS TO LIQUID}

Oxyoen transfer is an important unit operation in fermentation and waste treatment. It has been established that the overall transfer coefficient, $K_{L}$, is in one range for $5 m a l l$ rigid sphere bubbles $D_{B} L<2 \mathrm{~mm}$, and in another range - about twice as high, for larger bubbles $D_{B}>2 \mathrm{~mm}$. A number of correlations (for example as discussed in 21) have evolved for these bubbles of various size ranges. This would seem on the surface to implva difficult analytical situation. However, even with this disparity of transfer coefficient with bubble size it fortunately transpires that the coalescence and redispersion of bubbles in a rising swarn leads to a steady state size distribution a short distance above the sparger as discussed earlier (and as intuition would suggest). In this steady state the ratio of $K_{L a}$, the combined mass transfer coefficient (whose units can be $h_{r}{ }^{-1}$ or mollL.hr.atm) to volume of the rising gas, is constant. Also, gas oressure (hence solubility) and area teras cancel. A very important implication of this is that the fractional approach to liquid equilibrium activity of a given gas component in the gas phase is constant per unit time. (It has been established that power dissipation in the liquid does not affect $\left.K_{L}.\right)$ If thermodynanic activity of gas dissolved in the liquid phase stays constant relative to gas phase acativity, then the fraction of gas phase component which is lost from the gas is constant per unit time. Thus,

$$
d P_{g} / d t=P_{g} k_{g} /\left\{\left(P_{g}-P_{L}\right) / P_{g}\right\}
$$

where

$P_{g}=$ activity of species in gas phase, atm

$P_{L}=$ activity of species in liquid phase, atm

$K_{g}=$ transfer coefficient based on gas activity

nore specifically the transfer coefficient can be expressed as

Atmospheres gas lost/unit tine

$K_{g}=$ Atwosphere gas driving force 
The constant fractional stripping of of axygen per unit height has been established in particular for reference 8 (Hatch) and in reference 13 in the deep tank work of Schmidt and Redmond.

For oxygen, the fractional absorption per unit time from the gas phase is $.0065-.0075 \sec ^{-1}$ at $20^{\circ} \mathrm{C}(8,13)$. A value of 0.007 will be used in this analysis. However. the critical problen for algal growth systems is not oxygen transfer, but $\mathrm{CD}_{2}$ transfer. Though no literature was found directlly applicable to $\mathrm{CO}_{2}$ transfer in the situation envisioned for the algal growth system. a well established mass transfer correlation may be used to compare the $\mathrm{Kg}$ for $\mathrm{CO}_{2}$ trangfer from that of $\mathrm{O}_{2}[7,13]$.

Specifically, at a qiven gas ohase partial presgure the liquid side mass transfer coefficient per unit area, which controls $K_{L}$, is proportional to $D_{L} 0.67$ (where $D=$ gas diffusivity in liquid). $K a$ is in turn proportional to $k$ times solubility. Thus

$$
\frac{\mathrm{KgCO}_{2}}{\mathrm{KgO}_{2}}=\left(\frac{D_{\mathrm{LCO}}}{D_{\mathrm{LO}}}\right)^{2 / 3}\left(\frac{\mathrm{S}_{\mathrm{CO}_{2}}}{\mathrm{SO}_{2}}\right)=\left(\frac{1.77 \times 10^{-5}}{2.28 \times 10^{-5}}\right)^{.667}\left(\frac{29.1}{1.38}\right)=17.8
$$

and $\mathrm{Kg}$ for $\mathrm{CO}_{2}$ can be computed to be about $0.125 \mathrm{sec}^{-1}$ (though a cautionary note is that 5 maller bubble size with surfactant present could give a much higher $\mathrm{kg}$ ). With this $\mathrm{kg}$, a swarm of gas bubbles rising through gas-free liquid would lose about $13 \%$ of their remaining $\mathrm{CO}_{2}$ each second. IIn deriving $\mathrm{CO}_{2}$ transfer data from $\mathrm{O}_{2}$ data, note here that it has been established that there is negligible chemical acceleration of $\mathrm{CO}_{2}$ uptake see Ref. (7).

\section{A11.10 COMPUTATION OF TIME AND HEIGHT NEEDED FOR TRANSFER}

The limiting case will sometimes exist where back pressure of $\mathrm{CO}_{2}$ is negligible. This will be true in particular when the system is operated at low $\mathrm{CO}_{2}$ and high alkalinity to prevent $\mathrm{CO}_{2}$ escape to the atmosphera [17]. In this case computation of the required contact time is straightforward from equation (13) and $\mathrm{Kg}=0.125 \mathrm{sec}^{-1}$. Required contact times for $80 \%$ and $95 \%$ absorption of $\mathrm{CO}_{2}$, for both $15 \mathrm{~cm} / \mathrm{sec}$ and $30 \mathrm{~cm} / \mathrm{sec}$ Jraft tube velocities in each case, are shown in Table AlJ-2. These values of draft tube height and flow velocity are those which were used earlier to compute representive efficiencies.

In the majority of cases $\mathrm{CO}_{2}$ transfer will take place where backpressure is not zero. The partial pressure of $\mathrm{CO}_{2}\left(\mathrm{P}_{L}\right.$ in equation 13$)$ is needed and can be derived as a function of any of several interrelated parameters. One convenient derivation is as a function of $\mathrm{pH}$ (or $\mathrm{H}^{+}$concentration) and alkalinity, A. Here, alkalinity is defined as milliequivalents per liter excess of cations over all anions other than carbonate species. It is also 
assumed as a simplifying measure in this analysis that no buffers other than carbonate are present. The simplification can also be made for pH values of interest $(5-11)$ that $\mathrm{H}^{+}$and $\mathrm{OH}^{-}$are negligible relative to carbonate species. Data in the analysis to follow is from reference 18 and 19 . The term $\mathrm{CCO}_{2}$ is used to define the sum of $\mathrm{CO}_{2}$ and $\mathrm{H}_{2} \mathrm{CO}_{3}$ in solution.

$$
A=\text { meq/L alkalinity }=\mathrm{HCO}_{3}^{-}+2 \mathrm{CO}_{3}=
$$

given that $\frac{\left(\mathrm{H}^{+}\right)\left(\mathrm{CO}_{3}=\right.}{\mathrm{HCO}_{3}^{-}}=4.4 \times 10^{-11} \mathrm{Ref5}, 18,19$

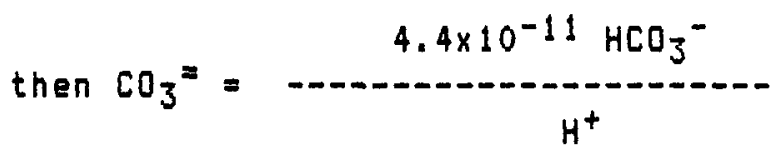

and

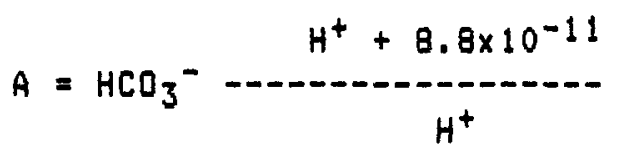

so $\mathrm{HCO}_{3}^{-}=\frac{\mathrm{AH}^{+}}{\mathrm{H}^{+}+8.8 \times 10^{-11}}$

Also, given that

$$
\left(\mathrm{H}^{+}\right)\left(\mathrm{HCO}_{3}{ }^{-}\right) / \mathrm{CCO}_{\mathrm{CO}}=4.31 \times 10-7
$$

$$
\text { and } \mathrm{C}_{\mathrm{CO} 2}=\underset{\mathrm{H}^{+}}{4.3 \times 10^{-7} \mathrm{H}^{+}+8.8 \times 10^{-11}}
$$

$$
C_{\mathrm{CO} 2}=\frac{A\left(H^{+}\right)^{2}}{\left(4.3 \times 10^{-7}\right)\left(H^{+}+8.8 \times 10^{-4}\right)}
$$


letting $K_{1}=4.31 \times 10^{-7}$ and $K_{2}=4.4 \times 10^{-11}$,

total carbon in solution, TC, is given by

$$
T C=\frac{A\left(H^{+}\right) 2}{K_{1}\left(H^{+}+2 K_{2}\right)}+\frac{A^{+}}{H^{+}+2 K_{2}}+\frac{K_{2} A}{-H^{+}+2 K_{2}}
$$

As solubility of $\mathrm{CO}_{2}$ is $29 \mathrm{mmol} / \mathrm{L}$. atm $\left(20^{\circ} \mathrm{C}\right)$ the term $\mathrm{P}_{\mathrm{L}}$ for use in equation (13) would be $1 / 29.1$ atm $\times \mathrm{CCO}_{2}$ or $0.034 \mathrm{C}_{\mathrm{CO} 2}$ at 200 . Other temperatures can be treated in the same way using the $\mathrm{CO}_{2}$ solubility for those temperatures.

\section{A11.11 COMPUTATION OF REQUIRED RESIDENCE TIME IN DRAFT TUBE}

The entire proacedure for computing transfer time (or height) is complex and only the briefest possible description will be given here. Given equation 19 and 20 a graph can be constructed showing total carbonate species (i.e. mol/L $C$ in liquid) and $\mathrm{PCO}_{2}$ as a function of $\mathrm{pH}$. It is assumed here that gas and liquid flows are known, and that the starting compositions of both the gas and liquid phases (at the sparger in the draft tube) are known. Thus a point can be drawn above the inlet liquid composition/pH point showing $\mathrm{PCO}_{2}$ of the inlet gas and liquid. Gas and liquid flows will be concurrent where the gaslift is used for pumping as well as $\mathrm{CO}_{2}$ transfer; thus the sum of gas and liquid fluxes upward is constant. Specifically,

$$
Q_{g}\left(V_{L}+30\right) P_{C O 2} / R T=Q_{L} V_{L} T C
$$

where $\theta_{g}$ and $Q_{L}$ are flow rates of gas (S.T.P.) and liquid. The material balance of equation 21 can be used to construct a $\mathrm{PCO}_{2}$ for the gas phase corresponding to each $\mathrm{PCO}_{2}$ of the 1 iquid phase. The time needed for transfer can then be computed through the following iteration:

1) Starting with initial $\mathrm{PCO}_{2}$ of gas and liquid elements, choose a $\mathrm{PCO}_{2}$ increment for each (negative for gas, positive for liauid) by equation 21 small enough that use of averages for $P_{L}$ and $P_{g}$ gives acceptable error. Then the average driving force for transfer is $\left(\mathrm{PCO}_{2} \mathrm{gI}+\mathrm{PCO}_{2} \mathrm{gF}\right)-\left(\mathrm{PCO}_{2} L I+\mathrm{PCO}_{2} L F\right)=\mathrm{PCO}_{2}$ average. The subseripts $g, L, I$, and $F$ are gas, liquid, initial, final respectively. 


$$
\Delta T=\frac{\left(P_{\mathrm{CO}_{2}, 9, I}-P_{\mathrm{CO}_{2}, 9, F}\right)}{R T \mathrm{~kg} \cdot \Delta P_{\mathrm{CO}_{2}, \text { average }}}
$$

3) Repeat procedure for the next chosen increment of gas and Iiquid $\mathrm{PCO}_{2}$.

The procedure is continued until the final desired Pco2 values for gas and liquid are attained. The height needed for transfer is easilv derived from this time and the gas velocity $\left(V_{L}+30\right)$.

There certainlv exists a rigorous analytical solution for the height calculation, but it is almost certainly too messy to be useful. The preceding computation should, however, be easy to accomolish with an appropriate computer program.

\section{A11.12 COMBINED PUMPING AND GAS TRANSFER}

To this point in the analysis expressions have been developed for gas flow required for the pumping function, and for the draft tube height needed for $\mathrm{CO}_{2}$ transfer. Regarding which independent variables are to be fixed, two sets of circumstances are of interest: one situation is where the draft tube height is sufficient only to accomplish needed $\mathrm{CO}_{2}$ transfer, with the balance of pumping - if needed - accomplished by other means. The other situation is where transfer requirements are met and gas does all of the pumping work as well.

In a typical channel flow system, depth and flow velocity will be fixed on the basis of various criteria such as l) sufficiency to mix algae, 2) avoidance of erosion and sediment transport in unlined pond sysstems, 3 ) spacing of gas transfer and mixing stations, and other factors imore discussion is presented in reference 17). Choice of depth and channel flow velocity dictate pumping energy requirements and grade, or liquid surface slope in the direction of flow. Grade in turn determines pumping head $l=$ grade $x$ length of flow pathl. Carbon dioxide addition must be sufficient to meet the needs of photosynthesis by the algae. The assumption here is that algal productivity will average 75 metric tons/hectare yr., with a maximum productivity of $20 \mathrm{gm} / \mathrm{m}^{2}$. day and that $2 \mathrm{gms}$ of $\mathrm{CO}_{2}$ must be transferred to the system per gram of algae which is grown [17]. It is assumed that $\mathrm{CO}_{2}$ loss from the liquid surface - or in alternate terms, back diffusion to the atmosphere - is minimal so that the $\mathrm{CO}_{2}$-containing gas stream can be introduced into the systen, and mixing can be carried out, $24 \mathrm{hr} / d a y$. This is an operating characteristic important for system economics. For purposes of illustration and analysis, model systems will be assured with characateristics shown in Table All-2. 
TABLE AII-2

SYSTEM CHARAACTERISTICS USED FOR ILLUSTRATIONS (SEe TEXt)

A. Stack gas use

I. Channel flow velocity $=15 \mathrm{~cm} / \mathrm{sec}$

Channel Depth $=30 \mathrm{~cm}$

Pumping head $=7.2 \mathrm{~cm}$ (From Manning equation, $\mathrm{n}=.02$, pumping station $=3240 \mathrm{~m}$, $6 \mathrm{hr}$ circulation time)

Algal Productivity $=20 \mathrm{gm} / \mathrm{m}^{2}$. day

$\mathrm{CO}_{2}$ requirement $=40 \mathrm{gm} / \mathrm{m}^{2}$, day

$80 \%$ absorption of $\mathrm{CO}_{2}$ from gas stream

Required $Q_{g} / Q_{L}=0.1551 Q_{g}$ expressed at $25^{\circ} \mathrm{C}, 1$ ath. $15 \%$

$\left.\mathrm{CO}_{2}\right)$

Required $h_{L}$ for $80 \%$ absorption $=5.4 \mathrm{M}$

11. As above, except

Channel Flow Velocity $=30 \mathrm{~cm} / \mathrm{sec}$

Pumping station spacing $=6480$ meters

Pumping head $=58 \mathrm{~cm}$ ( $6 \mathrm{hr}$ circulation time)

$Q_{g} / Q_{L}=0.1391 Q_{g}$ at $25^{\circ} \mathrm{C} 1$ atm, gas has $15 \% \mathrm{CO}_{2}$ by voluae)

Required $h_{L}$ for $90 \%$ absorption $=13.4$ meters

B. Pure $\mathrm{CO}_{2}$ use

With pure $\mathrm{CO}_{2}$ (other assumptions above hald):

For $I, Q_{g} / Q_{L}=0.023$

II, $Q_{Q} / Q_{L}=0.0205$

See text for further discussion of pure $\mathrm{CO}_{2}$ case. 


\section{A11.13 COMPARISON OF GASLIFT PUMPING CAPACITY WITH CHANNEL GROWTH SYSTEM}

NEEDS

The choices for $\mathrm{CO}_{2}$ content of the sparged gas, in combination with desired fractional $\mathrm{CO}_{2}$ stripping and desired fluid flow velocity in the gaslift draft tube fix the gaslift oraft tube height. (Calculated heights for the examples are shown in Table AII-2, V Values chosen for these parameters also fix the gas holdup in the system, and power input which is directly proportional to gas holdup. Holdup needed to provide a given punoing head, from equation b, can be compared to the actual holdup from chosen parameters by equation 4. If holdup by equation 4) is less than needed from equation 6 ) then auxilliary pumping power must be provided.

Holdups calculated by equation 4 for case AI and AII are 0.0406 and 0.045 respectively. If the pumping head needs for the two systems are 7.2 and 58 cm, respectively, then pumping power availability is a factor of above three tjmes need for case AI, but is in almost perfect balance holdup computed at 1.04 times need) for the assumptions of case AIl. As there are uncertainties (discussed under "uncertainties" later) this must be consjdered a perfect match within computational precision.

For the pure $\mathrm{CO}_{2}$ transfer case, it is necessary to take into account the volumetric change as $\mathrm{CO}_{2}$ is absorbed during bubble rise. The situation is complicated by back diffusion of oxygen into the bubbles. The assumption made here is that the $\mathrm{CO}_{2}$ volume of the rising gas decreases exponentially with height las would occur with the constant bubble size distribution discussed earlier) but that back diffusion of oxygen is equal to $25 \%$ of the $\mathrm{CO}_{2}$ which diffuses out. For the $80 \% \mathrm{CO}_{2}$ absorption case, this leads to a final gas volume of $40 \%$ of the initial, and for the $95 \%$ absurption case, a volume which is $29 \%$ of the initial. The average gas flow (STP) used in computing holdup is considered to be the log mean of inlet and outlet, times a pressure correction factor, $P_{1} / P_{2}$, for a depth of $2 / 3$ of $h_{L} 13.6 M$ for case BI, 9M for BII) to account for the fact that the majority of gas is at lower than mean depth. (This correction factor is to be distinguished from the term CPE used earlier). With these assumption, the holdups for cases $B I$ and BII are 0.0035 and 0.00304 . These values are only $15 \%$ and $5 \%$ of need, respectivelly, for 15 and $30 \mathrm{~cm} / \mathrm{sec}$ channel flow velocities, so that an auxilliary pumping process would be needed where pure $\mathrm{CO}_{2}$ is used to supply carbon needs.

The above calculations are only illustrations, but it is evident that when $\mathrm{CO}_{2}$ is supplied by stock gas with plausible requirements for mixing velocity and fractional stripping, that gaslift pumping capacity can be capable of meeting total system needs. It is worth noting that a value of 0.02 was used for the Manning equation roughness, $n$ (See 22 for discussion). A value of $n=0.01$ could equally well be encountered with a smooth channel botton, which would mean for even channel flow velocities of $30 \mathrm{~cm} / \mathrm{sec}$ that pumping power of the stack gas transfer system could be well in excess of needs. At $n=0.01$, power availability for the pure $\mathrm{CO}_{2}$ ease could supply a large function, or possibly all pumping needs, if channel 
velocities of 5-10 cm/sec could be tolerated. Uncertainties which attend the estimates are discussed later, but a good match between gaslift pumping power and needs seems possible with reasonable assumptions.

A further important consideration is that the system must also be energy efficient, which is to say that the $\mathrm{CO}_{2}$ transfer/pumping functions should not consume a large function of system energy outout. Net energetics are examined next.

A11.14 NET ENERGETICS; GASLIFT ENERGY CONSUMPTION AS A FRACTION OF TOTAL GROWTH SYSTEM OUTPUT

In addition to choices made earlier, two additional parameters must be assumed in order to calculate energy demand of the gaslift system as a function of system output. These are (1) the gross system energy output per unit area per day, and 2 ) the thermal to mechanical conversion efficiency which is obtained when converting the oross energy output, in the form of dilute algae, to mechanical energy. The working assumption here for 11 is that the $20 \mathrm{gm} / \mathrm{m}^{2}$ day of alqae have a gross heating value of $5000 \mathrm{cal} / \mathrm{gm}$ (= 9000 BTU/1b) so that system gross energy output is $100 \mathrm{Keal} / \mathrm{m}^{2}$.day. A second assumption, without specifying mechanism, is that this gross energy can be converted to mechanical energy at a thermal - to mechanical conversion ratio, or efficiency, of $30 \%$. Available mechanical energy, from which energy for gaslift operation must come, is with this assumption $1.26 \times 10^{2}$ erg/m².day. Using equation (8) and a value of $E_{M L}=0.8$, the fraction of total svstem energy requirement for sample case AI of Table 2 is $7.9 \%$ and for All, pumping through $13.4 \mathrm{M}$, it is $15.2 \%$. These are fairly major, but not intolerable, levels of energy consumption. For cases BI and BII, where $\mathrm{CO}_{2}$ is pumped tohrough the same heads, with other assumption as presented earlier, consumptions are $1.2 \%$ and $2.2 \%$ of total system output. Carbon dioxide from some sources (e.g. geological reservoirsl may be pressurized. No energy at all would be required to sparge this $\mathrm{CO}_{2}$ if it is available on site at more than about 2 atmospheres.

\section{A11.15 UNCERTAINTIES}

A number of uncertainties exist in the preceding calculations regarding efficiency of gas transfer and net energy consumption by the gaslift. Many of these have already been mentioned, but it is worthwhile to review the possible sources of error and uncertainty here. Some sources of error and their magnitude are discussed below.

\section{A11.15.1 Value_for_Iransfer_Rate_for_Carbon_Digxide_in_Rising_Bubble_Swarm}

A value of $0.125 \mathrm{sec}^{-1}$ for $\mathrm{Kg}$ was derived based on the premise that gas bubbles in algal systems will behave as air bubbles do in steady-state dilute aqueous systems. There is major uncertainty in the assumption, but a 
range cannot be given to the uncertainty at this time. Experimental values for $\mathrm{Kg}$ are being observed at 2-5 times the $0.125 \mathrm{sec}^{-1}$ assumed here [22]. This may indicate high fractional $\mathrm{CO}_{2}$ stripping from small bubbles near the sparger before coalescence/dispersion establishes a steady state, or else, prevention of coalescence (hence maintenance of $5 m a l l e r \mathrm{CO}_{2}$ bubbles and higher $\mathrm{Kg}$ ) by surfactants in algal growth systems. Experimentation will be required to give some answers in this area. This topic is quite important as both energy consumption (but also available pumping capacity) are inversely proportional to $\mathrm{Kg}$.

\section{Al1.15.2 Variatígng_in_Channel_Roughness}

Values for $n$, the channel wall and bottom roughness, could easily vary by a factor of 3 , which could change power requirements by an equal factor. Establishment of the value for $n$ (if not 0.02 as assumed) will require considerably more analysis and is beyond the scope of this treatment.

\section{Al1.15.3 Iemperature/Hater Vagor_Corrections}

In computing energy consumption by the compressor, and buoyancy effect of sparged gas, account must be taken of temperature differences between the compressor inlet and in the rising column of bubbles in the draft tube. Corrections should also be made for variations in water vapor content between the two points. However, these corrections are 5 mall with minimum total error at less than $5 \%$.

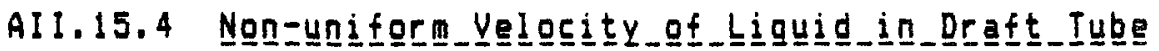

The calculation of pumping work done on the liquid by rising gas bubbles was predicated on liquid "plug flow," i.e. that all liquid elements in the draft tube had the same velocity. obviously, they do not, and there will be an efficiency loss relative to that calculated earlier if fluid has a velocity distribution characteristic of turbulent flow [21] even when gas bubbles are uniformly distributed over this area. This error in pumping efficiency calculating has been worked out [23; detail not shown] and is, surprisingly, less than $2 \%$. This error is small because the turbulent flow velocity profile is rather flat, though it does vary. If gas "channels," or is unequally distributed in the eross section, or travels in fluid elements having much greater than average velocity, then pumping efficiency losses could be large. It is not possible to state what the efficiency decrement might be, but in any event this situation can be avoided by sparaing so as to introduce gas uniformly over the draft tube cross section.

\section{AII.15.5 Changes_in_Eas_Streag}

Power input and efficiency were computed earlier for stack gas $\left(15 \% \mathrm{CO}_{2}\right)$ sparging on the basis of unchanging gas volume. However, the actual strean flow could actually change by as much as $15 \%$. This $15 \%$ seems to be the likely maximum error from this source. Back diffusion of $0_{2}$, and the fact that some $\mathrm{CO}_{2}$ remains with the gas stream during its rise, will probably 
keep this error to $10 \%$ or less, with stack gas. For pure $\mathrm{CO}_{2} 5$ parging, the gas absorption correction is obviously major, but $\mathrm{CO}_{2}$ pumping is not a major energetic drain (if any energetic drain at all) and pure $\mathrm{CO}_{2}$ sparging does not appear to suppiy enough pumping power in nost likely cases, to meet systen needs. Thus modeling gaslift pumping by pure $\mathrm{CO}_{2}$ streams does not seen to be a pressing need.

There are likely to be other sources of error which have not been considered. However, it seems that the surface roughness and $\mathrm{CO}_{2}$ absorption $\mathrm{Kg}$ uncertainties are dominant. Thus in summary, the conclusion must remain that a gaslift system capable of transferring stock gas should be capable of providing enough or more than enough pumping capacity to meet the needs of a high rate pond systen with channel flow velocities of $15-30$

cm/sec. Energy consumption for this approach should be a high $(5-25 \%)$ but tolerable function of systen output. 
REFERENCES

1. Hatch, R.T., Chemical Engineering Department, University of Maryland. Personal Communication, August 1984.

2. Parch, Proceedings of the Institute of Mechanical Engineers, 1917 ef Ref. 4 below.

3. Ivens, Trans. A.S.M.E. 1909 CF Ref. 4.

4. Mark's Mechanical Engineers Handbook p. 1874 Fourth Edition (1941).

5. Perry's Handbook of Chenical Engineering Pp. 5-39, 5-40, and 6-13. Fifth Edition, 1973 .

6. Dussap, C.J. and J.B. Gross. Energy Consumption and Interfacial Mass Transfer in an Airlift Fermenter. Chemical Engineering Journal (France) 25 151-162 (In English).

7. Moo-Young, M. and Blanch, H.W. Design of Biochenical Reactors: Mass Transfer Criteria for Simple and Complex Systems. Advances in Biochemical Engineering.

8. Hatch, R.T., Ph.D. Thesis, M.I.T., 1973.

9. Lippert, J., Adler, I., Meyer, M.0., Lubbert, A. and K. Schurgerl. Characterization of the Two-Phase Systems in Airlift Tower-Loop Readers During the Cultivation of E. Coli. Biotech. Bioeng. 25(2) p. 437-50 (1983).

10. Merchuk, J.C., Stern, Y. and R. I. Mateles. Distributed Parameter Model of an Airlift Fermenter. Biotech. Bioeng. 22 pp. 1189-1211 (1980).

11. Moresi, M. Optimal Design of Airlift Fermenters. Biotech. Biogng. 23 p. 2537-2560 (1981).

12. Schmid;t, F.L. alnd D.T. Redmon. Oxygen Transfer Efficiency in Deep Tanks. Journal Water Pollution Control Federation $47(11)$ 2586-2598 $(1975)$.

13. Augenstein, D.C. Oxygen Transfer in Fermenters at High Power Inputs. M.S. Thesis, M.I.T. (1967).

14. For example, in "Airlift Fermentation: A Bibliography to the BRL Airlift Fermenter, available from Bethesda Research Laboratories, Gartnersburg, Md. (1983). 
15. Vankrevelen. D.H. and Moftijzer, P.J. Studies of Gas Bubble Formation. Calculation of Interfacial Area in Gas-Liquid Contactors. Chemical Engineering Progress 46 p.29 (1950).

16. KCalderbank, R.M. and Moo-Young, M. "The Continuous Phase Heat and Mass Transfer Properties of Dispersions." Chemical Engineering Science $1639(1961)$.

17. Benemann, J.R., Goebel, R.P., Weissman, J.C. and D.C. Augenstein. "Algae as a Source of Liquid Fuels" Report for USDOE, DEACOS $81 \mathrm{ER}$ 30014, Mav, 1982.

18. Handbook of Chemistry and Physics. R.C. West, Ed. 90th Edition, 1958.

19. Lowenthal. R.E. and G.V.R. Marais, Carbonate Chemistry of Aquatic Systems, Ann Arbor Science, Ann Arbor, Mich. 1978.

20. McCabe, W. L. and Smith. J.C. Unit Operation of Chemical Engineering. MeGraw-Hill, 1956.

21. Aiba, S., Humphrey, A.E. and N.F. Millis. Gigochemigal Engingegring. Academic Press, N.Y. 1973.

22. Daugherty, R.L. and J.B. Fronzini. Fluid Mechanics with Engineering Applications. Seventh Edition MeGraw-Hill, 1977.

22. Weissman, J.C., and Goebel, R., Unpublished observations 1984.

23. Augenstein, D. Unpublished calculations, October 1984. 


\section{AIII-1 TRAVELLING SOLIDS REMOVER FOR POND SUMPS}

(By Joseph C. Dodd, Consulting Engineer)

Descrigtion_(See_Figure_AI $\underline{I}=\underline{1}$ )

Continuous rails are provided so that a single solids remover may service a number of pond sumps where the ponds are arranged to allow this. The rails are supported on piers and pond walls, with spacing to allow use of light rolled berms such as 6" or 8" WF or B sections (span 15-20 ft.). Steel sections at about $15 * / f t$ with a high quality protecive coating is preferred, although fiberglass sections are available but more expensive. The pier spacing must be coordinated with the walkway support requirements, which may be more critical if timber is used $12 " \times 10^{\prime \prime}$ stringers with 15 span previously used). Mininum pier thickness is b" for rebar cover.

The travelling solids renover is fabricated from 6" Cs, rolling on t" steel wheels with rubber treads (to protect coatings). Two wheels are driven by a hand crank to move the collector at the speed which just picks up the blanket of solids. A sight glass on the suction hose may be used to estimate the rate of travel. The collector is a stainless steel pipe arn with perforated tee pipe having rollers to maintain the desired botton elearance. The aris is pivoted up to clear the walls when transferring to another pond. It may also be moved along the solids remover rail to sweep several strips along the botton to remove as much settled solids as possible. The solids are pumped by a self-priming pump (e.g. progressing cavity).

Power supply to the pump and solids discharge hose are draped between a fixed mast at the center of the sump and a mast on the solids remover. Quick connect couplings allow transfer from one pond to the next. The discharge of solids is conveyed in a pipe supported along the walkway or rajl, either to disposal, or to a settling tank (s) for thickening and return of supernatant to the pond. The latter method reduces salt 1055 and disposal requirenents but adds to facilities cost and operational complexity.

\section{Cogts _for_-192_Hectare_(475_acrel__Systen}

For saline systems, frequency of cleaning is less than with wastewater systems, so two removers can probably handle 12 ponds, or a total of 4 removers for the 192 hectare systen. A 2" or 3" pump should be used, operated at a reduced speed (say 500 - $800 \mathrm{rpa}$ ) due to abrasive nature of solids. Settling tanks (if used) should be designed for 50 gp overflow rate of $3000 \mathrm{gpd} / \mathrm{ft}^{2}$. Need $24 \mathrm{ft}^{2}$ or approx. $6 \mathrm{ft}$. diameter, with hopper botton. 


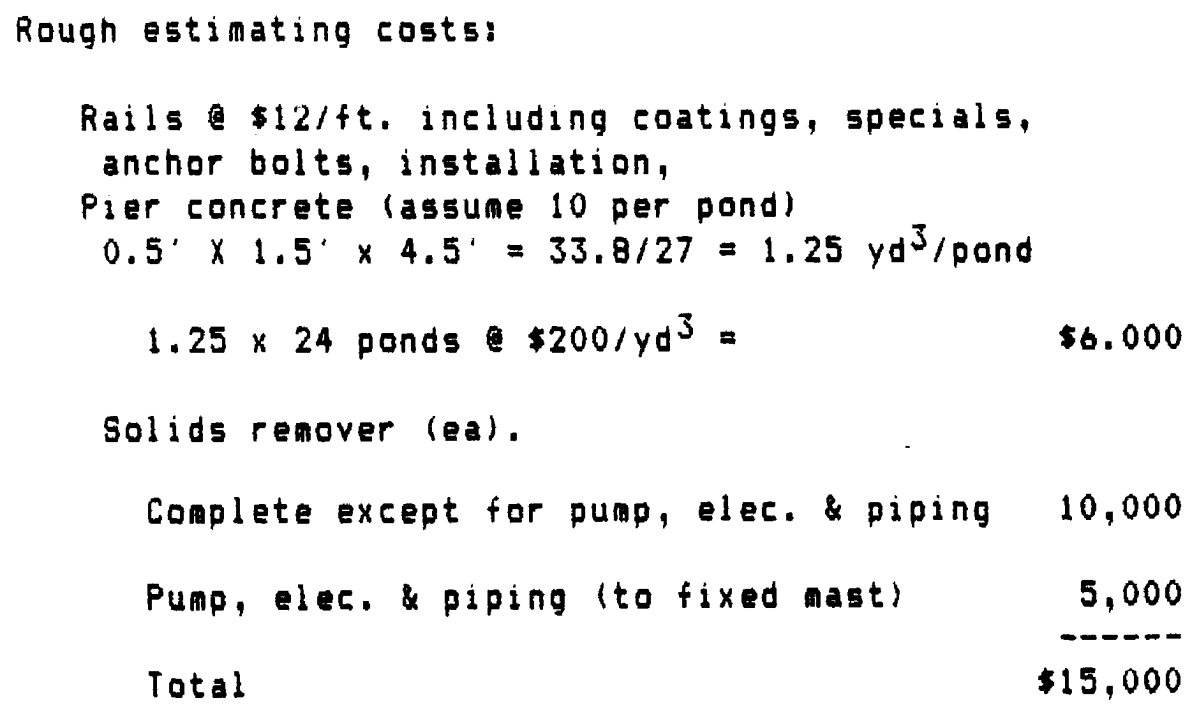


Figure A-III-1

Travelling Solids Remover for Pond Sumps

(Joseph Dodd, consulting engineer)

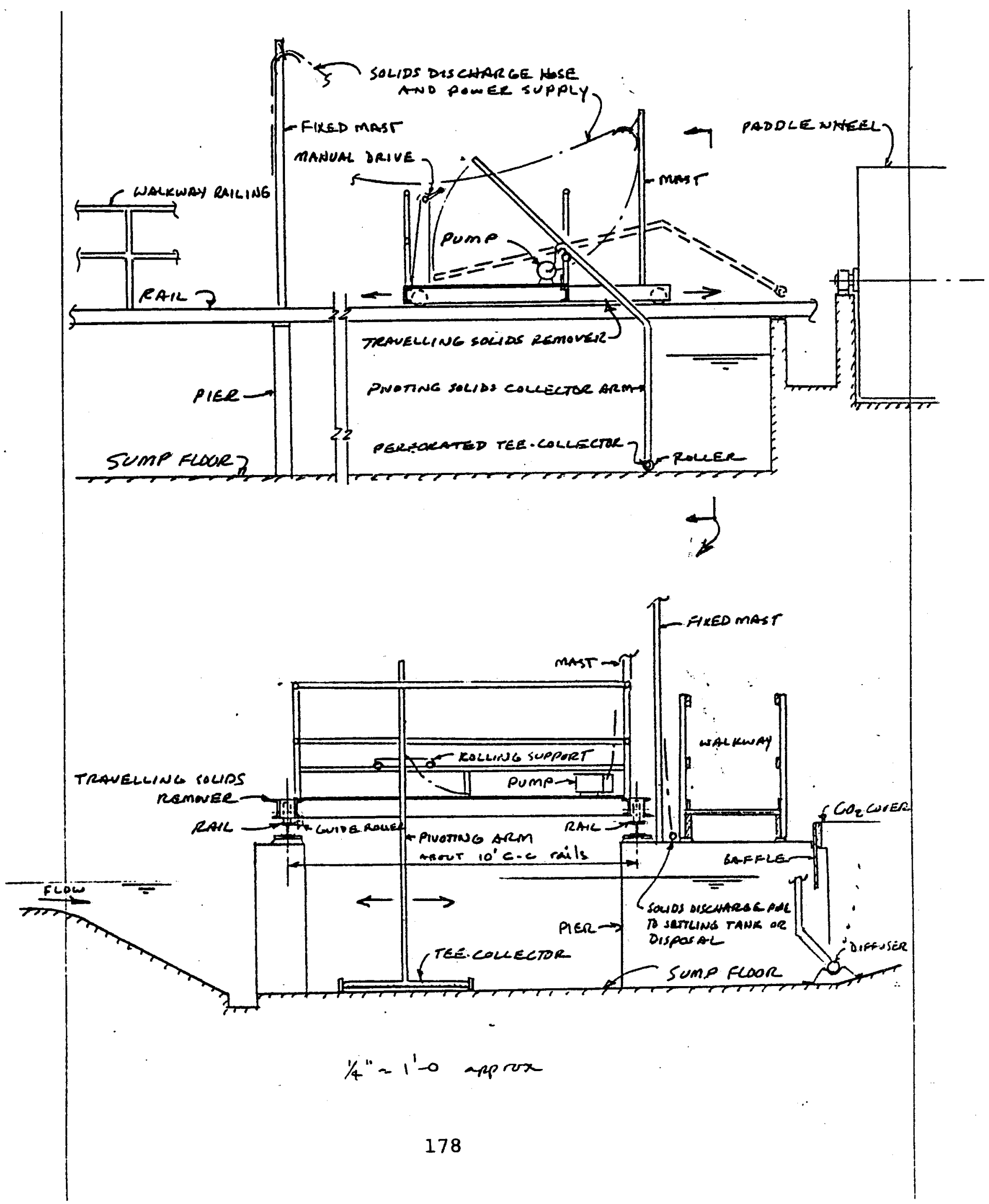


Appendix AIII-2

SLUDGE REMOVAL FROM SHALLOW GROWTH PONDS

(by Lloyd Bracewell, Consulting Engineer)

Shallow high rate algal growth ponds with mixing low velocities will eventually experience some settling out of organic and inorganic materials to form a sludge layer over the pond bottom. Since the growth ponds have only about 20 $\mathrm{cm}$ of depth, any significant layer of sludge would interfere in the pond's operation. It is therefore necessary to provide for the removal of sludges from the bottom of the growth ponds once the depth reaches about 15 percent of the water depth or $3 \mathrm{~cm}$. The proposed method of construction of the growth ponds and their layout create severe constrints on the methods that can be used cost-effectively for sludge removal. In particular, access is limited to the ends and the pond bottoms will be of earthen construction.

A form of hydraulic removal of sludge would therefore be most appropriate if required on a frequent basis. If the pond mixing velocity is increased several-fold then the sludge would be resuspended in the water column and the water could be withdrawn for settling in another basin with adequate detention time for solids removal. This approach would require sizing the mixer drive motors much larger than necessary for normal mixing purposes. One possible solution to keep the installed size of the motors to a minimum would be to design the mixing systm to include a power take-off so as to accommodate the installation of a supplemental driver only when sludge removal was needed.

The sludge removal approach proposed whenever thorough pond cleaning is required, such as annually, is to decant the pond water, install a boom and sludge pump arrangement, operated by $a$ winch and by a combination of dragging and pumping, move the sludge to small sumps at each end of each pond. The boom would be the width of the pond and dragged by several cables connected to winches installed on mounts for that purpose when needed to remove sludge. Small sludge pumps would be mounted on the boom with $100 \mathrm{ft}$ discharge pipes suspended along the pulling cables to keep excessive amounts of sludge from accumulating in front of the boom as it is dragged along the pond bottom toward a sludge sump. This reduces the load on the cables and boom as the sludge is gradually moved to the end of the pond. The sludge collected in the end slumps would be pumped to a storage pond for later disposal. The boom would be constructed of 12 by 12 inch wooden beams 20 feet long and hinged at each connecting joint for the width of the pond. A pulling cable would be attached at each of the connecting joints and attached to individual winches. A 3 horsepower sludge pump would be mounted on each section of the boom with its suction manifold set along the front of that section of the boom to pump sludge as it acculates in front of the boom. The pump discharge hose would be extended along the pulling cable approximately 100 feet to keep the pumped sludge ahead of the boom as it travels the length of the pond. The sludge as it was pumped would tend to flow, albeit slowly, toward the end of the pond since the dragging would be done in the direction of the pond gradient.

The estimated cost for a sludge removal system of this type is about $\$ 60,000$. A single system would be shared among all the ponds. 
Appendix AIII-3

DIVIDER WALL COST ESTIMATES*

METHOD
PETY MATERIALS
PER FT COST

1. HYPALON MEMBRANE

$\begin{array}{lrrrrrrr}\text { POSTS } & 0.250 & \$ 1.65 & \$ 0.41 & 0.025 & \$ 35.00 & \$ 0.88 & \$ 1.29 \\ \text { CONCRETE } & 0.004 & \$ 51.50 & \$ 0.19 & 0.004 & \$ 16.35 & \$ 0.06 & \$ 0.25 \\ \text { MEMBRANE } & 2.000 & \$ 0.50 & \$ 1.00 & 0.100 & \$ 16.35 & \$ 1.64 & \$ 2.64 \\ \text { RAILINGS } & 1.000 & \$ 1.00 & \$ 1.00 & 0.020 & \$ 16.35 & \$ 0.33 & \$ 1.33 \\ \text { TRENCHING } & 0.019 & \$ 1.00 & \$ 0.02 & & & & \$ 0.02 \\ & & & & & & & \\ & & & & & & & \end{array}$

2. CONCRETE BLOCK

\begin{tabular}{|c|c|c|c|c|c|c|c|}
\hline BLOCKSS & 1.780 & $\$ 0.66$ & $\$ 1.17$ & 0.130 & $\$ 16.35$ & $\$ 2.12$ & $\$ 3.30$ \\
\hline MORTAR & 0.080 & $\$ 2.60$ & $\$ 0.21$ & & & & $\$ 0.21$ \\
\hline GROUT & 0.244 & $\$ 2.25$ & $\$ 0.55$ & 0.067 & $\$ 16.35$ & $\$ 1.09$ & $\$ 1.64$ \\
\hline STEEL & 1.000 & $\$ 0.23$ & $\$ 0.23$ & 0.008 & $\$ 16.35$ & $\$ 0.13$ & $\$ 0.36$ \\
\hline FOOTING EXC & 0.019 & $\$ 1.00$ & $\$ 0.02$ & & & & $\$ 0.02$ \\
\hline CONCRETE & 0.019 & $\$ 50.00$ & $\$ 0.93$ & 0.041 & $\$ 16.35$ & $\$ 0.67$ & $\$ 1.60$ \\
\hline & & & & & \multicolumn{2}{|c|}{ TOTAL } & $\$ 7.1$ \\
\hline
\end{tabular}

3. POURED CONCRETE

$\begin{array}{lrrrrrrr}\text { CONCRETE } & 0.035 & \$ 51.50 & \$ 1.80 & 0.061 & \$ 14.40 & \$ 0.88 & \$ 2.68 \\ \text { STEEL } & 1.000 & \$ 0.23 & \$ 0.23 & 0.008 & \$ 16.35 & \$ 0.13 & \$ 0.36 \\ \text { FORMWORK } & 2.670 & \$ 0.10 & \$ 0.27 & 0.116 & \$ 17.35 & \$ 2.01 & \$ 2.28 \\ \text { FOOTING EXC } & 0.019 & \$ 1.00 & \$ 0.02 & & & & \$ 0.02 \\ & & & & & & & \\ & & & & & & & \end{array}$

4. PIFING**

\begin{tabular}{|c|c|c|c|c|c|c|c|}
\hline $\begin{array}{l}\text { PIPE } \\
\text { FOOTING }\end{array}$ & $\begin{array}{l}1.000 \\
0.025\end{array}$ & $\begin{array}{r}\$ 6.77 \\
\$ 50.00\end{array}$ & $\begin{array}{l}\$ 4.41 \\
\$ 1.25\end{array}$ & $\begin{array}{l}0.012 \\
0.055\end{array}$ & $\begin{array}{l}\$ 94.00 \\
\$ 16.35\end{array}$ & $\begin{array}{l}\$ 1.13 \\
\$ 0.90\end{array}$ & $\begin{array}{l}\$ 5.54 \\
\$ 2.13\end{array}$ \\
\hline & & & & & & TAL & $\$ 7.6$ \\
\hline
\end{tabular}

* Supplied by Lloyd Bracewell, consulting engineer ** Nat described in text 
Appendix AIII-5

Large Scale System Paddle Wheel Costs

- PADDLE WHEEL COST BREAKDOAH *

8.0 Hectare Basis

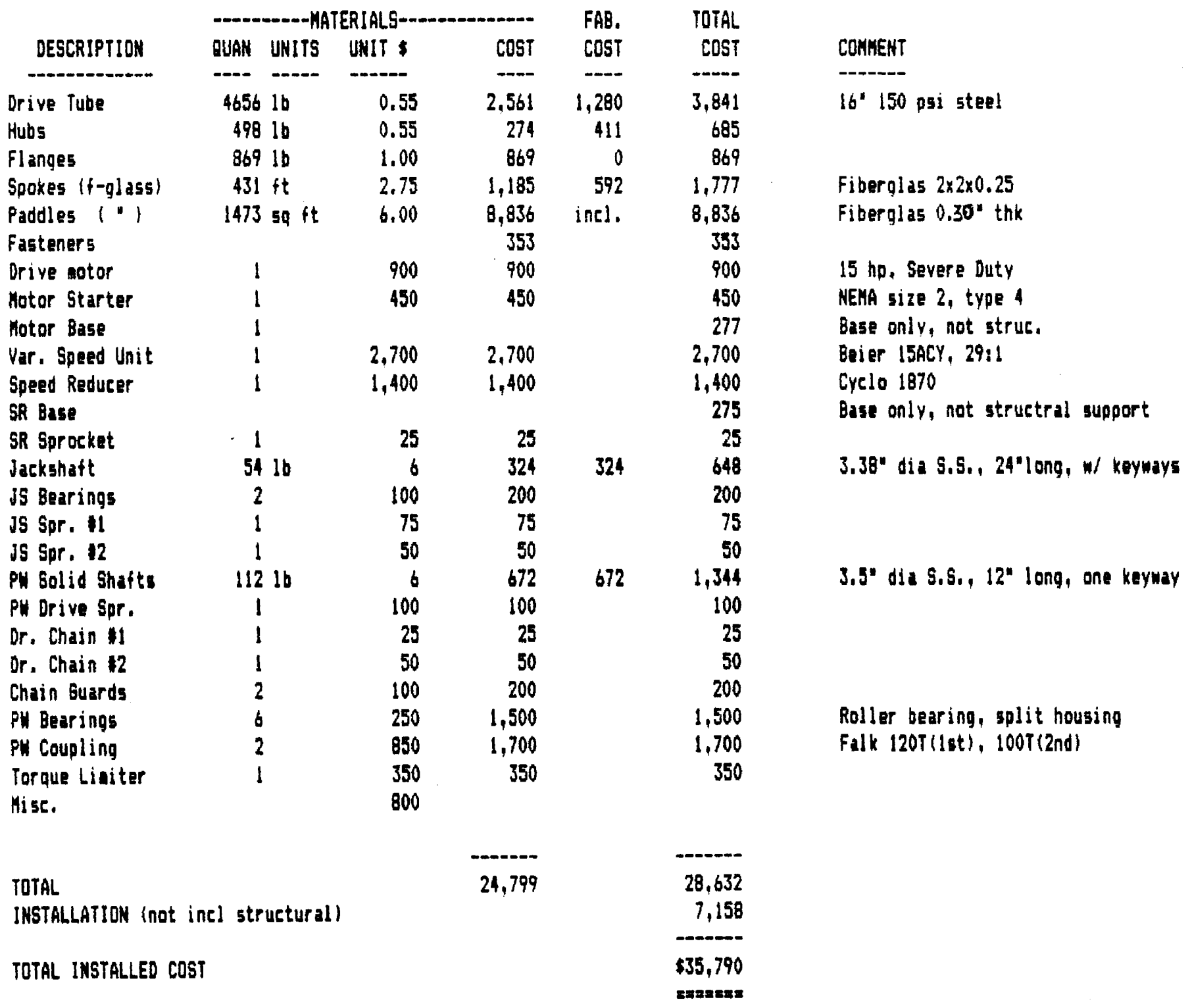


Appendix AIII-6

Experimental System Paddle Wheel Costs

- PADOLE MHEEL COST BREAKDOUN *

0.4 Hectare Basis

\begin{tabular}{|c|c|c|c|c|c|c|}
\hline \multirow[b]{2}{*}{ DESCRIPTION } & \multirow{2}{*}{\multicolumn{3}{|c|}{ - - }} & \multirow[b]{2}{*}{$\begin{array}{l}\text { FAB. } \\
\text { COST }\end{array}$} & \multirow[b]{2}{*}{$\begin{array}{l}\text { TOTAL } \\
\text { COST }\end{array}$} & \multirow{2}{*}{ COMMENT } \\
\hline & & & & & & \\
\hline - & -...- - & - no. & -- & $-\cdots$ & $\ldots$ & $-\cdots$ \\
\hline \multirow{2}{*}{$\begin{array}{l}\text { Drive Tube } \\
\text { Hubs }\end{array}$} & 819 16 & 0.60 & 492 & 246 & 737 & $8^{\prime \prime} \operatorname{sch} 40$ steel \\
\hline & 13916 & 0.60 & 84 & 125 & 209 & \\
\hline $\begin{array}{l}\text { Hubs } \\
\text { Flanges }\end{array}$ & 19516 & 1.00 & 195 & 0 & 195 & \\
\hline \multirow{2}{*}{$\begin{array}{l}\text { Spokes ( } f-g l a s s) \\
\text { Paddles }(\cdot) \\
\text { Fasteners }\end{array}$} & $140 \mathrm{ft}$ & 3.00 & 420 & 210 & 630 & Fitergl as $2 \times 2 \times 0.25$ \\
\hline & $331 \mathrm{sq} \mathrm{ft}$ & 6.00 & $\begin{array}{r}1,997 \\
79\end{array}$ & incl. & $\begin{array}{r}1,987 \\
79\end{array}$ & Fiberglas $0.25^{\prime}$ thk \\
\hline \multirow{2}{*}{$\begin{array}{l}\text { Drive notor } \\
\text { Hotor Starter }\end{array}$} & 1 & 350 & 350 & & 350 & 2 hp, Severe Duty \\
\hline & 1 & 200 & 200 & & 200 & NEFA size 0 , type 4 \\
\hline \multirow{2}{*}{ Motor Base } & 1 & & & & 47 & Base only, not strue. \\
\hline & 1 & 750 & 750 & & 750 & Beier 2ACY, $29: 1$ \\
\hline \multirow{2}{*}{$\begin{array}{l}\text { Speed Reducer } \\
\text { SR Base }\end{array}$} & 1 & 700 & 700 & & 700 & Cyclo 1870 \\
\hline & & & & & 273 & Base only, not structral support \\
\hline SR Sprocket & 1 & 25 & 25 & & 25 & \\
\hline \multirow{2}{*}{$\begin{array}{l}\text { Jackshaft } \\
\text { JS Bearings }\end{array}$} & 1416 & 7 & 99 & 98 & 196 & 1.63" dia S.5., 24"long, w/ keyways \\
\hline & 2 & 30 & 100 & & 100 & \\
\hline JS Spr. II & 1 & 50 & 50 & & 50 & \\
\hline JS Spr. 12 & 1 & 25 & 25 & & 25 & \\
\hline \multirow{2}{*}{$\begin{array}{l}\text { PU Solid Shafts } \\
\text { PW Drive Spr. }\end{array}$} & $10 \mathrm{lb}$ & 7 & 70 & 70 & 140 & 1.75' die S.S., 12" long, one keyway \\
\hline & 1 & 75 & 75 & & 75 & \\
\hline \multirow{2}{*}{$\begin{array}{l}\text { Or. Chain II } \\
\text { Or. Chain } 12\end{array}$} & 1 & 25 & 25 & & 25 & \\
\hline & 1 & 50 & 50 & & 50 & \\
\hline Chain Guards & 2 & 100 & 200 & & 200 & \\
\hline \multirow{2}{*}{$\begin{array}{l}\text { PW Bearings } \\
\text { PW Coupling }\end{array}$} & 2 & 150 & 300 & & 300 & Roller bearing, split housing \\
\hline & 0 & 850 & 0 & & 0 & \\
\hline Torque Liniter & 1 & 300 & 300 & & 300 & \\
\hline Misc. & 1 & 250 & 250 & & 250 & \\
\hline \multirow{2}{*}{\multicolumn{3}{|c|}{$\begin{array}{l}\text { TOTAL } \\
\text { INSTALLATION (not inel structural) }\end{array}$}} & 6,826 & & 7,897 & \\
\hline & & & & & 2,764 & \\
\hline \multicolumn{3}{|c|}{$\begin{array}{l}\text { TOTAL INGTALLED COST } \\
\text { (unit prices have been adjusted for quantity) }\end{array}$} & & & $\$ 10,661$ & \\
\hline
\end{tabular}


TABLE A-IV-1 SETTLING POND HARVEST OPTION 1st Stage Pumps and Pioing Costs

For one harvesting station serving 8 growth ponds (64 hectares). Includes 2 settling ponds, one pump station + piping.

Does not include secondary thickening (see $A-I V-2$ ).

PIPE: All pipe is "100 ft, head" PVC, includes installation

Pond orain lines

22 "dia $\times 2300 \mathrm{ft} \$ 20 / \mathrm{ft}=\$ 46,000$

Effluent return lines

22 " dia $\times 1100 \mathrm{ft} \$ 20 / \mathrm{ft}=$

22.000

Settling pond supernatant drain system

$16^{\prime \prime} \mathrm{dia} \times 200 \mathrm{ft} \$ 12 / \mathrm{ft}=2,400$

VALVES: All valves are low head type with epoxy coated cast iron bodies, stainless steel structurals, installed

Pond Drain (2 per pond)

$16 \times 22^{\prime \prime}$ canal gate $\$ 1200=19,200$

Effluent Return

$8 \times 22 "$ canal gate $\$ 1200=9,600$

$4 \times 18^{\prime \prime}$ adapt-to-line gates $\$ 1500=6,000$

Check valves at pumps $3 \$ 600=\quad 1,800$

Air release valves $10 \div \$ 250=\quad 2,500$

PUMPS: Primary supernatant, includes motor, starter and installation

$3 \times 12$ " vertical mixed flow pumps $\$ 9,000=27,000$

$\begin{array}{ll}\text { SuMP, with pump support } & 7,000\end{array}$

FITTINGS and MISC. $\quad 12,500$

TOTAL COST/HARVESTING STATION $\$ \$ 156,000$

TOTAL COST/HECTARE $\quad \$ 8,125$ 
TABLE A-IV-2. SETTLING POND HARVESTING OPTION Secondary Thickening Cost Breakdown

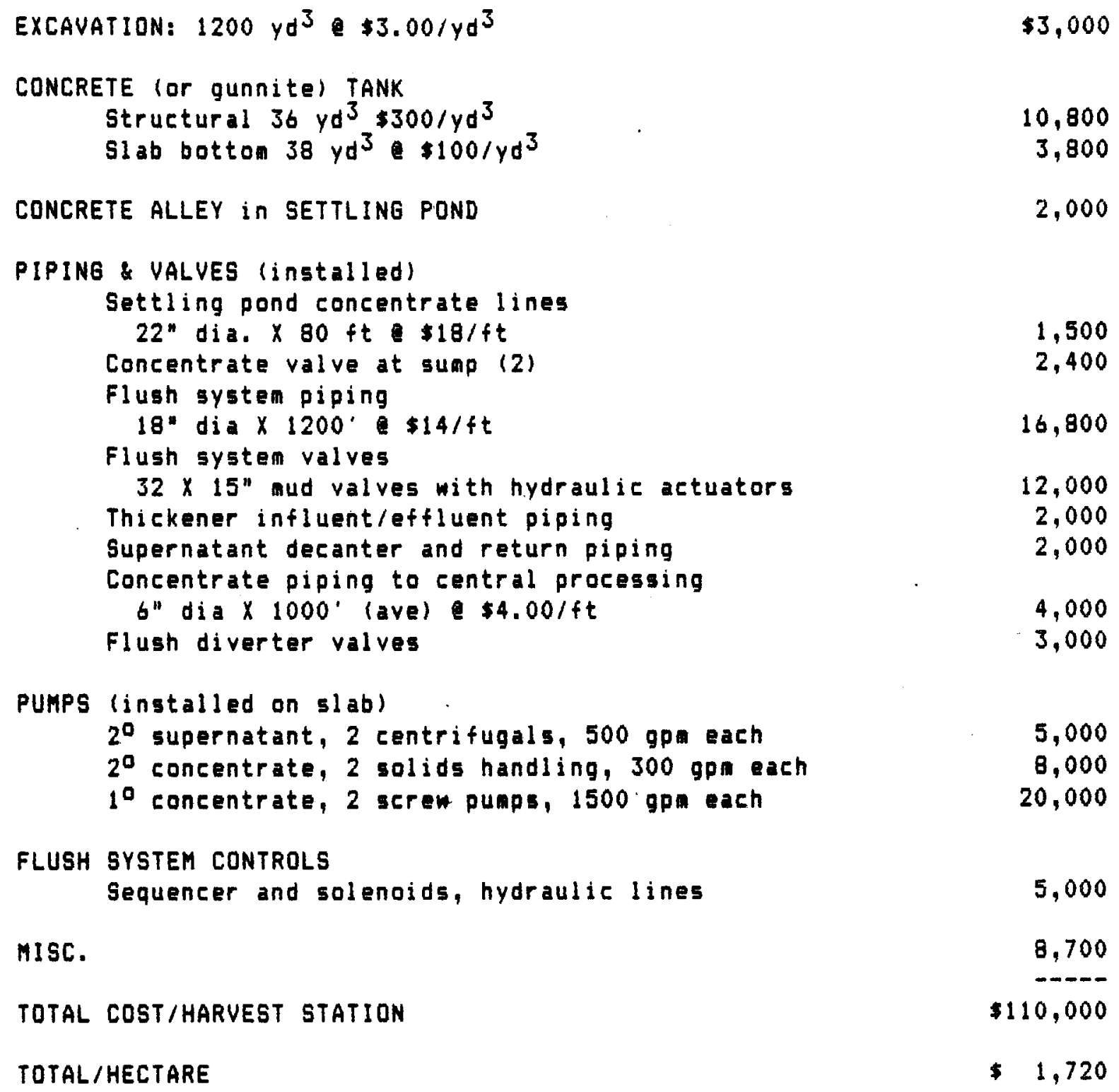


A COVEFED LAGOON BIOGAS SYSTEM

FOF ALGAE FROCESSING WASTES

\author{
by
}

\author{
Jeff Chandler \\ Jeff Chandler + Associates \\ 111421 st Street \\ Sacramento, California \\ (916) 456-0126
}

\title{
INTRODUCTION
}

The covered lagoon biogas system approach has been found wel $1-$ suited for a variety of 1 iquid wastes. For over 15 years 1 agoons have been covered for odor control or potable water protection. Hiogas produced by these first facilities was often viewed as a process byproduct requiring flaring. However in April of 1982 , the first covered lagoon system designed specifically for biogas collection and lutilization was placed into operation at a hog farm in California (Chandler et al, 198.). For the past three years this system has demonstrated itself as being efficient, low cost and easy to maintain system. Fiecently a similar system has been applied to distillery wastes. Thus the covered 1 agoon approach appears amendable to a large variety of agricultural and industrial 1 iquid wastes.

Covered 1 agoons are typically large unheated basins using floating rubber-like membrane covers. They have been found to be very efficient at converting wastes to biogas at temperatures as low as 50 degrees fahrenheit. Covered lagoons are suitable for ambient temperature waste streams in mild climate regions of the U.5. Since algae production facilities must also be located in warn regions, it appears that converting algae processing wastes to biogas using the covered lagoon approach holde promise.

In this report a covered lagoon biogas system for processing wastes from a 1000 acre al gae production facility is examined. This design uses the most current information and experience from other waste streams. This is a preliminary analysis and furtier worl: is necessary to verify the feasibility of the proposed design.

\section{DESIGN FARAMETERS}

The proposed 1000 acre facility is expected to produce 24,990 tons of processing waste volatile solids (VS) annually. The waste stream as-produced is 15 to 20 percent total solids (TS) of which 83 percent are VS. It has been assumed that 5,124 tons of VS are produced each month during a 6 month summer period is times anrual monthly average) and 1,041 tons of $V S$ are produced 
load during the summer months while only one unit will be operational during the winter. Each unit will be equipped with a automatic tracking device which will inatch gen-set cutput to biogas availability. These units are intended to be operated under lean burn conditions (air/fuel $=30 / 1$ ) inorder that air emission standards can be met without catalytic converters. Each unit will have its own heat rejection system. Both gen-set and heat rejection system will be trailer mounted by the system designer and delivered to the site as a turntey system. All three gen-sets will feed power to a single substation.

\section{DESIGN COST}

Table 5 presents the estimated installed cost of the covered lagoon system. The preparation and storage basin intended to have near-vertical gunite walls inorder to minimize the use of poured-in-place concrete. The covered lagoons were assumed not to need a bottom liner. Standard 45 mil 5 ply Hypalon is specified for the fluating covers. The total installed cost for the covered lagoon system including 15 perctent contingency and 20 percent engineering fee is $\$ 1,614,000$.

Table $b$ shows the turniey system costs for the 3 MW gen-set system. These costs were quoted by a commercial system fabricator with previous experience paclaging megawatt-size genset systems. The total turntey cost is $\$ 2,200,000$.

\section{DESIGN ECONOMICS}

lable? presents a economic suniary for the 3 MW covered 1 agoon biogas system. The total capital cost has been estimated at \$. 814,000. Gross electricity revenue has been estimated to exceed $\$ 1,000,000$ annually. Net electricity revenue is expected to exceed 745,000 and result in less than a 5 year paybact:

It should be again noted that the system described was sized to accomodate the maximum sumer processing waste production level. This to some degree has adverselv affected system economics because of the drastic seasonal variation in processing waste production. For example, the $g$ M system hes a very low instelled cost of 1,270 lul. If waste production could of been maintained at summer condition levels year round, the systen would poseibly pay for itself in lese than 3 yeare.

This simple analysis accounts oniy for the electricity derived revenue produced by the system. Obviously the system accomplishes some waste treatment and disposal berefit. It was assumed that the marlect value of solids removed from the lagoons and dried only equal their handling costs. Furthermore no credit has becn talken for the gen-set. recoverable waste heat. Thus the doscribed covered lagoon bicaas system could be beneficial in several ways to the 1000 acre alade production facility. 
each month during the o month winter period 0.5 times annual monthly average). This results in a three-fold seasonal variation in waste stream production. It was assumed for this design that conversion and treatment of all of the processing wastes year round is desirable thus 1 agoons and engine generators (gen-sets) were sized to accomodate summer production levels.

Table 1 presents important design parameters for sizing the covered 1 agoons. It has been assumed that the processing waste stream will require dilution to 7 percent $T S$ primarily due to it's high salt content. A high loading rate of 70 lbs/1000 cu ft - day was assumed. This loading rate has been employed with distillery wastes with low $\mathrm{pH}$ ( 4 or below). This is considered satisfactory given the long resulting hydraulic retention time (HRT) of 50 days and the near nuetral pH of the waste stream. In total, over 25 million gallons of covered lagoon volume is required.

Table 2 presents the estimated metharie and biogas yield from algae processing wastes. It has been assumed that algae processing will produce a readily degradable waste stream. A volatile solids destruction efficiency of 65 percent has been assumed. The high methane and biogas yields shown are assumed to be achievable year round. Any reduction in biogas production due to decreased winter lagoon temperatures should more than be compensated by very long winter HFT's of over 150 days.

Table 3 shows the estimated summer and winter average daily biogas and electricity production. Qver $1.6 \mathrm{million}$ standard cubic feet. (SCF) of biogas will be produced during summer months while only $0.5 \mathrm{mil} 1$ ion SCF is expected during winter months. Summer and winter electricity production capacities are 2970 and 990 kW respectively.

Table 4 presents a annual energy production summary for the covered lagoon system. Almost 373 million SCF of biogas Equivalent to 2.2 million therms of natural gas will be produced annually. A total of $15.9 \mathrm{mill}$ ion twh is expected to be produce. Recoverable waste heat from the gen-sets can range from $6.5,500$ to 103,100 mintul annually.

DESIGN DESCFIFIIGN

Figure 1 presents a block diagram of the 3 MW capacity covered 1 agoon biogas system. The system consists of a $110,000 \mathrm{ga} 110 \mathrm{n}$ waste preparation and storage basin where the as-recieved processing waste is diluted to 7 percent TS. The diluted waste is then pumped to three 8 million gallon capacity lagoons operated in parallel. Each lagoon has approximately $50,0005 q+t$ of Iiquid surface area. Liquid lagoon effluent is to be returned to the alqae production ponds as a nutrient supplement while solids will periodically be pumped from the bottom of each lagoon and undergo further 1 iquid solids separation in sand drying beds. Assuming less than 12 percent of inflow TS will reach the bottom and using a standard loading rate of $221 \mathrm{~b} / 5 \mathrm{f}$ f.t-yr (U.S.E.P.A., 1974), 8 acres of sand drying beds have been specified.

The biogas produced will be removed from the lagoons by suction blowers and used to directly fuel $\Xi$ - 1 MW turbocharged gen-sets. It is anticipated that all three units will be operated near full 
COVERED LAGOON SYSTEM DESIGN FARAMETERS

BASED ON SUMMEF PFIODUCTION LEVELS

Daily TS Froduction:
Daily US Froduction:
Influent TS Content:
Daily Flow:
Loading Fate:
Total Lagoon Volume Fequired:
Hydraulic Fetention Time:

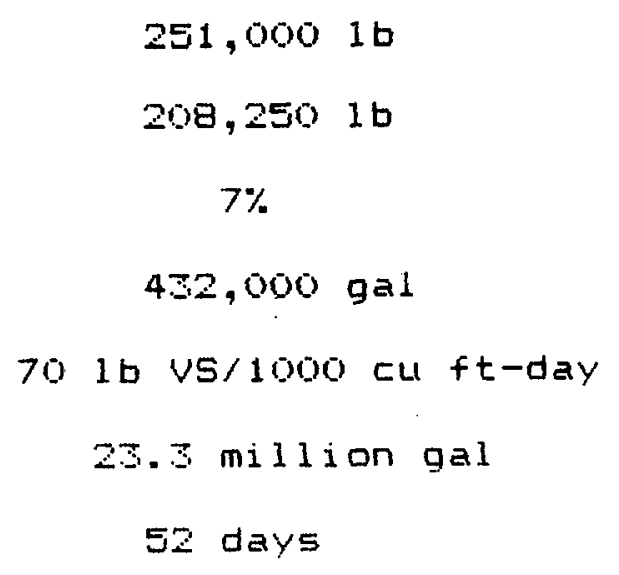

TABLE 2
US Destruction:

COD/VS (1):

Methane Content (1):

Methane rield:

Eiogas Yield:

1. Adapted from: Jewel 1 and Schraa, 1981
$65 \%$

1.25

$60 \%$

4. 85 SCF/16 VS added

8.04 SCF/1 1 VS added 


\section{TAGLE $\Xi$}

\section{SUMMEF: AND WINIEF AVEFAGE DAILY EIOGAS AND ELECTFICITY FFODUCTION}

$\begin{array}{lrr} & \text { Summer } & \text { winter } \\ \text { VS Froduction (1b): } & -08,250 & 69,400 \\ \text { Biogas Froduction (SCF): } & 1,074,550 & 558,100 \\ \text { Elec. Frod. (t:Wh/hr) (1): } & 71,250 & 29, \% 50 \\ \text { Ave. Capacity (f:W/hr): } & 2,970 & 990\end{array}$

1: 23.5 SCF/liwh average conversion efficiency assumed

\section{TABLE 4}

COVEFEO LGGOON BIOGAS SYSTEM ANINLIAL ENEFGY FRODULII ION SLMMAFY

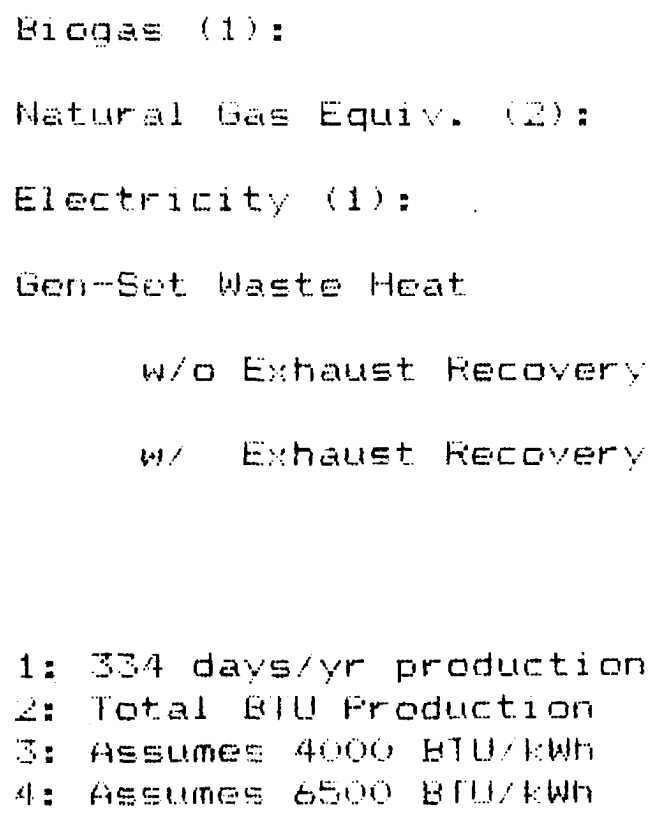




\section{ESTIMATED COVEFED LAGOON SYSTEM INSTALLED COST}

I. Freparation \& Storage Fit

1. 110,000 gal Gunite Easin @ $0.35 / g a 1$ :

38,500

2 Fump System:

17,500

3. Flumbing contrals:

25,000

4. Misc.

12,000

Subtotal:

$-\cdots-\cdots$

95,000

5. Contingency (15\%):

14,000

Total A:

$-\cdots$

107,000

II. Covered Lagoons

1. $3-50,000$ sq ft covers $0 \$ 2.35 / 5 q \mathrm{ft}$

2. Excavation 85,875 yds 保 $2.25 \% y d$ :

3 . Compaction 21,300 yds e $0.00 / y d:$

4. Lagoon Solids Flumbing:

5. Solids Drying 8 ar e 021,750 iac:

6. Gas Take-offs and Seals:

7. Gas Handling Serubbing:

8. Misc.:

Subtotal:

352,500

195,200

0.900

32,400

174,000

21,000

150,000

90,000

$1,07,000$

\%. Contingency (15\%):

162,000

Total B:

$1,239,000$

Total $A+E$ :

$1, .546,000$

II . Engineering (20\%):

268,000

lotal fnetalled cost:

$1,614,000$ 


\section{TAELE 6}

\section{S MW GEN-SET TUFNREY SYSTEM COSTS}

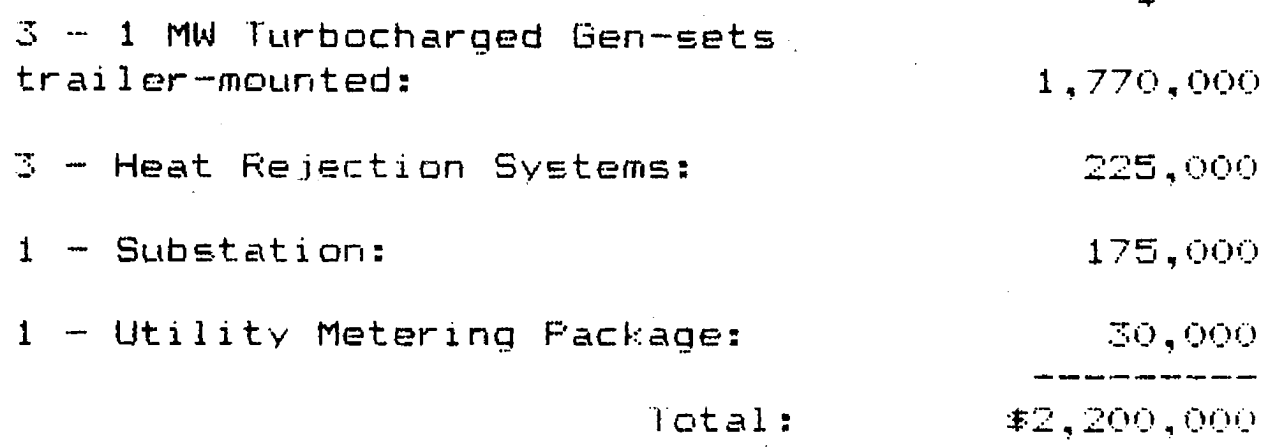

\section{TAELE 7}

I MW COVEFED LAGOON BIOGAS SYSTEM ECONOMIC SUMMAFYY

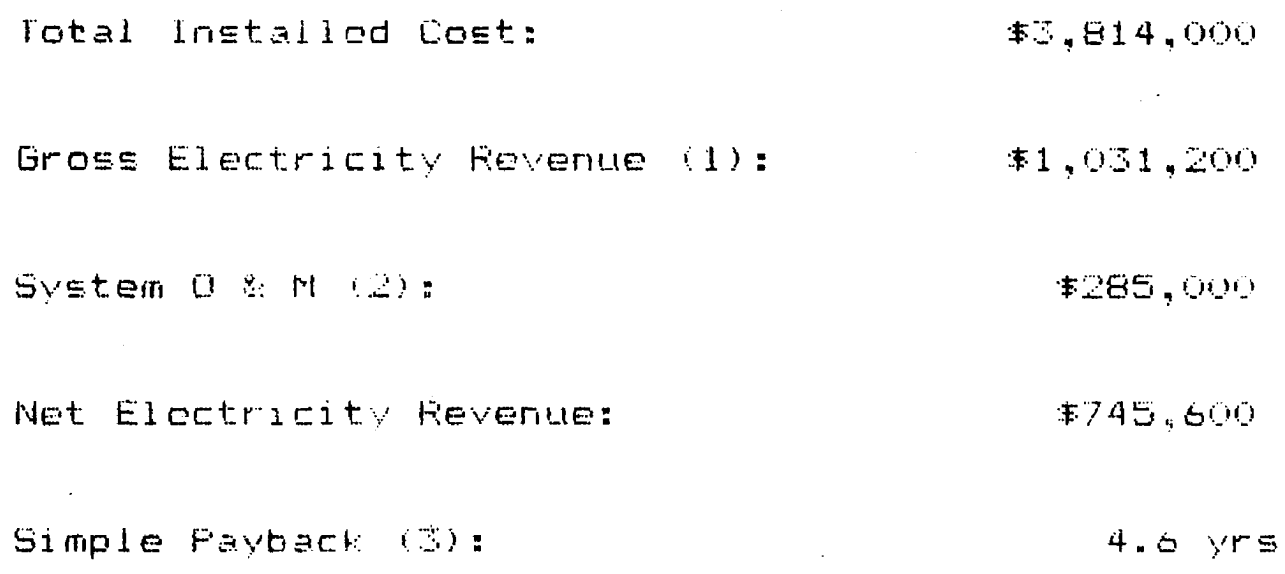




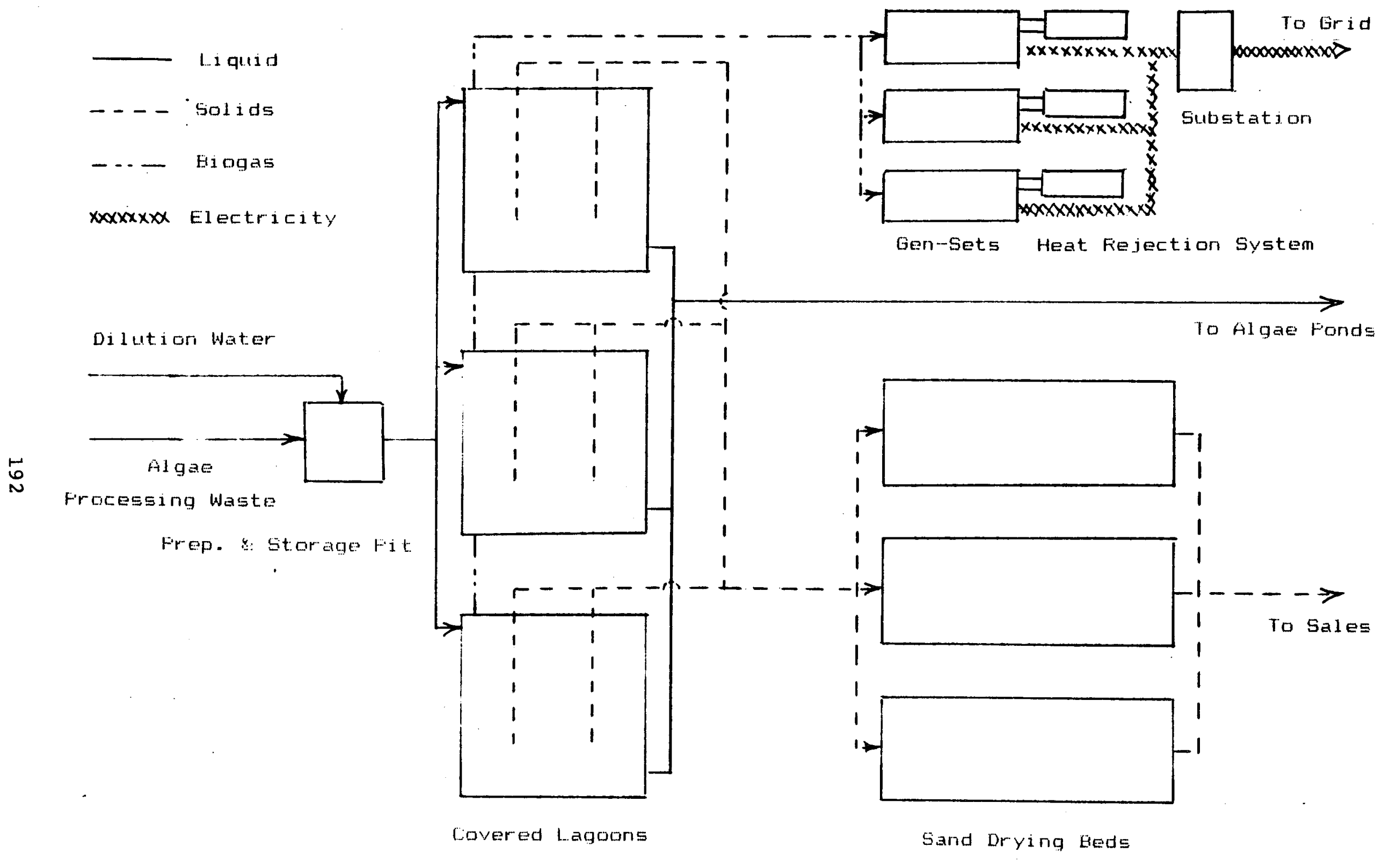

FIGURE 1: S WW CONEFED LAGOON BIOGAS SYSTEM FOK FROCESSING WASIES FFON A 1000 ACFE ALGAE FRODUCTION FACILITY 


\section{FEFEFEMUES}

1. Anonymous, USEFA "Frocese Design Manua1, Sludge Treatment Disposa1" EFA 625/1-74-000 Uctober 1974

2. Charider J. A., S. 3. Hermes, F. D. Smith "A Low Cost 75l:W Covered Lagoon Biogas System" Faper presented at ENEFGY FForl EIOMASS AND WASTES YII, Lette BuEne Vista, Florida January 251989

3. Jowall W. J. G. Gchra "Microalqae Separation, Concentration, Arrd Conversion 10 Fuel with Arr Anaerobic Expanded Eed Feactor" USDOE Finel Fefort \#xB-9-82-69-1-3 3uly 1981 
Table AVI-1a Capital Cost Sumary - Base Case

Basis: $\quad 112$ mt algae/ha/yr

GROWTH PONDS

Earthworks*

Walls \& Structural

Mixing System

Carbonation System

Instrumentation not included elsewhere

HARVESTING - Settling Pond Option

Primary**

Secondary (centrifugation)

SYSTEM-WIDE COSTS

Water Supply

Water Distribution

CO2 Distribution

Nutrient Supply Systen

Blowdown Disposal System*

Buildings (harv. blds. not included)

Roads drainage*

Electrical Distribution (3\% of above)

Electrical Supply

Machinery

ENGINEERING ( $10 \%$ of above)*

CONTINGENCY $(15 \%$ of above $) *$

LAND COSTS ( $\$ 1250 /$ hectare)*

TOTAL CAPITAL COST

DEPRECIABLE PORTION

NON DEPRECIABLE PORTION

\section{0 acres}

TOTAL \$

- -...--

$\$ 4,102,083$

$3,360,763$

$1,991,083$

740,667

202,368

$3,027,088$

$1,602,080$

15,766

8,344

$1,391,280$

398,412

105,400

316,200

337,280

231,880

210,800

540,522

238,204

168,640

\$ /HECTARE

$\$ 21,365$

17,504

10,370

3,858

1,054

$1,896,475$

$3,129,184$

7,246

2,075

549

1,647

1,757

1,208

1,098

2,815

1,241

878

9,877

16,298

$1,011,840$

5,270

$\ldots$

$\$ 25,002,250$

$---.---$

$\$ 130.220$

$\$ 13,939,587$

$\$ 72,602$

$\$ 11,062,662$

$\$ 57,618$

Notes:

* non-depreciable item

* partially non-depr. $(\$ 375,000)$

$112 \mathrm{mt} / \mathrm{ha} / \mathrm{yr}=30 \mathrm{~g} / \mathrm{m} 2 / \mathrm{day}$

Land area $=2 \times$ growth pond area 


\section{Table AVI-1b Operating Costs - Base Case}

Basis: $\begin{aligned} & 112.3 \mathrm{mt} \text { algae/ha/yr } \\ & (30 \mathrm{gm} / \mathrm{sq} \mathrm{m} / \mathrm{day})\end{aligned}$

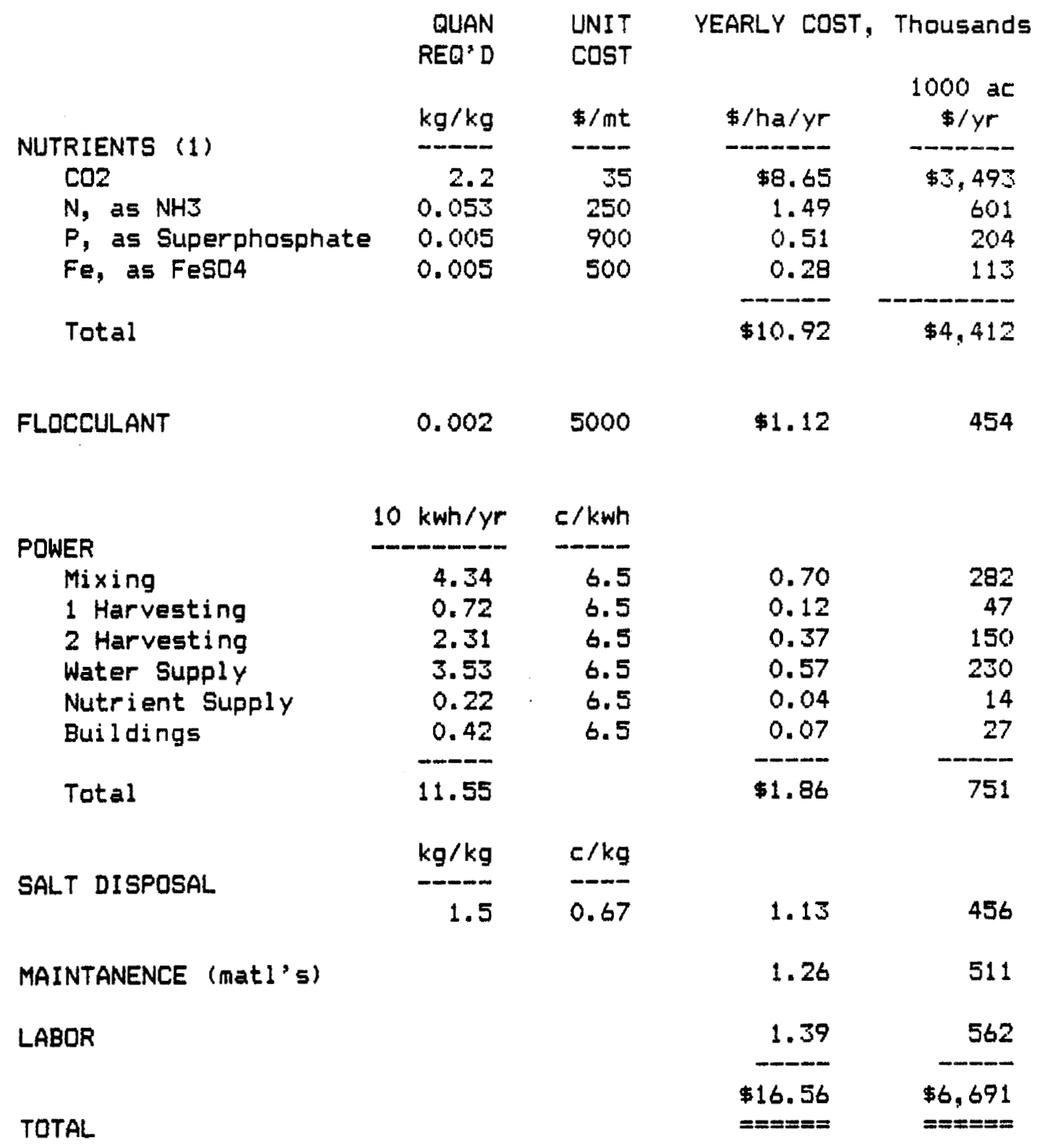

(1) $\mathrm{kg} / \mathrm{kg}=\mathrm{kg}$ required / $\mathrm{kg}$ algae produced 
Table AVI-2a Capital Cost Summary - Base Case + Nutrient Recycle Basisi $\quad 112$ mt algae/ha/yr

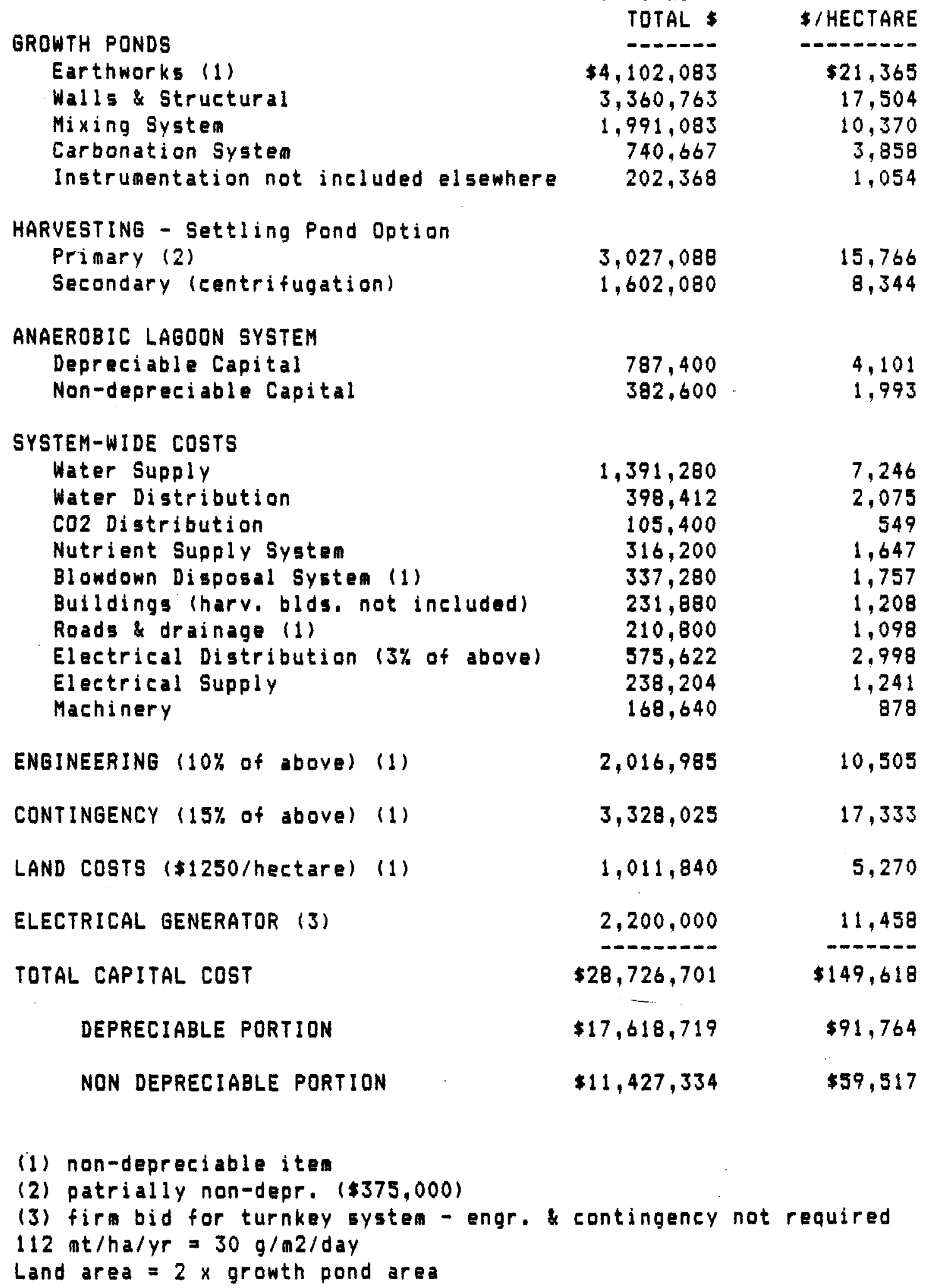

(1) non-depreciable iten

(2) patrially non-depr. $(\$ 375,000)$

(3) firm bid for turnkey system - engr. \& contingency not required $112 \mathrm{mt} / \mathrm{ha} / \mathrm{yr}=30 \mathrm{~g} / \mathrm{m} 2 / \mathrm{day}$

Land area $=2 \times$ growth pond area 
Table AVI-2b Operating Costs - Base Case + Recycle

Basis: $112.3 \mathrm{mt}$ algae/ha/yr

( $30 \mathrm{gm} / \mathrm{sq} \mathrm{m} / \mathrm{day}$ )

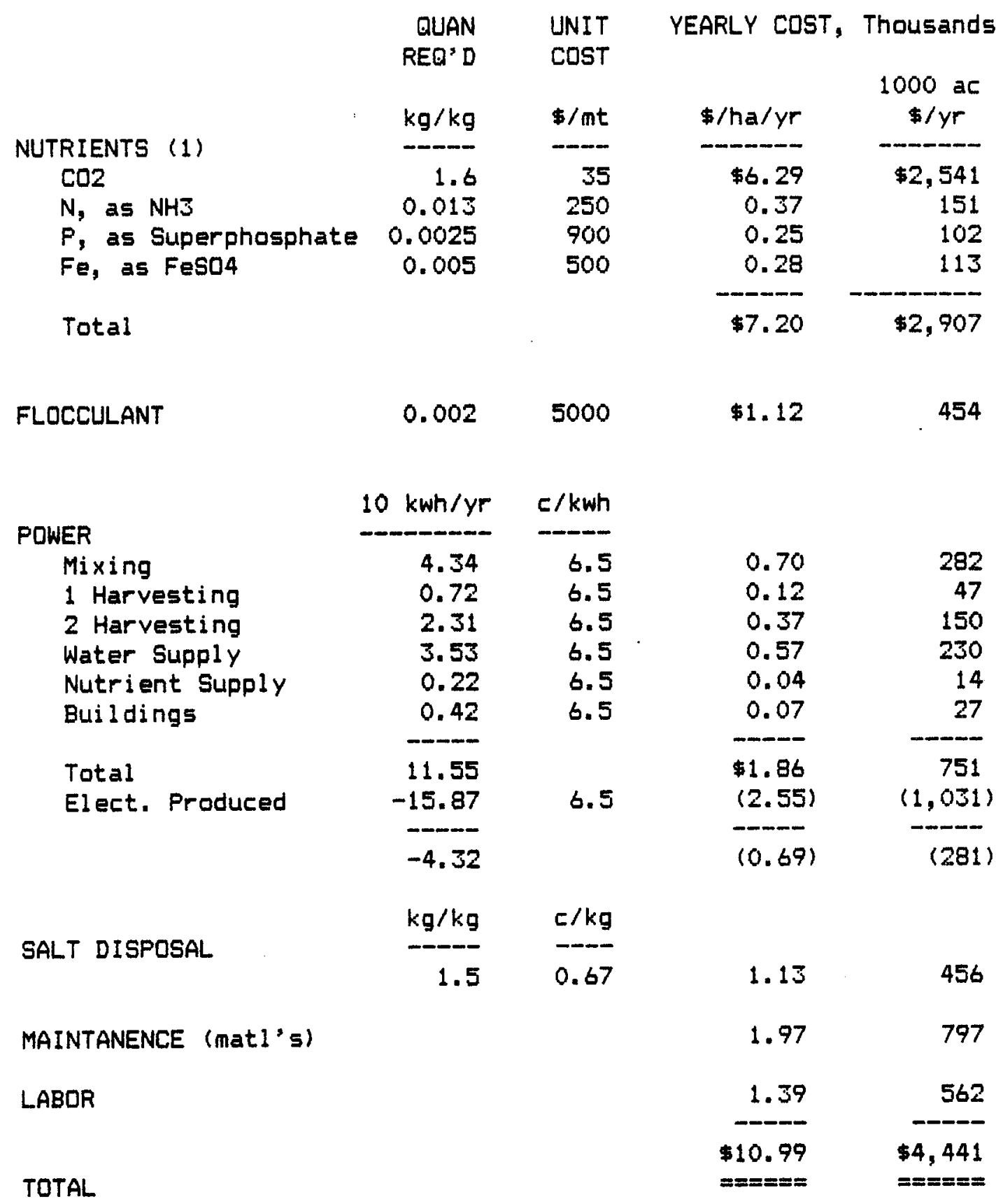

(1) $\mathrm{kg} / \mathrm{kg}=\mathrm{kg}$ required / $\mathrm{kg}$ algae produced 
Table AVI-3a Capital Cost Sumary - $0.5 \times$ Prod. + Recycle

Basis: 56.2 mt algae/ha/yr

GROWTH PONDS

Earthworks (1)

Walls \& Structural

Mixing System

Carbonation System

Instrumentation not included sewhere

$$
1000 \text { acres }
$$

TOTAL \$

TOTAL

$\$ 4,102,083$

$3,360,763$

$1,991,083$

457,073

$\$$ /HECTARE

202,368

$\$ 21,365$

17,504

10,370

2,381

1,054

HARVESTING - Settling Pond Option

Primary (2)

Secondary (centrifugation)

$3,027,088$

988,660

15,766

5,149

ANAEROBIC LAGOON SYSTEM

Depreciable Capita]

Non-depreciable Capital

SYSTEM-WIDE COSTS

Water Supply

Water Distribution

CO2 Distribution

Nutrient Supply System

Blowdown Disposal Systen (1)

Buildings (harv, blds, not included)

Roads \& drainage (1)

Electrical Distribution (3\% of above)

Electrical Supply

Machinery

ENGINEERING (10\% of above) (1)

CONTINGENCY (15\% of above) (1)

LAND COSTS (\$1250/hectare) (1)

ELECTRICAL GENERATOR (उ)

TOTAL CAPITAL COST

DEPRECIABLE PORTION

NON DEPRECIABLE PORTION
191,300

$1,391,280$

398,412

65,043

316,200

337,280

231,880

210,800

529,950

238,204

168,640

$3,069,299$

$1,011,840$

$1,100,000$

-.-.-.-.--

$\$ 25,643,129$

$\$ 14,566,771$

$\$ 10,820,503$
393,700

$1,860,181$
2,051

996

7,246

2,075

339

1,647

1,757

1,208

1,098

2,760

1,241

878

9,688

15,986

5,270

5,729

$-0-0-$

$\$ 133,558$

$\$ 75,869$

$\$ 56,357$

(1) non-depreciable itea

(2) patrially non-depr. $(\$ 375,000)$

(3) firm bid for turnkey systen - engr. contingency not required

$112 \mathrm{mt} / \mathrm{ha} / \mathrm{yr}=30 \mathrm{~g} / \mathrm{m} 2 / \mathrm{day}$

Land area $=2 \times$ growth pond area 
Table AVI-3b Operating Costs - .5xProd. + Recycle

Basis: $\quad 56.15 \mathrm{mt}$ algae/ha/yr

(15 gm/sq $\mathrm{m} /$ day)

\begin{tabular}{|c|c|c|c|c|}
\hline & $\begin{array}{r}\text { QUAN } \\
\text { REQ'D } \\
\mathrm{kg} / \mathrm{kg}\end{array}$ & $\begin{array}{l}\text { UNIT } \\
\text { COST } \\
\text { \$/mt }\end{array}$ & YEARLY COST, & $\begin{array}{c}1000 \text { ac } \\
\$ / y r\end{array}$ \\
\hline $\begin{array}{l}\text { NUTRIENTS (1) } \\
\text { CO2 } \\
\text { N, as NH3 } \\
\text { P, as Superphosphate } \\
\text { Fe, as FeSO4 }\end{array}$ & $\begin{array}{r}1.6 \\
0.013 \\
0.0025 \\
0.005\end{array}$ & $\begin{array}{r}35 \\
250 \\
900 \\
500\end{array}$ & $\begin{array}{r}\$ 3.14 \\
0.19 \\
0.13 \\
0.14\end{array}$ & $\begin{array}{r}\$ 1,270 \\
75 \\
51 \\
57\end{array}$ \\
\hline Total & & & $\$ 3.60$ & $\$ 1,454$ \\
\hline FLOCCULANT & 0.002 & 5000 & $\$ 0.56$ & 227 \\
\hline & $10 \mathrm{kwh} / \mathrm{yr}$ & c/kwh & & \\
\hline $\begin{array}{l}\text { Mixing } \\
1 \text { Harvesting } \\
2 \text { Harvesting } \\
\text { Water Supply } \\
\text { Nutrient Supply } \\
\text { Buildings }\end{array}$ & $\begin{array}{l}4.34 \\
0.72 \\
1.43 \\
3.53 \\
0.22 \\
0.42\end{array}$ & $\begin{array}{l}6.5 \\
6.5 \\
6.5 \\
6.5 \\
6.5 \\
6.5\end{array}$ & $\begin{array}{l}0.70 \\
0.12 \\
0.23 \\
0.57 \\
0.04 \\
0.07\end{array}$ & $\begin{array}{r}282 \\
47 \\
93 \\
230 \\
14 \\
27\end{array}$ \\
\hline $\begin{array}{l}\text { Total } \\
\text { Elect. Produced }\end{array}$ & $\begin{array}{l}10.67 \\
-7.93\end{array}$ & 6.5 & $\begin{array}{l}\$ 1.72 \\
(1.28)\end{array}$ & $\begin{array}{l}693 \\
(516)\end{array}$ \\
\hline & 2.74 & & 0.44 & 178 \\
\hline & $\mathrm{kg} / \mathrm{kg}$ & $\mathrm{c} / \mathrm{kg}$ & & \\
\hline 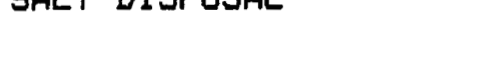 & 1.5 & 0.67 & 1.13 & 457 \\
\hline MAINTANENCE (matl's) & & & 1.64 & 663 \\
\hline LABOR & & & 1.39 & 562 \\
\hline TOTAL & & & $\begin{array}{r}\$ 8.20 \\
======\end{array}$ & $\begin{array}{l}\$ 3,312 \\
======\end{array}$ \\
\hline
\end{tabular}

(1) $\mathrm{kg} / \mathrm{kg}=\mathrm{kg}$ required / $\mathrm{kg}$ algae produced 
Table AVI-4a Capital Cost Summary - $0.67 \times$ Prod. + Recycle

Basis: $75 \mathrm{mt}$ algae/ha/yr

\begin{tabular}{|c|c|c|}
\hline $\begin{array}{l}\text { GROWTH PONDS } \\
\text { Earthworks (1) } \\
\text { Walls Structural } \\
\text { Mixing System } \\
\text { Carbonation Systen } \\
\text { Instrumentation not included el sewhere }\end{array}$ & $\begin{array}{r}\text { TOTAL } \$ \\
-1,--- \\
3,362,083 \\
1,991,083 \\
560,646 \\
202,368\end{array}$ & $\begin{array}{r}\$ \text { /HECTARE } \\
\$ 21,365 \\
17,504 \\
10,370 \\
2,920 \\
1,054\end{array}$ \\
\hline $\begin{array}{l}\text { HARVESTING - Settling Pond option } \\
\text { Primary (2) } \\
\text { Secondary (centrifugation) }\end{array}$ & $\begin{array}{l}3,027,088 \\
1,212,690\end{array}$ & $\begin{array}{r}15,766 \\
6,316\end{array}$ \\
\hline $\begin{array}{l}\text { ANAEROBIC LAGOON SYSTEM } \\
\text { Depreciable Capital } \\
\text { Non-depreciable Capital }\end{array}$ & $\begin{array}{l}527,558 \\
256,342\end{array}$ & $\begin{array}{l}2,748 \\
1,335\end{array}$ \\
\hline $\begin{array}{l}\text { SYSTEM-WIDE COSTS } \\
\text { Water Supply } \\
\text { Water Distribution } \\
\text { CO2 Distribution } \\
\text { Nutrient Supply Systen } \\
\text { Blowdown Disposal Systen (1) } \\
\text { Buildings (harv. blds. not included) } \\
\text { Roads \& drainage (1) } \\
\text { Electrical Distribution (3\% of above) } \\
\text { Electrical Supply } \\
\text { Machinery }\end{array}$ & $\begin{array}{r}391,280 \\
398,412 \\
79,782 \\
316,200 \\
337,280 \\
231,880 \\
210,800 \\
546,188 \\
238,204 \\
168,640\end{array}$ & $\begin{array}{r}7,246 \\
2,075 \\
416 \\
1,647 \\
1,757 \\
1,208 \\
1,098 \\
2,845 \\
1,241 \\
878\end{array}$ \\
\hline ENGINEERING (10\% of above) (1) & $1,915,929$ & 9,979 \\
\hline CONTINGENCY (15\% of above) (1) & $3,161,283$ & 16,465 \\
\hline LAND COSTS ( $\$ 1250 /$ hectare) (1) & $1,011,840$ & 5,270 \\
\hline ELECTRICAL GENERATOR (उ) & $1,474,000$ & 7,677 \\
\hline TOTAL CAPITAL COST & $\$ 26,722,339$ & $\$ 139,179$ \\
\hline DEPRECIABLE PORTION & $\$ 15,293,753$ & $\$ 79,655$ \\
\hline NON DEPRECIABLE PORTION & $\$ 11,03$ & $\$ 57,465$ \\
\hline
\end{tabular}
1000 acres

ROWTH PONDS

Eartiworks (1)

Walls \& Structural

Mixing System

Carbonation System

Instrumentation not included elsewhere

VESTING - Settling Pond option

Prinary $(2)$

$3,027,088$

5,766

$991,083 \quad 10,370$

$560,646 \quad 2,920$

, 054

AEROBIC LAGOON SYSTEM

Depreciable Capital

527,558

2,748

, 335

TEM-WIDE COSTS

Water Supply

Water Distribution

CO2 Distribution

Nutrient Supply System

Blowdown Disposal Systen (1)

Buildings (harv, blds. not included)

Roads \& drainage (1)

Electrical Distribution (3\% of above)

546,188

, 246

, 075

, 647

, 757

1,208

1,098

2,845

, 241

878

Machinery

238,204

, 979

CONTINGENCY (15\% of above) (1)

$3,161,283$

, 465

LAND COSTS ( $\$ 1250 /$ hectare) (1)

$1,011,840$

, 270 
Table AVI-4b Operating Costs - .67xProd. + Recycle

Basis: $75 \mathrm{mt}$ algae/ha/yr
$(20 \mathrm{gm} / \mathrm{sq} \mathrm{m} /$ day)

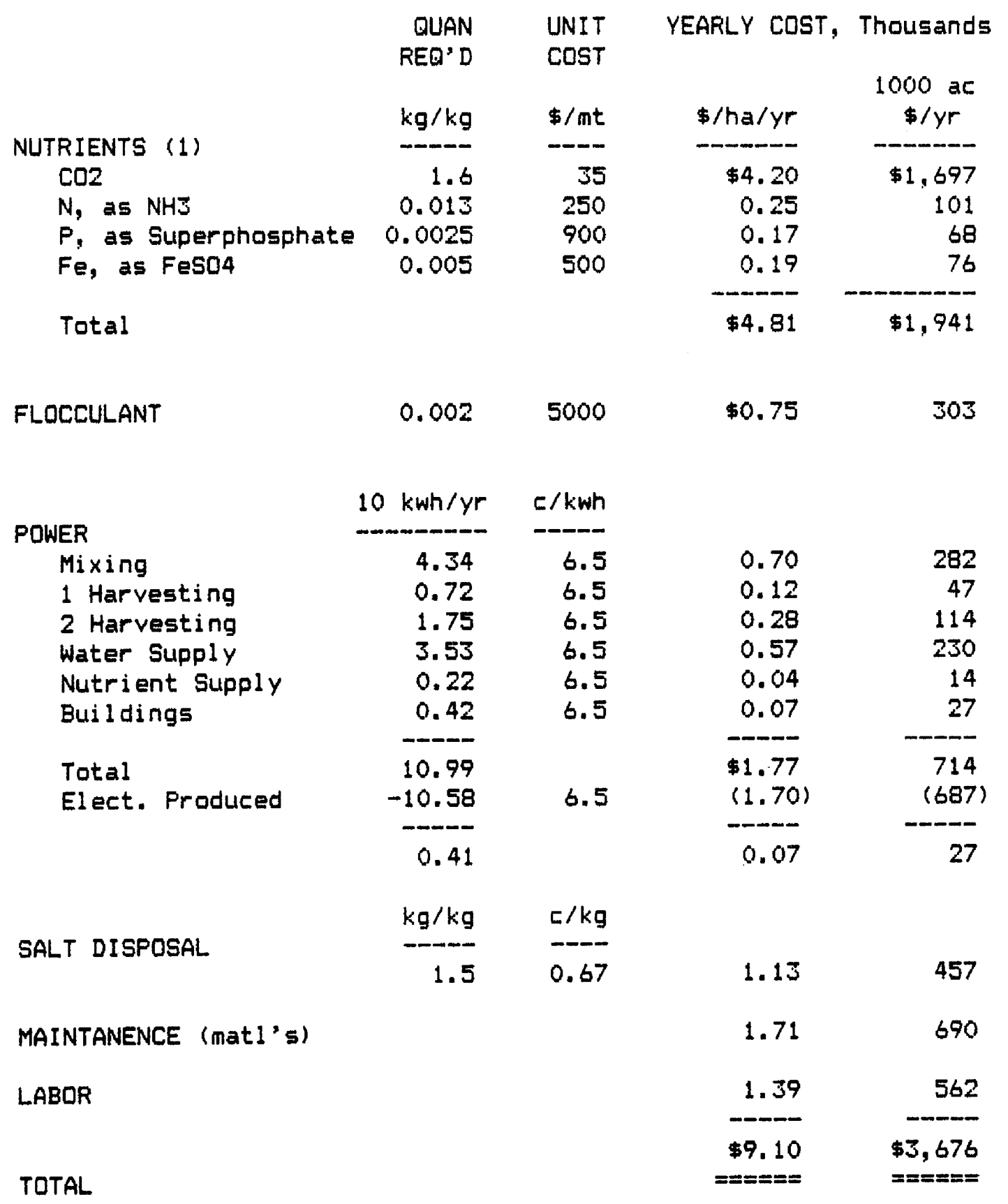

(1) $\mathrm{kg} / \mathrm{kg}=\mathrm{kg}$ required / $\mathrm{kg}$ algae produced 
Table AVI-5a Capital Cost Summary - $1.5 \times$ Prod. + Recycle

Basis: $\quad 168$ mt algae/ha/yr

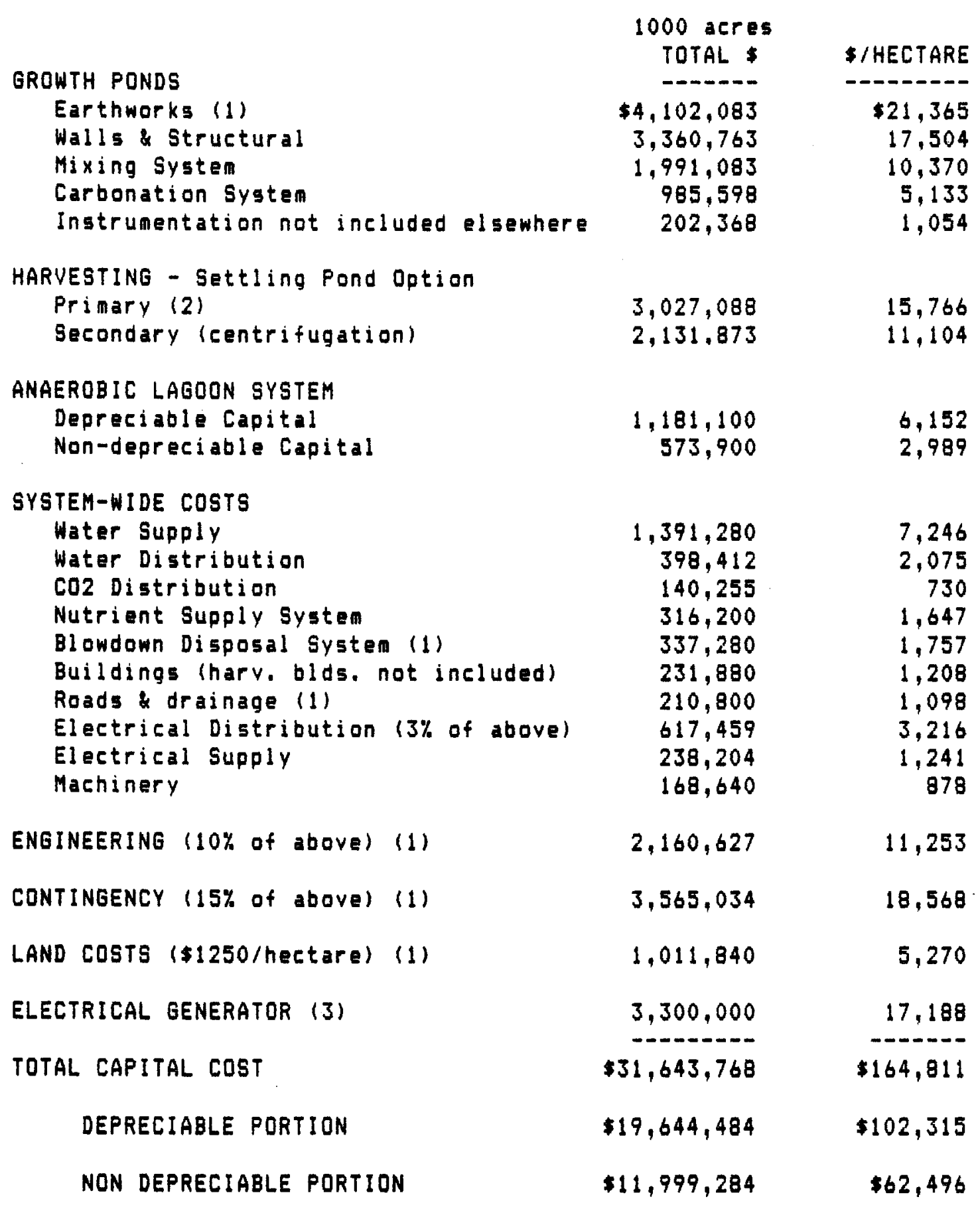

(1) non-depreciable iten

(2) patrially non-depr. $(\$ 375,000)$

(3) firm bid for turnkey system - engr. L contingency not required

$112 \mathrm{mt} / \mathrm{ha} / \mathrm{yr}=30 \mathrm{~g} / \mathrm{m} 2 / \mathrm{day}$

Land area $=2 \times$ growth pond area 


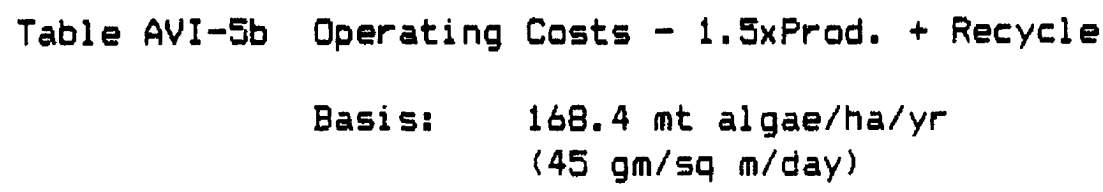

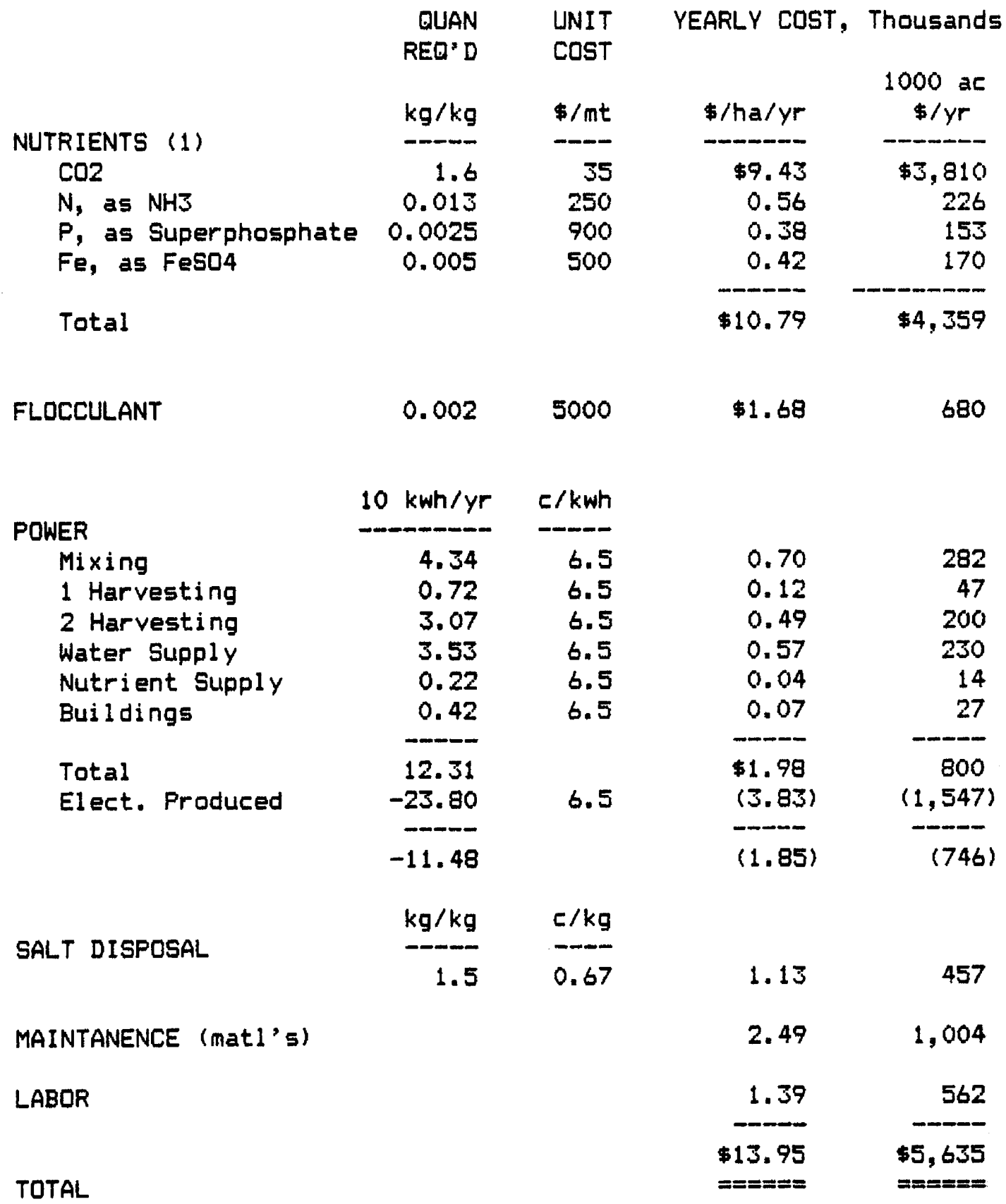

(1) $\mathrm{kg} / \mathrm{kg}=\mathrm{kg}$ required / $\mathrm{kg}$ algae produced 
Table AVI-6a Capital Cost Summary - 2.0 x Prod. + Recycle

$$
\text { Basis: } 225 \text { at algae/ha/yr }
$$

GROWTH PONDS

Earthworks (1)

Walls \& Structural

Mixing System

Carbonation System

Instrumentation not included elsewhere

HARVESTING - Settling Pond Option

Priaary (2)

Secondary (centrifugation)

ANAEROBIC LAGOON SYSTEM

Depreciable Capital

Non-depreciable Capital

SYSTEM-WIDE COSTS

Water Supply

Water Distribution

CO2 Distribution

Nutrient Supply Systen

Blowdown Disposal Systen (1)

Buildings (harv. blds. not included)

Roads \& drainage (1)

Electrical Distribution (3\% of above)

Electrical Supply

Machinery

ENGINEERING (10\% of above) (1)

CONTINGENCY (15\% of above) (1)

LAND COSTS ( $\$ 1250 /$ hectare) (1)

ELECTRICAL GENERATOR (3)

TOTAL CAPITAL COST

DEPRECIABLE PORTION

NON DEPRECIABLE PORTION

\section{0 acres}

TOTAL \$

$\$ 4,102,083$

$3,360,763$

$1,991,083$

$1,205,472$

202,368

$\$$ / HECTARE

$\$ 21,365$

17,304

10,370

6,279

1,054

$3,027,088$

$2,607,465$

15,766

13,581

$1,574,800$

765,200

8,202

3,985

$1,391,280$

398,412

171,544

316,200

337,280

231,880

210,800

656,812

238,204

168,640

7,246

2,075

893

1,647

1,757

1,208

1,099

3,421

1,241

878

$2,295,737$

11,957

$3,787,967$

19,729

$1,011,840$

5,270

$4,400,000$

22,917

$4,-\ldots-\ldots$

$---.--$

$\$ 34,452,918$

$\$ 179,442$

$\$ 21,904,291$

$\$ 114,085$

$\$ 12,548,628$

$\$ 65,357$

(1) non-depreciable iten

(2) patrially non-depr. $(\$ 375,000)$

(3) firm bid for turnkey systen - engr. \& contingency not required

$112 \mathrm{mt} / \mathrm{ha} / \mathrm{yr}=30 \mathrm{~g} / \mathrm{m} 2 / \mathrm{day}$

Land area $=2 \times$ growth pond area 
Table AVI-6b Operating Costs - 2xProd. + Recycle

Basis: $224.6 \mathrm{mt}$ algae/ha/yr (60 $\mathrm{gm} / \mathrm{sq} \mathrm{m} / \mathrm{day}$ )

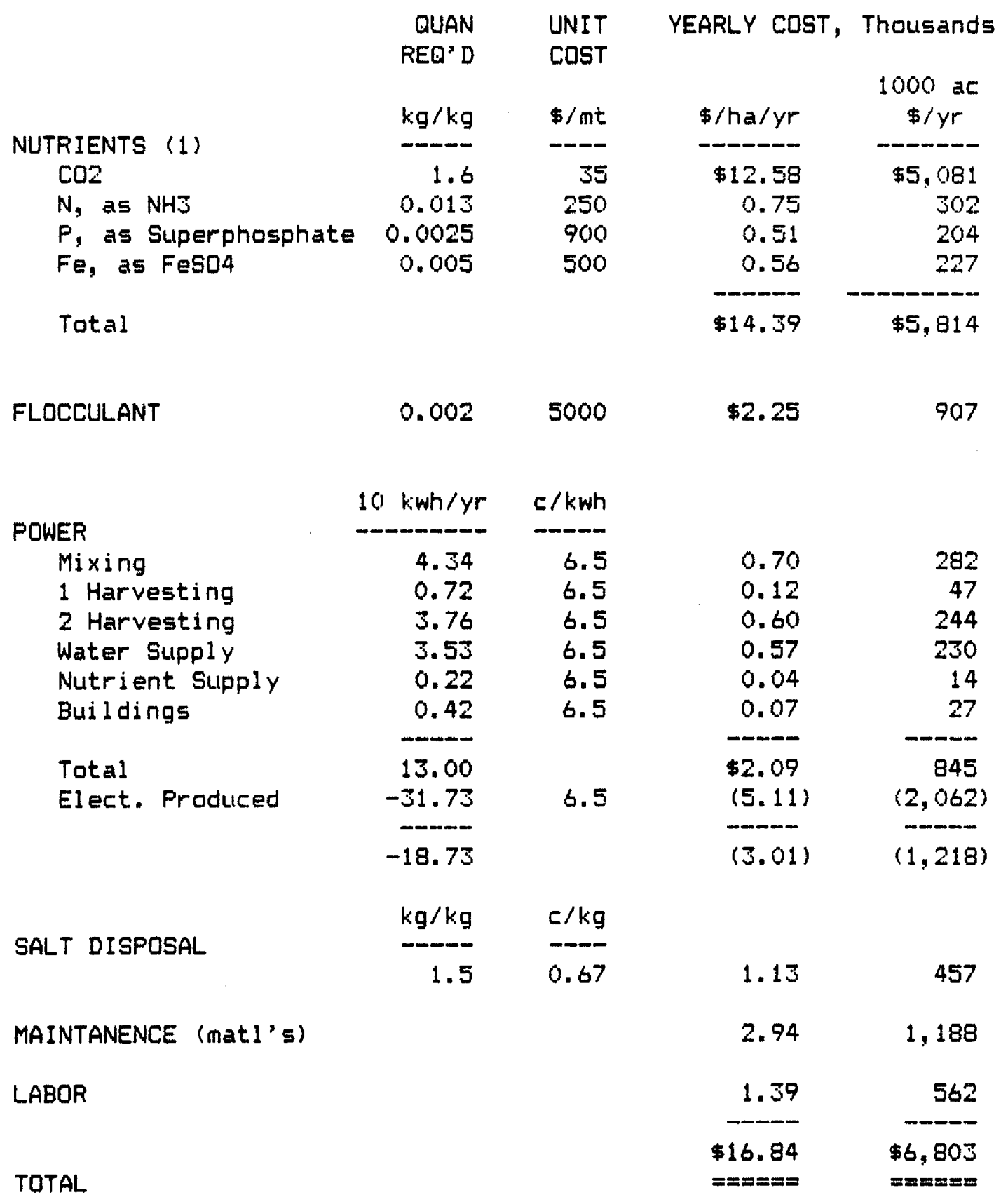

(1) $\mathrm{kg} / \mathrm{kg}=\mathrm{kg}$ required / $\mathrm{kg}$ algae produced 
Table AVI-7a Capital Cost Sumary - Free CO2 + Recycle

Basisi $\quad 112$ mt algae/ha/yr

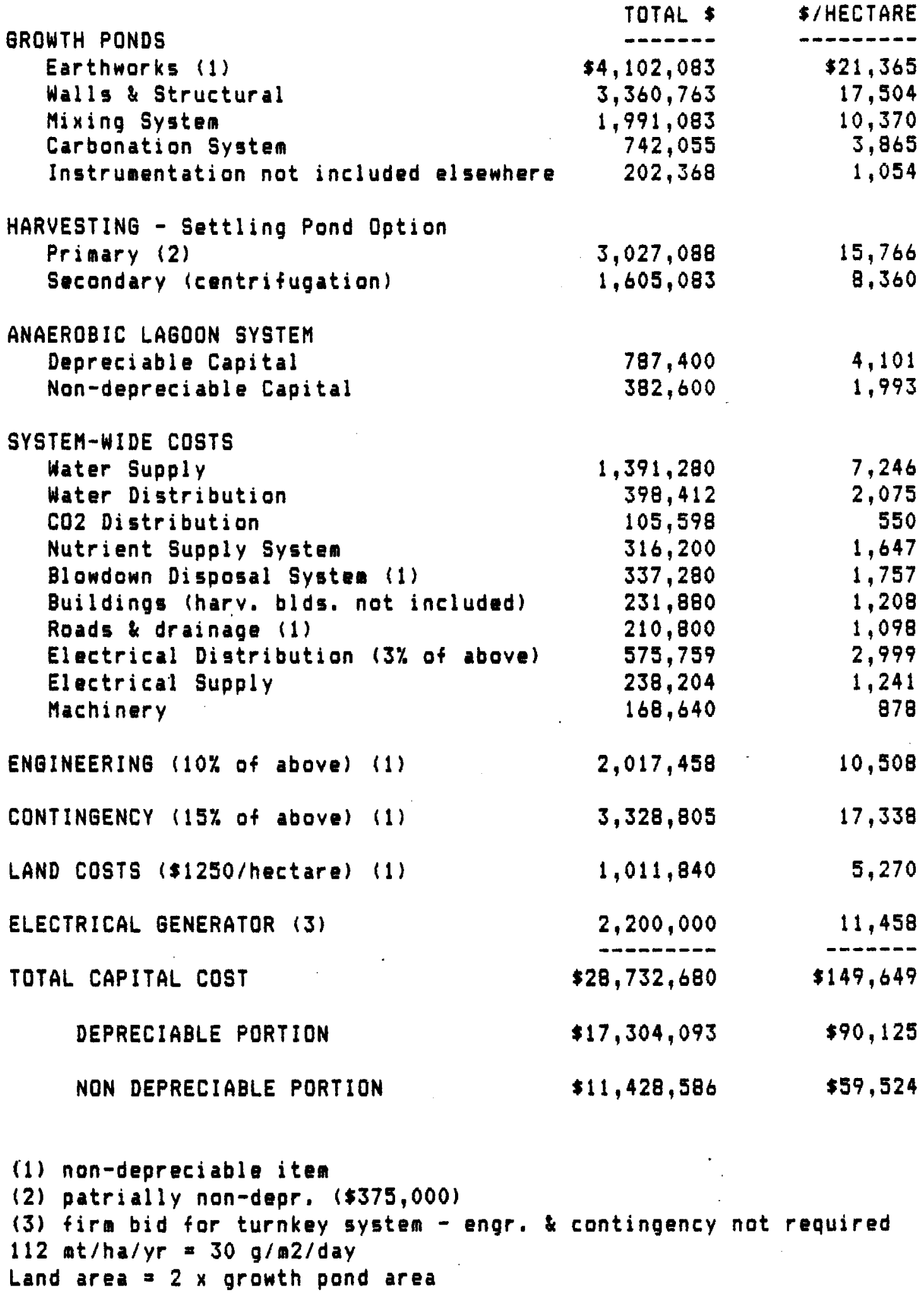


Table AVI-7b Operating Costs - Free CO2 + Recycle

Basis: $112.3 \mathrm{mt}$ algae/ha/yr

(30 $\mathrm{gm} / \mathrm{sq} \mathrm{m} / \mathrm{day}$ )

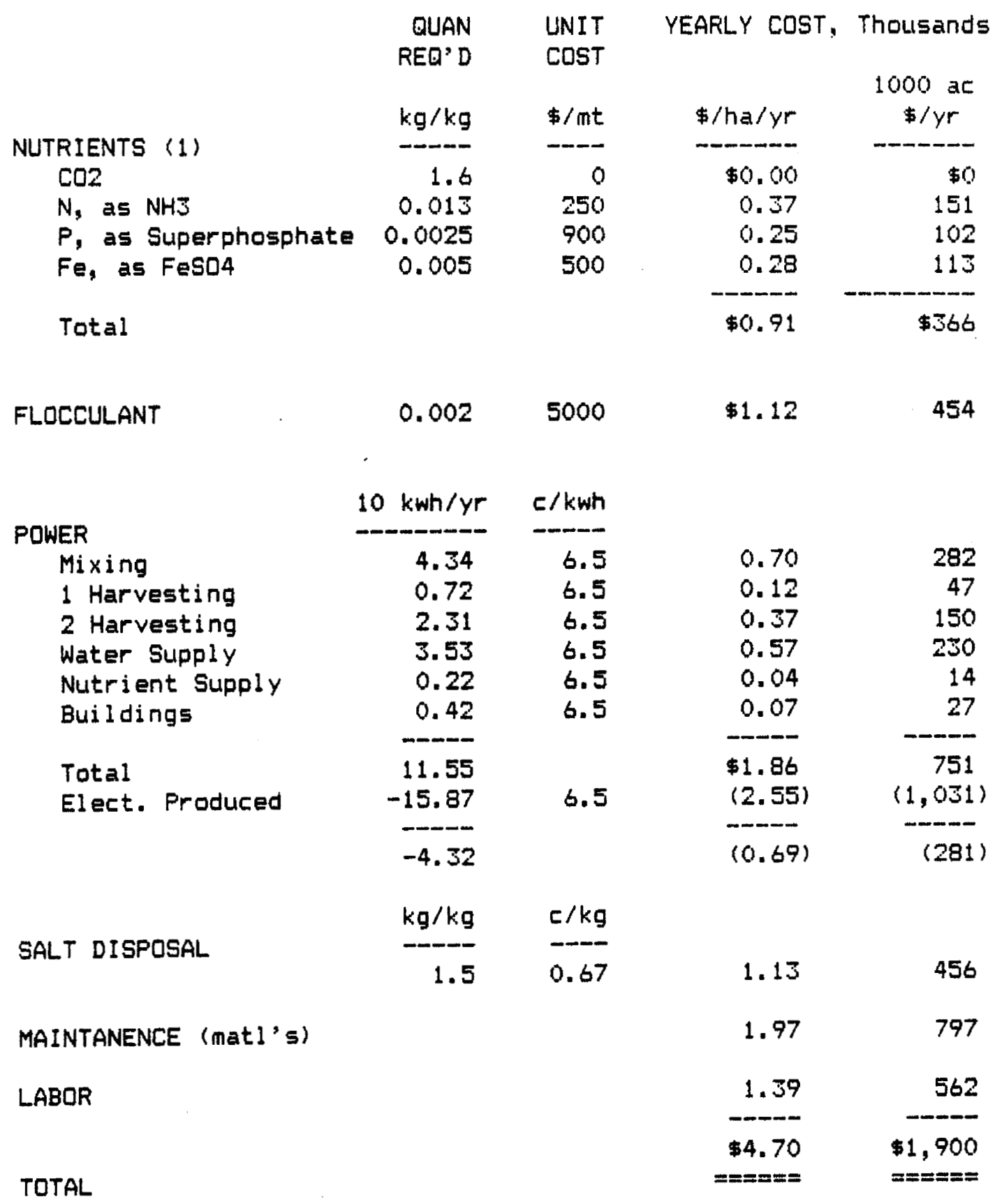

(1) $\mathrm{kg} / \mathrm{kg}=\mathrm{kg}$ required / $\mathrm{kg}$ algae produced 
Table AVI-8b Operating Costs - \$70/mt CO2 + Recycle

Basis: 112.3 mt algae/ha/yr

(30 $\mathrm{gm} / \mathrm{sq} \mathrm{m} /$ day)

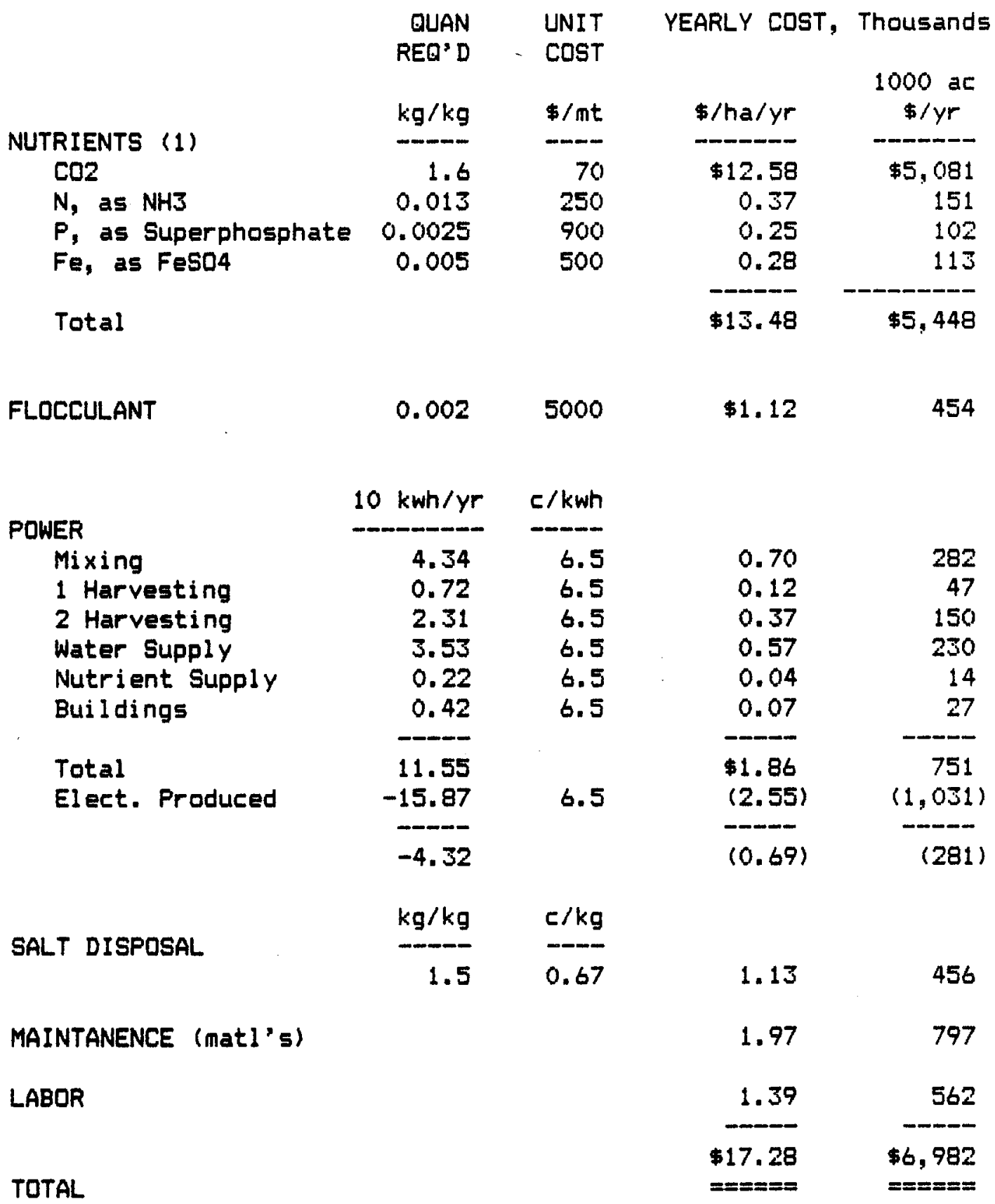

(1) $\mathrm{kg} / \mathrm{kg}=\mathrm{kg}$ required $/ \mathrm{kg}$ algae produced 
Table AVI- 9a Capital Cost Summary - $20 \%$ Lipid Content + Recycle Basis: $\quad 112 \mathrm{mt}$ algae/ha/yr

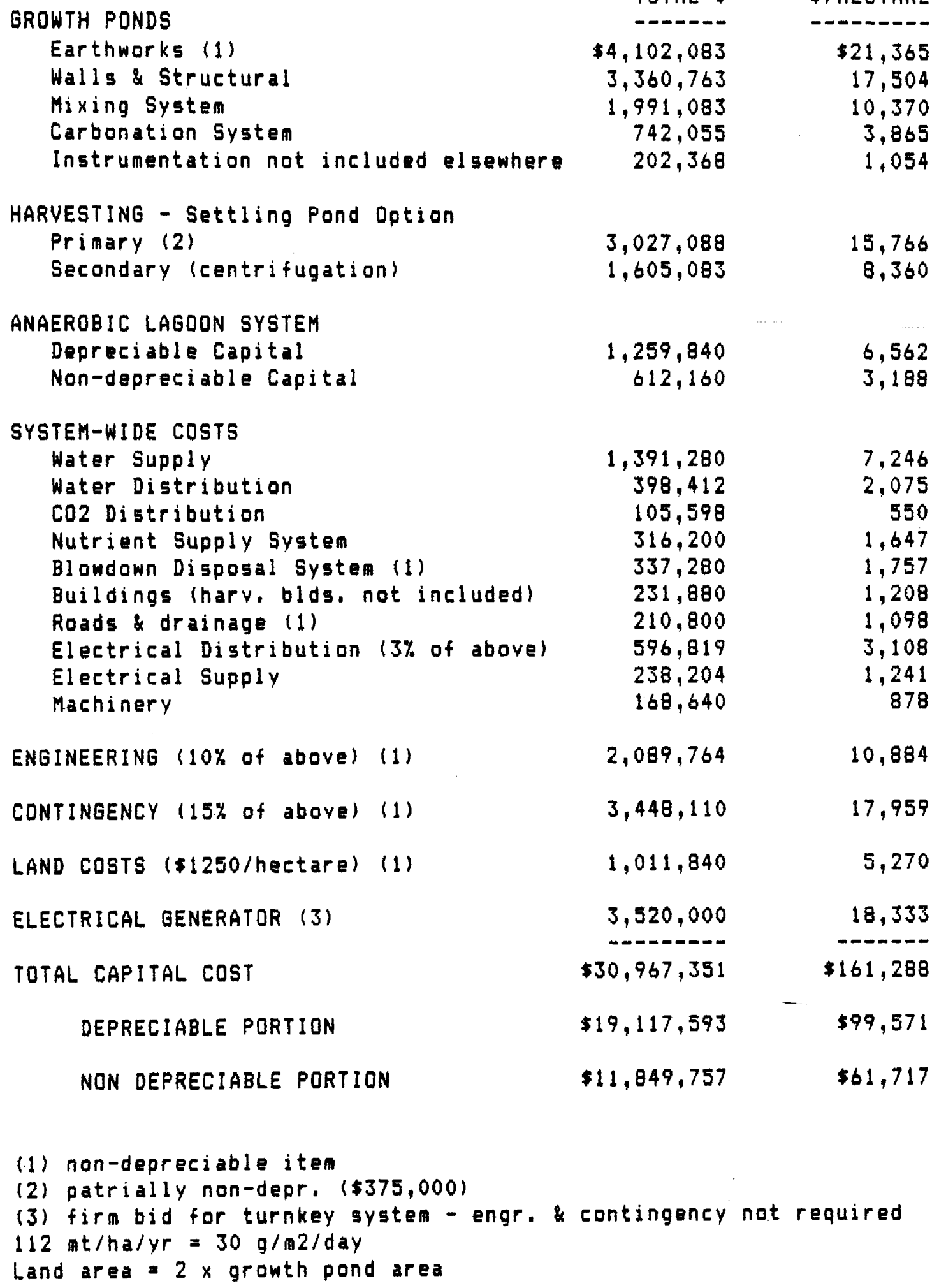

$\$ 61,717$

(1) non-depreciable iten

(2) patrially non-depr. $(\$ 375,000)$

(3) firm bid for turnkey system - engr. \& contingency not required $112 \mathrm{mt} / \mathrm{ha} / \mathrm{yr}=30 \mathrm{~g} / \mathrm{m} 2 / \mathrm{day}$ Land area $=2 \times$ growth pond area 
Table AVI-9b Operating Costs - 20\% Lipid Content + Recycle Basis: $\begin{aligned} & 112.3 \mathrm{mt} \text { algae/ha/yr } \\ & (30 \mathrm{gm} / \mathrm{sq} \mathrm{m} / \mathrm{day})\end{aligned}$

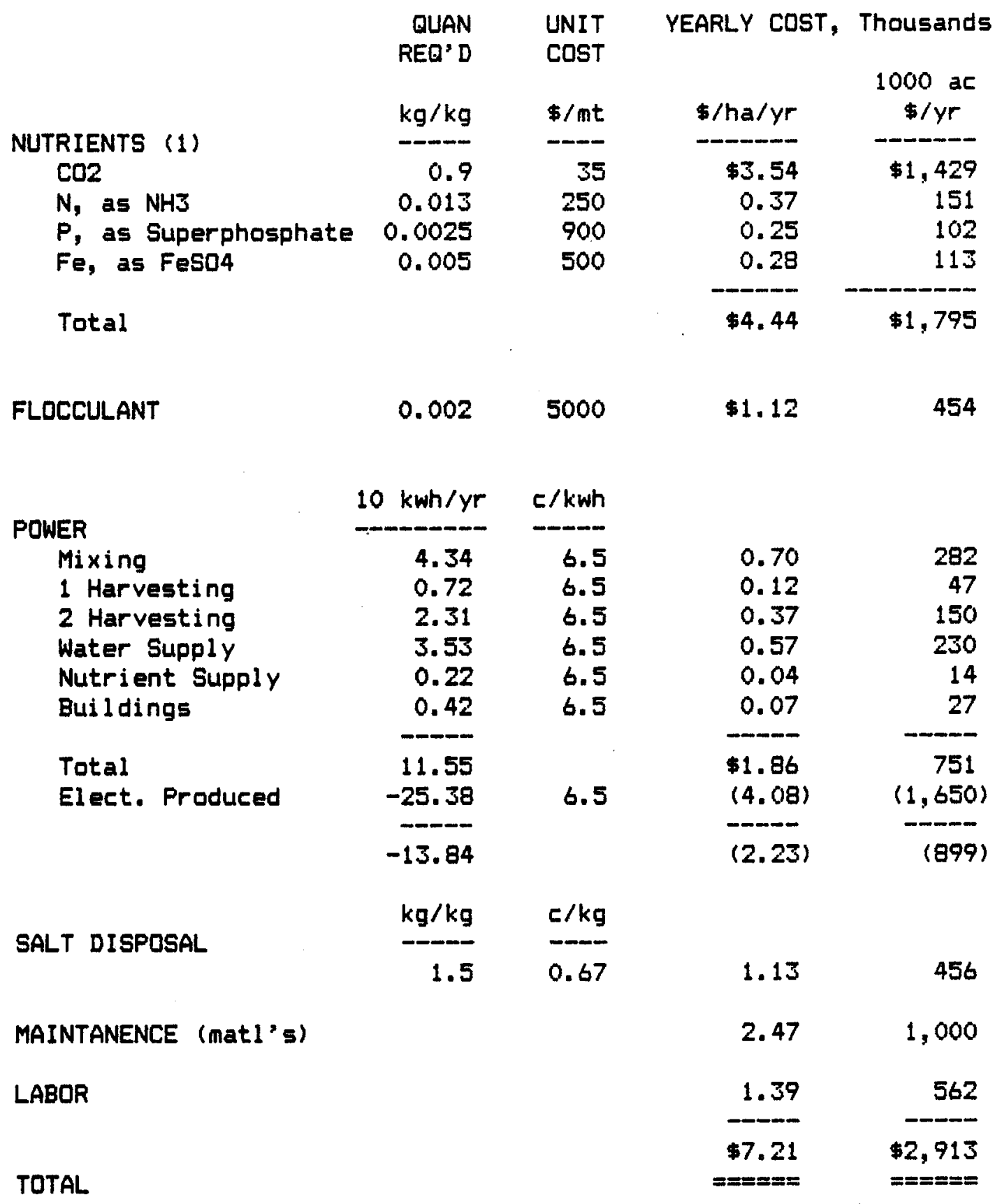

(1) $\mathrm{kg} / \mathrm{kg}=\mathrm{kg}$ required / $\mathrm{kg}$ algae produced 
Table AVI-10a Capital Cost Sumary - 30\% Lipid Content + Recycle

$$
\text { Basis: } 112 \text { mt algae/ha/yr }
$$

GROWTH PONDS

Earthworks (1)

Walls \& Structural

Mixing System

Carbonation System

Instrumentation not included elsewhere

haRVESTING - Settling Pond Option

Primary (2)

Secondary (centrifugation)

ANAEROBIC LAGOON SYSTEM

Depreciable Capital

Non-depreciable Capital

SYSTEM-WIDE COSTS

Water Supply

Water Distribution

CO2 Distribution

Nutrient Supply System

Blowdown Disposal System (1)

Buildings (hary. blds. not included)

Roads \& drainage (1)

Electrical Distribution (3\% of above)

Electrical Supply

Machinery

ENGINEERING (10\% of aboVe) (1)

CONTINGENCY (15\% of above) (1)

LAND COSTS (\$1250/hectare) (1)

ELECTRICAL GENERATOR (3)

TOTAL CAPITAL COST

$$
\text { DEPRECIABLE PORTION }
$$

NON DEPRECIABLE PORTION

\section{0 acres}

TOTAL \$

TOTAL

$\$ 4,102,083$

$3,360,763$

$1,991,083$

742,055

202,368

$\$$ /HECTARE

$\$ 21,365$

17,504

10,370

3,865

1,054

$3,027,088$

$1,605,083$

15,766

8,360

$1,102,360$

535,640

5,741

2,790

$1,391,280$

398,412

105,598

316,200

337,280

231,880

210,800

589,799

238,204

168,640

7,246

2,075

550

1,647

1,757

1,208

1,098

3,072

1,241

878

$2,065,662$

10,759

$3,408,342$

17,752

$1,011,840$

5,270

$3,080,000$

16,042

-......-.

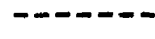

$\$ 30,222,460$

$\$ 157,409$

$\$ 18,372,703$

$\$ 95,691$

$\$ 11,709,367$

$\$ 60,986$

(1) non-depreciable item

(2) patrially non-depr. $(\$ 375,000)$

(3) firm bid for turnkey systen - engr. \& contingency not required

$112 \mathrm{mt} / \mathrm{ha} / \mathrm{yr}=30 \mathrm{~g} / \mathrm{m} 2 / \mathrm{day}$

Land area $=2 \times$ growth pond area 
Table AVI-10b Operating Costs - 30\% Lipid Content + Recycle Basis: $112.3 \mathrm{mt}$ algae/ha/yr (30 $\mathrm{gm} / \mathrm{sq} \mathrm{m} /$ day)

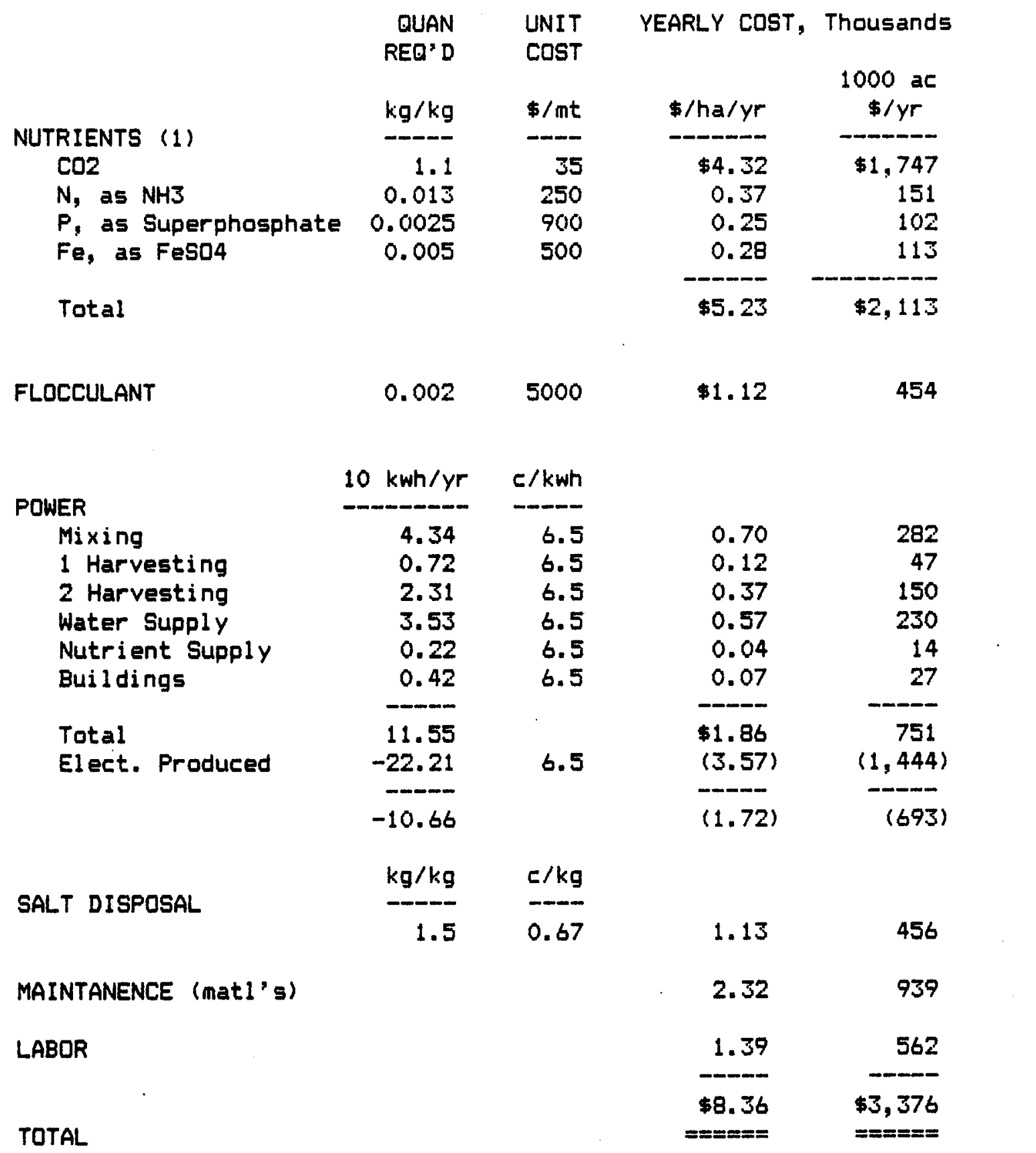

(1) $\mathrm{kg} / \mathrm{kg}=\mathrm{kg}$ required / $\mathrm{kg}$ algae produced 
Table AVI-11a Capital Cost Sumary - 40\% Lipid Content + Recycle Basis: 112 mt algae/ha/yr

GROWTH PONDS

Earthworks (1)

Walls \& Structura!

Mixing System

Carbonation System

Instrumentation not included elsewhere

HARVESTING - Settling Pond Option

Prinary (2)

Secondary (centrifugation)

ANAEROBIC LAGOON SYSTEM

Depreciable Capital

Non-depreciable Capital

SYSTEM-WIDE COSTS

Water Supply

Water Distribution

CQ2 Distribution

Nutrient Supply Systen

Blowdown Disposal Systea (1)

Buildings (harv. blds. not included)

Roads \& drainage (1)

Electrical Diatribution ( $3 \%$ of above)

Electrical Supply

Machinery

ENGINEERING (10\% of above) (1)

CONTINGENCY (15\% of above) (1)

LAND COSTS ( $\$ 1250 /$ hectare) (1)

ELECTRICAL GENERATOR (3)

TOTAL CAPITAL COST

DEPRECIABLE PORTION

NON DEPRECIABLE PORTION
1000 acres

TOTAL \$

- D.-.--

$\$ 4,102,083$

$3,360,763$

$1,991,083$

742,055

202,368

$\$$ / HECTARE

D21,365

17,504

10,370

3,865

1,054

$3,027,088$

$1,605,083$

15,766

8,360

944,880

459,120

4,921

2,391

$1,391,280$

398,412

105,598

316,200

337,280

231,880

210,800

582,779

238,204

168,640

7,246

2,075

550

1,647

1,757

1,208

1,098

3,035

1,241

878

$2,041,560$

10,633

$3,368,573$

17,545

$1,011,840$

5,270

$2,640,000$

13,750

$-0-\cdots-\cdots$

$-0-0-0$

$\$ 29,477,570$

$\$ 153,529$

$\$ 17,908,593$

$\$ 93,274$

$\$ 11,568,977$

$\$ 60,255$

(1) non-depreciable iten

(2) patrially non-depr. $(\$ 375,000)$

(3) firm bid for turnkey systen - engr. \& contingency not required

$112 \mathrm{mt} / \mathrm{ha} / \mathrm{yr}=30 \mathrm{~g} / \mathrm{m} 2 / \mathrm{day}$

Land area $=2 \times$ growth pond area 
Table AVI-11b Operating Costs - 40\% Lipid Content + Recycle Basis: $\quad 112.3 \mathrm{mt}$ algae/ha/yr (30 $\mathrm{gm} / \mathrm{sq} \mathrm{m} /$ day)

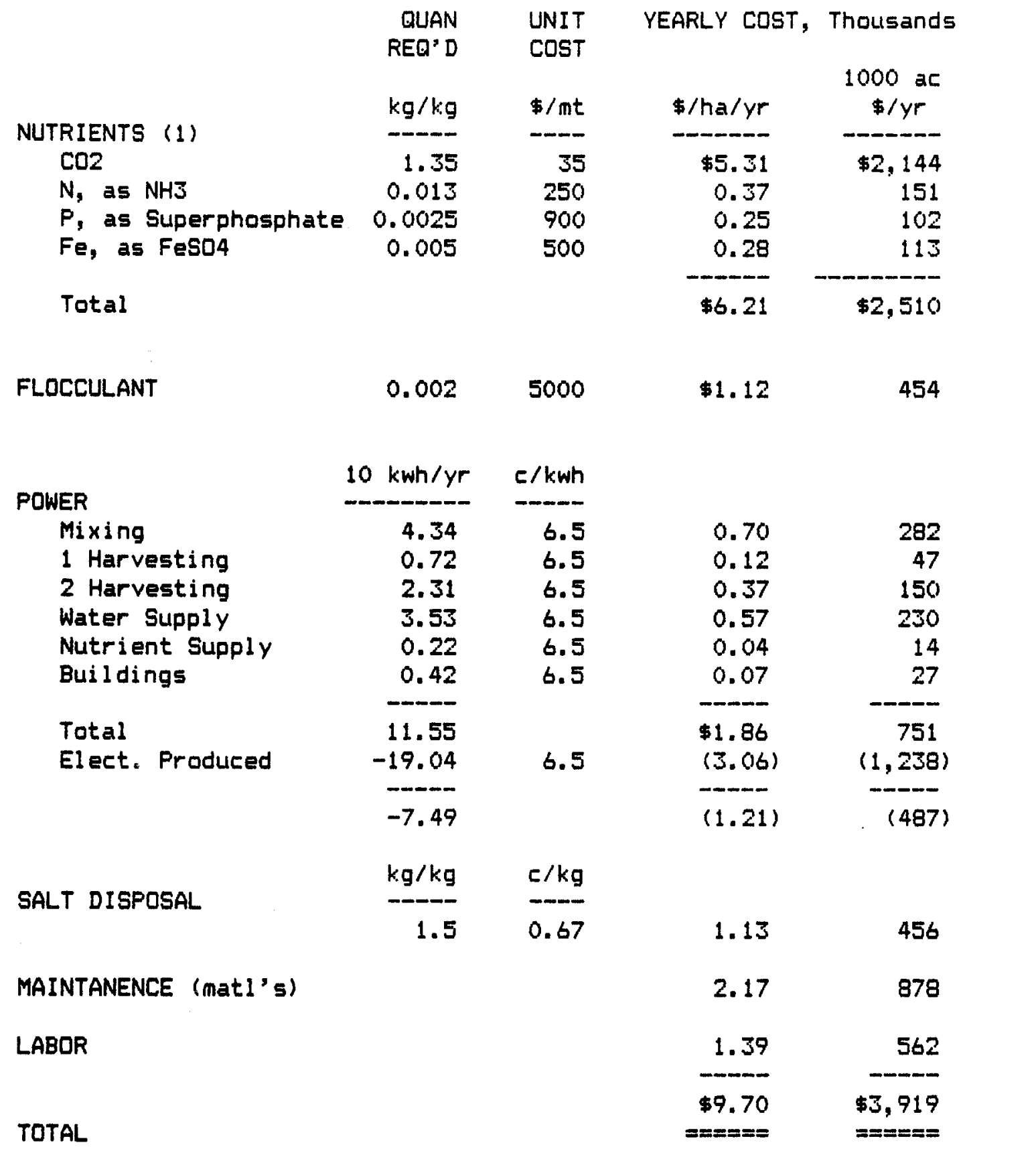

(1) $\mathrm{kg} / \mathrm{kg}=\mathrm{kg}$ required / $\mathrm{kg}$ algae produced 


\begin{tabular}{|c|c|c|}
\hline $\begin{array}{l}\text { Document Control } \\
\text { Page }\end{array}$ & \begin{tabular}{|l|l|} 
1. SERI Report No. & 2. NTIS Accession No. \\
SERI/STR-23]-2840 &
\end{tabular} & 3. Recipient's Accession No. \\
\hline \multirow{2}{*}{\multicolumn{2}{|c|}{$\begin{array}{l}\text { 4. Title and Subtitle } \\
\text { Design and Analysis of Microalgal Open Pond Systems } \\
\text { for the Purpose of Producing Fuels }\end{array}$}} & $\begin{array}{r}\text { 5. Publication Date } \\
\text { October } 1985 \\
\end{array}$ \\
\hline & & 6. \\
\hline \multicolumn{2}{|c|}{$\begin{array}{l}\text { 7. Author(s) } \\
\text { J. C. Weissman, R. P. Goebel }\end{array}$} & 8. Performing Organization Rept. No. \\
\hline \multirow{2}{*}{\multicolumn{2}{|c|}{$\begin{array}{l}\text { 9. Performing Organization Name and Address } \\
\text { Microbial Products, Inc. } \\
\text { Fairfield, Cal if }\end{array}$}} & \multirow{2}{*}{$\begin{array}{l}\text { 10. Project/Task/Work Unit No. } \\
4513.10 \\
\text { 11. Contract (C) or Grant (G) No. } \\
\text { (C) XK-3-03153-1 } \\
\text { (G) }\end{array}$} \\
\hline & & \\
\hline \multirow{2}{*}{\multicolumn{2}{|c|}{$\begin{array}{l}\text { 12. Sponsoring Crganization Name and Address } \\
\text { Solar Eniergy Research Institute } \\
\text { A Division of Midwest Research Institute } \\
1617 \text { Cole Boulevard } \\
\text { Golden, Colorado } 80401-3393\end{array}$}} & $\begin{array}{c}\text { 13. Type of Report \& Period Covered } \\
\text { Technical Report }\end{array}$ \\
\hline & & 14. \\
\hline \multicolumn{3}{|c|}{ 15. Supplementary Notes } \\
\hline \multicolumn{3}{|c|}{$\begin{array}{l}\text { 16. Abstract (Limit: } 200 \text { words) The designs and systems developed include many innovative con- } \\
\text { cepts and experiments, including the design and operation of a low-cost system. } \\
\text { Cost-effectiveness is realized by minimizing capital costs of the system and } \\
\text { achieving efficient use of inputs. Extensive engineering analysis of carbonation, } \\
\text { mixing, and harvesting subsystems has elucidated both the lowest cost, most effi- } \\
\text { cient options and the essential parameters needed to construct, test, and evaluate } \\
\text { these subsystems. The use of growth ponds sealed with clay and lined with crushed } \\
\text { rock results in construction cost savings of } 50 \% \text { over ponds lined with synthetic } \\
\text { membranes. In addition a low-cost but efficient design allows improvments in } \\
\text { technology to have maximum impact on final product cost reductions. In addition to } \\
\text { the innovations in low-cost construction, the operational efficiency of the design } \\
\text { is both higher and more feasible than that attained by any previous system concept } \\
\text { of comparable scale. The water chemistry analysis has led to operational specifi- } \\
\text { cations that minimize water use and virtually eliminate losses of carbon dioxide to } \\
\text { the atmosphere. The carbon dioxide injection system is designed for 95\% efficiency } \\
\text { but is still low in cost. The construction of a large-scale, covered anaerobic } \\
\text { lagoon to recycle carbon, nitrogen, and phosphorus has not been attempted at the } \\
\text { scale analyzed here. Yet efficient recycling is essential for achieving economic }\end{array}$} \\
\hline \multicolumn{3}{|c|}{$\begin{array}{l}\text { 17. Document Analysis affordability. } \\
\text { a. Descriptors } \\
\text { Biomass ; Carbon Dioxide ; Cultivation ; Cultivation Techniques ; Ponds ; } \\
\text { Productivity ; Unicellular Algae } \\
\text { b. Identifiers/Open-Ended Terms }\end{array}$} \\
\hline \multicolumn{3}{|l|}{$\begin{array}{l}\text { c. UC Categories } \\
61 \mathrm{C}\end{array}$} \\
\hline \multirow{2}{*}{\multicolumn{2}{|c|}{$\begin{array}{l}\text { 18. Availability Statement } \\
\text { National Technical Information Service } \\
\text { U.S. Department of Commerce } \\
5285 \text { Port Royal Road } \\
\text { Springfield, Virginia } 22161\end{array}$}} & 19. No. of Pages \\
\hline & & $\begin{array}{r}\text { 20. Price } \\
\text { A11 }\end{array}$ \\
\hline
\end{tabular}

